University of San Diego

Digital USD

2013-05-01

\title{
Leadership for Innovation in the Memories Business: A Mixed Methods Study of a Hospitality and Tourism Marketplace
}

Lori J. Sipe PhD

University of San Diego

Follow this and additional works at: https://digital.sandiego.edu/dissertations

Part of the Leadership Studies Commons

\section{Digital USD Citation}

Sipe, Lori J. PhD, "Leadership for Innovation in the Memories Business: A Mixed Methods Study of a Hospitality and Tourism Marketplace" (2013). Dissertations. 850.

https://digital.sandiego.edu/dissertations/850

This Dissertation: Open Access is brought to you for free and open access by the Theses and Dissertations at Digital USD. It has been accepted for inclusion in Dissertations by an authorized administrator of Digital USD. For more information, please contact digital@sandiego.edu. 
LEADERSHIP FOR INNOVATION IN THE MEMORIES BUSINESS: A MIXED METHODS STUDY OF A HOSPITALITY AND TOURISM MARKETPLACE

by

Lori J. Sipe

A dissertation submitted in partial fulfillment of the requirements for the degree of

Doctor of Philosophy

May 2013

Dissertation Committee

Robert Donmoyer, Ph.D

Fred J. Galloway, Ed.D

Lea Hubbard, Ph.D

University of San Diego 
(C) Copyright by Lori J. Sipe All Rights Reserved 2013 


\begin{abstract}
In the past 35 years, substantial research has been conducted examining innovation in the business environment. Despite the vast quantity of innovation studies, a large percentage of the contributions are focused on product innovation outputs in manufacturing, while innovation theory in the services industry is still struggling to emerge. The hospitality and tourism industry is one of the largest service industries in the world. In this industry context, innovation is less about producing new things and more about delivering unique experiences to create lasting memories. The purpose of this study was to extend the work already done regarding innovation in business by examining innovation in an understudied context; the goal was to offer a back of the house view of the ways senior managers influence innovation in organizations whose main economic offering is an experience.

An exploratory sequential mixed-methods study was conducted in three phases. In Phase One, a short survey was used to identify the ways organizations of a local hospitality and tourism marketplace measure innovation. Concurrent to the quantitative survey, interviews were conducted to identify the ways senior managers influence innovation in their organizations. A conceptual model of leadership for innovation in the experience context was developed from the qualitative data. In Phase Two, the conceptual model was translated into a list of leadership practices, and a composite measure of innovation performance was finalized.

Qualitative and quantitative results from the first two phases informed the design of a survey for Phase Three of the study. The survey included eighteen leadership practices intended to measure idea generation, shared understanding, and idea
\end{abstract}


implementation in the experience context. Statistical techniques of principal component analysis and multiple regression analysis were used to validate the conceptual model and measure the relationships among the variables of senior manager influence and innovation performance.

This back of the house view of innovation in the experience context offers an updated perspective of innovation in business and a context-specific look at strategic leadership at the business unit level. Findings also provide insights for leaders of organizations faced with providing compelling experiences for increasingly demanding and savvy consumers. 


\section{ACKNOWLEDGEMENTS}

Family: First, I want to thank my mom, Gerry, whose generosity and encouragement made it possible to complete this work-she inspires me daily. Allen, Lindsay, and Tristan have shared this journey with me-their emotional support and personal sacrifices, especially during the home stretch, will always be remembered. And I want to thank my uncle, Jim, for fueling my interest in business and mailing me a copy of The Fifth Discipline when I asked him to recommend a leadership book.

Industry Leaders: I am indebted to the professionals who shared their time, insights, and organizations with me - especially advisory group members Chris, Ted, Terri, David, Brian, and Stephanie. SeaWorld mentors Marnie, Mary, Christina, Dave, Penny, and Bill were also instrumental in shaping my personal perspective on leadership.

Friends and Colleagues: I am lucky to work with innovative people like Gene, Mark, Carl, and Jeff, who challenge my thinking and share my passion for leadership studies. And it has been a joy to engage with committed students in the doctorate program at USD, too many to list, who offered feedback and always kept me curious.

Dissertation Committee: I have been deeply influenced by the academic role models who served on my dissertation committee. Bob Donmoyer, $\mathrm{PhD}$, was always accessible and committed to helping me become a better researcher, writer, and thinkermy heartfelt thanks to a world-class chair and special person. Fred Galloway, EdD, has a rare talent for making numbers come alive--he inspired me to remain open to possibilities. And Lea Hubbard, $\mathrm{PhD}$, provided key advice and foundations that I know I will access in my future research—she exemplifies what it means to be a teacher/scholar. 


\section{TABLE OF CONTENTS}

CHAPTER ONE: BACKGROUND AND PURPOSE OF THE STUDY........................1

Background to the Study.............................................................................................................2

Statement of the Problem....................................................................................................

Purpose of the Study and Research Questions..................................................................11

CHAPTER TWO: REVIEW OF THE LITERATURE..............................................14

Integrating Innovation Theory in Business ........................................................................14

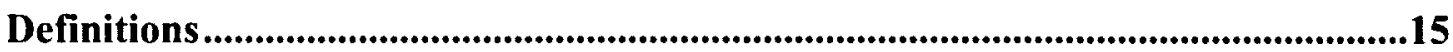

Innovation as Outputs ..................................................................................................17

Product innovation outputs: new or modified. ...........................................................17

Service innovation outputs: fuzzy nature. ……................................................18

Process/administrative innovation outputs: basic work activities ......................18

Innovation as Process .................................................................................................19

Innovation Inputs................................................................................................................20

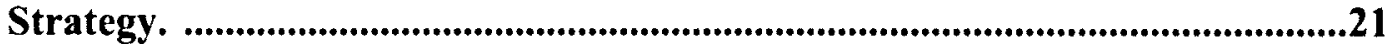

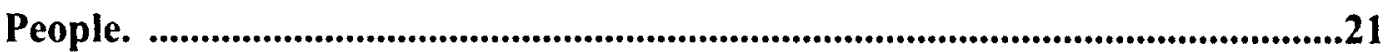

Knowledge management. ....................................................................................22

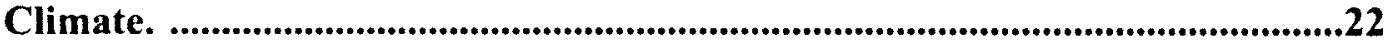

Leadership ..............................................................................................................23

Innovative Organizational Culture/Orientation ...........................................................23

An Integrated Framework ......................................................................................24

Summary of Section .................................................................................................................27

Applying Experience Innovation to the Hospitality and Tourism Context..................28 
The Experience Economy ..................................................................................................29

Overview of the paradigm. ........................................................................................29

Realms of experience. ...............................................................................................29

Critiques of the experience economy paradigm. ...........................................................30

Experience Innovation in the Hospitality and Tourism Industry .............................33

Evolution of the customer experience. ..............................................................33

Challenges for the hospitality and tourism industry. .............................................35

Emergent Research in Experience Innovation..............................................................36

Examples of recent studies in context. ...........................................................36

Convergent approaches. .................................................................................................37

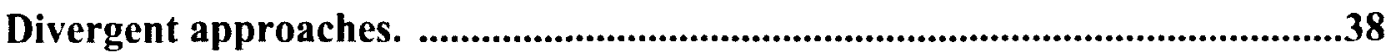

Implications of emergent research. .........................................................................40

Summary of Section ................................................................................................................40

Strategic Leadership for Experience Innovation ..................................................................41

Tracing Major Leadership Theories.............................................................................41

Thinking in time. ..............................................................................................................41

Trait based leadership theory. ......................................................................................42

Behavior based leadership theories. ..................................................................................43

Contingency theory. .......................................................................................................44

Transformational views. ...................................................................................................44

Contemporary leadership theories. ........................................................................45

Studies Linking Types of Leadership and Innovation ................................................45

Contemporary Views of Strategic Leadership ..............................................................47 
The essence of strategic leadership. ...........................................................................47

The innovation dilemma, ...............................................................................47

Innovation ambidexterity. ..............................................................................................48

Ambidextrous leadership. ....................................................................................................48

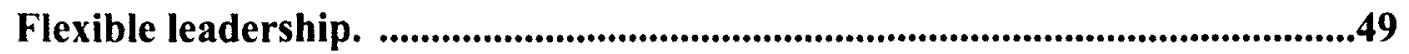

The tensions of strategic leadership. .......................................................................49

Summary of Section ...................................................................................................................50

Summary of Literature Review ..................................................................................50

CHAPTER THREE: METHODOLOGY OVERVIEW .................................................52

Definitions and Terms ..............................................................................................................52

The Research Design .................................................................................................................53

Graphic Depiction and Notation ...............................................................................................55

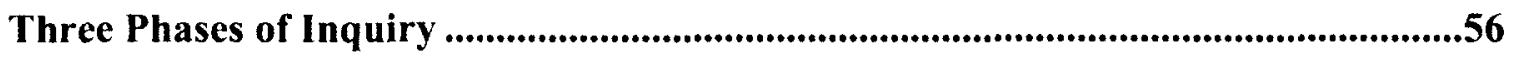

Presentation of the Research Journey ................................................................................58

CHAPTER FOUR: PHASE ONE METHODS AND RESULTS..................................60

Phase One: Quantitative - Measures and Outputs Survey.............................................60

Research Participants and Segments ................................................................................61

Data Collection and Analysis .......................................................................................62

Survey instrument design and pilot. ....................................................................62

Data collection and cleaning. ..........................................................................................65

Analytical strategies. ..................................................................................................65

Results from Measures and Outputs Survey .............................................................67

Outputs of innovation activities. ........................................................................67 
Measures of innovation performance. .71

Summary of Phase One: Quantitative - Measures and Outputs Survey ...............73

Phase One: Qualitative - Toward a Theory of Leadership in Context .........................75

Interview Subjects and Industry Segments .................................................................76

Data Collection and Analysis ............................................................................................77

Unit of analysis aligned with research question. ……………....................................77

Interview guide as a reflection of propositions. ........................................................78

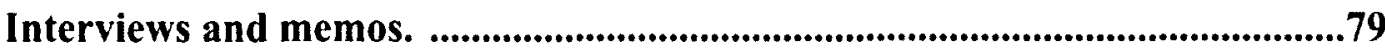

Codes and categories. .......................................................................................................80

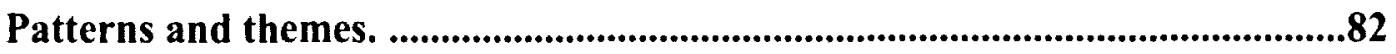

Data and researcher integration. ..........................................................................85

Results from Senior Manager Interviews ...........................................................................87

Strategic context. .........................................................................................................89

Strategy and purpose. .............................................................................................90

Innovation strategy. ..................................................................................................93

Strategic leadership. ................................................................................................95

Idea generation. .................................................................................................................96

Focus on the experience. ...........................................................................................98

Idea implementation. .................................................................................................101

Summary of Phase One: Qualitative - Senior Manager Interviews ......................103

Conclusions from Phase One ............................................................................................104

Innovation Findings ..............................................................................................................105

Strategic Leadership Findings ............................................................................................106 
The Relationships Between Innovation and Strategic Leadership 107

CHAPTER FIVE: PHASES TWO/THREE METHODS AND RESULTS ............108

Phase Two: Qualitative - Advisory Group Working Session .................................109

Advisory Group Participants ................................................................................109

Feedback and Interpretation of Findings from Phase One ...............................110

Feedback on innovation findings. .............................................................110

Feedback on strategic leadership findings. ..................................................111

Development of Managerial Behaviors and Leadership Practices .....................112

Summary of Phase Two: Qualitative - Advisory Group .....................................117

Phase Three: Quantitative - Leadership and Innovation Survey ...........................118

Research Participants and Segments .............................................................19

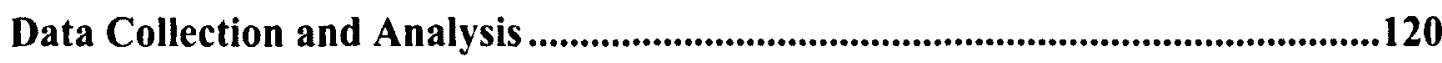

Survey instrument design and pilot. ................................................................120

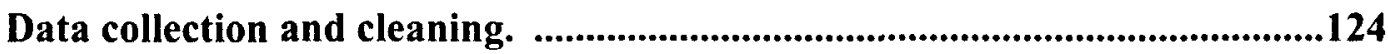

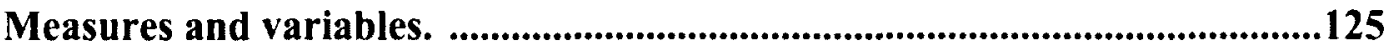

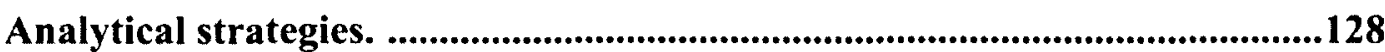

Results from Leadership and Innovation Survey ..........................................130

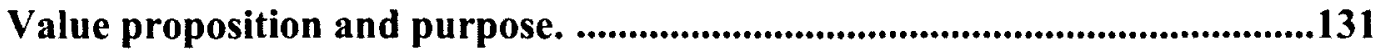

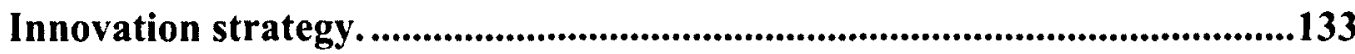

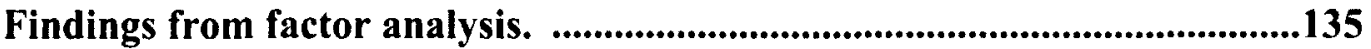

Innovation performance composite measure ...........................................139

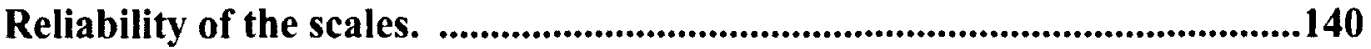

Findings from regression analysis. .......................................................141 
Correlations.

Digging a bit deeper into importance and extent of use.

Outputs of innovation activities.

Summary of Phase Three: Quantitative - Leadership \&Innovation Survey...........154

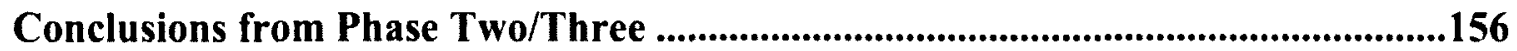

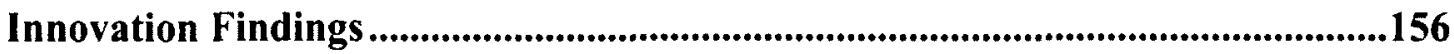

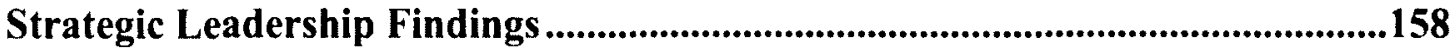

The Relationships Between Innovation and Strategic Leadership ......................159

Summary of Research Journey ............................................................................160

CHAPTER SIX: DISCUSSION AND IMPLICATIONS.....................................163

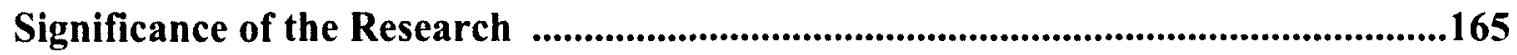

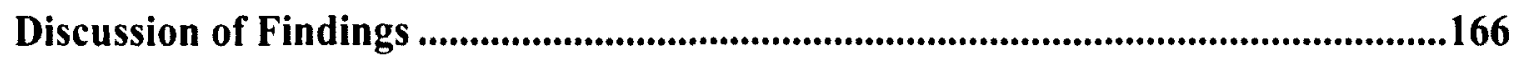

Research Questions \#1: Definitions and Measures of Innovation ........................169

Experience innovation is collective, incremental and ongoing. .....................169

Experience innovation involves front $\&$ back of the house initiatives. ..........171

Experience innovation should lead to improved performance. .....................174

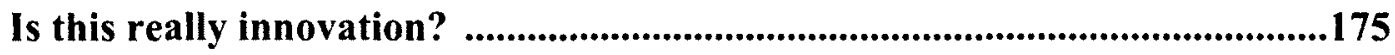

Summary of findings about innovation. .........................................................176

Research Question \#2: Senior Manager Influence for Innovation.......................178

Leadership for experience innovation requires idea generation.....................178

Leadership for innovation requires shared understanding. ..........................179

Leadership for experience innovation requires idea implementation. ..........180

Senior managers influence innovation at the business unit level. .................181 
Toward a theory of leadership for innovation in experience context.

Summary of findings about strategic leadership.

Research Question \#3: Innovation \& Senior Manager Influence Relationships..185

The empirical evidence confirms a relationship. ..........................................186

Leadership practices associated with innovation performance. ....................187

Limitations

Implications

Bridging Theory and Application

Dive Deeply into Conversations about Experience 191

Refresh the Leadership Toolkit-From Service to Experience.

Define Innovation Strategy at the Business Unit Level. .193

Transition to an Experience Scorecard

Make the Business Case for Passion

Directions for Future Research .196

Conclusion 198

REFERENCES.

APPENDICES

A. Sample Email Invitation for Measures and Outputs Survey .215

B. Measures and Outputs Survey.

C. Consent Form for Measures and Outputs Survey .226

D. Sample Email Invitation for Senior Manager Interviews . .228

E. The Interview Guide 230

F. Consent Form for Senior Manager Interviews .232 
G. Theme Pages ............................................................................................................................235

H. Sample Email Invitation for Advisory Group Working Session.............................246

I. Leadership Constructs Referenced During Advisory Group ..................................248

J. Consent Form for Advisory Group Working Session .............................................253

K. Sample Email Invitation for Leadership \& Innovation Survey ............................256

L. Leadership and Innovation Survey ............................................................................258

M. Consent Form for Leadership and Innovation Survey..........................................269 


\section{LIST OF TABLES}

Table 1. Measures and outputs survey: segment, size, and longevity of participating organizations

Table 2. Measures and outputs survey: frequencies of innovation ratings by

innovation

Table 3. Leadership and innovation survey: segment, size, and longevity of participating organizations

Table 4. Summary of independent variables: senior manager influence 126

Table 5. Summary of independent variables: innovativeness of front of the house and back of the house innovation activities 127

Table 6. Summary of dummy variables: general organizations

Table 7. Summary of dependent variables: innovation performance.

Table 8. Leadership and innovation survey: principal component matrix

Table 9. Innovation performance composite mean scores by industry segment ..140

Table 10. Leadership and innovation survey: scale reliability

Table 11. Leadership and innovation survey: senior manager influence and innovation

Table 12. Leadership and innovation survey: correlations of leadership practices and innovation performance.

Table 13. Leadership and innovation survey: extent of use (mean score all segments) and importance 


\section{LIST OF FIGURES}

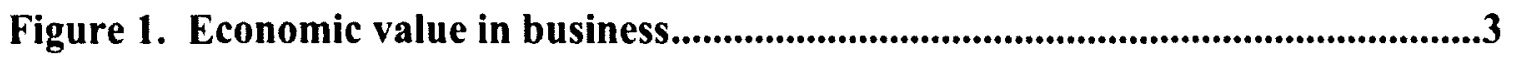

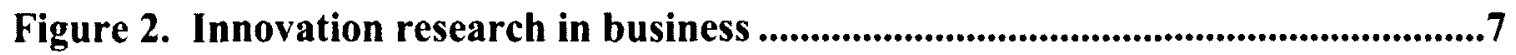

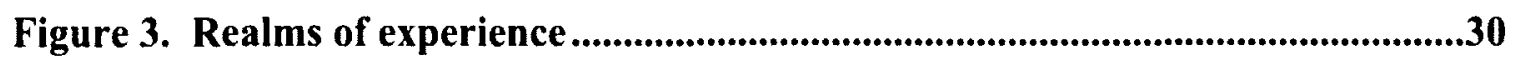

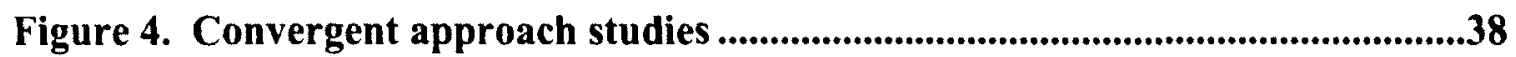

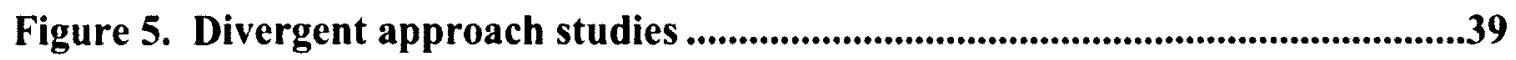

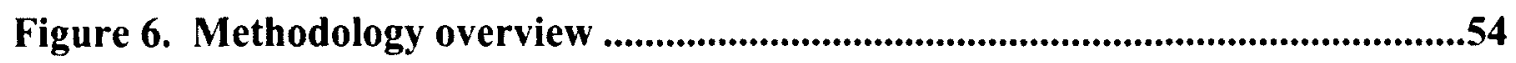

Figure 7. Study components reference............................................................60

Figure 8. Measures and outputs survey: sample question ....................................64

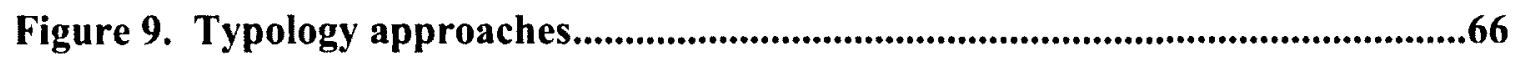

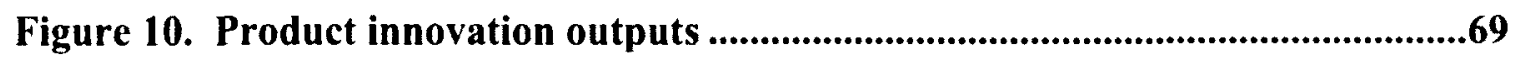

Figure 11. Leadership and innovation survey: senior manager influence and

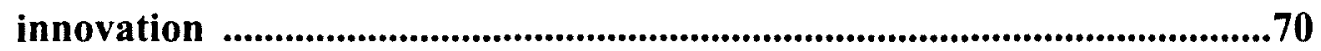

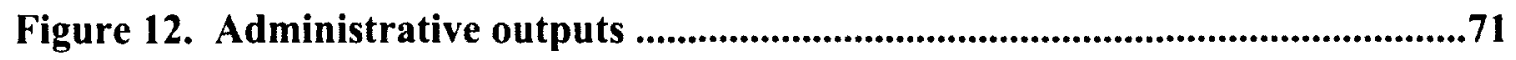

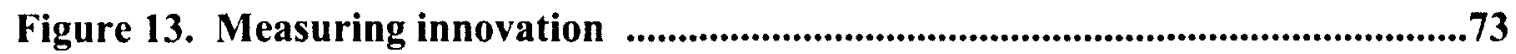

Figure 14. Senior manager interviews by industry segment .....................................77

Figure 15. Excerpt of codes and categories .........................................................82

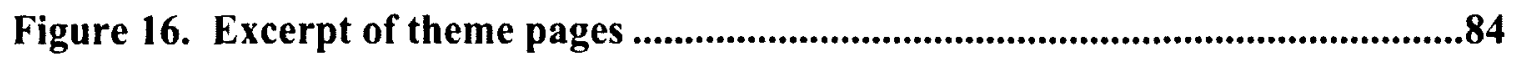

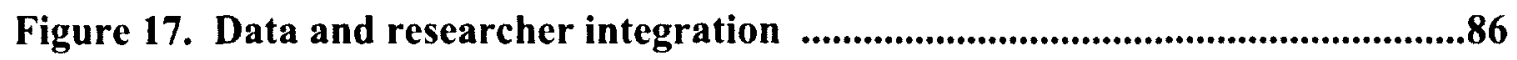

Figure 18. Conceptual model of leadership for innovation in the experience context

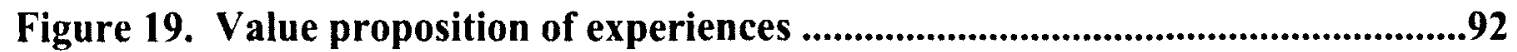

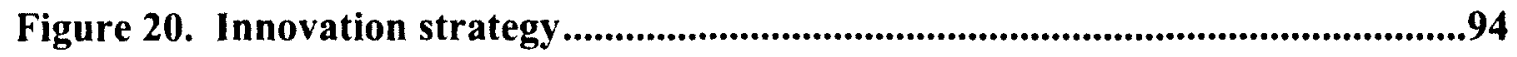


Figure 21. The refresh dimension represents idea generation in the experience

context

Figure 22. The connect dimension represents ways to focus innovation activities on the unique guest experience 101

Figure 23. The energize dimension represents idea implementation in the experience context

Figure 24. Preliminary list of managerial behaviors and leadership practices ......114 Figure 25. Managerial behaviors and leadership practices in the experience context

Figure 26. Excerpt of survey items from the leadership and innovation survey introducing the five-point scale description 122

Figure 27. Leadership and innovation survey: value proposition .132

Figure 28. Innovation strategy: more than $\mathbf{5 0 \%}$ respondents

Figure 29. Innovation strategy: less than $\mathbf{5 0 \%}$ respondents .135

Figure 30. Scree plot showing eigenvalues of factors 137

Figure 31. Senior manager influence vs. correlation with innovation based on low, medium, high distinctions per rank ordered list 147

Figure 32. Leadership and innovation survey: front of the house output examples

Figure 33. Examples of back of the house innovation outputs 153 


\section{CHAPTER ONE}

\section{BACKGROUND AND PURPOSE OF THE STUDY}

Business organizations are in the midst of transition, driven in large part by globalization and technological advances. Harvard Business Review (2011) recently devoted an entire issue to the topic of embracing complexity, while a recent cover of Fast Company magazine (2012) declares: Modern Business is Pure Chaos. During this "unhinging of the expected" (Boyd, 2012, p. 71), as command and control hierarchical structures disintegrate amidst chaotic conditions, industries must apply different techniques. In what the Fast Company editor terms a world of flux, what constitutes success for one industry or company doesn't necessarily work for another and even if it does, it may not work for long (Safian, 2012). Clearly, the art and science of managing and leading in business organizations is getting more difficult and complex, even as budgets and resources are being reduced to mitigate the challenges of tough economic times.

Although the tendency in organizations during times of increasing chaos is for managers to seek more control (Wheatley, 2010), it seems clear that the organizations that embrace complexity and adapt to change are most suited for these fast-paced, evershifting business conditions. This dissertation inquiry sought to explore the state of transition facing many business organizations. More specifically, this study examined organizations in the hospitality and tourism industry as they wrestled with their own transitions during what some have called the experience economy (Pine \& Gilmore, 1998; 2011). 


\section{Background to the Study}

The hospitality and tourism marketplace, comprising organizations that offer lodging, dining, transportation, events, attractions, and other visitor services, is one of the largest industries in the world. It fuels economic growth in many countries while providing lasting memories to travelers across the globe. The World Tourism Organization estimates that there will be almost one billion tourists per year by 2013 , increasing to two billion by 2030 (WTO, 2012). The future traveler will be more global, more experienced, more informed, and more varied in their desires than ever before (Williams, 2006), challenging hospitality businesses to continuously innovate in order to provide compelling experiences to an increasingly demanding consumer.

Organizations in the hospitality and tourism marketplace may find keeping pace with the future traveler even more challenging as the industry transitions to what some have called the experience economy. This term, originally introduced by Pine and Gilmore (1998), suggests that the economy has evolved from the delivery of commodities to the delivery of goods, from goods to services, and presently, from services to experiences. According to these authors, delivering a total experience that differentiates from other related service competitors and resonates with target markets, is the most important factor in sustaining a premium pricing strategy and increasing brand equity over time.

Coffee illustrates this well. Coffee beans were originally considered an undifferentiated commodity. Then, companies like Folgers created grounded coffee products in a can, which consumers could purchase at the grocery store and prepare at home. During the service economy, the delivery of coffee became a service offered by 
restaurants and coffee carts, and even drive-thru coffee kiosks. Today, Starbucks, with their premium-priced coffee drinks, is most often credited with transforming coffee into an experience.

An adaptation of Pine and Gilmore's (1998) graph from their first book on the experience economy (Figure 1), demonstrates the evolution of economic value and its relationship to competitive position and pricing.

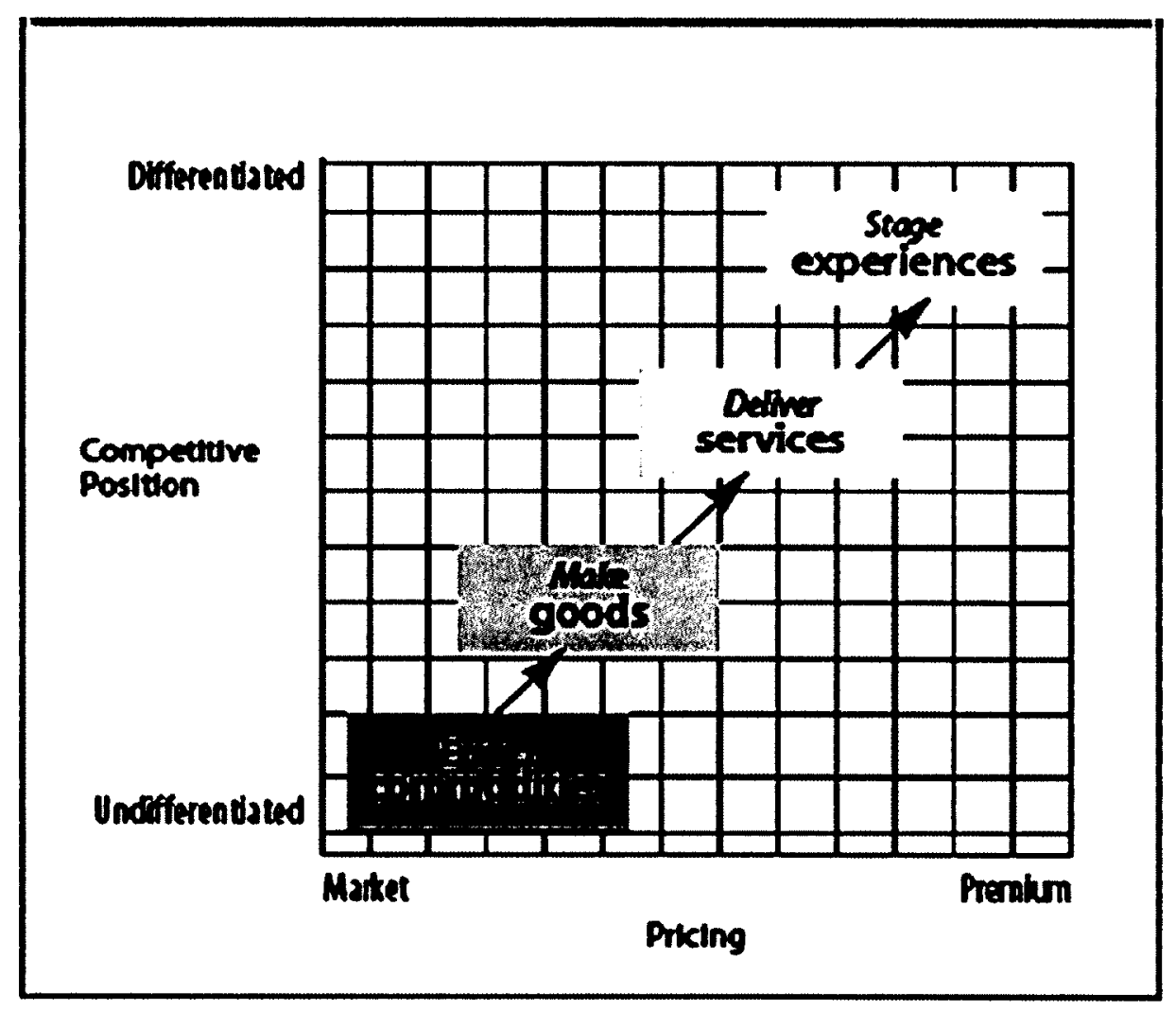

Figure 1. Economic value in business

The evolution of competitive strategy in hotels is also fairly consistent with the economic evolution posited by Pine and Gilmore-product to service to experience. In the product era, customers were promised a set of property attributes such as room size, swimming pools, architecture and design. Soon all hotels began to offer similar amenities, with very little differentiation in regards to customers (Boone \& Kurtz, 2004). 
A transition to a service orientation came next, when hospitality managers sought to respond to customer needs and focused on the consistent delivery of the service encounter (Carlzon, 1987). The lodging industry appears to be in the midst of transitioning to strategies that go beyond competition with service quality. Good service is now a given, at least in the hotel visitor's mind. Some of the leading companies like Ritz Carlton bundle amenities, service, personal values and emotional symbols into brand promises as a means to further distinguish their offerings in the competitive marketplace, a move that often pays off in terms of price premium (Keller, 2003).

As indicated, this transition from a service economy to an experience economy means that as services become more commoditized, perceptions of competitive advantage diminish. Therefore, all actions of the organization must contribute to the deliverance of experiential offerings that engage customers in a memorable way (Petkus, 2002). Travelers view destinations as a collection of engaging experiences delivered over time, accompanied by relevant goods and/or services components, resulting in lasting memories (Richards, 2001). It stands to reason that to continuously provide memorable experiences to destination travelers, organizations throughout the hospitality and tourism marketplace may need to transform the way their offerings are "deployed, configured, staffed, marketed, and sold" (Erdly \& Kesterson-Townes, 2003).

A commitment to promoting innovation is undoubtedly a prerequisite for organizational transformation, especially for firms operating in the memories business, where a unique and memorable experience is the predominant economic offering. Peter Drucker (1985) defined innovation as an "opportunity" that results in the creation of a new or different product or service. More recent definitions differentiate between the 
development of a new product or service and the implementation of the invention (Garcia \& Calatone, 2002). Thus, while an "innovative" individual or group may generate many new and novel ideas, for the idea to be defined as an innovation, it must be "combined with the market introduction...to end users" (p. 112). Innovation in the memories business, then, requires ongoing efforts to foster and encourage suggestions about how the guest experience is delivered, as well as support for new ideas for products and services. But ideas are not enough. Implicit in the definitions above, innovation requires an organizational strategy, culture, and procedures that can turn ideas into new and enhanced guest offerings for economic advantage.

It hardly seems necessary to tout the benefits of continuous innovation anymore (Wolcott \& Lippitz, 2009). Innovation has long been considered a major source of competitive advantage and economic growth, especially in turbulent environments (Schumpeter, 1934; Lawless \& Anderson, 1996; Porter \& Ketels, 2003; Chen \& Sawhney, 2008; Wolcott \& Lippitz, 2009). In contexts where the customer is always looking for new and different ways to satisfy their rising expectations, ongoing innovation of an experience that results in unique memories and provides emotional value seems necessary to sustain economic growth. Indeed, Pine (2010) recently declared that experience innovation is the future of hospitality and tourism strategy, although the specific means of deploying this strategy remains theoretical and anecdotal.

There is evidence that some organizations throughout the hospitality and tourism marketplace have embraced the experience economy paradigm and are transitioning from merely providing efficient and friendly service to a differentiated experience. The trade journals are rife with stories of experience-driven companies promoting the importance 
of continuously refreshing their guest offerings in innovative ways. For example, the Harvard Business Review blog suggests organizations look to Starbucks as a best-practice innovator of the customer experience in light of the fact that they market their locations as much more than a place to pick up a cup of coffee, calling them the "third space" (Rayport, 2012). Lodging Magazine highlights brands like Radisson that are attempting to "set a new experience in Chicago for urban hotel amenities, unparalleled service and exceptional design" (Savitt, 2012, p. 12). Readers of Fun World, the trade journal for amusement park operators, learn to emulate well-known innovators like Disney, which recently invested in a major refresh of its California Adventure Park to better connect guests to the Disney brand (O'Brien, 2010).

It seems important for practitioners to understand more about the nature of experience innovation and the means of delivering emotional value to their guests, particularly during these turbulent economic times. Although stories of best practices and headliner companies like Disney can be inspiring to organizations wrestling with the implementation of experience-oriented innovation, they are no substitute for systematic empirical research.

Figure 2 illustrates a synthesis of the scholarly research contributions from a variety of business disciplines during the past three decades. As the following chapter on the literature will explicate, innovation has been extensively studied using a model that entails examining the relationships between particular drivers of innovation inputs and outputs. However, very few of these studies examine the entire model as presented in Figure 2. In fact, most studies focus narrowly on new product development in manufacturing. In contrast to manufacturing companies, the major challenge for 
hospitality and tourism organizations that seek to compete through continuous innovation of the guest experience, is the integration and collaboration required to succeed. The essence of experience innovation seems to require continuously enhancing and clarifying the brand promise while simultaneously delivering that which is expected in all operational aspects, while keeping the guest experience at the core (Kwortnik \& Thompson, 2009).

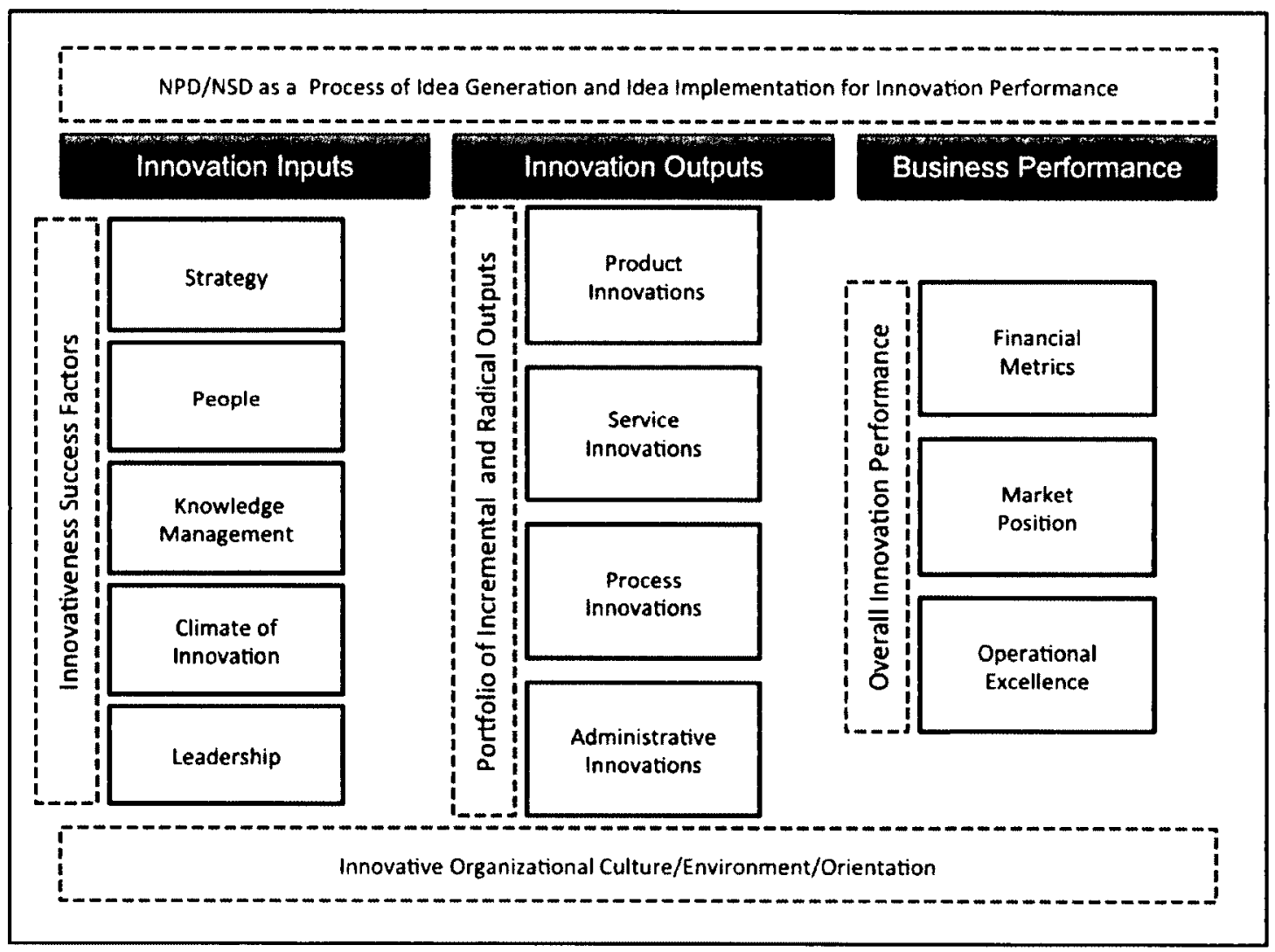

Figure 2. Innovation research in business

\section{Statement of the Problem}

Despite the vast quantity of innovation studies, a large percentage of the contributions are focused on product innovation outputs in manufacturing, while innovation theory in the services industry is still struggling to emerge. Less than fifteen years ago, research on "all but new product innovation (was) scant to nonexistent in the 
literature" (Han, Kim \& Srivastava, 1998). This is unfortunate, given that service organizations generate 85 percent of the current economy's gross domestic product in the United States (Rayport, 2012). In the last decade, some progress has been made to advance innovation theory in the context of the services sector, but the difficulties in applying product development theories to services are apparent. Scholars argue that the intangible nature of service outputs makes it difficult to measure and question whether innovation in the services sector can be understood through a similar theoretical framework as that used for manufacturing (Gallouj, 2002).

Competing in the experience economy requires an updated perspective on the innovation framework. The inherent challenges in applying the manufacturing innovation model to services are heightened when attempts are made to apply the framework to organizations operating within the experience economy paradigm as depicted in Figure 2. There are three major problems in using the current body of literature on innovation theory in business to address the hospitality and tourism industry-contextual issues, measurement, and a narrow focus.

First, the intangible nature and emotional value of the experience context is not represented by most studies found in the literature. A memorable hospitality experience goes beyond just good, or even great service. It is co-constructed by the guest, the interactions with employees, and the environment (Prahalad \& Ramaswamy, 2004). The power of innovations geared to providing unique experiences resides in an innovation's ability to create a strong emotional bond with customers, resulting in a greater likelihood of customer loyalty and premium prices (Lebel, Dube, Sears \& Renaghan, 2010). The 
current literatures' emphasis on product development ignores the co-constructed nature and emotional value of the hospitality and tourism experience.

The second problem in making the innovation literature relevant to managers in hospitality and tourism organizations relates to measurement. Clearly, traditional measures in manufacturing like the number of patents or research and development spending associated with the innovation outputs do not capture the emotional value associated with experience innovation (Hjalager, 2009). At the same time, the measures that the hospitality and tourism industry commonly uses to assess elements of service quality, such as speed of service and courtesy ratings (Zeithaml, Parasuraman, \& Berry, 1985) are not robust enough. Output typologies and outcome measures that accurately determine the value of innovations in the experience context are lacking.

Finally, it is becoming apparent that applying innovation theory to the hospitality and tourism industry requires a broader view of the innovation phenomenon. Scholars suggest that the current state of the innovation literature is too narrow, fragmented, and partial, limiting innovation to new product development, research and development processes, and the adoption and implementation of new technology (Chen \& Sawhney, 2008). Hospitality researchers echo the need for comprehensive examinations of innovation in the hospitality industry, noting that the narrow focus of prior innovation research ignores the "propensity of an organization to continually innovate as an organizational objective" (Siguaw, Simpson \& Enz 2006, p. 556).

There is evidence, however, of a recent trend supporting expansion of the concept of innovation that is consistent with organizations offering experiences. The Office of Economic Cooperation and Development (OECD, 2005) broadened the concept of 
innovation to encompass marketing, internal organizational and external relationship innovation. A recent instrument, Innovation Radar, segments innovation activities into three generic strategies based on customer value-functional, economic, or emotional (Wolcott \& Lippitz, 2009). Additionally, terms like demand-side innovation have been offered to encourage focus on innovation based not on what a company sells, but how a company sells it (Rayport, 2012).

In summary, studies relevant to managers in the memories business will address the problems with the current innovation literature related to context and measurement. Useful research initiatives will also employ a broad perspective of innovation that attends to the full spectrum of innovation success factors like strategy and culture, as well as policies that support a diversity of innovation outputs for improved business performance. A national employee survey of hospitality workers found that while 78 percent of hospitality employees said their organization is committed to quality service, only 56 percent feel their organization's administrative policies and practices promote the best guest experience (Savitt, 2012). Using the language of the hospitality and tourism context, perhaps what is needed is a new perspective that begins with examining what goes on in the back of the house to influence organizational innovation. The new perspective, in other words, should be on strategy, culture, policies and practices, and leadership of the organization.

The management of comprehensive organizational transformation, strategy, and culture in business has long been considered the purview of senior level managers. Strategic leadership theory emphasizes the influence of top-level managers on an organization's ability to adapt and change (House, Wright, \& Aditya, 1997). Strategic 
leadership theory, with its emphasis on leadership of organizations, as distinguished from leadership in organizations, is consistent with the notion of broad-based organizational change efforts. The salient question becomes: What does leadership for innovation within the context of the experience economy look and feel like?

Unfortunately, there are very few studies of comprehensive approaches to innovation in the services sector, and even fewer within the hospitality and tourism subsector. The small number of studies conducted in the experience economy context focused on guest satisfaction ratings. For example, Hosany and Witham (2009) studied guest ratings of entertainment, education, esthetics, and escapism in the cruise industry. The means to achieving innovations in guest experiences has been discussed theoretically, but empirical studies that focus on what the industry calls back of the house influences are scant. There also is little empirical research regarding leadership within the context of the experience economy, leaving senior managers in industries like hospitality and tourism to wrestle with having to improvise regarding their role in the development of compelling experiences for an increasingly demanding and savvy consumer. There is a pressing need for comprehensive examinations of leadership for innovation within the context of the experience economy paradigm.

\section{Purpose of the Study and Research Questions}

The hospitality and tourism marketplace in San Diego provides a rich environment for studying leadership in the context of the experience economy. The San Diego visitor industry is the third largest industry in San Diego. It provides $\$ 16$ billion in economic impact and, consequently, is a very important piece of the economic health of 
the region. Indeed, San Diego is one of the top five leisure vacation destinations in the United States and one of the top ten destinations for business travelers (SDCVB, 2012).

There is much to learn about the current state of innovation from organizations in the San Diego context representing experience-oriented businesses across the lodging, dining, meetings/events, and attractions segments. The senior managers of these San Diego companies certainly are able to provide insights into the ways they define, measure, and attempt to influence innovation during these chaotic and complex economic times.

The purpose of this dissertation inquiry was three-fold. First, this study was intended to provide measures of innovation within the context of the experience economy paradigm. Second, this study was intended to explore the ways senior managers, those key to organization-wide change and innovation strategy, influence what they perceive as organizational innovation, broadly conceived. And finally, this study was designed to examine the relationships of senior manager influence (leadership), and various innovation outcomes within a local hospitality and tourism marketplace.

Hence, this study was designed to help answer the overarching research question: How does strategic leadership influence innovation in organizations whose main economic offering is an experience? Additional research questions embedded in the design were:

1. To what extent is innovation defined and measured in the segments of the San Diego hospitality and tourism marketplace, and what are these definitions and measures? 
2. In what ways, if any, do senior managers influence innovation in the hospitality and tourism industry in San Diego?

3. What are the relationships, if any, between senior manager influence and innovation in organizations whose main economic offering is an experience?

The overall intent of this inquiry, then, was to extend the work already done regarding innovation in business by examining the construct in an understudied context. The goal was to offer a back of the house view of the ways senior managers influence innovation in organizations whose main economic offering is an experience. 


\section{CHAPTER TWO}

\section{REVIEW OF THE LITERATURE}

A review of the relevant literature in several fields of study-including, but not limited to innovation, the experience economy, the hospitality and tourism industry context, and leadership-is presented in three sections. The three objectives of this literature review are: a) to examine the vast innovation literature in order to arrive at a conceptual framework that is representative of the ways innovation has been studied from the business perspective $b$ ) to consider the emerging paradigm of the experience economy, including its critiques, in order to understand how extant innovation theory converges and diverges within the context of the hospitality and tourism industry and c) to trace the evolution of major leadership theories in order to understand how contemporary views of strategic leadership may be helpful to senior managers in hospitality and tourism organizations whose main economic offering is an experience.

\section{Integrating Innovation Theory in Business}

Innovation has long been considered a major source of competitive advantage and economic growth, particularly in turbulent environments (Schumpeter, 1934; Lawless \& Anderson, 1996; Porter \& Ketels, 2003), and research about innovation is plentiful and diverse. For example, in the past 35 years substantial research has been conducted to examine innovation in the business environment, where innovation can be thought of as a means of changing a business organization, either as a response to the environment or a preemptive action intending to influence the environment (Damanpour, 1991). The broad topic of innovation has been studied by various academic disciplines including marketing, organizational behavior, strategic management, and economics. Despite the 
vast quantity of innovation studies, a large percentage of the contributions are focused on product innovation outputs in manufacturing, while innovation theory in the services industry is still struggling to emerge. The purpose of this section of the literature review is to examine the vast bodies of innovation literature in order to arrive at a conceptual framework that is representative of the ways innovation has been studied in business.

\section{Definitions}

Despite the quantity and breadth of the innovation research, ambiguities about the definitions of innovation exist, and findings, within and across disciplines, have not been cumulative (Adams, Bessant, \& Phelps, 2006). Innovation has been defined as both a means and an end, as a process and an outcome. For example, the innovation process has been defined as "the successful exploitation of new ideas" (Adams, Bessant, \& Phelps, 2006, p. 21). Innovation outputs have been distinguished as new products (Gallouj \& Weinstein, 1997), technological and organizational innovations (Van der Aa \& Elfring, 2002), and new services (Gallouj, 2002) among other designations. Most definitions of innovation in business contain basic elements regarding newness and novelty, although new is a relative term, that may simply mean new for the particular business unit (Damanpour, 1996). Peter Drucker (1985) defined innovation as an "opportunity" that results in the creation of a new or different product or service.

In most of the research that explicates overall innovation performance comprehensively, researchers differentiate the development of new products and services from the implementation of the invention (Garcia \& Calatone, 2002). Thus, while an "innovative" individual or group may generate many new and novel ideas, for any of these to be defined as an innovation, it must be "combined with the market 
introduction...to end users" (p. 112). This is an important distinction, because as some research indicates (Mumford, Scott, Gaddis, \& Strange, 2002), the behaviors needed to stimulate idea generation may be different than the behaviors required for successful implementation of these ideas. Indeed, this differentiation has been viewed as a key structural and contextual paradox for organizations seeking innovation as the overriding organizational objective because it requires both exploration and exploitation activities (Tushman \& O’Reilly, 1996).

In order to arrive at a conceptual research framework of innovation in business, I will discuss the relevant literature as it relates to three things: innovation outputs, the innovation process, and the factors affecting overall innovation performance. Although the concepts of creativity, entrepreneurism, and organizational change are closely related to the notion of innovation, and even used interchangeably in some instances, they are not reviewed here. I limit the discussion to the following innovation definitions, as they best represent the business-related literature and serve to provide some boundaries for examining the extensive streams of innovation theory research: Innovativeness - the development of novel ideas Innovation Outputs - new or improved products, services, processes, or administrative practices that have been generated by the business organization Overall Innovation Performance - successful development and implementation of novel ideas, products, services, process, and/or administrative practices to bring about improved business performance 


\section{Innovation as Outputs}

Classifying innovation outputs has been the subject of much confusion and discussion among practitioners and researchers alike. This seems to center around the various forms that innovation outputs can take, as well as the degree of novelty or newness in various outputs. Although innovation research has advanced greatly in the past two decades, concerns remain about ambiguity in defining the innovation types (Garcia \& Calantone, 2002).

Product innovation outputs: new or modified. The majority of the business studies in innovation have focused on the manufacturing sector and new products as innovation outputs. New product innovation outputs are often measured through patents (Gallouj \& Weinstein, 1997), and are the subject of much of the extant innovation research (Utterback, 1994; Damanpour, 1991; Subramanian \& Nilakanta, 1996; Adams, Bessant, \& Phelps, 2006). While it might seem that classifying the tangible nature of a product would be simple, confusion arises around the level of novelty of the new product. Innovation scholars, concerned with whether a product innovation is really a new product or merely a modification of an existing product have produced a stream of literature that seeks to create output typologies based on the level or degree of innovativeness (Damanpour, 1996). Hence, innovation outputs have been classified as radical, meaning they redefine the market, or incremental, meaning they are defined as minor improvements (Lawless \& Anderson, 1996). Other studies have used the terms breakthrough and reformulated (Yoon \& Lilien, 1985) and disruptive and sustaining (Christensen, 1997) to distinguish between innovations that are truly new or merely incremental improvements. Reviews of the new product development literature indicate 
that these ambiguities in the classification schemes make it difficult to compare research studies and build new knowledge (Garcia \& Calatone, 2002).

Service innovation outputs: fuzzy nature. Fifteen years ago, research on "all but new product innovation [was] scant to nonexistent in the literature" (Han, Kim \& Srivastava, 1998). In the past decade, some progress has been made to advance innovation theory in services, but researchers continue to point to the dearth of studies in the services sector relative to manufacturing (Prajogo, 2006). Studies from the services sector also acknowledge the vague and inconsistent conceptualizations of what innovation means, as well as the confusion surrounding service innovation outputs as new products/services versus modifications of existing products and services (Jones, 1996).

Ambiguities about the different types of service innovations and the "fuzzy nature of service outputs" make it difficult to measure and detect improvement (Van der Aa \& Elfring, 2002). Scholars have found it difficult to explain innovation in service terms using traditional typologies (Damanpour, 1996), and they question whether innovation in the services sector can be understood from a theoretical framework that is similar to manufacturing (Gallouj, 2002).

Process/administrative innovation outputs: basic work activities. Additional discussion of innovation outputs in business extends beyond the spectrum of incremental and radical product and service innovations that are directly observed by the customer. Process and administrative innovations refer to the basic work activities of the firm (Tushman \& O’Reilly, 1996). Process innovations are changes in ways of doing business or the way execution occurs (Barret \& Sexton, 2006). Much of the process innovation 
studies relate to technological processes; in some instances, process innovation outputs are referred to as technical innovations (Hjalager, 2009). Tushman \& Nadler (1986) used the term administrative innovations to describe outputs resulting from administrative activities and organizational structure. Similarly, the term managerial innovation is used to classify outputs reflecting new ways of organizing, directing, and empowering staff (Hall \& Allan, 2008).

\section{Innovation as Process}

The categories of innovation outputs-product, service, process, and administrative - are important for both practitioners and academics as they seek to understand and manage innovation actions (Adams, Bessant, \& Phelps, 2006). Scholars have investigated questions of how best to develop or adopt products, services, processes, and administrative actions in a manner that focuses on both project selection and implementation (Cooper, 2006). Hence, a large collection of studies examines innovation as a process, a multi-phase activity of adopting innovation outputs (Van de Ven, Angle, \& Poole, 2000). Much of the innovation as process research is aimed at practitioners, and is fairly prescriptive in nature (Siguaw, Simpson, \& Enz, 2006). Research has empirically demonstrated that using formal processes in the development of new products is associated with organizational success in terms of time to market and number of innovation outputs (Griffin, 1997).

There have been a number of studies focused on the new product development process as a sequential collection of activities that include identifying an opportunity, investment in research, opportunity evaluation, design and engineering, experimentation and testing, and product launch (Hidalgo \& Albors, 2008). Consistent with the notion 
that the innovation process involves both idea generation and idea implementation, is the work of Damanpour and Schneider (2006) on the phases of adoption of innovation in organizations. They identified three phases of innovation adoption - initiation, adoption decision, and implementation-representing activities from pre-adoption through postadoption. The emerging view in business is that product development is an end-to-end process of ideation to implementation that draws on engineering, manufacturing, marketing, and organizational development literature (Hauser, Tellis, \& Griffin, 2006).

Delineating the new service development process has been more problematic. A few researchers have taken what has been called an "assimilative approach" (Flikkema, Janssen, \& Van Der Sluis, 2007, p. 543), seeking to understand new service development in the same way that new product development is theorized. Barras (1986), for example, introduced a three-stage model of increasing efficiency in stage one, service quality improvement in stage two, and new service generation in stage three. In service industries that are highly dependent on customer interaction, the service development process has been described as ranging from a "highly systematic research and development process to a chaotic, reckless dash to beat competitors to the market" (Jones, 1996, p. 2). The current view in the service innovation literature is that the nature of service innovation as a process is vastly different from new product development, and scholars are exploring a broad range of new theories, instruments, typologies, and success factors (Van der Aa \& Elfring, 2002).

\section{Innovation Inputs}

Scholars from economics, management, marketing, and engineering offer a variety of contributions related to the factors that affect innovation outputs and 
performance. I will discuss briefly the various factors, sometimes referred to in the literature as drivers, inputs, determinants, and antecedents, in five broad areas-strategy, people, knowledge, climate, and leadership.

Strategy. Schumpeter (1934) is credited with being the first to recognize that an innovation strategy is key to economic growth in organizations. An innovation-focused business strategy is one in which a firm emphasizes innovativeness in its problem solving, constantly seeks to exploit new product and market opportunities, explores emerging trends and attempts to be on the cutting edge (Miles \& Snow, 1978). Businesses employing the innovation strategy have been shown to outperform their competitors (Hill \& Jones, 1998, Hippel, Thomke, \& Sonnnack, 1999; Kim \& Mauborgne, 2005; Anthony, Eyring, and Gibson, 2006). Several of the studies related to the deployment of an innovation strategy focus on the positive relationship between innovation as a strategic intent and business performance, although a few include the perceptions of executives that innovation strategy can also be costly and amplify employee dissatisfaction, stress, and turnover (Siguaw, Simpson \& Enz, 2006).

People. Deploying an innovation strategy requires involving people throughout the organization. Individuals' innovativeness improves when they are engaged in meaningful issues (Wheatly, 2010). Innovation at the work group and project team level is enhanced when a combination of learning, organizing, and building personas interact (Kelly \& Littman, 2005). A study of the firms in Spain with the largest number of registered patents found that new product innovation outputs required diverse, cohesive, and autonomous work teams whose employees used many informal communication methods (Carmen, de la Luz, \& Salustiano, 2006). 
An emerging stream of innovation literature acknowledges the importance of behavioral ambidexterity to organizational innovation, which is defined as the capacity to conduct exploration and exploitation activities simultaneously (Lin \& McDonough, 2011). Innovation requires businesses to execute fundamentals while continuously pursuing new endeavors. This paradox requires people who can navigate the innovate/execute tension (Rosing, Frese \& Bausch, 2011).

Knowledge management. Organizational knowledge has been linked with innovation and change since Peter Senge (1990) popularized the notion of the learning organization. Knowledge management is considered an important innovation-enabling competency (Gumusluoglu \& Ilsev, 2009). Manufacturing firms have long considered investment in research and development (R\&D) to be a knowledge enhancing capability, although the actual return on investment from $R \& D$ spending is not always consistent with business performance (Jaruzelski, Loehr, \& Holman, 2011). Although measurement inconsistencies make it difficult to determine the relationships among learning and innovation, a learning philosophy is often discussed in theoretical papers (Damanpour, 1991; Amabile, 1998; Worren, Morre, \& Cardona, 2002; Siguaw, Simpson, \& Enz, 2006).

Climate. Innovative climates are related to innovation in both manufacturing (Scott \& Bruce, 1994) and service sectors such as healthcare, banking, social services, consulting and education (Mathison \& Einarsen, 2004). The 22 item questionnaire developed by Scott and Bruce (1994) and 61 item inventory developed by Anderson and West (1996) operationalize a climate for innovation across four dimensions--support for innovation, participative safety, vision, and task orientation. A climate for innovation has 
frequently been associated with innovation outputs (Anderson, \& West, 1998; Loo, 2003; Burch \& Anderson, 2004; Ragazzoni, Baiardi, \& Zotti, 2002) and overall innovation performance (Scott \& Bruce, 1994; Jung, Chow, \& Wu, 2003; Gil, Rico, Alcover, \& Barrasa, 2005; Sarros, Cooper, \& Santora, 2008).

Leadership. The role of leadership in relation to climate for innovation, innovation as a process, outputs, and overall performance has received some attention in the literature in the past decade, with studies of flexible leadership (Yukl, 2004) and transformational leadership (Jung, Wu, \& Chow, 2008) contributing. Leadership for innovation is discussed in greater detail later in the third section of this literature review-strategic leadership for experience innovation.

\section{Innovative Organizational Culture/Orientation}

The inclusion of climate and culture in the innovation literature is important. Culture and climate can be viewed as distinct but interrelated constructs. Culture refers to the meanings inherent in the actions, procedures, and protocols of an organization (Driskill \& Brenton 2005). Culture is specific to an organization and relatively constant (Smircich, 1983). Climate describes the way individuals perceive the personal impact of their work environment on themselves (Glisson \& James, 2002).

Past studies have looked extensively at the relationship between organizational culture and important organizational variables including organizational performance (Kotter \& Heskett, 1992; LeBlanc \& Mills, 1995; Xenikou \& Simosi, 2006), effectiveness (Denison \& Mishra, 1995; Kemp \& Dwyer, 2001), work-related attitudes (Birnbaum \& Sommers, 1986) and profitability (Tidball, 1988). Innovation research findings indicate that change-oriented leaders (Gil et al., 2005) and transformational 
leaders (Jung et al., 2003; Sarros et al., 2008) help build a strong organizational culture in support of a positive climate for innovation.

Similarly, Hargadon, and Sutton (2000) make explicit what is well known by leading hospitality organizations with rich cultures such as Southwest Airlines, Ritz Carlton, and Starbucks, which is that service innovation "has everything to do with organization and attitude" (p. 157). An extension of this notion, then, is that experience innovation has everything to do with fostering a compelling, innovation oriented culture that focuses on the customer experience. Since stronger organizational cultures exert greater influence on individual and group behavior (Trefry, 2006), organizations competing in the experience economy would do well to develop and enable an innovation oriented, customer experience focused organizational culture.

There is emerging support for studies that offer a more comprehensive approach to the study of innovation such as the research agenda submitted by Siguaw, Simpson, and Enz (2006), which examines a concept they define as innovation orientation. They provide theoretical arguments for an overarching innovation orientation that begins with an innovation-enabling culture.

A multidimensional knowledge structure, composed of a learning philosophy, strategic direction, and transfunctional beliefs that, in turn, guide and direct all organizational strategies and actions, including those embedded in the formal and informal systems, behaviors, competencies, and processes of the firm to promote innovative thinking and facilitate successful development, evolution, and execution of innovations (p. 560).

\section{An Integrated Framework}

Making sense of the innovation phenomenon in order to study it in a comprehensive way can be daunting because empirical inquiries usually examine only a small aspect of innovation. Figure 2 illustrates my own synthesis of the literature related 
to business innovation, as outlined in the previous sections of this review. In this

framework, I attempt to conceptually integrate the considerable contributions made by scholars in a variety of business disciplines.

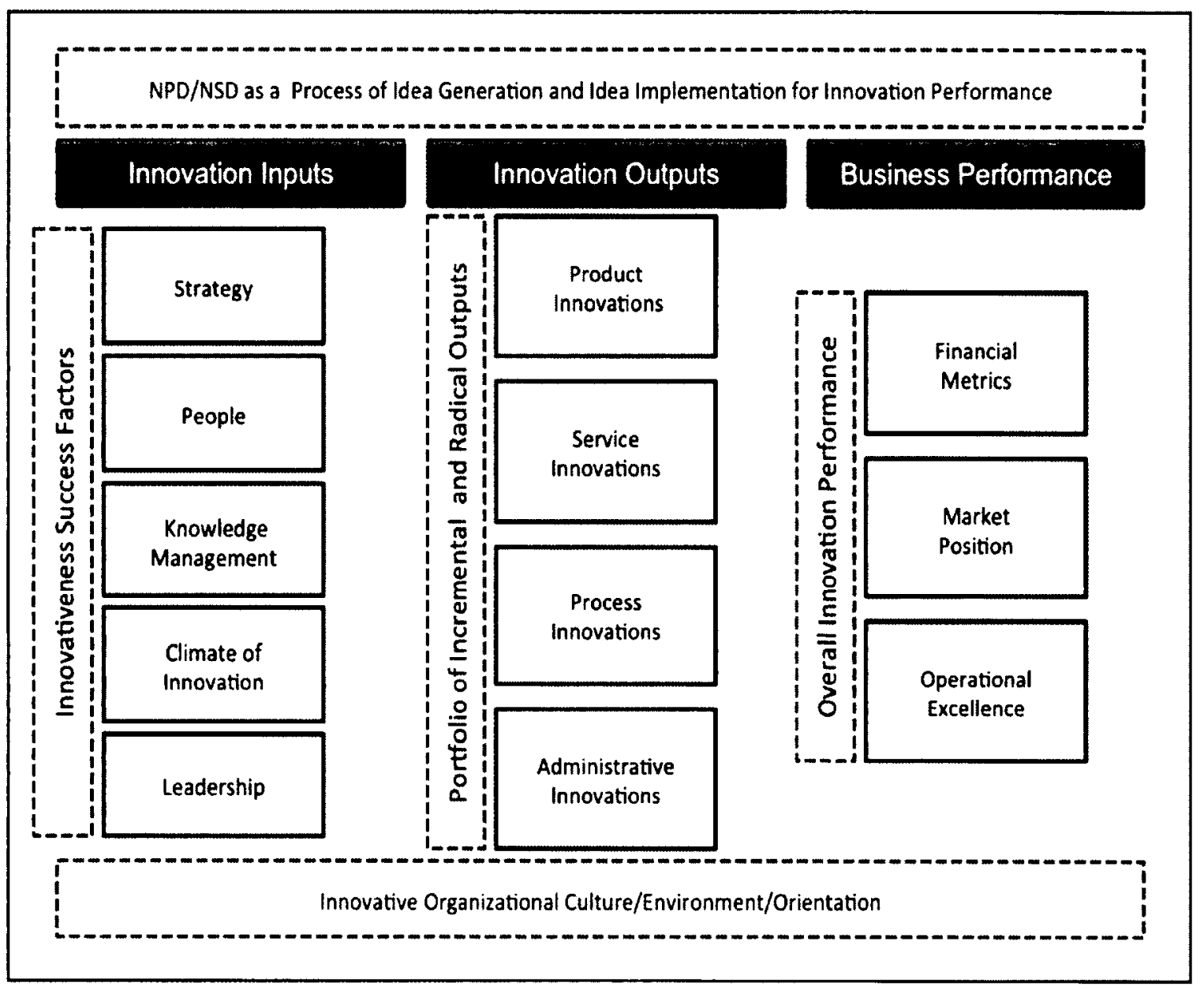

Figure 2. Innovation research in business (from Chapter One) is repeated here

Much of the research in business is quantitative in nature and views innovation as an input/output model. A large number of innovation inputs have been examined, and the five areas I chose as broad input categories are listed on the left side of the framework. Collectively, these inputs might be called success factors, or factors that are associated with innovativeness - the development of novel ideas. The innovation outputs column of the framework has been the focus of much of the theoretical work in the literature. The 
outputs of a business that is innovative are a collection of incremental and radical product, service, process, and administrative innovations. The far right hand column represents the ideal, measurable business results that innovative businesses, with the right collection of innovation outputs purchased by consumers, would expect to achieve, which is a competitive advantage and economic growth, as Schumpeter (1934) posited.

Economic benefits continue to be at the heart of why businesses innovate.

The framework also recognizes that innovation has been studied as a process that spans the input/output model and includes idea generation and idea implementation for innovation performance. The product development process has been studied theoretically and empirically, and accounts for the bulk of the research consumed by practitioners today. Embedded in the innovation as process approach is the concept of ambidexterity (Tushman \& O’Reilly, 1996; Lin \& McDonough, 2011), in which businesses strive to simultaneously execute business fundamentals while improving their current offerings and innovating for the future.

The comprehensive approach to business innovation as an environment/culture/orientation, which permeates all aspects of the organization, is shown across the bottom of the framework, although this remains largely theoretical in the existing scholarly literature. Indeed, this research framework is largely a theoretical undertaking - a depiction of the considerable ways that innovation has been studied, mostly in product manufacturing. 


\section{Summary of Section}

This first section of the literature review serves as the foundation for a study of experience innovation in context, synthesizing 35 years of scholarly contributions to the innovation literature in business. The manufacturing industry provides the bulk of the research backdrop, with studies of innovation inputs, outputs, and their relationships to overall business performance. While there is little controversy regarding the importance of innovation for businesses operating in contexts of intense competition and rapidly changing markets, the paths to overall innovation performance are varied, and comprehensive studies are rare. Despite the vast quantity of research, there remain ambiguities in definitions, levels of innovativeness, and ways of measuring, all of which make cross-discipline and comprehensive generalizations difficult. These challenges are heightened as the economic offering becomes more intangible in nature and traditional measures like research and development costs and patents are less relevant.

The literature is clear about the paradox of innovation in business organizations. Innovation goes beyond creativity, invention, or innovativeness; innovation requires idea generation and idea implementation, exploring and exploiting activities. The

fundamentally different activities involved in sustaining business fundamentals while pursuing new and improved products, services, processes, and other work activities present inherent tensions for organizations seeking continuous innovation as an overriding organizational objective.

A conceptual framework integrating the ways that business has studied innovation was offered in section one and provides a natural starting point for inquiries into innovation in the hospitality and tourism industry. What we still need to know, though, is 
how extant theory converges and diverges within the context of the hospitality and tourism industry. Therefore, the second section of this paper explores literature related to the context of the hospitality and tourism industry.

\section{Applying Experience Innovation to the Hospitality and Tourism Context}

The hospitality and tourism industry, comprised of organizations offering lodging, dining, transportation, events, attractions, and other visitor services, is one of the largest service industries in the world. The World Tourism Organization estimates there will be more than one billion tourists a year by 2013 (WTO, 2011). Innovation is a means of achieving improved business performance, particularly in contexts with intense competition, rapidly changing markets, and increasing customer demand for higher quality products and services (Damanpour \& Schneider, 2006). It hardly seems necessary to justify the importance of studying innovation in the hospitality and tourism context. The future traveler will be more global, more experienced, more informed, and more varied in their desires than ever before (Williams, 2006), challenging hospitality and tourism businesses to continuously innovate their offerings in order to provide compelling experiences to an increasingly demanding and savvy consumer.

Researchers continue to point to the dearth of innovation studies in services relative to manufacturing while simultaneously calling for a broader perspective of innovation in the services sector (Van der Aa \& Elfring, 2002; Prajogo, 2006). Some scholars argue that the fuzzy nature of service outputs make it difficult to measure and detect improvement (Gallouj \& Weinstein, 1997) and question whether innovation in the services sector can be understood from a theoretical framework similar to that of manufacturing (Gallouj, 2002). Hospitality researchers echo the need for comprehensive 
examinations of innovation in the services industry, observing in the process that the narrow focus of prior innovation research ignores the "propensity of an organization to continually innovate as an organizational objective" (Siguaw, Simpson \& Enz 2006, p. 556). The purpose of this section of the literature review is to consider the emerging paradigm of the experience economy in order to understand how extant innovation theory in business can be applied within the context of the hospitality and tourism industry.

\section{The Experience Economy}

Overview of the paradigm. Pine and Gilmore's (1998) work related to the experience economy provides an intriguing argument for why studying innovation in the hospitality and tourism industry using only the input/output framework useful to product innovation research is inadequate. They argue that the American economy has evolved from commodities to goods, and from goods to services, and we are now evolving from services into an experience economy. A business creates an experience when it "intentionally uses services as the stage and goods as props, to engage individual customers in a way that creates a memorable event" (p. 98).

Coffee provides an illuminative example. Coffee beans were considered a commodity until companies like Folgers created coffee products in a can that consumers could purchase at the grocery store and prepare at home. During the service economy, the delivery of coffee became a service offered by restaurants and coffee carts, and even drive thru coffee kiosks. Today, Starbucks is most often credited with transforming coffee into an experience.

Realms of experience. Pine and Gilmore segment experiences into four broad categories based on where they fall along the dimensions of passive/active participation 
and absorption/immersion connection. Entertainment experiences such as watching a show tend to be passive and involve more absorption than immersion, while esthetic experiences such as a visit to an art gallery are immersive, but in both cases the participants remain fairly passive. Educational and escapist experiences require active participation on the part of the consumer, like descending the Grand Canyon (escapist) or taking a ski lesson (educational). The richest experiences (like going to Disneyland) encompass all aspects, forming a "sweet spot" (p. 102).

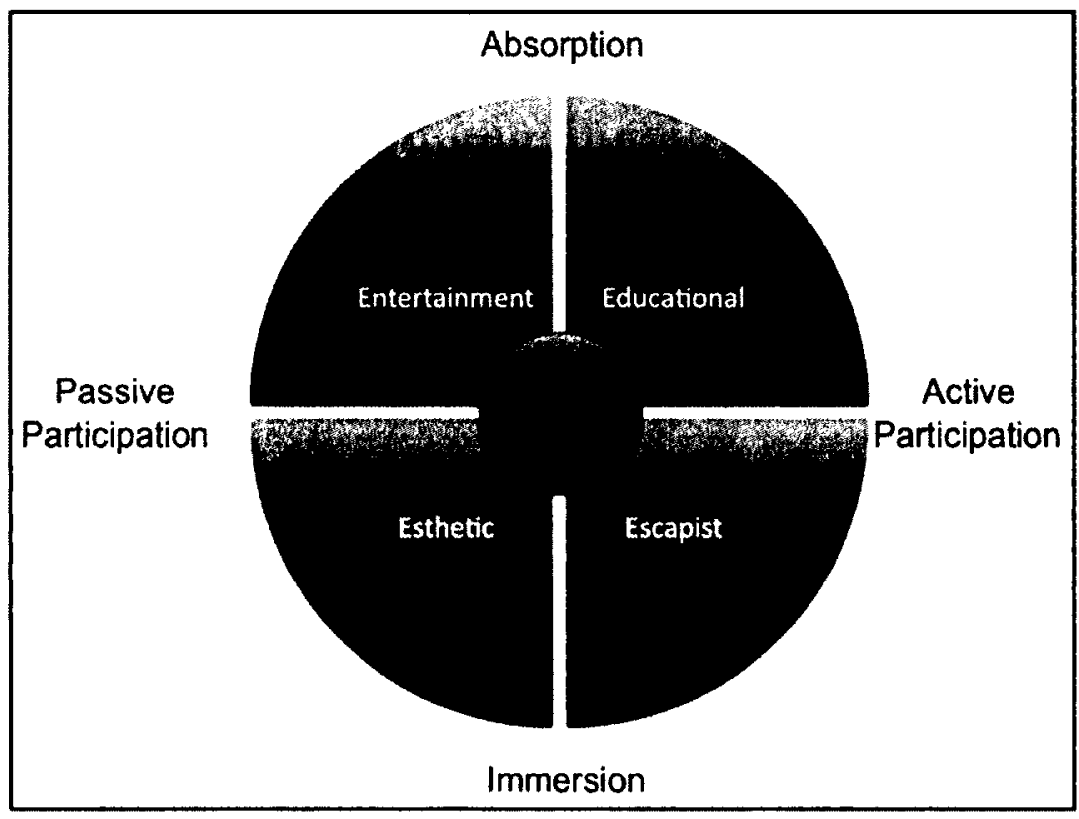

Figure 3. Realms of experience

Critiques of the experience economy paradigm. Although Pine and Gilmore's work is often cited, even making the lists of the all time best 100 business books, their work has received some critiques. These include a group of scholars who claim that the experience economy isn't really a new paradigm at all, voices that criticize the overly capitalistic nature of the book, and claims that the theory ignores the co-constructed nature of consumer experiences. I will address each of these in terms of its significance for innovation research in the hospitality and tourism industry context. 
Alvin Toffler, in his book Future Shock (1970), may have been the first to envision experience industries emerging as a new sector of the economy of the future. Other authors have used terms similar to Pine and Gilmore's to describe a developing economic sector. The terms knowledge economy (Neef, 1998), attention economy (Davenport \& Beck, 2001), and the emotion economy (Nijs, 2003) have been used to describe emerging economic societies.

It has also been suggested that experience could merely be a subset of the services sector (Gronroos, 2000), and that the hospitality and tourism industry has been discussing Pine and Gilmore's theoretical notions for years (Palmer, 2008). These critiques, however, don't necessarily serve to diminish the utility of the experience economy paradigm. Indeed, they affirm the notion that new economic offerings are of necessity, going to be about differentiation, personalization, and emotion, potentially requiring new strategic approaches (Kim \& Mauborgne, 2005).

There is some merit and utility in Pine and Gilmore's theory, especially in their ability to distinguish services from experiences. The economic distinctions between goods, services, and experiences that they offer in the updated edition of The Experience Economy (2011) seem to hold true for the hospitality and tourism industry. For example, Pine and Gilmore argue that the nature of the economic offering for a good is tangible, for services intangible, and for experiences memorable. The method of supply for a good is inventoried after production, for a service is delivered on demand, and for an experience, is revealed over time. The factors of demand are differentiated as features for a product, benefits for a service, and sensations for an experience. Similarly, experience has served as a key theoretical construct in the tourism related literature. Destinations are 
viewed as a collection of engaging experiences, delivered over time, accompanied by the goods and/or services components of the destinations, resulting in lasting memories (Richards, 2001).

A second critique of Pine and Gilmore's body of work is that their theory takes too narrow a view of experience (Quan \& Wang, 2004) and focuses only on the money making potential of the experience as an economic offering (Rifkin, 2000). These critics have difficulty with the experience as theater metaphor that Pine and Gilmore use throughout the book and imply that "staged events" (Pine \& Gilmore, 1998, p. 98) are inauthentic. Perhaps Pine and Gilmore took this particular criticism to heart as their follow up book is titled Authenticity (Gilmore \& Pine, 2007). In terms of application to the hospitality and tourism industry, the revenue producing potential of experience as an economic offering is a valid concern; after all, innovation in business is about ideas implemented in the marketplace. The discussion around the relative authenticity of these experiences also seems applicable to the hospitality and tourism industry, particularly in light of the third critique of the experience economy paradigm - that it shortchanges the co-construction characteristic of experience.

A unique characteristic of the hospitality and tourism related experience is that it is simultaneously produced and consumed. The consumer is co-creating the experience, and often plays an active role (Prahalad \& Ramaswamy, 2004). Although Pine and Gilmore allude to the active involvement of the consumer, the authors admit that they "focus primarily on the supply side of experiences" (Pine \& Gilmore, 2011, p. 16). Indeed, it is the co-constructed nature of the hospitality and tourism experience that 
makes measurement so difficult (Hjalager, 2009) and continues to present obstacles for experience innovation researchers (Sundbo, 2009).

\section{Experience Innovation in the Hospitality and Tourism Industry}

One definition of experience innovation integrates the theoretical constructs of the experience economy and innovation, describing hospitality and tourism businesses that create memorable experiences: Experience innovation is the ongoing development and implementation of novel ideas, processes, products, and services to bring about continuous innovation in the customer experience.

Evolution of the customer experience. Researchers and practitioners in the hospitality and tourism industry, particularly those in marketing demonstrate appreciation for the notion of selling a total experience. The evolution of the strategic approaches to competition in hospitality and tourism businesses is fairly consistent with the economic evolution posited by Pine and Gilmore-product to service to experience.

Prior to the 1970s most hospitality companies were product oriented. For example, Kemmons Wilson, considered the pioneer of the lodging industry, developed the Holiday Inn concept based on consistent execution of standard operating procedures (LeBel, Dube, Sears, \& Renaghan, 2010). Customers were promised a set of property attributes such as room size, swimming pools, architecture and design (Boone \& Kurtz, 2004). This instigated a trend in which all hotels began offering similar amenities, resulting in very little differentiation in the customer's mind.

During the 1980s, a service orientation dominated as the source of differentiation in hospitality and tourism organizations. Properties sought to respond to customer needs and focused on the consistent delivery of the service encounter (Carlzon, 1987). The 
importance of the employee in the service offering was articulated (Gronroos, 1990) and integrated models linking the employee, customer, and business performance were hypothesized and tested (Heskett, Jones, Loveman, Sasser \& Schlesinger, 1994). The SERVQUAL Survey (Zeithaml, Parasuraman, \& Berry, 1985), originally created for the financial services industry and since adapted to several other service sectors, emerged as the preferred instrument to assess service quality in hospitality and tourism. Their survey includes items related to tangibles, reliability, responsiveness, assurance, and empathy.

Branding was the focus of the 1990s. By the end of the decade, organizations like Marriott, Ritz Carlton, Brinker Restaurants, and a large number of convention centers and tourist destinations were bundling amenities, services, personal values and emotional symbols into brand promises as a means to further distinguish their offerings in the competitive marketplace (Keller, 2003).

During the last decade, communicating brand promises in terms of delivering a unique and memorable experience has received ample attention in the marketing literature, with much of the hospitality and tourism related literature addressing the challenges of this approach (Keller, 2003; Dube \& Renaghan, 2000; Kwortnik, 2008; LeBel, Dube, Sears, \& Renaghan, 2010). Strategic experiential marketing requires a cohesive, aligned approach, beginning with a clear commitment by the company as to the nature of the economic offering. As one hotel researcher noted, you either sell an experience or you sell hotel rooms-you cannot do both (Shaw \& Ivens, 2005). Perhaps the major challenge for hospitality and tourism organizations seeking to compete through continuous innovation of the guest experience is the integration and collaboration required to succeed. The essence of experience innovation seems to require continuously 
enhancing and clarifying the brand promise while simultaneously delivering as expected in all operational aspects, keeping the guest experience at the core (Kwortnik \& Thompson, 2009).

Challenges for the hospitality and tourism industry. Beyond the recognition that competing in the experience economy will likely require hospitality and tourism organizations to transform the way their offerings are "deployed, configured, staffed, marketed, and sold" (Erdly \& Kesterson-Townes, 2003, p. 684), the body of scholarly research related to innovation in the hospitality and tourism context is nascent. The hospitality and tourism industry literature seems to embrace the paradigm of the experience economy, but the unique characteristics of the industry present challenges for innovation researchers. The literature clearly delineates the factors that distinguish the hospitality industry and tourism context as intangibility, simultaneous production and consumption, perishability, and the importance of a service climate (Schneider, Salvaggio \& Subirats, 2002).

The intangible nature of the tourism experience makes an outputs typology similar to the one outlined in the earlier section of this literature review problematic. Even if the memorable event or series of memorable events culminating in an experience could be identified and described, the co-constructed nature of the offering presents real challenges to researchers and practitioners alike. Every experience is a unique combination of customers (and the values they bring into the experience) interacting with a variety of employees and environments, resulting in a complex collection of unmanageable (and maybe immeasurable) variables. Additionally, the perishable nature of the economic offering (for example: hotel room nights not sold today cannot be stored 
and sold tomorrow) may contribute to a perception of an industry overly focused on short-term results $(\mathrm{Enz}, 2010)$.

Consistent with the notion that a service climate is critical in the industry, senior managers in hospitality consider the most important factor in innovation to be the employees (Ottenbacher \& Gnoth, 2002). Of the 24 factors examined in a study of new service development, strategic human resources was the second most important factor in their regression model, after targeting the appropriate customer market (Ottenbacher \& Gnoth, 2005), prompting the authors to posit "hospitality innovations must match appropriate market segments with existing human resources capabilities" (p. 220).

\section{Emergent Research in Experience Innovation}

While the complex context of hospitality and tourism offers its share of research challenges, it also provides a varied marketplace of interrelated companies with rich environments in which to examine the emerging concept of experience innovation. As synthesized in the following tables, the character of innovation in the experience economy is just beginning to take shape. This collection of very recent studies depicts a community of scholars wrestling with how to build upon existing research while exploring new approaches to innovation, given the shifting economic paradigm and the increasing complexity of savvy, demanding travelers.

Examples of recent studies in context. The examples of studies from the past three years focusing on innovation in the context of the experience economy and the hospitality and tourism industry offer insights into convergent and divergent research approaches. Overall, the summaries presented in Figure 4 and Figure 5 comprise theoretical, quantitative, and qualitative approaches that highlight the challenging 
research context of the hospitality and tourism industry. Convergent approaches (Figure 4) conceptualize innovation as an input/output model similar to the integrated framework presented in section one of the literature review. Divergent approaches, summarized in Figure 5, include new typologies, archetypes, constructs, and instruments, as well as critical reviews of recent approaches. The innovate/execute tension is present in both the convergent and divergent research inquiries.

The collection of recent studies includes a few familiar names in terms of innovation research, but most contributions are from scholars new to the field of innovation, even if they are not new to the study of the hospitality and tourism industry. Given the global nature of the context it is perhaps not surprising that only one of the ten studies in the following tables involves American researchers studying American organizations. The community of scholars is strikingly international, with Swiss hotels, Danish firms, and British nationals among the respondents.

Convergent approaches. The convergent studies tend to approach innovation in the hospitality and tourism industry as an input/output model consistent with the framework presented in section one of this literature review (see figure 2). However, these recent studies also take a broader view of innovation as an organizational objective. 


\begin{tabular}{|c|c|c|}
\hline Article & Method, Context, Findings & Convergence/Divergence \\
\hline $\begin{array}{l}\text { Kwortnik, J. (2008). } \\
\text { Shipscape influence on the } \\
\text { leisure cruise experience. } \\
\text { International Journal of } \\
\text { Culture, Tourism, and } \\
\text { Hospitality Research, 2(4), } \\
289-311 .\end{array}$ & $\begin{array}{l}\text { Research method and context: Qualitative analysis } \\
\text { of customer comment data collected from online } \\
\text { community dedicated to leisure cruises. } \\
\text { Findings: Operations struggles to deliver on } \\
\text { promises that services marketers make. } \\
\text { Management is needed to mitigate the marketing- } \\
\text { operations gap. }\end{array}$ & $\begin{array}{l}\text { Convergent with market } \\
\text { research approach. } \\
\text { Innovation as Process. }\end{array}$ \\
\hline $\begin{array}{l}\text { Hosany, S. \& Witham, M. } \\
\text { (2009). Dimensions of } \\
\text { cruisers' experiences, } \\
\text { satisfaction and intention to } \\
\text { recommend. The School of } \\
\text { Management Working } \\
\text { Paper Series. London: } \\
\text { Royal Holloway University } \\
\text { of London. }\end{array}$ & $\begin{array}{l}\text { Research method and context: Regression analysis } \\
\text { of education, esthetics, escapism, and } \\
\text { entertainment constructs related to memories, } \\
\text { arousal, and satisfaction in cruising. Modified and } \\
\text { validated the instrument developed by Oh, Fiore, \& } \\
\text { Jeoung in } 2007 \text { to measure Pine and Gilmore's } \\
\text { realms of experience. } \\
\text { Findings: Esthetics and entertainment were } \\
\text { significant in predicting positive memories. }\end{array}$ & $\begin{array}{l}\text { Convergent with innovation as } \\
\text { input/output model. Divergent } \\
\text { using experience realms and } \\
\text { memories as outputs. }\end{array}$ \\
\hline $\begin{array}{l}\text { Tejeddini, K. (2011). } \\
\text { Customer orientation, } \\
\text { learning orientation, and } \\
\text { new service development: } \\
\text { An empirical investigation } \\
\text { of the Swiss hotel industry. } \\
\text { Journal of Hospitality and } \\
\text { Tourism Research, } 35(4) \\
437-468 \text {. }\end{array}$ & $\begin{array}{l}\text { Research method and context: Hierarchical } \\
\text { regression analysis of } 118 \text { hotel manager } \\
\text { respondents in Switzerland to measure } \\
\text { relationships among drivers, outputs, and } \\
\text { performance as integrated model. } \\
\text { Findings: NSD important for competitiveness } \\
\text { achievement but not significant as determinant of } \\
\text { financial performance or service quality. Learning, } \\
\text { customer, and managerial attitude toward change } \\
\text { had positive impacts on NSD. }\end{array}$ & $\begin{array}{l}\text { Convergent with innovation as } \\
\text { inputoutput model. Service } \\
\text { innovation is the output. }\end{array}$ \\
\hline $\begin{array}{l}\text { Hjalager, A. (2009). A } \\
\text { review of innovation } \\
\text { research in tourism. } \\
\text { Tourism Management, } 31 \text {, } \\
1-12 .\end{array}$ & $\begin{array}{l}\text { Research method and context: Literature review on } \\
\text { innovation in tourism contributions spanning } 20 \\
\text { years. } \\
\text { Findings: There is still only limited systematic and } \\
\text { comparable empirical evidence of the level of } \\
\text { innovative activities and their impacts. Innovation } \\
\text { systems and cross-cluster collaboration important } \\
\text { for destination innovation, mostly driven by tourism } \\
\text { policy. }\end{array}$ & $\begin{array}{l}\text { Mixed. Converge with review } \\
\text { of similar inputs. Diverge in } \\
\text { terms of innovation systems } \\
\text { and collaborative networks. }\end{array}$ \\
\hline
\end{tabular}

Figure 4. Convergent approach studies

Divergent approaches. These studies seek to understand innovation with

approaches that imply acceptance of the experience economy paradigm. 


\begin{tabular}{|c|c|c|}
\hline Article & Method, Context, Findings & $\begin{array}{c}\text { Convergence/Divergenc } \\
\mathbf{e}\end{array}$ \\
\hline $\begin{array}{l}\text { Alotaibi, E., Al-Sabbahy, } \\
\text { H., Lockwood, A. (2011). } \\
\text { Interaction quality in } \\
\text { service encounter: Scale } \\
\text { development and } \\
\text { validation. International } \\
\text { CHRIE Conference. }\end{array}$ & $\begin{array}{l}\text { Research method and context: Scale } \\
\text { development and validation of interaction quality } \\
\text { includes task related and personal connection } \\
\text { related items. } \\
\text { Findings: Courteous expressions, originally } \\
\text { considered part of social interaction was } \\
\text { considered more task-related than personal } \\
\text { connection related. }\end{array}$ & $\begin{array}{l}\text { Divergent. Envisions } \\
\text { employee interaction as part } \\
\text { of the economic offering. }\end{array}$ \\
\hline $\begin{array}{l}\text { Prange, C. and } \\
\text { Schlegelmilch,B. (2010). } \\
\text { Heading for the next } \\
\text { innovation archetype? } \\
\text { Journal of Business } \\
\text { Strategy, } 31(1), 46-55)\end{array}$ & $\begin{array}{l}\text { Research method and context: Theoretical paper } \\
\text { suggesting the notion of an "innovation archetype" } \\
\text { that results from the combination of outputs. } \\
\text { Findings: Draws upon portfolio research and the } \\
\text { phenomenon of exploration vs. exploitation } \\
\text { activities to theorize } 8 \text { innovation archetypes. }\end{array}$ & $\begin{array}{l}\text { Divergent. Combination of } \\
\text { outputs combine to form } \\
\text { archetype as output. Implied } \\
\text { strategy. }\end{array}$ \\
\hline $\begin{array}{l}\text { Hosany, S., \& Gilbert, D. } \\
(2010) \text {. Measuring } \\
\text { tourists' experiences } \\
\text { toward hedonic holiday } \\
\text { destinations. Journal of } \\
\text { Travel Research, 49(4), } \\
513-526 \text {. }\end{array}$ & $\begin{array}{l}\text { Research method and context: Rigorous scale } \\
\text { development procedure to capture range of } \\
\text { tourists' emotional responses to destinations. } \\
\text { Regression analysis of emotions and intention to } \\
\text { recommend. } \\
\text { Findings: Survey of } 520 \text { British nationals found joy } \\
\text { and positive surprise significantly related to } \\
\text { satisfaction. Joy, love, positive surprise } \\
\text { associated with higher levels of intention to } \\
\text { recommend. }\end{array}$ & $\begin{array}{l}\text { Diverge. Outputs as } \\
\text { emotion constructs of joy, } \\
\text { love, and surprise. }\end{array}$ \\
\hline $\begin{array}{l}\text { Chen, J., \& Sawhney, J. } \\
\text { (2008). A proposal to } \\
\text { improve our } \\
\text { understanding of } \\
\text { innovation using the } \\
\text { Innovation Radar } 2.0 . \\
\text { Kauffman Organization } \\
\text { Data Symposium. }\end{array}$ & $\begin{array}{l}\text { Research method and context: Creation of } \\
\text { Innovation Radar Survey } 2.0 \text { identifying } 12 \\
\text { innovation dimensions from a broad view. } \\
\text { Classifies innovation strategies based on } \\
\text { customer value as economic, functional, or } \\
\text { emotional. } \\
\text { Findings: Generated from } 765 \text { respondents from } \\
52 \text { business units. Confirmed } 12 \text { innovation } \\
\text { dimensions. Considered new practical tool to } \\
\text { measure innovation from a broad view across } \\
\text { different contexts including experience. }\end{array}$ & $\begin{array}{l}\text { Diverge. Broad based } \\
\text { perspective grounding } \\
\text { innovation activities in the } \\
\text { type of customer value } \\
\text { promised by the business. } \\
\text { Practical tool responding to } \\
\text { the U.S. Department of } \\
\text { Commerce initiative on } \\
\text { innovation. }\end{array}$ \\
\hline $\begin{array}{l}\text { Sundbo, J. (2009). } \\
\text { Innovation in the } \\
\text { experience economy: a } \\
\text { taxonomy of innovation } \\
\text { organizations. The } \\
\text { Services Industry } \\
\text { Journal, } 29(4), 431-455 .\end{array}$ & $\begin{array}{l}\text { Research method and context: Case based } \\
\text { taxonomy of experience firms according to their } \\
\text { dynamic drivers. Inductively developed from } 60 \\
\text { case studies of Danish firms held at the Centre for } \\
\text { Experience Reusearch in Denmark. } \\
\text { Findings: Reveals a taxonomy based on the } \\
\text { drivers of the business to include artistic interest } \\
\text { driven, technology-driven, market opportunity- } \\
\text { driven, collective interest drive, and task-driven. }\end{array}$ & $\begin{array}{l}\text { Divergent. Completely new } \\
\text { taxonomy of experience } \\
\text { industry sector based on the } \\
\text { drivers of the experiential } \\
\text { offering. }\end{array}$ \\
\hline
\end{tabular}

Figure 5. Divergent approach studies 
Implications of emergent research. There is certainly much to glean from extant innovation research that applies to the experience economy. The success factor categories outlined in the traditional framework-strategy, people, knowledge management, climate, and leadership — are still part of the scholarly discourse in experience innovation (Hjalager, 2009). There does seem to be recognition that a broad based view of innovation is consistent with organizations whose main economic offering is an experience (Hosany \& Gilbert, 2010; Tejeddini, 2011), while the innovate/execute tension for organizations that deploy innovation strategies remains (Kwortnik, 2008).

On the other hand, evidence suggests that the economic offering of an experience requires new ways of thinking about several issues. These include positioning (Sundbo, 2009; Prange \& Schlegelmilch, 2010), measuring (Palmer, 2008; Alotaibi \& Sabbahy, 2011), and the role of people (Tejeddini, 2011; Alotaibi \& Al-Sabbahy, 2011) in a coconstructed experience, with emotional value at its core and memories as the innovation output (Hosany \& Gilbert, 2010; Chen \& Sawhney, 2008).

\section{Summary of Section}

Section two of this review was intended to examine ways to apply the learning regarding innovation research from section one to the hospitality and tourism industry. The paradigm of the experience economy provides a theoretical lens through which to view the context of an industry whose main economic offering is an experience. The innovate/execute tension is confounded by tensions inherent in organizations in the business of co-constructing memories. As one researcher put it, continuously innovating the experience is an ongoing process of clarifying the brand promise while consistently delivering at the operational level (Kwortnik \& Thompson, 2009). 


\section{Strategic Leadership for Experience Innovation}

Although the character of experience innovation is just beginning to take shape, there seems to be ample evidence to suggest that experience innovation is an ongoing organization-wide change initiative. Broad based organizational change is the focus of strategic leadership, "marked by a concern for the evolution of the organization as a whole" (Selznick, 1984, p. 5). What strategic leadership looks like within the context of the hospitality and tourism marketplace and the evolving paradigm of the experience economy, though, remains to be explored. The purpose of this section is to trace the evolution of major leadership theories in order to understand how contemporary views of strategic leadership may be helpful to senior managers in organizations whose main economic offering is an experience.

\section{Tracing Major Leadership Theories}

Thinking in time. Neustadt and May (1986) offer an interesting perspective on how strategic leaders can link history to the present and future. In the mini-methods section of their book, the authors outline a systematic method they call thinking in time for using history as a decision-making tool. They suggest that individuals plot major issues on a chronological timeline, and then compare the timelines to other historical streams as a way to learn from overlapping stories. Applying the thinking in time method to the first two sections of this literature review reveals overlapping stories of increasing complexity for scholars and practitioners who seek to understand and apply innovation to organizations whose main economic offering is an experience.

For example, consider the first section of this literature review and imagine a timeline of the innovation literature in business. It begins with a story of scholarly 
discourse that progresses from a robust discussion of the product development process, through struggles to apply the same theoretical framework to the services sector, to glimpses of recent interactions that wrestle with a broader, more integrated, and emotioncentric view of innovation in experiences. As the nature of the economic offering becomes more intangible, the process of defining, measuring, and explaining relationships becomes more difficult.

The story of the customer experience literature in the hospitality and tourism marketplace follows a similar timeline, beginning with a product view, progressing to conversations about ways to differentiate services, and then focusing on the integration of the emotional and intangible branding and human aspects of the total customer experience. Hence, the first two sections of this literature review, although not necessarily outlined as chronologies, depict stories of progressions toward more synthesized, broader, and more integrated understandings of complex phenomena. Likewise, a chronological review of the leadership theory literature traces major theories from individual leader traits, through dyadic behaviors, to collective processes within complex adaptive organizational systems--a story of increasingly complex mental models of leadership in business organizations.

Trait based leadership theory. Researchers who take a trait approach to the study of leadership often begin by privileging "the study of great leaders" (Bass, 1990, p. 50). They present stories about leaders as prophets, priests, chiefs, and kings. They examine what leaders did and why they did it. They use heroes to exemplify the concepts of leadership. During the trait period of 1910 to World War II the goal of leadership studies was to identify what unique features of the individual differentiated the leader 
from the non-leader. A typical definition of leadership from this period comes from Bogardus who wrote in 1934 that "leadership is personality in action under group conditions" (as cited in Rost, 1991, p. 47). Several research studies were inspired by the trait approach, but no combination of personality traits has been found that consistently results in effective leadership. In 1948, a review of 120 trait studies was unable to discern a reliable pattern (Chemers, 1984). Although still present in the leadership literature today, the study of great leaders can be inspirational, but is also anecdotal and prone to reflect the biases of the era.

Behavior based leadership theories. In the 1950s researchers moved away from trait theory and into the direction of behaviorism to help explain the concept of good leadership. Writing in 1952, Halpirn and Winter (as cited in Rost, 1991, p. 51), defined leadership as "the behavior of an individual when he is directing the activities of a group toward shared goals." Behavior based leadership research focused on relations-oriented behavior and task-oriented behavior (Yukl, Gordon, \& Taber, 2002). Behavioral studies looked at what leaders did, as opposed to who they were, often in relation to a follower. Two dyadic leadership theories in particular, path/goal theory, and leader member exchange, exemplify behavior-based dyadic theory. Path/goal theory (House, 1971) describes how a leader motivates a follower to accomplish a goal. Behaviors are described as directive, goal clarifying, supportive, or participative. Leader/member exchange theory (Graen \& Cashman, 1975) suggests leaders and followers develop relationships based on social exchanges. These dyadic relationships are described as three phases—-stranger, acquaintance, and partnership. 
Contingency theory. In the late 1960s, leadership scholars began writing about what is now called contingency theory. Researchers who published during this contingency period advocated a perspective that took into account various aspects of followers as well as the situation when trying to understand effective leadership. For example, Fiedler (1978) proposed that the best type of leader for a given situation depended on leader-member relations, leader position power, and task structure. Situational leadership provides a framework for the leader/follower dyad that combines leader style with follower readiness (Hersey, Blanchard \& Johnson, 1977). Although Fiedler, Blanchard, and other contingency theorists helped to bring the role of context into the leadership literature, some researchers continue to advocate for context to take a more central role in leadership research and theory (Shamir \& Howell, 1999; Lowe \& Gardner, 2000).

Transformational views. The theory of transformational leadership launched a renaissance in leadership studies research. "Transforming leadership occurs when one or more persons engage with others in such a way that leaders and followers raise one another to higher levels of motivation and morality" (Burns, 1978, p. 20). Texts about leadership theory from the transformational viewpoint often begin by emphasizing what leadership is not. They clarify that leadership is not status, power, position, or authority (Gardner, 1990). They differentiate the term leader from the process that is leadership. They also distinguish management from leadership (Bennis \& Thomas, 2002), and technical problem solving from the adaptive work, which they view as the essence of leadership (Heifitz, 1994). 
Some researchers believe that in order to understand transformational leadership we should measure its components to determine if they are related to leadership outcomes. They use a quantitative approach and develop instruments such as the multileadership questionnaire (Bass \& Avolio, 1995) and the leadership practices inventory (Kouzes \& Posner, 1987), in an attempt to operationalize transformational leadership theory. Other researchers take an interpretive approach to understanding how leadership emerges (Ospina \& Sorenson, 2006). The influence of Burns is evident in these researchers' description of their approaches to leadership because they rest "on the assumption that leadership is intrinsically relational and social in nature, is the result of meaning-making, and is rooted in context or place" (p. 188). The scholars who hold transformational leadership views tend to dismiss earlier or more primitive perspectives on leadership as inconsistent with the new era of leadership theory.

Contemporary leadership theories. Contemporary leadership theory reflects a holistic approach, integrating a diversity of insights and practices. The story being told by contemporary leadership theorists is one of synthesis (Sternberg, 2008), complexity (Wheatley, 2010), integration (Wilber, 2000) and continuous change (Rooke \& Torbert, 2005). Scholars such those listed above and others are trying to find a way to fit the pieces together without discarding disparate views. They continue to seek "to fulfill the promise of an approach to leadership which is broadly conceived" (Wren, 1995, p. xi).

\section{Studies Linking Types of Leadership and Innovation}

Leadership and innovation are both complex phenomena dealing with change. While there are several contemporary theoretical offerings by well-known scholars that explore leadership for innovation and change, empirical studies that link holistic theories 
of leadership with overall innovation performance in business organizations are limited. Still, some recent studies have made contributions with findings linking certain types of leadership with innovation inputs and outputs, the innovation process, and overall innovation performance in manufacturing and services.

A pair of studies of Taiwanese electronics manufacturing firms was conducted using structural equation modeling to test the hypothesis that transformational leadership positively affected innovation. The authors reported associations with transformational leadership and innovation as well as demonstrated moderating effects of climate for innovation, structure, and company size on overall innovation performance (Jung, Chow, \& Wu, 2003; Jung, Wu \& Chow, 2008). A similar study of Spanish firms with the highest number of patents found that the visioning dimension of transformational leadership had a critical influence on overall innovation performance, while goal setting had a somewhat smaller, but still meaningful impact (Sarros, Cooper \& Santora, 2008).

In services, Gil, Rico, Alcover, and Barrasa (2005) studied the impact of changeoriented leadership behaviors consistent with flexible leadership (Yukl, 2008), on group innovation outputs of health-care teams in Spain's public hospitals. Using regression analysis, they found that change-oriented leadership behaviors and innovation were mediated by a climate for innovation (Gil et al., 2005). A qualitative study of European knowledge-intensive service firms found that there were thirteen leadership behaviors relevant to innovation as a process in their context (De Jong \& Den Hartog, 2007). Six leadership behaviors were believed to relate to a single aspect of innovation as process, either idea generation or application. For example, stimulating knowledge diffusion was related to idea generation, but not application. Providing resources was related to 
application but not idea generation. The other seven leadership behaviors they uncovered related to both the idea generation and implementation of new service development.

\section{Contemporary Views of Strategic Leadership}

Early strategic leadership theorists differentiated theories of leadership concerned with leadership in organizations from leadership of organizations (Hunt, 1991). Drawing upon upper echelon theory (Hambrick \& Mason, 1984) and stratified systems theory (Hunt \& Ropo, 1995), strategic leadership theory emphasizes the influence of top level managers on the organization's ability to adapt and change the leadership of organizations(House, Wright \& Aditya, 1997).

The essence of strategic leadership. Contemporary strategic leadership theorists describe the essence of strategic leadership as creating, developing, and enhancing absorptive and adaptive capacities of organizations (Boal \& Hooijberg, 2000) within strategic fit (Carmeli, Gelbard, \& Gefen, 2010). Absorptive capacity (Cohen \& Levinthal, 1990) is the capacity to learn, whereas adaptive capacity (Christensen, 1997) is the capacity to change. Strategic fit is concerned with aligning internal capacities with factors in the external environment (Carmeli, Gelbard, \& Gefen, 2010).

The innovation dilemma. As explicated in section one of this literature review, innovation requires both idea generation and implementation processes, activities which researchers contend are fundamentally different. The inherent paradox of innovation in organizations was first introduced by March (1991). He argues that exploration activities require searching based on variation, experimentation, and discovery, while exploitation requires refinement, choice, and execution. Clayton Christensen, in his seminal book, The Innovator's Dilemma (1997), describes the difficulties facing organizations that must 
embrace sustaining technologies while simultaneously seeking what he called disruptive technologies.

Innovation ambidexterity. Innovation researchers use ambidexterity as a metaphor to describe organizations that are equally proficient at exploration and exploitation activities. Structural ambidexterity is suggested as a means by which organizations can "simultaneously pursue both incremental and radical change" (Tushman \& O'Reilly, 1996, p. 24). The author argues that senior leaders can influence innovation by structuring departments to focus on either innovation or execution.

Contextual ambidexterity refers to the behavioral capacity to demonstrate both alignment and adaptability activities simultaneously (Birkinshaw \& Gibson, 2004). Unlike structural ambidexterity, which emphasizes either/or as a mechanism for managing the inherent tension of innovation, contextual ambidexterity promotes the dual capacity (both/and) within an organization's context. Senior leaders, then, are responsible for cultivating a context that "encourages individuals to make their own choices as to how they divide their time between alignment and adaptability activities" (p. 211$)$.

Lin \& McDonough (2011) use the term innovation ambidexterity to describe organizations with high levels of both incremental and radical innovations. In their study of Taiwanese firms, they found that strategic leadership, measured by both internal and external oriented leadership behaviors as well as a knowledge sharing culture, fostered innovation ambidexterity.

Ambidextrous leadership. The term ambidextrous leadership was recently used to describe leadership that coalesces opening (variation increasing) and closing (variation 
decreasing) leadership behaviors. One study suggests that this behavioral complexity can reside in a single leader (Rosing, Frese, \& Bausch, 2011) while another notes that the make-up of the senior management team and their prior firm experience can facilitate innovation ambidexterity (Beckman, 2011).

Flexible leadership. Yukl (2008) is a prolific leadership scholar and researcher who has made various attempts to provide a road map of influences at all leadership levels. He recently offered the term flexible leadership to describe a model that integrates task, relationship, and change-oriented leadership behaviors. The author suggests that flexible leadership is "formulated in response to the need for a more comprehensive theory of strategic leadership "that takes into account how multiple leaders interact to influence organizational performance" (p. 709). Yukl (2008) claims that his theory is a more distributed model of leadership than strategic leadership and is applicable for organizations that involve multiple managers of subunits.

The tensions of strategic leadership. The issue that contemporary views regarding strategic leadership have in common, whether exercised only at the upper echelons of the organization or across multiple profit centers, is the need for leaders to navigate a variety of tensions in-context. The following definition teases out the essence of strategic leadership and offers a narrative that illuminates the inherent tensions of leadership for overall innovation performance.

Strategic leadership is a series of decisions and activities, both processoriented and substantive in nature, through which, over time, the past, the present, and the future of the organization coalesce. Strategic leadership forges a bridge between the past, the present, and the future, by reaffirming core values and identity to ensure continuity and integrity as the organization struggles with known and unknown realities and possibilities. Strategic leadership develops, focuses, and enables an organization's structural, human, and social capital and capabilities to 
meet real-time opportunities and threats. Finally, strategic leadership makes sense of and gives meaning to environmental turbulence and ambiguity, and provides a vision and road map that allows an organization to evolve and innovate (Boal, 2004, p. 1504).

This comprehensive description acknowledges leaders as meaning makers, recognizing that their influence lies in managing the meaning of a situation in a constructive way, often through forms of symbolic interaction (Smircich \& Morgan, 1982).

\section{Summary of Section}

The final section of this chapter traced the evolution of leadership theories, privileging contemporary views of strategic leadership as the work of senior managers. The emerging concept of ambidexterity and ambidextrous leadership is central to the needs of organizations with experience innovation as an overriding organizational objective. Therefore, a contemporary view of strategic leadership for experience innovation requires navigating a variety of tensions and coalescing competing activities-past and future, stability and change, internal and external factors, culture and strategy, and ambiguity and a road map-in increasingly complex organizations. The specific ways in which senior managers exercise strategic leadership in order to increase organizational capacities for experience innovation in the memories business is still unknown. These conversations are just beginning.

\section{Summary of Literature Review}

A ten-year review of the Leadership Quarterly suggests that leadership in context is underrepresented in the publication and represents an opportunity for new researchers (Lowe \& Gardner, 2000; Bryman, 2004). Contexts include national culture, organizational characteristics, level of managerial position, gender, type of work, and type of industry. The streams of literature examined in this review provide ample 
justification for a study of leadership in context. The interplay of the leader level context, the economic offering context, and the industry context provides opportunity to contribute to the emerging conversation among scholars who are studying innovation theory as well as support for practitioners wrestling with the transition to the experience economy.

The overlapping stories depicted in the three sections of this literature review reveal that understanding innovation and strategic leadership of organizations who promise emotional value to their customers requires a synthesis of approaches. If "innovation swims in the richness and complexity of living" (Denning, 2005, p. 273), then a study of strategic leadership for experience innovation requires inquiries that embrace the interrelatedness of various factors, methods, and organizational complexities, so that we might be able to connect them in new ways to deepen our understanding. 


\section{CHAPTER THREE METHODOLOGY OVERVIEW}

The overriding research question guiding this study is: How does strategic leadership influence innovation in organizations whose main economic offering is an experience? Additional research questions embedded in the study's design are:

1. To what extent is innovation defined and measured in the different segments of the San Diego hospitality and tourism marketplace, and what are these definitions and measures?

2. In what ways, if any, do senior managers influence innovation in the hospitality and tourism industry in San Diego?

3. What are the relationships, if any, between senior manager influence and innovation in organizations whose main economic offering is an experience?

\section{Definitions and Terms}

Before providing an overview of the research methodology, it is necessary to clarify some of the key terms used in this study's research questions. These definitions were first introduced in the literature review chapter and will be referenced throughout the remaining chapters of this dissertation.

Innovation in Business - idea generation and idea implementation $\underline{\text { Innovativeness }}-$ the development of novel ideas Innovation Outputs - new or improved products, services, processes, or administrative practices that have been generated by the business organization 
Overall Innovation Performance - successful development and implementation of novel ideas, products, services, process, and/or administrative practices to bring about improved business performance

Strategic Leadership - creating, developing, and enhancing absorptive (learn) and adaptive (change) capacities of organizations

Strategic Leadership - the influence of top level managers on the organization's ability to adapt and change the leadership of organizations as a whole

Mechanisms of Senior Manager Influence - strategy, culture, policies, programs, knowledge management, rewards and recognition

Experience Economy Context - industry context in which the economic offering is an experience, an integration of the customer with products, services, human interactions, and other offerings of the organization, delivered over time

\section{The Research Design}

This study employed a mixed-methods design because no single type of data collection was deemed sufficient to address the research questions. The brief discussion paragraphs and graphic included in this overview are provided as a general orientation to the mixed methods inquiry, summarizing the priority, timing, and interfacing (Creswell \& Plano Clark, 2011) of the quantitative and qualitative components. As depicted in the accompanying graphic (Figure 6), I used a three-phase, exploratory mixed methods design, collecting, analyzing, and integrating both qualitative and quantitative data in order to address the study's research questions. As Creswell and Plano Clark (2011) indicate, a mixed methods exploratory design is well suited for exploring phenomenon 
when variables are unknown. The authors also state that the design is an effective way to assess the extent to which the results from a few participants generalize to a population.

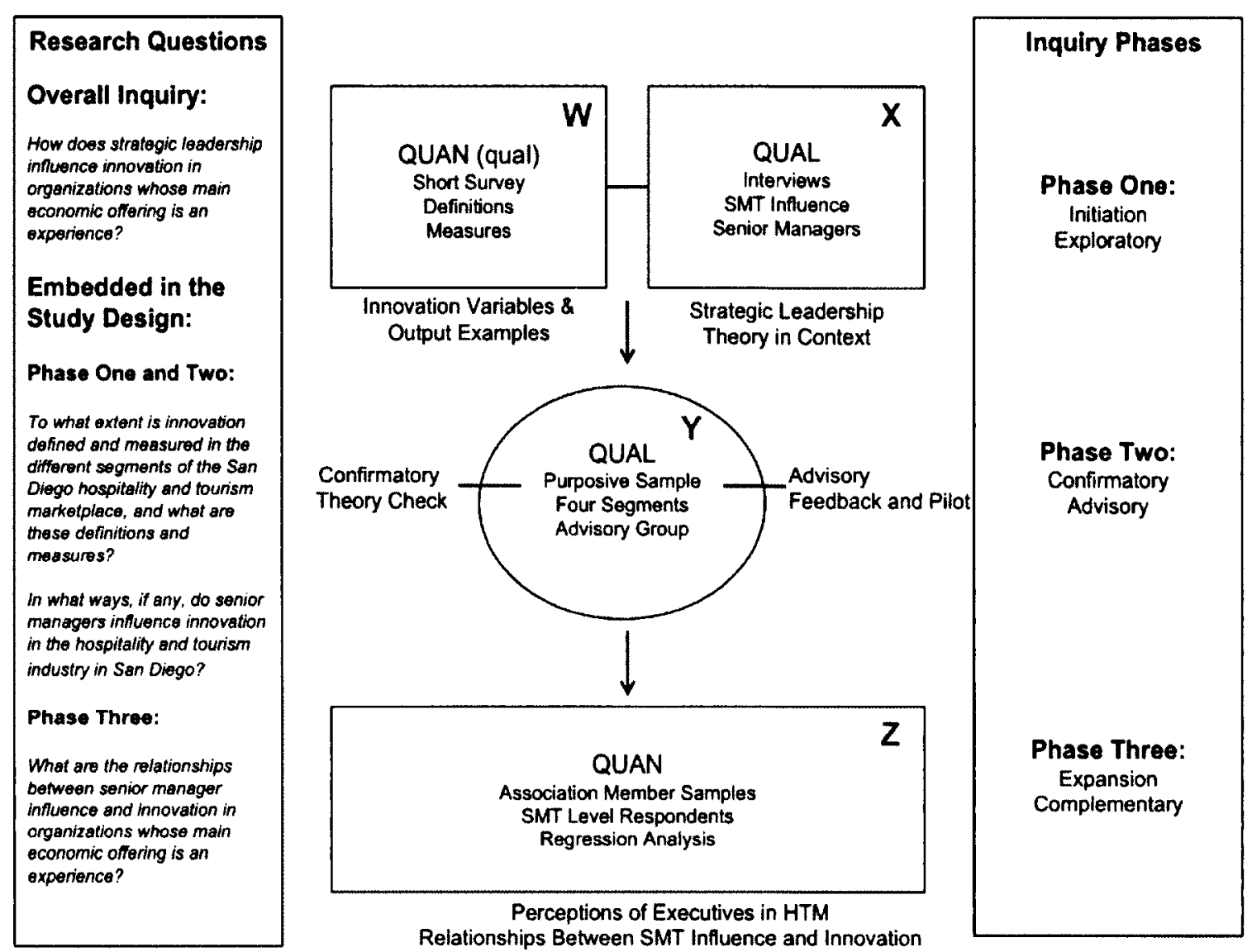

Figure 6. Methodology overview

In the classic version of this design, labeled exploratory sequential (p. 69) in the Creswell and Plano Clark typology, there are two stages in the overall design. The researcher collects qualitative data in the initial stage, and then uses that data to inform the second, quantitative stage. For this study, I modified the exploratory sequential design somewhat by embedding two additional components. In ensuing chapters of this dissertation I will discuss the modification of the classic design used in this study, labeled QUAL Phase One (X) and QUAN Phase Three (Z), as illustrated in Figure 6. I will also discuss the impetus behind the two additional study components as they are seen in 
Figure 6, a quantitative piece (labeled W) in Phase One and an advisory group working session (labeled Y) in Phase Two.

\section{Graphic Depiction and Notation}

Procedural diagrams and visual graphics are often used in mixed methods studies to convey the complexity of the research inquiry. The graphic in Figure 6 incorporates several of the guidelines and notations suggestions summarized in Creswell and Plano Clark's (2011) mixed methods textbook. For example, upper and lowercase letters indicate the relative priority of the quantitative and qualitative components of the study. As depicted, the first phase of this study involved simultaneous quantitative (QUAN) and qualitative (QUAL) strands, with the notation of QUAN (qual) conveying that in addition to the QUAL strand, there is a qualitative element of lesser priority embedded within the quantitative survey of Phase One. Directional arrows illustrate the sequencing of the study components. Hence, the diagram shows that after completing Phase One, which included concurrent QUAN (qual) and QUAL components, a working session (QUAL) with an advisory group was conducted, followed by the third and final, quantitative component (QUAN), which was implemented in order to expand upon the data collected and analyzed in the first two phases.

The research procedures used are listed within each component box, and the outcomes or "research products" are listed just below each of the boxes (Creswell and Plano Clark, p. 111). As shown, the first phase of the study yielded suggestions for innovation variables gathered from the data collected and represented by box $\mathrm{W}$ or QUAN (qual). Additionally, data represented by box X or QUAL provided a conceptual framework of strategic leadership in context. Phase Two involved an advisory group 
working session, represented by box $\mathrm{Y}$ or QUAL, which provided information, as well as feedback on data gathered in Phase One. Finally, Phase Three utilized a survey in order to explore the relationships between senior manager influence (leadership) and innovation, represented by Box Z or QUAN.

The study's research questions along the left side of the graphic (Figure 6), as well as the general purposes of each phase (Greene, Caracelli \& Graham, 1989) on the right side of the graphic, were added to further orient the reader. In addition, each research component is labeled with a letter $\mathrm{W}, \mathrm{X}, \mathrm{Y}$, or $\mathrm{Z}$. These labels are not part of the guidelines from the mixed methods literature, but they may be helpful when reading through the rest of the methodology chapters of this dissertation. The letter designations may make it easier to locate the specific study component on the graphic while simultaneously reading the details of that component's methods and results in the text.

\section{Three Phases of Inquiry}

The first phase of the overall inquiry was exploratory, using quantitative and qualitative methods to gather data related to the first two research questions. This was the starting point because little was known about the innovation measures or the means of achieving innovation performance in this local hospitality and tourism marketplace context. The purpose of this initiation phase in mixed methods studies is to seek broad perspectives, discover paradoxes and contradictions, and increase the breadth and depth

of inquiry (Greene, Caracelli \& Graham, 1989). As discussed previously in the literature review, the innovation measures and innovation output typologies used in the business innovation literature are narrowly focused on the manufacturing context. The quantitative component $(\mathrm{W})$ in the first phase of this study was designed to answer 
research question \#1: To what extent is innovation defined and measured in the different segments of the San Diego hospitality and tourism marketplace, and what are these definitions and measures?

In contrast, the second component (labeled $\mathrm{X}$ ) of the exploratory phase was qualitative and focused on the second research question: In what ways, if any, do senior managers influence innovation in the hospitality and tourism industry in San Diego? As discussed earlier, researchers have limited information about some of the success factors associated with innovation in business. These include strategy, knowledge management, climate, and leadership. However, we don't know if managers in experience-oriented contexts influence innovation in their organizations in these same ways. In order to explore these potential success factors in-depth and in-context, I conducted face-to-face interviews with a small quantity of senior managers in hospitality and tourism companies across four segments-lodging, dining, attractions and meetings/events. This qualitative piece $(X)$ focused on the inputs, or means of achieving innovation, while the quantitative piece $(W)$ focused on the measures and outputs of innovation in the experience context. These concurring components ( $\mathrm{W}$ and $\mathrm{X}$ ) were of equal importance during this initial exploration, although the data was collected from different samples and targeted different research questions.

During the second phase (labeled $Y$ ) of the study, I convened a working session with an advisory group of eight industry leaders. They provided feedback and interpretation of the qualitative and quantitative data that had been collected in the initial exploration phase. They also provided additional input about potential survey items for the third and final quantitative phase of the inquiry. Mixed methods researchers call the 
purpose of this design component confirmatory (Teddlie \& Tashakkori, 1998), while qualitative researchers might use the term member checking (Charmaz, 2000) to describe this method of increasing meaningfulness and validity.

The third and final phase of the study was conducted shortly after the advisory group working session $(\mathrm{Y})$ in the second phase. Quantitative and qualitative data from the first two phases of the inquiry informed this final quantitative component (labeled Z) of the study. Essentially, a survey instrument was developed based on the ways that senior managers influence innovation (as determined through the qualitative component) and innovation performance measures (as understood from the quantitative component), in order to help answer the third research question: What, if any, are the relationships between senior manager influence and innovation in organizations whose main economic offering is an experience? The nature of this question lends itself to quantitative methods that can examine relationships between variables, as informed by the data collected in earlier phases of the research.

\section{Presentation of the Research Journey}

The mixed methods design for this study integrated qualitative and quantitative methods to answer research questions about senior manager influence in the experience economy context. I have chosen to present these methodologies, as well as the data they produced in two chapters that correspond to the inquiry's phases. These chapters are titled Methods and Results Phase One and Methods and Results Phases Two/Three. While this diverges from the five-chapter dissertation model, it offers an opportunity for the reader to experience the research journey as it unfolded. This is important because of the mixed methodology and phased nature of the inquiry. 
To summarize the three-phase process: In Phase One, I used descriptive statistics from a short survey to identify potential metrics to measure innovation performance. I also conducted interviews and borrowed from the interpretation strategies of qualitative researchers to develop a theoretical model of strategic leadership for innovation in the hospitality and tourism industry context. In Phase Two, I facilitated an advisory working group to provide feedback on the results and data interpretations from the first phase. The conceptual model was translated into a list of management behaviors and leadership practices evidenced by the senior manager interview data. A composite measure of innovation performance was finalized. The results and interpretations from the first two phases informed the design of a survey for Phase Three of the overall inquiry. Statistical techniques of factor analysis and regression were used to present the relationships among the independent variables of strategic leadership (senior manager influence) and the dependent variables of innovation performance.

Chapter Four will cover the methods in more detail, as well as the results for Phase One. Chapter Five will detail the methods and results for Phases Two and Three. I will begin each of the chapters with an in-depth discussion of the strategies used to analyze and interpret the data. I will conclude each of the chapters with a summary of what was learned about innovation, strategic leadership, and the relationships between innovation and strategic leadership in the experience context. 


\section{CHAPTER FOUR}

\section{PHASE ONE METHODS AND RESULTS}

Chapter Three presented an overview of the research design and mixed methods approach used during the three phases of this dissertation. The purpose of each phase, as well as an overview of each of the study components, $\mathrm{W}, \mathrm{X}, \mathrm{Y}$, and $\mathrm{Z}$ were depicted in a methodology overview graphic (See Figure 6). Figure 7, a simplified version of that graphic provides a study components reference tool for use in this chapter, which will cover the methods and results of the quantitative component $(\mathrm{W})$ and qualitative component $(\mathrm{X})$ of Phase One. The purpose of this first phase was to explore leadership for innovation and the ways in which innovation is defined and measured in context.
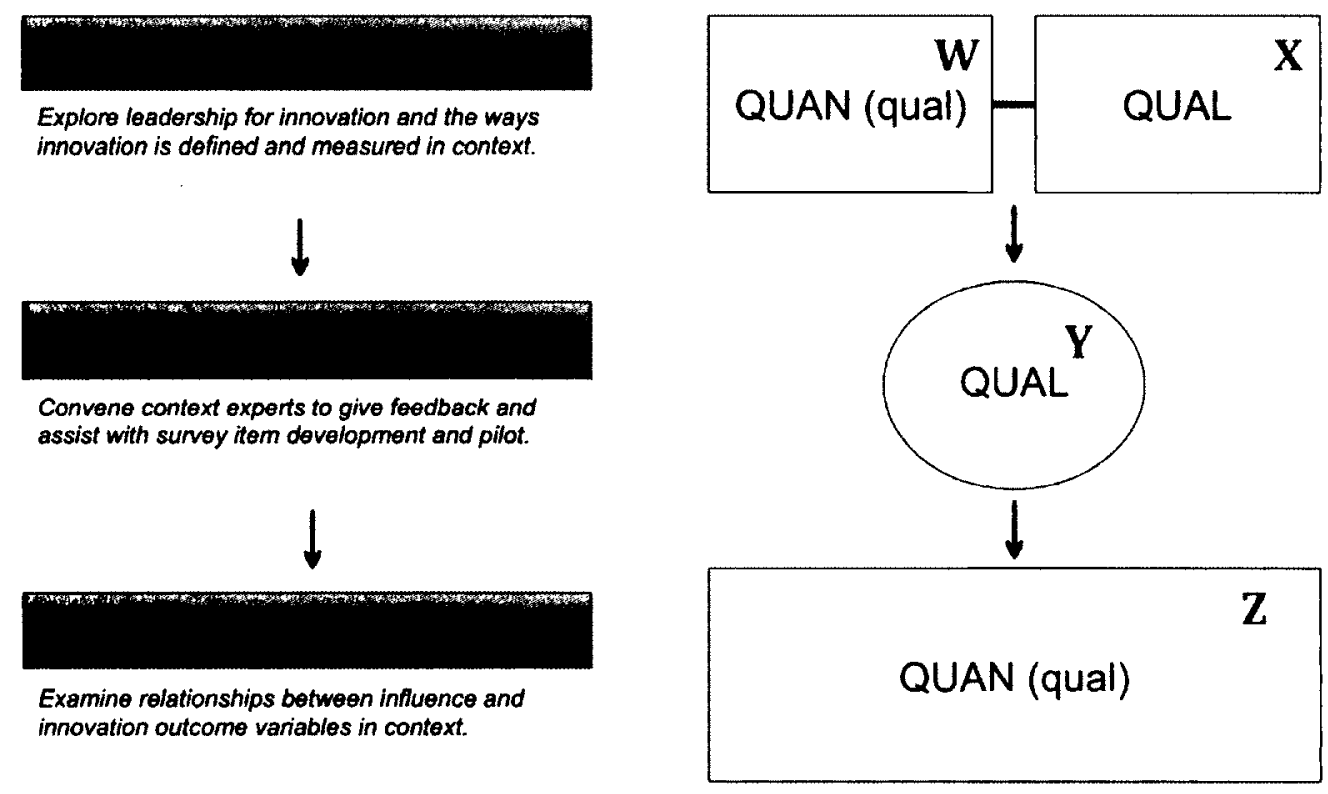

Figure 7. Study components reference

\section{Phase One: Quantitative - Measures and Outputs Survey (W)}

The quantitative component of Phase One (labeled W) was designed to gather a variety of responses about the outputs of innovative activities and the ways in which innovation performance is measured in the hospitality and tourism industry in San Diego. 
Quantitative data allows us to measure the reaction of many respondents to a limited set of questions (Hinton, 2004). Specifically, this component sought to provide a breadth of responses to research question \#1: To what extent is innovation defined and measured in the different segments of the San Diego hospitality and tourism marketplace, and what are these definitions and measures?

\section{Research Participants and Segments}

A short survey, aimed at identifying the measures and outputs of innovation, was sent to a list of managers that is maintained by the School of Hospitality and Tourism Management at San Diego State University. This database contained 840 contact emails of managers in organizations spanning the lodging, dining, meeting/events, and attractions industry segments in San Diego. Studies in the hospitality and tourism scholarly literature tend to focus exclusively on hotels, so using a cross-segment sample provided a diversity of respondents.

Table 1 summarizes the general characteristics of the participant organizations and industry segments represented in the quantitative component $(\mathrm{W})$ of the study. These were mostly large, established hospitality and tourism companies. For example, 71 percent of the organizations have been in operation more than ten years. 
Table 1

Measures and outputs survey: segment, size, and longevity of participating organizations

\begin{tabular}{lllr}
\hline Variable & Category & (N=112) & Percentage \\
\hline \multirow{2}{*}{ Industry Segment } & Lodging & 41 & 37 percent \\
& Dining and Nightlife & 27 & 24 percent \\
& Meetings and Events & 23 & 21 percent \\
& Attraction & 21 & 19 percent \\
Size & Small: Less than 50 employees & 12 & 10 percent \\
& Mid: 51-300 employees & 51 & 45 percent \\
Years in Operation & 49 & 44 percent \\
& Large: More than 300 employees & & \\
& & 10 & 9 percent \\
& New: Less than 5 years & 21 & 20 percent \\
& Mid: 6-10 years & 76 & 71 percent \\
& Long: More than 10 years & 5 & \\
\hline
\end{tabular}

\section{Data Collection and Analysis}

Survey instrument design and pilot. Creating survey instruments is both a science and an art (Rea \& Parker, 2005). For this survey, as well as the one conducted in the final phase of the inquiry, several efforts were made to enhance quality. For example, in a survey research methods textbook, Fowler (2009) recommends referencing other researchers' work, as well as pilot testing and revising the instrument based on feedback from the eventual respondent population. Consistent with this advice, I adapted design principles used by other innovation-related research, as well as conducted a pilot test of the survey instrument, each of which I will discuss in greater detail. I also used a checklist compiled by Rea and Parker (p. 82) on survey design before finalizing the short survey instrument. The email inviting participation in the survey is included in Appendix A. Appendix B includes the survey used, which can also be accessed online at http://www.surveymonkey.com/s/Measures and Outcomes in HTM . 
The survey consisted of five questions about innovation measures and outputs and five questions about the manager's organization/company. Questions related to measures and outputs were intended to tease out context-specific measures that are not available in the literature, which relies predominantly on patents and research and development expenditures as measures in the manufacturing context (Hauser, Tellis, \& Griffin, 2006).

The use of a scale asking respondents to compare their organization's innovation to that of similar organizations is based on reported success using this approach in service related industries (Mathisen \& Einarsen, 2004). In one innovation study, the researcher indicated that this frame of reference allowed respondents to answer even if they lacked clear definitions of what poor, average, or excellent might mean (Prajogo, 2006).

The decision to include open-ended questions regarding types of innovation outputs draws upon the work of Anderson and West (1996) and the work they did with healthcare work groups. In addition to their empirically based team climate for innovation instrument (Anderson \& West, 1998; Loo, 2003; Burch \& Anderson, 2004), the researchers used a panel of raters to assess actual innovations that healthcare teams implemented (Anderson \& West, 1996).

These design decisions are illustrated in Figure 8, which includes a sample question from the measures and outputs survey (Appendix B). Respondents were asked to rate their innovation relative to others in their industry segment and provide examples of recently implemented innovation outputs for their organization. 
Service innovation is the ability to bring new or improved services to the hospitality and tourism marketplace

Example: Curbside service introduced by Chili's that allows customers to phone in orders and pick them up from a restaurant employee at designated parking spaces outside the restaurant.

Indicate your perception of your organization's service innovation against similar organizations in your industry segment during the past 5 years:

Much less Somewhat less

innovative innovative

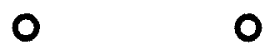

Please provide an example of a service innovation in your organization implemented in the past 5 years
About the same Somewhat more

level of innovation innovative

0

0

Much more

innovative

o

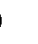

\section{Service innovation
in my organization}

0

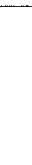

Figure 8. Measures and outputs survey: sample question

This version of the survey also reflects the input from 24 hospitality managers and seven leadership doctorate students who tested a pilot of the survey and suggested that it:

- Provide definitions of product, service, administrative and overall innovation in the survey instructions

- Give an example of each type of innovation outcome to begin each question about the perception of their innovation versus that of other companies

- Move the overall innovation question to the end of the innovation section 
- Begin with the critical research questions, moving the demographic questions to the end so they are quickly drawn in by the content of the survey

Data collection and cleaning. A convenience sample was drawn from the database maintained by the HTM program at San Diego State University in order to solicit a large quantity of responses during the exploratory phase of the study. From the 840 names, there were 223 kickbacks, or invalid emails. Two additional rounds of emails were sent to the remaining email addresses and during the eight weeks that the online survey link was open, 128 surveys were taken.

The data was prepared for analysis by exporting the information into a spreadsheet and Statistical Product and Service Solutions (SPSS). The dataset was then examined for missing cases. Sixteen cases were eliminated because they were incomplete. The remaining 112 surveys were used in the analysis.

Analytical strategies. The structure of the short survey included closed and open-ended questions. Analytical techniques made operational by SPSS were used to explore the quantitative data and prepare frequency charts. Mean scores by segment were examined for each of the different innovation output items. The types of measures used, as indicated by the respondents, were displayed in a bar chart in descending order. The relevant results of the analysis of the quantitative data are presented in tables and figures in the results section of this chapter.

This short survey also included open-ended questions about examples of innovation outputs. There were three opportunities to write in examples of outputsproduct innovation, service innovation, and administrative. More than half of the surveys 
included responses in all three categories with 58 examples of product innovation output, 61 of service innovation output, and 49 of administrative innovation output.

Empirically driven typology studies of innovation outputs in the literature are almost exclusively based on manufacturing segment studies (Sundbo, 2009). Based on these, which are detailed in the literature review section of this dissertation, I determined several analytical strategies for the qualitative outputs data. Figure 9 summarizes these. I began by assigning categories of radical or incremental, similar to the most widely reported methods in the manufacturing literature. Very few outputs rated the radical category. Having observed three natural groupings, I chose to use high, medium and low ratings during the second round of categorizing. The third sorting was by industry segment.

\begin{tabular}{|c|c|}
\hline Business Innovation Typologies & Examples of Output Categories \\
\hline Manufacturing Typologies & $\begin{array}{l}\text { Truly new vs. Incremental Improvements } \\
\text { - Radical vs. Incremental } \\
\text { - Breakthrough vs. Reformulated } \\
\text { - Disruptive or Sustaining }\end{array}$ \\
\hline Service Typologies & $\begin{array}{l}\text { Addition of Back of the House Improvements } \\
\text { - Technical } \\
\text { - Process } \\
\text { - Mdministrative } \\
\text { Managerial }\end{array}$ \\
\hline Emergent Studies in HTM & $\begin{array}{l}\text { Affective Approaches } \\
\text { - Emotion and Attitude Outputs } \\
\text { - Interaction Quality as Output } \\
\text { Drivers of the Output }\end{array}$ \\
\hline Best Practice Approach in HTM & $\begin{array}{l}\text { Case Studies from Hospitality Segments } \\
\text { - Technology } \\
\text { - Marketing } \\
\text { - Customer Relationships }\end{array}$ \\
\hline
\end{tabular}

Figure 9. Typology approaches 


\section{Results from Measures and Outputs Survey (W)}

Outputs of innovation activities. A series of questions asked the managers to assess their innovation performance and innovation outputs in relationship to similar organizations in their industry segment, as was seen in the example provided earlier in this chapter (see Figure 8). These results are reported in Table 2. There were four innovation questions. One asked respondents to rate their overall innovation performance, while the other three asked them to rate their product, service, and innovation. A sample question, corresponding to the service innovation output ratings, was included earlier in this chapter (see Figure 8). See Appendix B to review the entire measures and outputs survey.

Table 2

Measures and outputs survey: frequencies of innovation ratings by innovation type

\begin{tabular}{lccccccc}
\hline & $\begin{array}{c}\text { Much } \\
\text { less } \\
\text { innovative }\end{array}$ & $\begin{array}{c}\text { Somewhat } \\
\text { less } \\
\text { innovative }\end{array}$ & $\begin{array}{c}\text { About the } \\
\text { same } \\
\text { level of } \\
\text { innovation }\end{array}$ & $\begin{array}{c}\text { Somewhat } \\
\text { more } \\
\text { innovative }\end{array}$ & $\begin{array}{c}\text { Much } \\
\text { more } \\
\text { innovative }\end{array}$ & \\
\hline Rating Scale 1-5 & & & Total & Mean \\
\hline Innovation Type & 2 & 14 & 23 & 40 & 20 & 99 & 3.63 \\
\hline Overall Innovation & 2 & 15 & 36 & 36 & 19 & 110 & 3.46 \\
Product Innovation & 4 & 15 & 33 & 35 & 12 & 101 & 3.32 \\
Service Innovation & 6 & 15 & 23 & 40 & 20 & 99 & 3.63 \\
Admin Innovation & 7 & 14 & & & & & \\
\hline
\end{tabular}

According to the frequencies reported in Table 2, overall mean scores for all types of innovation outputs rated in the survey were between 3 and 4 on a comparison rating scale of 1-5. This suggests that the managers in this survey perceive their organizations, on 
average, to be about the same or somewhat more innovative than similar organizations in their industry segment.

After rating their level of innovation in product, service, and administrative innovation outputs, respondents were prompted to provide an example. A definition and an example were given for each of the output questions-product, service, and administrative. More than half of the respondents provided examples of innovation outputs from their own organizations. As discussed earlier in this chapter, I categorized each example of innovation output provided by the survey respondents. Examples of innovation outputs taken directly from the complete collection of innovation outputs data are identified in Figure 10, Figure 11, and Figure 12.

The survey defined product innovation as the ability to bring new and improved products to the hospitality and tourism marketplace. 58 of the survey respondents chose to provide an example of a product innovation output implemented in their organization during the past five years. Based on the analysis categorizing of high, medium and low, 7 were rated high, 34 medium and 27 low. Figure 10 provides an overview of the examples of product innovation outputs provided by the survey respondents of each industry segment, as well as their ratings. 


\begin{tabular}{|c|c|c|c|c|}
\hline & Dining & Lodging & Meeting/Events & Attractions \\
\hline High & $\begin{array}{l}\text { Guests can cut herbs } \\
\text { from plants servers } \\
\text { bring and add them to } \\
\text { supplement the meal } \\
\text { flavors }\end{array}$ & $\begin{array}{l}\text { Interactive } \\
\text { program on the } \\
\text { television for } \\
\text { ordering room } \\
\text { service and it } \\
\text { suggests wine } \\
\text { pairings }\end{array}$ & & \\
\hline Medium & $\begin{array}{l}\text { Culinary theater } \\
\text { where chef and } \\
\text { customer interact } \\
\text { while meal is } \\
\text { prepared }\end{array}$ & $\begin{array}{l}\text { Smartphone } \\
\text { apps }\end{array}$ & $\begin{array}{l}\text { Training team } \\
\text { members on } \\
\text { interaction as } \\
\text { part of the } \\
\text { meeting and } \\
\text { event } \\
\text { experience }\end{array}$ & $\begin{array}{l}\text { Refreshed break } \\
\text { area where } \\
\text { employees have } \\
\text { games, television, } \\
\text { massage chair } \\
\text { and concierge }\end{array}$ \\
\hline Low & Online ordering & $\begin{array}{l}\text { Refreshing } \\
\text { service provides } \\
\text { hotel wide } \\
\text { service } \\
\text { standards and } \\
\text { department } \\
\text { service } \\
\text { examples }\end{array}$ & $\begin{array}{l}\text { To scale } \\
\text { diagrams on the } \\
\text { tablet. }\end{array}$ & New uniforms \\
\hline
\end{tabular}

Figure 10. Product innovation outputs

The survey defined service innovation as the ability to bring new and improved services to the hospitality and tourism marketplace. 61 respondents used the space provided to write in examples of service innovation outputs implemented by their organization in the past five years. Only 2 of these received high ratings. 31 rated medium and 28 rated low. Typical examples of each rating by segment are summarized in Figure 11. Based on a comparison of the product and service innovation output responses, it seems participants did not make clear distinctions between product and service innovations. 


\begin{tabular}{|c|c|c|c|c|}
\hline & Dining & Lodging & Meeting/Events & Attractions \\
\hline High & & $\begin{array}{l}\text { Branded kid's } \\
\text { spa } \\
\text { Hotel workout } \\
\text { gear lending } \\
\text { program }\end{array}$ & & $\begin{array}{l}\text { Triple tantrum } \\
\text { slide w/ double } \\
\text { bowling alley - } \\
\text { showed } 50 \\
\text { percent profit over } \\
\text { previous years }\end{array}$ \\
\hline Medium & $\begin{array}{l}\text { Added mid-day } \\
\text { menu of small } \\
\text { plates and } \\
\text { handcrafted } \\
\text { cocktails - } \\
\text { essentially added a } \\
\text { new meal period }\end{array}$ & $\begin{array}{l}\text { Integrated sales } \\
\text { and catering } \\
\text { program for front } \\
\text { desk and billing }\end{array}$ & $\begin{array}{l}\text { Proprietary e- } \\
\text { conference } \\
\text { solutions and } \\
\text { web } \\
\text { reservations } \\
\text { product }\end{array}$ & $\begin{array}{l}\text { Premium product } \\
\text { with up close and } \\
\text { personal tactile, } \\
\text { visual, photo ops } \\
\text { with animals }\end{array}$ \\
\hline Low & $\begin{array}{l}\text { Using local } \\
\text { products with } \\
\text { tavern style menu } \\
\text { that is } \\
\text { unpretentious }\end{array}$ & $\begin{array}{l}\text { Arrival } \\
\text { ambassador in } \\
\text { lobby during peak } \\
\text { times for more } \\
\text { seamless arrival } \\
\text { experience }\end{array}$ & $\begin{array}{l}\$ 50 \text { gift card for } \\
\text { referring anyone } \\
\text { who becomes a } \\
\text { customer }\end{array}$ & $\begin{array}{l}\text { E-family rewards } \\
\text { program offerings }\end{array}$ \\
\hline
\end{tabular}

Figure 11. Service innovation outputs

Administrative innovation outputs were defined as the ability to implement new and improved business process and practices within the hospitality and tourism organization. There were 0 high, 11 medium and 38 low ratings. Figure 12 provides examples of the types of outputs for this survey item. There were only 49 responses to this question, as compared to 58 and 61 in the product and service innovation output questions. 


\begin{tabular}{|l|l|l|l|l|}
\hline & \multicolumn{1}{|c|}{ Dining } & \multicolumn{1}{c|}{ Lodging } & Meeting/Events & \multicolumn{1}{|c|}{ Attractions } \\
\hline Medium & $\begin{array}{l}\text { Secret shoppers } \\
\text { help create the } \\
\text { training program }\end{array}$ & $\begin{array}{l}\text { Screening and } \\
\text { rating system } \\
\text { keeps track of } \\
\text { employee hard } \\
\text { and soft skills } \\
\text { and interests }\end{array}$ & $\begin{array}{l}\text { Asked } \\
\text { managers what } \\
\text { they're } \\
\text { passionate } \\
\text { about and } \\
\text { reorganized } \\
\text { based on talents } \\
\text { plus passions }\end{array}$ & $\begin{array}{l}\text { Weekly WIG } \\
\text { (wildly important } \\
\text { goal) created by } \\
\text { each department } \\
\text { and shared each } \\
\text { week }\end{array}$ \\
\hline Low & $\begin{array}{l}\text { Customer feedback } \\
\text { tied to webpage }\end{array}$ & $\begin{array}{l}\text { Fully linked } \\
\text { customer data } \\
\text { between all } \\
\text { hotels within the } \\
\text { brand }\end{array}$ & $\begin{array}{l}\text { Rewards for } \\
\text { increased } \\
\text { volume and } \\
\text { client } \\
\text { satisfaction } \\
\text { scores }\end{array}$ & $\begin{array}{l}\text { Internal and } \\
\text { external mentor } \\
\text { program }\end{array}$ \\
\hline
\end{tabular}

Figure 12. Administrative innovation outputs

Measuring innovation in organizations whose main economic offering is an experience presents challenges. As discussed in-depth in the literature review, this is one of the critical issues for researchers who try to apply the innovation theories, typologies, and extant quantitative studies from new product development to the services sector. The intangibility of services, the dispersed nature of a total customer experience, and the multiple points of interaction with customers make it difficult to measure experience innovation (Hjalager, 2009).

Measures of innovation performance. This survey asked respondents to select all of the ways they currently measure innovation in their organizations and provided an opportunity for open-ended responses to the measurement question. These findings are summarized in a bar chart shown in Figure 13. Measures are organized in descending order, beginning with the most used, which is guest satisfaction at a 66 percent response rate. Measures regarding percentage of revenue from new products or services were 
second and other operational process measures were third. All other measures were used by less than 50 percent of the managers surveyed in this component of the study. At the bottom of the list was training hours, selected by less than 20 percent of the survey respondents. Training hours has been mentioned in the literature as the service industry alternative to R\&D investment in manufacturing (Hjalager, 2009).

There were a few responses to the open-ended question of other ways that the organization measured innovation or determined whether or not a particular innovation activity was worthwhile. For example, eight managers discussed custom assessments for measuring innovation activities. These included assessments created by an outside vendor for their entire brand or a proprietary composite measure created internally that measures the success of department projects. Other responses included comparing themselves to their competitors using third party sources and reliance on online sites, like Yelp and others. These results are not particularly surprising. The lack of innovationspecific measures for service industries is well documented by innovation researchers (Hjalager, 2009; Sundbo, 2009). It is discouraging to note, however, that almost one fourth of the respondents, as shown in Figure 13, said they did not measure innovation at all in their hospitality and tourism organizations. 


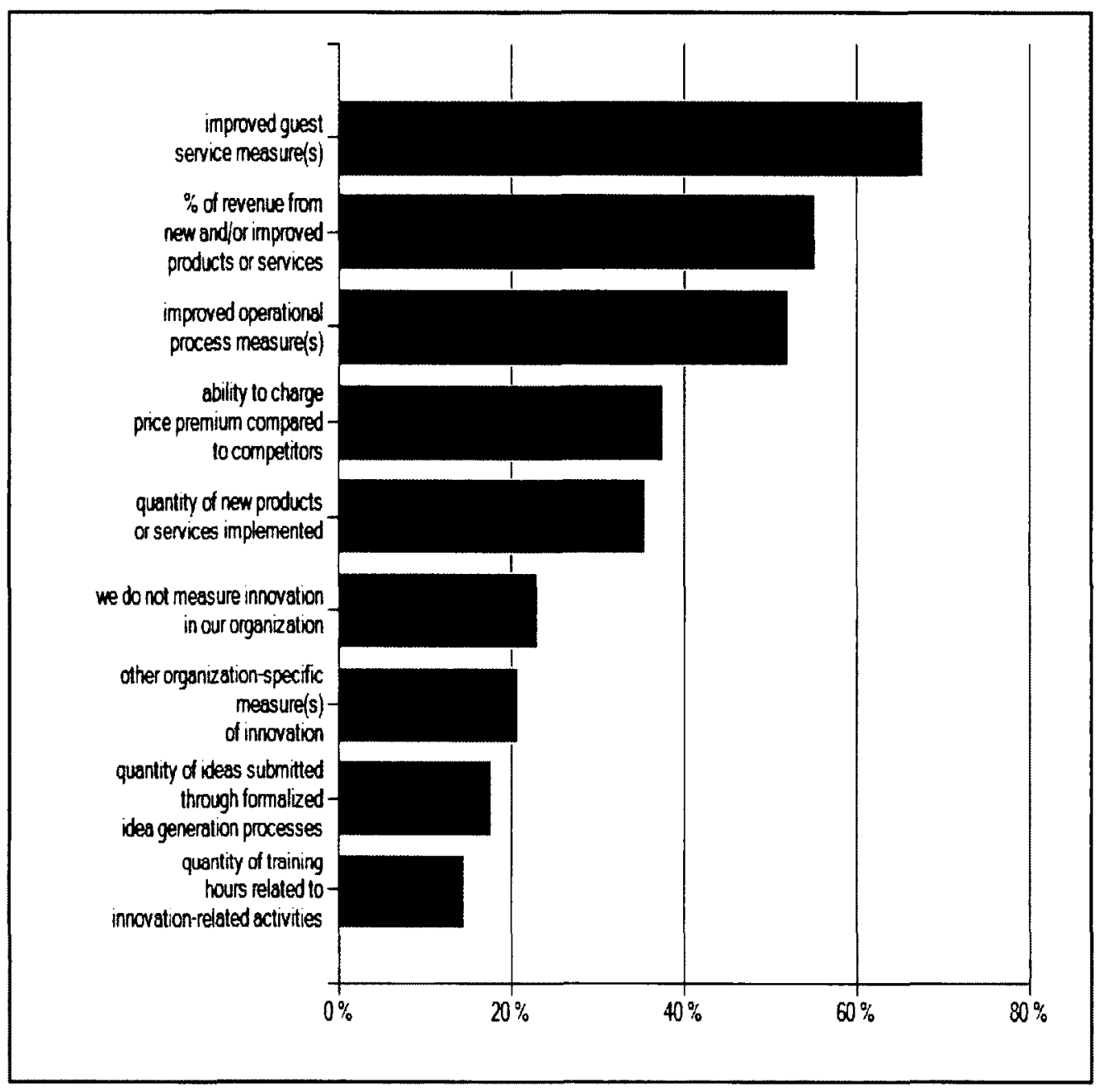

Figure 13. Measuring innovation

\section{Summary of Phase One: Quantitative - Measures and Outputs Survey (W)}

The purpose of the short survey was to obtain a large quantity of responses about the ways innovation is defined and measured in various segments of the hospitality and tourism industry in San Diego. The results section of this chapter provided descriptive summary figures and tables of data collected from 112 managers of the local marketplace comprised of lodging, dining, meetings/events, and attraction segments of the hospitality and tourism industry.

Most organizations use guest ratings and increased revenues to measure innovation performance, although almost 25 percent of the organizations don't measure 
innovation at all. According to the data, most of the managers that were surveyed perceived their organizations to be about as innovative or somewhat more innovative as those in their industry segment. The examples of innovation outputs they provided confirm this perception as most were rated low or medium in terms of innovation. Classifying outputs as radical or disruptive, as is often done in manufacturing, does not seem to apply to this marketplace. Instead, innovation seems to be more of an ongoing organizational objective that involves continuously improving the guest experience in incremental ways.

The information from the quantitative component (labeled W) proved useful, both in terms of results and methods, for the ensuing phases of the research inquiry. The exploration brought to light the ways in which innovation is currently being measured in the local hospitality and tourism marketplace. The data also helped identify possible dependent variables to measure innovation in this context. I also learned things about survey design from this first survey that I applied to subsequent phases of the research inquiry. For example, asking respondents to rate their business performance by comparing them to similar organizations was a useful way to gauge perceptions in that it was familiar and easily understood by managers in this local context. The quantity of write-in responses was a pleasant surprise. More than half of those who took the survey offered detailed examples of innovation outputs implemented by their organization. Hence, this strategy could be employed in future surveys to add depth to quantitative innovation results. 


\section{Phase One: Qualitative - Toward a Theory of Strategic Leadership in Context (X)}

The quantitative component during Phase One provided information about the measures and outputs of innovation. The short, targeted survey, however, did not explore the means to achieving those innovation outputs. For this purpose, a qualitative component was conducted concurrently. This study component is labeled X in the study component reference graphic (Figure 7) presented at the beginning of this chapter. The qualitative component $(\mathrm{X})$ was intended to provide a conceptual understanding of strategic leadership in the context of experience innovation and was designed to help answer research question \#2: How do senior managers influence innovation in organizations whose main economic offering is an experience?
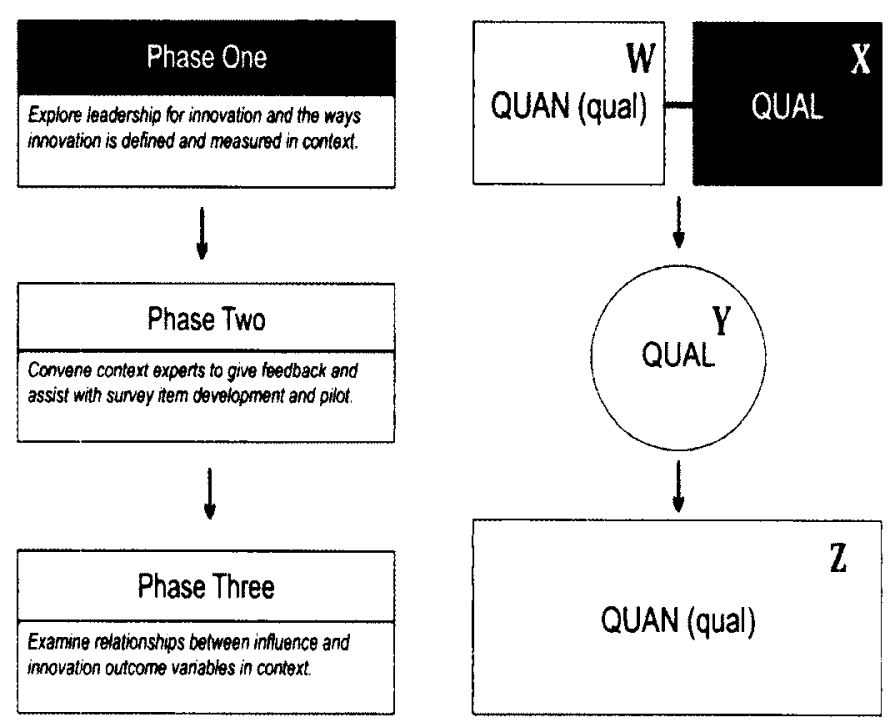

Figure 7. Study components reference

I chose a qualitative approach for this component $(\mathrm{X})$ because it provides the flexibility and depth needed to explore dynamic phenomena such as leadership. Qualitative methods such as the semi-structured interview approach allow for the context and nuances of the phenomena to be explored with depth (Patton, 2002). 


\section{Interview Subjects and Industry Segments}

Qualitative interview participants were purposively-selected executive-level leaders who were known for innovation and who represented different segments of the hospitality and tourism marketplace in San Diego. The decision to focus on the most senior executives stemmed from research on upper echelon theory and strategic leadership which argues that broad-based organizational transformation initiatives are the purview of senior managers (House, Wright \& Aditya, 1997). My goal was to study those who represented the best practices in innovation in the San Diego hospitality and tourism industry. For this component of the study, I was not necessarily looking for a large quantity of responses or broad range of perspectives. Instead, I wanted to find out how those executives with reputations for being influential members of their strategic management teams influenced innovation in their own organizations. A copy of a typical email inviting senior managers to participate in an interview is included in Appendix D.

Eleven interviews with executives from lodging, dining, meetings/events, and attractions, and two with executives from a well- known health care organization in San Diego were conducted. The health care organization was selected to provide perspectives of experience innovation outside the hospitality and tourism industry. This particular company is well known for its work in improving the overall patient experience, and they employ a chief experience officer. The interview subjects and the industry segments they represent are summarized in Figure 14. 


\begin{tabular}{lll}
\hline Segment & Interview Subjects & Quantity \\
\hline Lodging & $\begin{array}{l}\text { Hotel General Manager } \\
\text { Hotel General Manager }\end{array}$ & 3 interviews \\
& Global Brand Corporate Vice President & $60-90$ min. each \\
Dining & Multi Restaurant Group CEO & 2 interviews \\
& Restaurant General Manager & $60-90$ min. each \\
Meetings \& Events & Destination Management CEO & 3 interviews \\
& DMC Manager of Operations & $60-120$ min. each \\
Attractions & Convention Vice President & \\
& GM of Large Attraction & 3 interviews \\
& Dept. Vice President Medium Attraction & $40-80$ min. each \\
Healthcare & Corporate Director of Marketing & \\
& CEO & 2 interviews \\
& Chief Experience Officer & $10-30$ min. each \\
\hline
\end{tabular}

Figure 14. Senior manager interviews by industry segment

\section{Data Collection and Analysis}

Mindful that the researcher becomes the primary tool of investigation in qualitative components of inquiry (Merriam, 1998), I will attempt to outline my approach to this component $(\mathrm{X})$ in a way that offers a clear learning logic. This section describes decisions related to the interview protocol - an alignment between the research questions, interview questions, and unit of analysis - as well as a systematic approach to interpreting the meaning of the participant voices, individually and collectively.

Unit of analysis aligned with research question. Yin (2009) notes that selection of the unit of analysis in qualitative research is connected with the fundamental problem of defining what the case is-e.g., individual, group, entity, decision, or phenomena. The unit of analysis for this qualitative component is senior manager influence. Because, as Yin suggests, the unit of analysis is often embedded in a well-crafted research question, I 
was reminded to anchor my interview questions in the specific ways that the participants influence innovation in their own organizations.

Throughout this dissertation, I will use the terms senior manager influence and strategic leadership almost synonymously. Using these concepts interchangeably is consistent with contemporary definitions of strategic leadership discussed in greater detail in the literature review. Drawing upon upper echelon theory (Hambrick \& Mason, 1984) and stratified systems theory (Hunt \& Ropo, 1995), strategic leadership theory emphasizes the influence of top level managers on the organization's ability to adapt and change (House, Wright \& Aditya, 1997). Senior managers are responsible for leadership of organizations, as opposed to leadership in organizations (Boal, 2004).

Senior managers influence change through a) systems, structures and strategies b) development and focus on the collection of skills, knowledge and behaviors of individuals and c) organizational climate and culture (Yukl, 2008). These areas of senior manager influence—strategy, culture, climate, policies, for example-are also consistent with the innovation research in business framework that was depicted earlier in this dissertation (see Figure 2). It stands to reason that these types of senior manager influence strategies are what one might expect to hear when interviewing executives of hospitality organizations.

Interview guide as a reflection of propositions. The Interview Guide (Appendix E) was designed as a semi-structured interview protocol. I relied primarily, on semi-structured interviews because this enabled me to cover a wide range of topics, tailor new questions to participants' prior responses, and compare results across interview subjects (Kvale, 1996). The Interview Guide (Appendix E) aligns the research question 
and unit of analysis; it also reflects the theoretical frames presented in the literature review regarding innovation and senior manager influence. For example, the major lines of inquiry in The Interview Guide were consistent with the drivers/inputs of innovation depicted in the framework of innovation research in business from the literature review (see Figure 2). They are also consistent with contemporary views of strategic leadership as referring to the influence of top-level managers.

Study propositions direct attention to something that should be examined within the scope of the study and tell you where to look for relevant evidence (Yin, 2009). Study propositions reflected in The Interview Guide for research component $(\mathrm{X})$ included the following: a) senior leaders influence organizational performance through strategy, culture, processes, projects, and measurement b) innovation is defined as both a means and an end to include idea generation and implementation c) interview participants will be senior managers with knowledge of the experience economy.

Interviews and memos. I drew from my current professional contacts as well as the list of industry professionals connected to the Hospitality and Tourism Management Program at SDSU in order to invite potential interview subjects via personal email. In some instances, I sent the email directly. In a few cases, I relied on the positional power or relationship of someone that I knew would be able to recommend me to the executive. Each person I contacted agreed to the interview. Information about the interviewees and the length of their interviews was presented previously (see Figure 14). I knew one of the interviewees professionally and had some, limited contact with four of the interviewees. The other eight executives I met for the first time. Most interviews were scheduled at the executive's place of business. Two interviews were held at my 
place of business at San Diego State University. One interview occurred at a VIP event following the annual meeting of the healthcare organization's staff. With prior consent, interviews were recorded and transcribed, and each participant was given an opportunity to review and validate the contents. Three interviews were not recorded, and instead, notes from the interviews were sent to the executive. All of the direct quotations in this chapter are provided with explicit permission from the interview subjects.

The interviews were held concurrent to conducting the quantitative survey during Phase One and spanned three months. Immediately after each interview I wrote a page or two of notes summarizing my overall sense of the data, key interpretations, links to the literature, and questions for myself. This method of analysis is referred to as keeping analytic memos by many qualitative researchers. It is one of five main approaches outlined by Kvale (1996) that is available to qualitative researchers. This interpretation method entailed an "abridgement of the meanings" (Kvale, 1996, p. 190) expressed by the interview subjects, as well as my own perspective on the phenomenon. It was also a place I returned to often in order to center myself in the qualitative data during the interpretation and writing stages of this dissertation.

Codes and categories. I coded each interview transcription following strategies outlined by Saldana (2009). The initial round of coding can be categorized as elemental. First, holistic coding was implemented in order to grasp basic passages by absorbing them as a whole rather than analyzing them line-by-line. This coding method chunks the interview data into broad topics to see what is there. It is a natural way to begin engaging with the text of a structured interview conversation. At times, I returned to the memo I 
had written and made additional notes. This was an ongoing process throughout the three-month time period spent interviewing senior managers.

After all of the interviews were completed, I created a list of codes using another elemental method Saldana (2009) calls structural coding. Structural codes, in this case, followed the main headings of The Interview Guide (Appendix E). Phrases from the holistic coding were labeled for a particular type of senior manager influence (unit of analysis) within a particular heading. A list of other codes that did not fit under the structure was still maintained. For example, a holistic coding of a passage that read "we hired two people whose only job was to go around the country and see what else was out there...kept us on our toes" was coded as see what others do. This code was placed under the structural heading of innovation as idea generation.

From the codes, I began to chunk together categories. To do so, I first created a list of categories within the major headings as well as outside of them for each segment of the industry. I reviewed each segment's codes and the related interview passages, and then created a list of combined codes (categories). Additionally, I made notes of the similarities and differences for each segment as well as my interpretations of those. For example, I noted that the lodging segment seemed to have to deal with issues of service standards of the parent company brand, something that did not appear to be a tension in the other segment's interview data.

Based on the list of categories compiled by industry segment, I developed a series of categories that spanned all segments. In Figure $15 \mathrm{I}$ have provided a partial list of these categories compiled from structural codes under the Purpose/Strategy section of the interviews. 
amenities, animal encounters, shows, food, beverage, venues, props, products, basic offerings

guest oriented, employee/guest mimicry, dual purpose, individualized, co-create, share with each other, connect together, interactions

dominate competition, see what others do, stay ahead of competition, perceived value goes beyond others, benchmark, visit other, other experience venues

effectiveness, personality of service, technical service

years of experience, methods, soft strengths, empowerment, entrepreneurial spirit, convenience, peace of mind, brand promises, equities, excellence

heritage, past and future intertwined, soul, uniqueness, essence, grander purpose, can only talk metaphorically, our culture, can't explain in words
Functional

Interactions
Service

Explainable Intangibles

Unexplainable intangibles

Figure 15. Excerpt of codes and categories

After category and memo revisions, I went back through the interview transcripts and highlighted only those passages I called phrase gems. These were passages that struck me after having already spent some significant time with coding. Identifying phrase gems is what Saldana (2009). refers to as in vivo coding. These direct quotes often ended up summarizing or providing depth to the meaning of a category.

Patterns and themes. I then engaged in the process of moving from the codes and categories to themes, utilizing several strategies. I began by overlaying a few theoretical frames onto the categories in order to look for relationships. I went through at least three iterations of this. First, I mined the data for context patterns, asking "What 
about the voices from these executives is different from other contexts?" Then I considered what the data might be saying about leadership and/or innovation in this context, asking "How is this different than what is already in the literature?" For the most part, this was a messy endeavor conducted on the floor, with the codes and categories pages spread out in front of me in hard copy and the interviews and memos documents on the laptop. The synthesis process was an ongoing one over the course of months as the interconnectedness of the data became more compelling.

Charmaz describes sorting, diagramming, and integrating memos as strategies of theoretical sampling (2006). Her depictions of these inter-related processes are consistent with the pattern-seeking activities I used. As patterns revealed themselves through different methods of combining the categories, I would create a one-page summary. Many of these one-pagers were reworked into new combinations that I ended up calling theme pages. Most theme pages contained a collection of interview data as well as my interpretations from memos. Some theme pages had graphics or models that I developed along the way. Theme pages did not all follow the same structure, but each represented a sanitized version of my messy efforts to make meaning of the data. Figure 16 demonstrates a table of contents and excerpt of one theme page. 


\section{Theme Pages - Data Interplay}

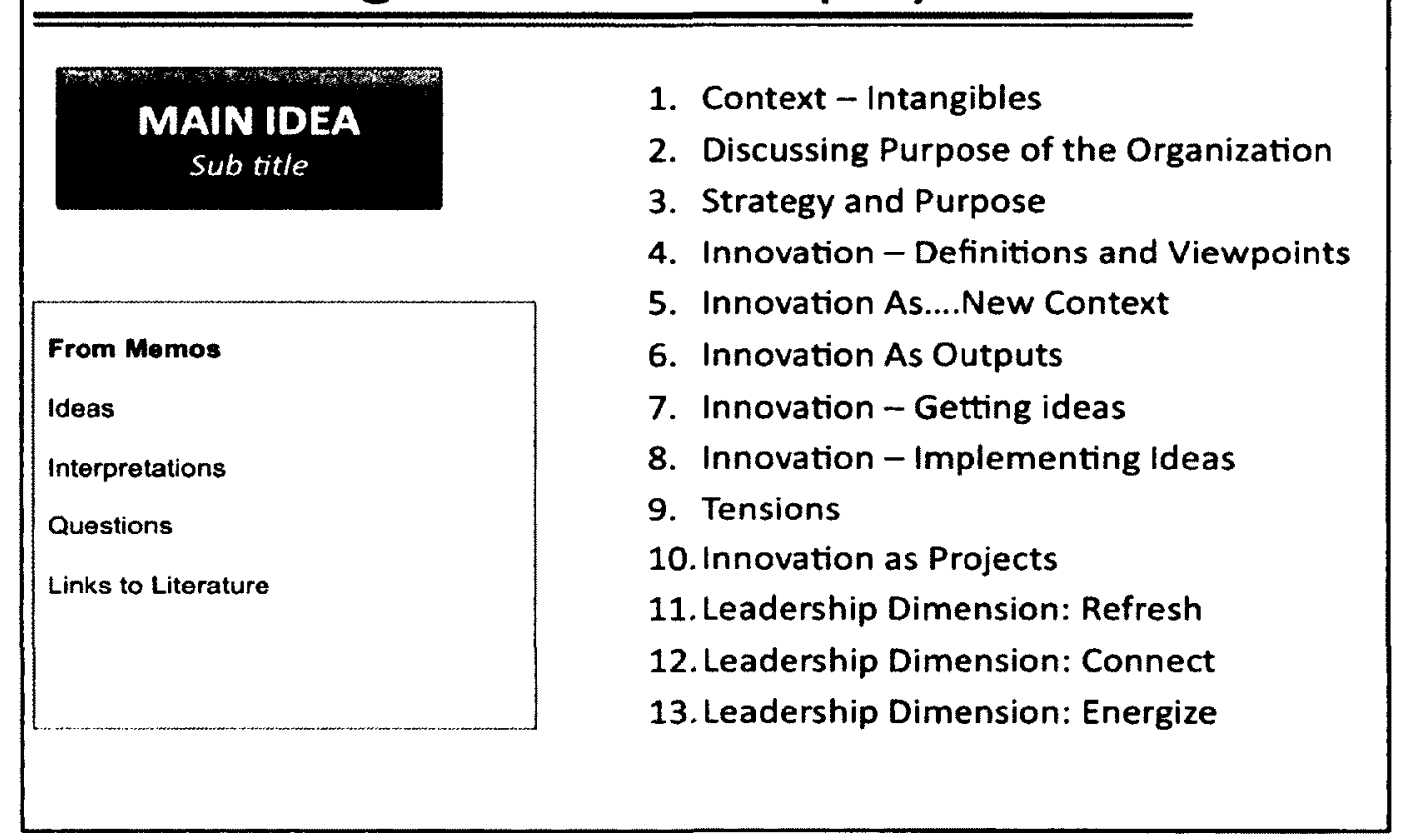

\section{Strategy and Purpose}

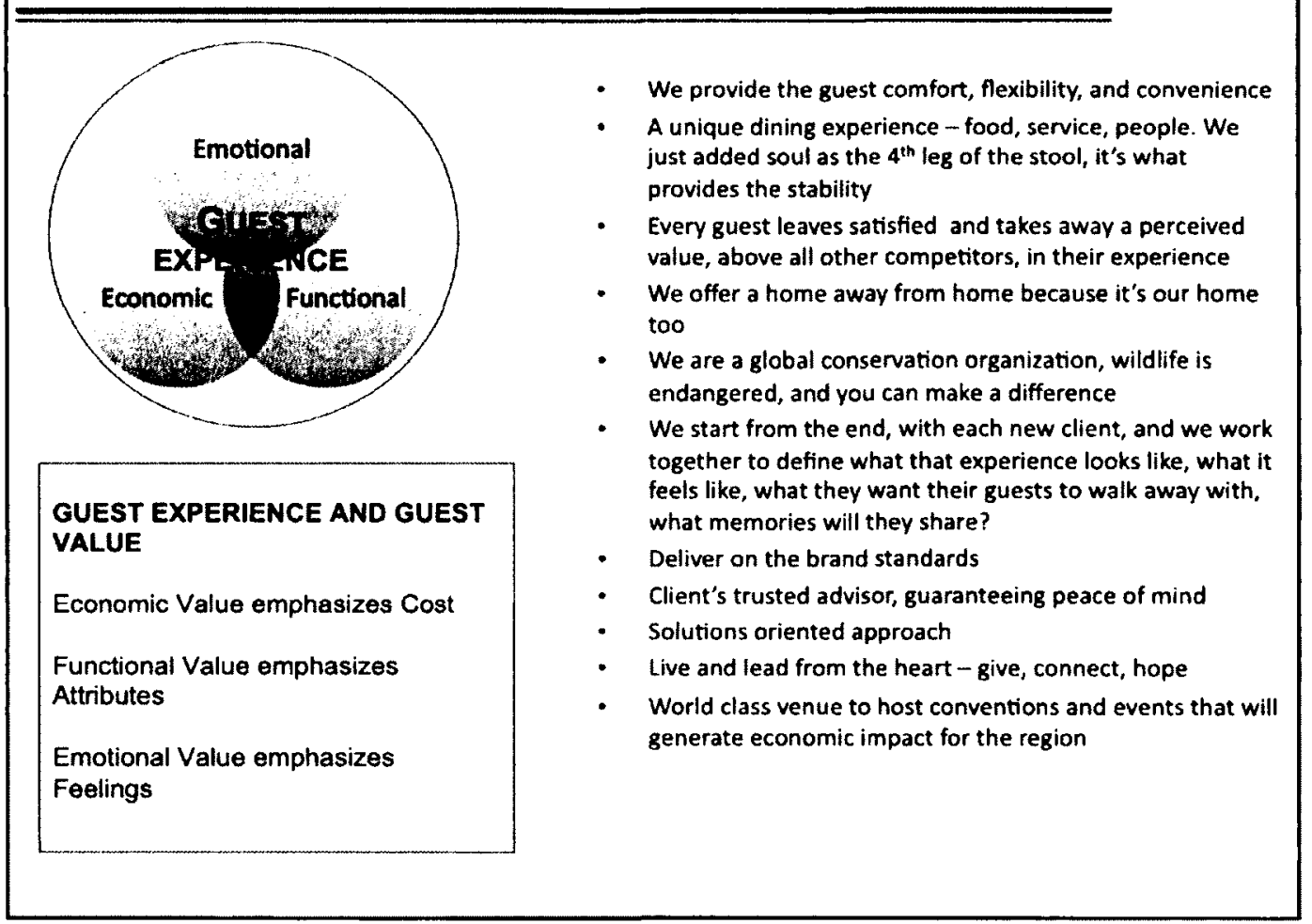

Figure 16. Excerpt of theme pages 
The table of contents, titled Theme Pages-Data Interplay in Figure 16 includes a list of thirteen theme page titles about the industry context, innovation, and leadership. A template on the left side shows the main idea, as well as memo data that were mined. The actual theme page, titled Strategy and Purpose in Figure 16, roughly follows this template. This theme page includes data in the form of quotes along the right side. The left side includes a graphic and a text summary of the ways the categories of data about purpose can be related. This particular theme page evolved from the codes and categories under Strategy/Purpose (shown in Figure 15) and a reread of an innovation article (Chen \& Sawney, 2008) included in the literature review chapter. The complete collection of theme pages is included in Appendix G. These capture some of the processing back and forth between the data, the literature, and my own reflections, as well as patterns that emerged over the life of the inquiry.

Data and researcher integration. When using qualitative methods of analysis, the researcher becomes the primary tool, and qualitative researchers use a variety of methods to analyze their data. As outlined here, I relied on qualitative research methods offered that worked for this particular research inquiry. Kvale (1996) influenced the approach taken to create The Interview Guide and develop memos. The section on unit of analysis in Yin's text (2009) helped me stay focused on the research question, to the extent possible, when conducting the semi-structured interviews. The broad scheme offered by Glesne (2006) helped to envision the process of going from data to patterns. Saldana's coding schemes (2009) are a valuable resource for new researchers. The descriptions provided by Charmaz (2006) helped make sense of the sorting, diagramming, and memo relating strategies used by many qualitative researchers. 
As suggested in Figure 17, my own perspectives were also present throughout this study, but particularly during the interviews with senior managers. Although I primarily took on the role of researcher, my background as a senior manager of a large attraction in San Diego, my connection to the literature, and my role as an educator in the hospitality and tourism context were not sidelined during the inquiry process. I did, however, make attempts in the research design as well as throughout the study, to attend to researcher bias. I did this by purposely selecting interview subjects with whom I had little or no prior affiliation, not interviewing anyone from my previous place of employment and seeking out contrary perspectives. For example, one of the hotel managers I interviewed had a negative perception of the role that innovation played in attending to the fundamentals of the business. I eagerly pursued his thoughts with follow up questions, and incorporated his viewpoints in the survey in Phase Three. Finally, I included the qualitative component of Phase Two in the design of this dissertation inquiry in order to have my interpretations of the data reviewed by external participants.

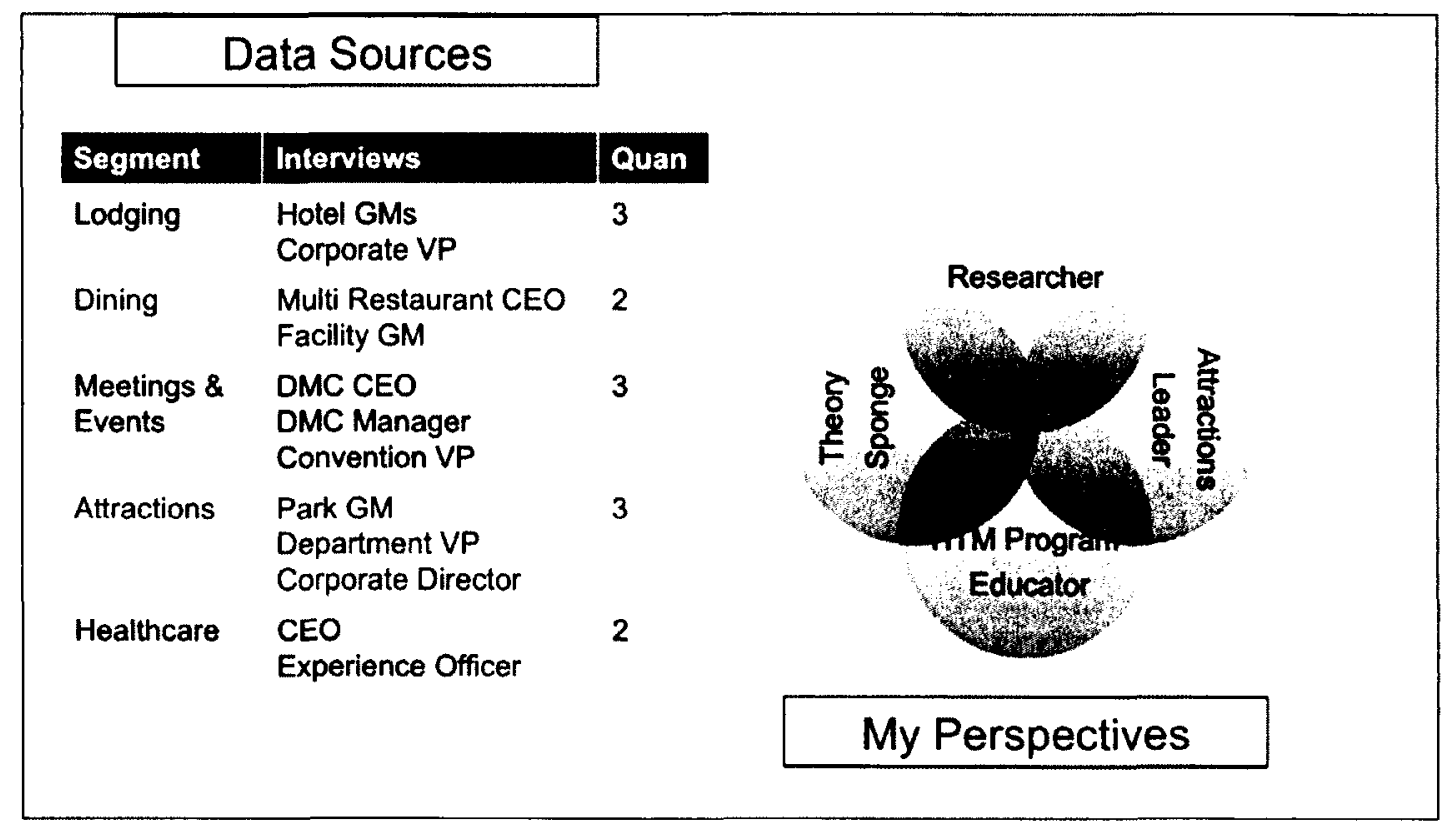

Figure 17. Data and researcher integration 


\section{Results from Senior Manager Interviews (X)}

The interviews focused on the ways in which senior managers, usually as part of a senior management team, influenced innovation in their own organizations over the past two years. Many of the managers' responses to interview questions about strategy, culture, idea generation, idea implementation, and innovation projects from The Interview Guide (Appendix E) are included as direct quotes and as categories throughout the theme pages. The collection of themes was a place to mine the data for the senior manager influence unit of analysis. By re-connecting the themes while paying particular attention to the contextual purpose of this inquiry, I was able to develop a conceptual, theoretical model of leadership for innovation in the experience context.

The model of strategic leadership in context, presented in Figure 18, graphically illustrates the results of the generative theory-building journey just described in the data collection and interpretation section of this qualitative study component. The strategic context is represented by the guest experience focus of the model. The guest experience is made up of a unique combination of products, services, human interactions, and other attributes that offer emotional, functional, and economic value, in some combination, to the visiting guest or customer. Therefore, competing in the hospitality and tourism industry context requires an approach to innovation that is about continuously enhancing the unique guest experience of the organization.

The complex and personalized nature of the economic offering - a total experience - presents challenges for leadership of the organization. Leadership for innovation in this strategic context involves three categories of senior manager influence 
or three dimensions of leadership. Based on interview responses, these are labeled Refresh, Connect, and Energize in the theoretical model presented in Figure 18.

The Refresh dimension is representative of the way in which senior managers enhance the organization's capacity for idea generation. The Connect dimension represents the ways that senior managers influence the organization's shared understanding of the unique guest experience. The Energize dimension symbolizes idea implementation in support of the unique guest experience.

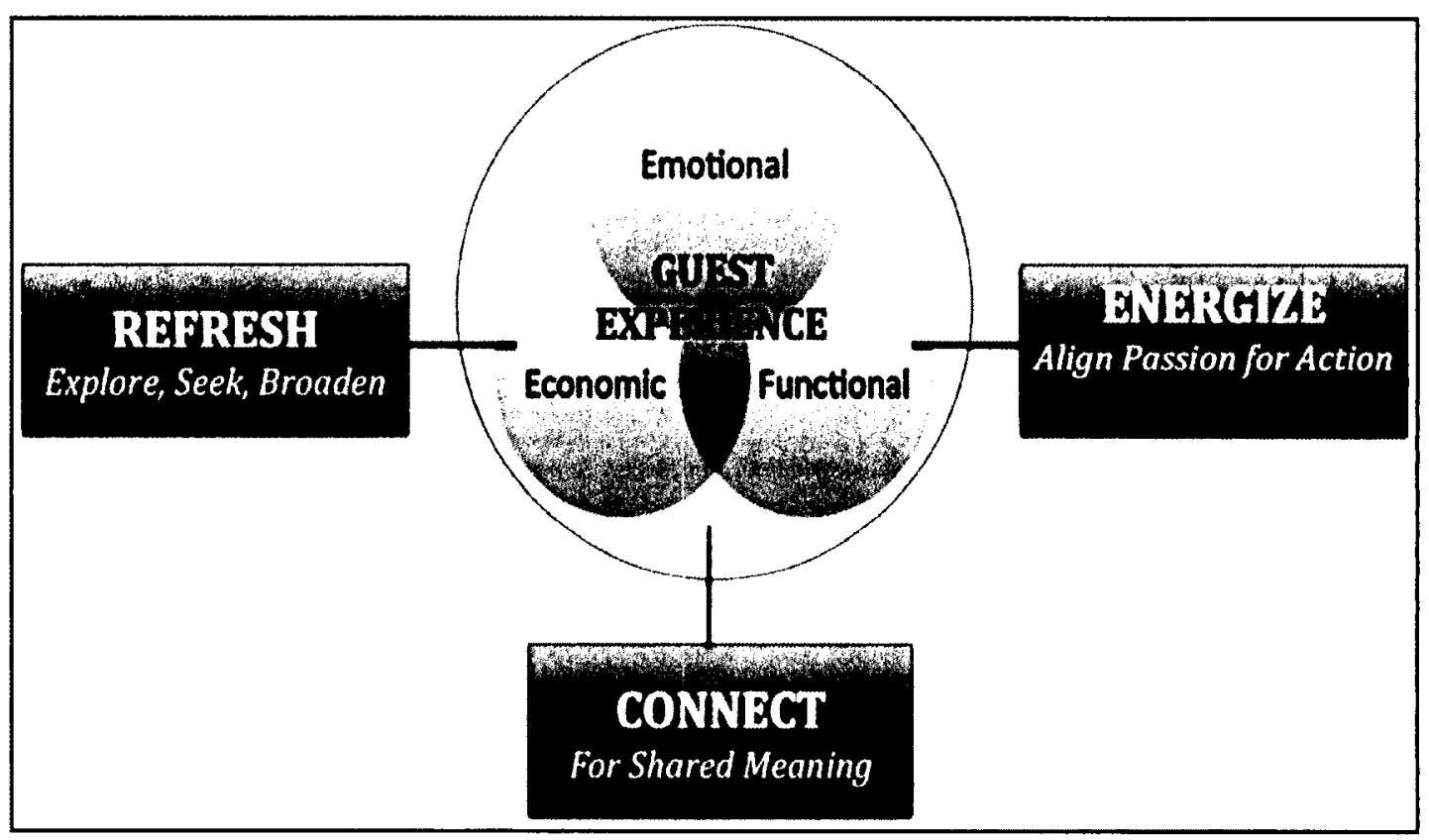

Figure 18. Conceptual model of leadership for innovation in the experience context

I will relate the qualitative data in the ensuing paragraphs to the conceptual model of leadership for innovation presented in Figure 18. First I will present data in support of the strategic context and the nature of innovation in this operating context, represented in the center of Figure 18. Then, I will define and present data in support of the three categories of senior manager influence (leadership dimensions) labeled in the conceptual model as Refresh, Connect, and Energize. 
Strategic context. The unique characteristics of the industry context include the intangibility of the customer offerings and the simultaneous nature of the production and consumption of the total customer experience. These contextual factors significantly impact the ways in which senior managers approach all aspects of influencing innovation and change in their organizations. References to the unique challenges of the industry context peppered the interview responses to questions regarding organizational purpose and strategy, views and approaches to innovation, and organizational leadership. Strategic context plays a central role in the theoretical model of strategic leadership (Figure 18).

It was clear from the onset of the interview phase that the input/output model of innovation research, conducted primarily in the manufacturing industry, would not be readily transferable to firms competing in an industry context where many of the customer offerings are of an intangible nature. One executive summarized the challenging contextual factors in comparison to manufacturing companies:

The analogy of product versus service innovation is like mathematics. They both are in the same category, in this case innovation strategy, but one has everything fixed and the other is dealing with all variables simultaneously. I think it takes a different mindset to wrap your head around innovation in the service industry versus innovation in products. The notion of building a better mousetrap is... go build a better one. Not that it is easy, but it's very different than saying... how do you build a better mousetrap of what you can't see, hear or touch? It's experiential...so how do you build a better experience, and then what defines better?

Other respondents from the meetings and events segment of the industry echoed this CEO's sentiment in terms of the difficulty in defining the "mousetrap" or core products and services of their own companies. 
Strategy and purpose. For almost every person I interviewed, a unique guest experience was the focal point of the company strategy and purpose, regardless of the industry segment. One dining CEO described his company as a "family of brands that share a unique culture and soul," adding, "The culture at its core is about providing unforgettable dining experiences." One of the lodging participants also described his company as a family of unique experience brands, and indicated that differentiating the brands was at the heart of their current corporate strategy. Creating lasting memories for client partners was central to another meeting and events company purpose. Responses like these are consistent with organizations transitioning to the experience economy and employing an experiential branding strategy (Lebel \& Dube, 2010).

It is not surprising that the executives interviewed for this research study component cited "creating compelling customer experiences" as their organization's purpose. It has been more than a decade since Pine and Gilmore began using the now ubiquitous term the experience economy (1998). I was surprised, however, by the variety of ways in which the interview subjects articulated the uniqueness of their guest experience in terms of the value derived by the customer. These included product attributes (like location, amenities, menu items), functional attributes (like supplier relationships, technological efficiencies), and emotional attributes (like soul, memories, connection). For example, the $\mathrm{CEO}$ of a meetings and events company discussed the importance of defining the business in terms of the memories that the client hopes attendees at a particular event will accumulate. It is interesting to note this participant's recognition of the co-constructed nature of the experience in the quote below, a factor 
that the literature identifies as a key characteristic of the hospitality and tourism experience.

I start from the end. We can work together to define what the experience looks like, what it feels like. We are driving with the client. You want loyalty? What else? You are communicating. So you really want an experience that is not just recognition... it's loyalty, it's values based. What do you want people to go back home with after this trip in their head? What are the memories you want them to walk away with? We are co-creating it together. So we have the image, the end result, then we can go about matching that with some more tangible parameters. A lot of DMCs don't think that way. We get into the feel of it, the psychology of what the client wants. Everything else is built around the memories.

On the other hand, some discussions about strategy and purpose focused on efficient service or functional attributes, while a few continued to emphasize economic values such as low cost, as the differentiating factor for guest offerings. Some of the participants seemed uncomfortable moving beyond the phrase outstanding service to express their unique competitive advantage. These responses seemed inconsistent with the experience economy paradigm detailed in the literature review of this dissertation.

A summary of brief interview excerpts in Figure 19 provides additional examples of the ways that senior managers spoke of the uniqueness of the guest experience in their organization. I chose to categorize these examples in terms of economic, functional, or emotional value as suggested by the Innovation Radar instrument (Chen \& Sawney 2008). The authors argue that their instrument addresses the need for expanded approaches to innovation that go beyond the manufacturing context, recognizing that the innovation strategy depends on the value derived by the customer. 
Economic Value

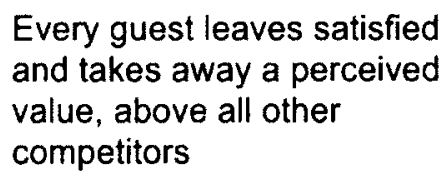

Every guest leaves satisfied and takes away a perceived value, above all other competitors

World class venue to host events that will generate economic impact for the region
We provide the guest comfort, flexibility, and convenience

Solutions oriented approach guaranteeing peace of mind

Deliver on differentiated brand standards
Emotional Value

A unique dining experience that conveys our soul - the $4^{\text {th }} \mathrm{leg}$ in the stool after food, service, and engaged people

Celebrate, connect, and care for the natural world we share

Live and lead from the heart - give, connect, hope

We offer a home away from home because it's our home too

Figure 19. Value proposition of experiences

It was not unusual to find a variety of mental models of the experience offering within the same interview, as evidenced by the fact that statements about the uniqueness of the experience spanned more than one of the value categories.

A few of the interviews such as the one from which the quotation below was taken, could legitimately be coded for all three of the value categories:

The dining experience is unique for our demographic. They want to be able to bring their kids into the bar, watch sports or socialize with people and not necessarily have to have that within a pre-defined dinner hour. It's much more of a hybrid kind of thing - going to a space where the vibe and feel is cool and hip and new and modern but at the same time it has to be totally unpretentious and casual. It's that both/and mentality...I want it all, and I want to feel like I got a deal because there's a lot of competition.

I struggled to make sense of this particular collection of data. It seemed that the way in which the senior manager talked about the organization's experience might influence how far the organization had indeed transitioned from a service focus to an 
experience focus. I spent considerable time examining the strategy and purpose data in hopes of uncovering a compelling pattern.

Some of the ways I combined these particular codes and categories make appearances in the theme pages (see Appendix G). For example, an initial version of the conceptual model of leadership for innovation displayed a pyramid of offerings in the center of the diagram to depict the unique guest experience. The qualitative results that were discussed in the first few paragraphs of interview responses are integrated into the center of the conceptual model of leadership for innovation (see Figure 18). All senior manager influence activities begin and end with the unique guest experience, however defined. It is central to leadership of organizations in the experience context.

Innovation strategy. Most definitions of innovation in business include idea generation and implementation of new and novel ideas. Although a majority of the interview participants had initiated projects to enhance the guest experience in some way within the past six months, most of the respondents did not articulate a systematic innovation strategy or approach that would match the business model with an end to end idea generation and implementation process for new product development.

In contrast, the need for ongoing change in support of the unique guest experience seemed to be an underlying assumption for hospitality and tourism organizations. Only one participant differed, suggesting that "chasing after change distracted from serving guests." The majority of interview responses suggested that innovation could be viewed as a way of thinking and a collective process of keeping the guest experience fresh. Innovation performance, according to the senior managers interviewed for this study, seems to be assessed by staying ahead of the competition in providing new and improved 
products and services to the guest. The remaining definitions of innovation strategy from the interviews are categorized in Figure 20.

\begin{tabular}{|c|c|}
\hline Innovation Strategy & Examples of Interview Subject Definitions \\
\hline \multirow{3}{*}{ Way of Thinking Differently } & $\begin{array}{l}\text { Thinking entirely differently about the sustainability of our } \\
\text { business }\end{array}$ \\
\hline & Getting at the why questions \\
\hline & Being a thought leader \\
\hline \multirow{2}{*}{$\begin{array}{l}\text { Collective Process of Enhancing the } \\
\text { Guest Experience }\end{array}$} & $\begin{array}{l}\text { Change is a constant, so I spend a lot of my time } \\
\text { checking with the staff and staying in tune with how they } \\
\text { are doing and how they think they can make the dining } \\
\text { experience more uniaue because of their strenaths }\end{array}$ \\
\hline & $\begin{array}{l}\text { Keeping brands fresh and differentiated is a continuous/ } \\
\text { collective process that involves people close to the guest }\end{array}$ \\
\hline \multirow{3}{*}{$\begin{array}{l}\text { Staying Ahead of Market Trends and } \\
\text { the Competition }\end{array}$} & $\begin{array}{l}\text { Anticipating what might happen next out of competitive } \\
\text { spirit and curiosity }\end{array}$ \\
\hline & $\begin{array}{l}\text { Being ahead of the curve to better the guest experience } \\
\text { and get an advantage over the competition }\end{array}$ \\
\hline & $\begin{array}{l}\text { Always on the lookout for new ideas and talking with like- } \\
\text { minded people }\end{array}$ \\
\hline \multirow{2}{*}{$\begin{array}{l}\text { Novel Outputs Impact Business } \\
\text { Performance Measures }\end{array}$} & Better products and services tied to the guest experience \\
\hline & Guest improvements that have measurable outcomes \\
\hline
\end{tabular}

Figure 20. Innovation strategy

Interviewees suggested that new ideas and a willingness to adapt to change are important at all levels of the organization. Several interviewees conveyed anecdotes about innovations that were initiated by line level employees. The collection of responses demonstrated that innovation in the hospitality and tourism marketplace will not be limited to ideas developed and implemented by research and development specialists. The importance of the guest/employee interaction that is characteristic of this industry context was evident in developing innovative initiatives. The intangible nature 
of the economic offering, however, makes it difficult to define the starting point for innovation activities, and the experience is usually deployed throughout the organization, prompting one executive from the attractions industry to comment, "innovation is everywhere, and we need all people involved, but they have to feel like they can contribute."

Strategic leadership. Understanding the strategic context and innovation strategy viewpoints is important because it underscores that in organizations in which the main economic offering is an experience, leadership is about ongoing, albeit incremental, change. Broad based organizational change is the focus of strategic leadership, "marked by a concern for the evolution of the organization as a whole" (Selznick, 1984, p. 5). As delineated in the definitions provided in the literature review and methods chapter, contemporary strategic leadership theorists describe the essence of strategic leadership as creating, developing, and enhancing absorptive and adaptive capacities of organizations (Boal \& Hooijberg, 2000) within strategic fit (Carmeli, Gelbard, \& Gefen, 2010). Absorptive refers to (Cohen \& Levinthal, 1990) is the capacity to learn, while adaptive (Christensen, 1997) addresses the capacity to change. Strategic fit is concerned with aligning internal capacities with factors in the external environment (Carmeli, Gelbard, \& Gefen, 2010). In addition, innovation in business involves both idea generation and idea implementation activities.

The data representing the ways in which executives who participated in the interviews exercise leadership for innovation in their organizations constitute three themes. These are labeled Refresh, Connect, and Energize in the conceptual model (see Figure 18). These dimensions of leadership are indicative of the ways in which senior 
managers influence idea generation and idea implementation needed for ongoing improvement of the guest experience.

Idea generation. The word Refresh describes the body of interview responses regarding the ways that ideas are generated in the participant's organizations. The refresh dimension of leadership is about broadening the perception of the business and the pool of ideas for incremental change. It addresses the notion of exploring new and innovative ideas for improving and enhancing the guest experience. Senior managers influence idea generation by benchmarking the ways that other organizations deliver unique guest experiences. They participate in industry associations and keep abreast of changes in customer attitudes and market conditions.

The participant's influence on practices represented by the Refresh theme is consistent with senior manager influence strategies for adaptation and change. The increasingly demanding consumer requires that organizations competing in the experience context continuously engage in idea generation to refresh the collection of offerings that make up the total experience. For example, one of the eight interview participants, a general restaurant manager, had been involved in substantial projects to redefine, remodel, repurpose, or refresh the guest experience in some way. They had altered the physical spaces, décor, menu offerings, and entertainment options for what he referred to as the hybrid consumer. As he described it, the "restaurant re-launch offered a way to get the associates excited...talking about their passions to deliver great dining experiences." 
A vice president from the attractions segment shared the following story, providing additional insight into the value of defining the purpose of the organization in terms of an expanded vision through key messages:

We realized people felt they could only discuss their own area. So, as a management team, we sat down and started talking about how we could expand, in general how people, even we, thought about the business. We came up with a refreshed and updated version of our vision...that we connect people to wildlife. And we went from there. We're more than a zoo, but getting people, a lot of stakeholders to realize that, has been challenging. We now have three messages... we are a global conservation organization, wildlife is endangered, you can make a difference. Then we set about embedding these messages throughout the park. Every department was asked to get involved in their own way.

The most common mechanism associated with the Refresh dimension in this study was exploring the ways other organizations create and deliver unique guest experiences to their customers. Many respondents benchmark competitor organizations as well as explore experiences outside their segment of the industry from a consumer perspective. This exploration is frequently ad hoc, as was the case with one hotel general manager who said, "Quick story: I sat next to a gentleman on a plane and we started talking about hospitality. Both of us in two different industries, but I got the best ideas when just talking about experiences."

Guests and other employees are a key source of new ideas in this industry context. While experiential benchmarking is often haphazard, seeking feedback from guests and employees is more systematic. Yelp and other third party feedback sources were monitored by several of the executives. Others used variations of a direct-contact-withcustomers-strategy. One hotel general manager boasted, "I send out personal emails [to customers] daily and get about 10 percent back." A dining executive commented that guests were a good source of ideas and that a key member of his staff personally 
answered every guest correspondence. Additional examples from the qualitative interviews about senior manager influence for idea generation are included in Figure 21.

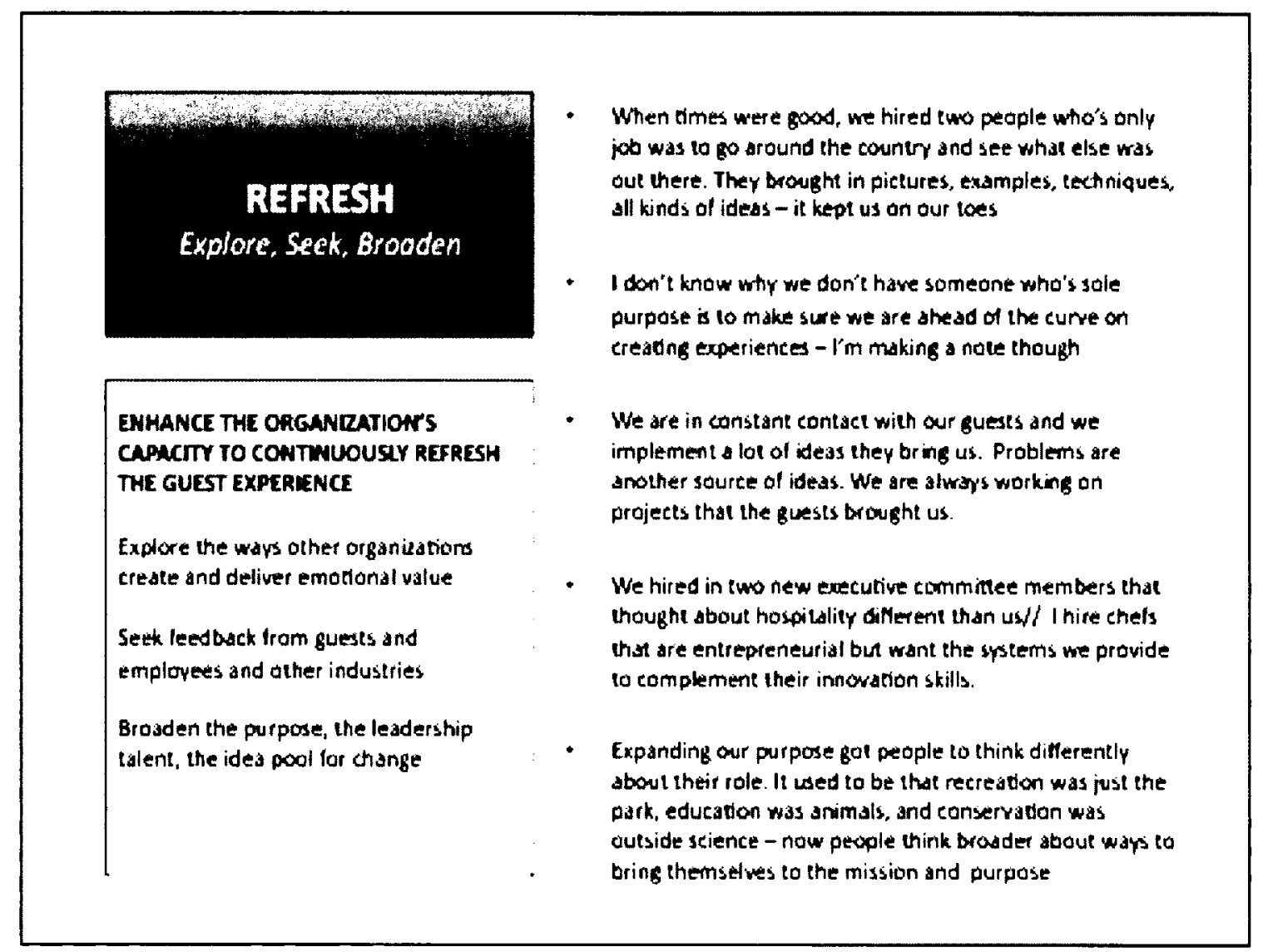

Figure 21. The refresh dimension represents idea generation in the experience context

Focus on the experience. Another dimension of leadership is labeled Connect in the theoretical model (Figure 18), which refers to focusing on the unique guest experience through innovative activities. Specifically, this is about co-constructing and interpreting the core of the experience that the organization provides the customer, as well as providing ongoing opportunities for shared understanding of the intangible customer offerings. Managers associated with making connections identified activities such as hosting events like new hire orientation and developing formal methods that encourage employees to share stories to reinforce the unique guest experience. 
The most elaborate example of this capacity was demonstrated during the healthcare company's annual All Staff assembly. After interviewing the chief experience officer and CEO, I was invited to observe this event, which human resources personnel promote for its ability to incite shared passion for patient experiences. Each year they come up with new ways for employees to come together and interact over their organization's unique patient experience. At the event I attended, they offered what they called experience salons. In one of these, employees were invited to write down phrases to describe the essence of the patient experience in their own words. The phrases were then continuously displayed in an electronic stream that circled the room. Another salon had strips of hospital gowns hanging from the ceiling, each one bearing a leadership quote that the managers used to begin staff meetings, which they referred to as reflections. A third salon allowed employees to convey stories about the ways they shared their goodness bag. These bags had been distributed the prior year with a note to use it to "share goodness in some way".

A memo that I wrote after the event to convey the impact of my observation contained this excerpt:

Overall, the salons were a way to experience how people connected to the purpose of the organization. No one judged these voices. They were the voice of the people. There was structure with flexibility. You could "experience" the collection of the voices, the wholeness of it, and get an overall sense of the purpose in an immersive way.

Although new hire orientations that focus on reinforcing the heritage and culture of the company are common practice in many hospitality organizations today, the commitment to the annual event showcased by the healthcare company was definitely a best practice. 
Symbolism and storytelling were used extensively by managers across all the segments of the hospitality and tourism marketplace. In some cases, special time was carved out in meetings to highlight stories that illustrated company values. One general manager explained that their senior management team never discussed finances in meetings because he preferred that face time be used to reinforce the culture. He said:

Spend management retreats only talking about people. Don't use meetings to discuss numbers. Celebrate employee service initiatives. Leaders are always messaging. Ours is consistent. We hire nice, engaged, service minded individuals, and we talk about how to entrust them with our guests' memories.

Other ways in which senior managers influence innovation by focusing on innovative activities related to the guest experience are further demonstrated through the interview quotes under the Connect dimension in Figure 22. Influence strategies and managerial practices aimed at helping people connect with the core experience that their organizations provided were a priority for most of the executives. Clearly, the intangible nature of many of the offerings in organizations intent on providing memorable experiences for customers requires ongoing efforts to allow a variety of stakeholders to connect to the total guest experience in their own ways. 


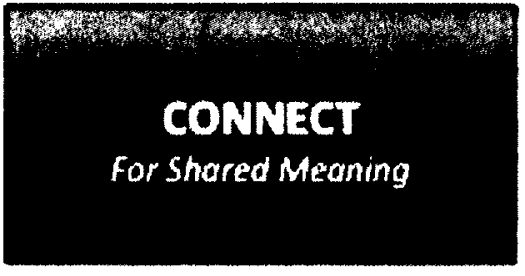

EMHANCE THE ORGANRATIONS CAPACTY TO CONHECT WITH THE ESSENCE OF THE GUEST EXPERIENCE

Host Events/Use Symbolism Stories to Encourage Collectre Understanding around Experience

Invile Guests to Co-Cieate Mental Models of Guest Experience

Develop Dislogut Sessions with Seniar Manzers around intangibles
- $n$ isn't one thing. It's everything. It's the wholeness of il. It's important for people to connect the dots on their own. People want to leel like they con interpret the experience in their own way - makes them leet special - makes them want to pass along their commitment

- Our senior management team has quarterly retreats and all we do is walk about our values and share specifie staries of how people in the keld have brought these values alive

- I use these pernies and these containers when we get together. Talk about simple. This a how we deepen our understanding of our detisions around profles. We physically start with 100 pennies and divide up into these trays ...then we move permies... that's lood cost gaing up...

- Each event is unique. We start with the end, and we ask questons, trying to get the client to paint a picture of the teelings, the emotion, the values, they wam in the erent. n's not about the props, and the of the shefl theme as muxh as we try to get aher the memories intended..

Figure 22. The connect dimension represents ways to focus innovative activities on the unique guest experience

Idea implementation. Innovation theory requires both idea generation and idea implementation. The ways in which senior managers influence implementation of innovation activities in the hospitality and tourism context is conveyed by the leadership dimension labeled Energize in the conceptual model (Figure 18). This concerns tapping into the passions of employees in ways that align emotion with the operational needs for continuous improvement of the guest experience. When asked about the role of the steering committee in his organization, one executive replied, "Leadership is all about aligned passion. We structure [the employee work] to get [the employees] to do something they're passionate about. So, we're encouraging progress, but we don't say exactly how - that is based on their interpretation." 
The need to align new ideas with a task orientation is consistent with what has been written in the literature on innovative work group climates (Lawless \& Anderson, 1996). In this context however, the innovation is much more about the roles that senior managers play in aligning employee passions with projects in order to implement guest experience improvement ideas. Indeed, the word passion is heavily sprinkled throughout the collection of interview transcripts. One executive used an analogy of the hypnotist stage show to describe his role:

I think it's everyone's job to recognize when a theme or concept has become passé and not drag the old stuff along with us. It's also important to be on the lookout for creativity and connect that with the project at hand. A weird analogy is that a hypnotist can tell who is really out and who is just hanging on stage and they will excuse the people. I think it's the same with creativity... when you see that certain people are connected and really get into what's going on. You are mining for who is on this wavelength... Who is present?

Engaging people's passions can be contagious. One can't help but envision an

energetic workplace when reading the words that follow from a restaurant general manager interview:

We are high energy here too. People take the lead from the management team. [We] always want to be doing something. If we appear energized and engaged then our guests will feed off of that. Keeping that energy up, in positive ways, not just because you're running round busy during race season is key. Energy and excitement is contagious. The remodel has served as a launching off point to start fresh conversations about the Brig and how it's better than the competition around the area. It gives people a new spark.

Additional data, in the form of quotes from the interview transcripts, are displayed in Figure 23. These demonstrate the balancing of emotion with task orientation, which is characteristic of the Energize dimension of strategic leadership in the experience context. 


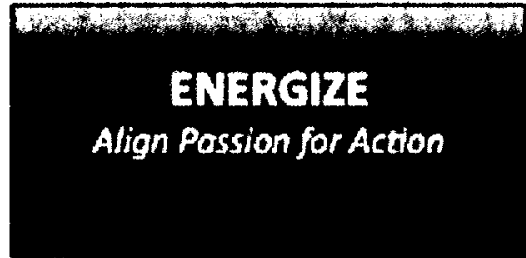

$$
\begin{aligned}
& \text { ENERGIZE THE ORGMNRATIOAYS } \\
& \text { PASgONS AND AUGN FOR ACTION } \\
& \text { Tap into and Unleash Passions around } \\
& \text { Grander Purpose } \\
& \text { Opefatlonalize Intungibles } \\
& \text { Seck Balance ol Business and Emotion }
\end{aligned}
$$

- We implemented Round with Purpose - a way for our leaders to anchor everything to the essence insteda of just walking wound. There's focus.

- Our managers begin every meeting with a reflection. It's a way to oderabionalize our soft side and remind evervone the value ol leading from the heart

- I took the feports we shared at our quarterly team meetings, and I highlighted what was going on behind the numbers. I todd storits - I tried to bring them to lile. I was really proud of that, because I had been doing it for myseh, and I knew it hebed others sur motrated

- We have a power of one program. We celetorate when someone makes the guest experience great by doing whatever they can for the guest. Our managers are mesaging all the time about how each person can make a difference in their owm way. We believe it too. It's part of our cullure.

Figure 23. The energize dimension represents idea implementation in the experience context

\section{Summary of Phase One: Qualitative - Senior Manager Interviews (X)}

The purpose of the senior manager interviews was to explore senior manager

influence for innovation in some depth. The expected research outcome was a conceptual understanding of strategic leadership in context. I borrowed from the methods used by qualitative researchers to design a structured interview protocol consistent with what was written in the literature about strategic leadership and innovation in the business context. Data from thirteen interviews with senior managers of organizations that appear to exhibit best practices in the local hospitality and tourism industry, was interpreted to develop a theoretical model of leadership for innovation in the experience context (see Figure 18). Innovation is considered a collective process, with the guest experience as 
the focus. Hence the theoretical model of leadership for innovation in the local context depicts the unique guest experience in the middle of the graphic and three dimensions of leadership for innovation stemming from the guest experience focus.

According to the data, executives in this study component influence ongoing innovation of the customer experience by exercising leadership in three dimensions. These theoretical dimensions of senior manager influence (leadership) were labeled Refresh, Connect, and Energize. The refresh dimension of leadership reflects the ways that senior managers influence idea generation. The connect dimension of leadership represents the ways in which senior managers focus innovation activities on the unique guest experience. The energize dimension represents the ways that senior managers align employee passions with projects for idea implementation.

\section{Conclusions from Phase One}

As intended, the first phase of this inquiry was exploratory. Although much has been written about innovation in business, most of the research has been conducted in the context of new product development. The bulk of research examining overall innovation performance comprehensively differentiates the development of new products and services from the implementation of the invention (Garcia \& Caltone, 2002). Thus, while an "innovative" individual or group may generate many new and novel ideas, for the idea to be defined as an innovation, it must be "combined with the market introduction...to end users" (p. 112). Very little is known about innovation within the context of organizations operating in the experience economy. As depicted in the study component reference (see Figure 7) used to begin this chapter, the purpose of the first phase was to 
explore leadership for innovation and the ways in which innovation is defined and measured in a local hospitality and tourism marketplace.

Contemporary strategic leadership theorists describe the essence of strategic leadership as creating, developing, and enhancing organizational capacities for adaptation and change (Boal \& Hooijberg, 2000). The framework provided in this study in Figure 18 illustrates a conceptual understanding of strategic leadership for innovation in a local context. This theoretical framework in context has a lot in common with existing leadership frameworks. At the same time, it provides a context-specific approach that might offer what Charmaz (2006) describes as a different vantage point from which to create new meanings.

At the end of Chapter Three I indicated that each subsequent chapter of this dissertation would conclude with a summary of what was learned about innovation, strategic leadership, and the relationships between strategic leadership and innovation in the experience context. I now turn to these.

\section{Innovation Findings}

Based on the data from the structured interviews, most organizations do not have an explicit, systematic innovation strategy at the business-unit level of the organization. Instead, innovation is viewed as a way of thinking and a collective process of keeping the guest experience fresh. Competing in the hospitality and tourism industry context requires continuous improvement of the various offerings that make up the total experience. Innovation strategy is based upon the unique combination of tangible and intangible attributes that deliver emotional, functional, and economic value to the customer. 
Staying ahead of the competition in providing new and improved products and services to customers seems to be the goal in innovation performance, which is currently measured by customer-related metrics, a percent of revenues from new products and services, and the quantity of new and improved customer offerings implemented. Measuring performance based on specific innovation-related activities is not a widespread practice. The data indicates that the dependent variables related to innovation performance are generally based on internal senior manager's perceptions. Most senior managers view themselves as about the same or somewhat more innovative than similar organizations in their industry segment. A review of the examples of innovative activities provided by the respondents not only confirms this assertion, but indicates that it is difficult for senior managers to distinguish between product and service innovation outputs, even when provided with definitions and examples.

\section{Strategic Leadership Findings}

The context presents challenges for senior managers responsible for leadership of organizations whose main economic offering is an experience. The complex and cocreated nature of a total experience cannot be managed with strict adherence to a set of rigid service standards. Instead, senior managers influence continuous improvement of the guest experience by exercising strategic leadership of the organization. In the local hospitality and tourism industry context, senior managers indicated that they influence innovation by exercising three dimensions of strategic leadership. Idea generation practices such as benchmarking, seeking feedback from guests and other stakeholders, and staying on top of current trends in the marketplace allow the organization to continuously refresh its unique guest experience. Focusing innovation activities on the 
unique guest experience requires leadership practices that help develop shared understanding of the total experience. This requires influence strategies to help employees connect with the vision and brand messaging of the organization. Idea implementation involves exercising leadership in order to energize and enable employees to enhance the guest experience, by aligning employee passions with projects. Among other things, this dimension of leadership involves empowering employees to make guest improvements and encourages managers to balance business and emotion in their leadership practices.

\section{The Relationships Between Innovation and Strategic Leadership}

Although the exploration in Phase One provided some findings about innovation and strategic leadership in the experience context, it did not provide many clear answers regarding the relationships between leadership and innovation. In order to evaluate these, the conceptual model needed to be operationalized in a way that was compatible with analyzing relationships among variables. In other words, innovation and each of the three theoretical dimensions of leadership - refresh, connect, and energize--needed to be measurable. The purpose of Phase Two/Three then, was to take the data from the two study components ( $\mathrm{W}$ and $\mathrm{X}$ ) and translate the findings into independent variables that would measure senior manager influence, as well as dependent variables that would measure innovation. The Methods and Results of Phase Two/Three are the focus of Chapter Five. 


\section{CHAPTER FIVE}

\section{PHASES TWO/THREE METHODS AND RESULTS}

Chapter Three presented an overview of the research design and mixed methods approach used during the three phases of this dissertation. The purpose of each phase, as well as an overview of each of the study components, was depicted in a methodology overview graphic (see Figure 6). Each study component, labeled W, X, Y, and Z, was described in a general way. Figure 7 represents a simplified version of that graphic, which can be used as a reference tool for this chapter in which I will discuss the methods and results of the qualitative component $(\mathrm{Y})$ of Phase Two and the quantitative component $(Z)$ of Phase Three. The purpose of Phase Two was to convene an advisory group to give feedback on results and interpretations of the first phase and to assist with survey item development and a pilot of a survey instrument to be used in Phase Three. The purpose of Phase Three was to conduct the survey developed in Phase Two in order to examine the relationships between leadership and innovation.
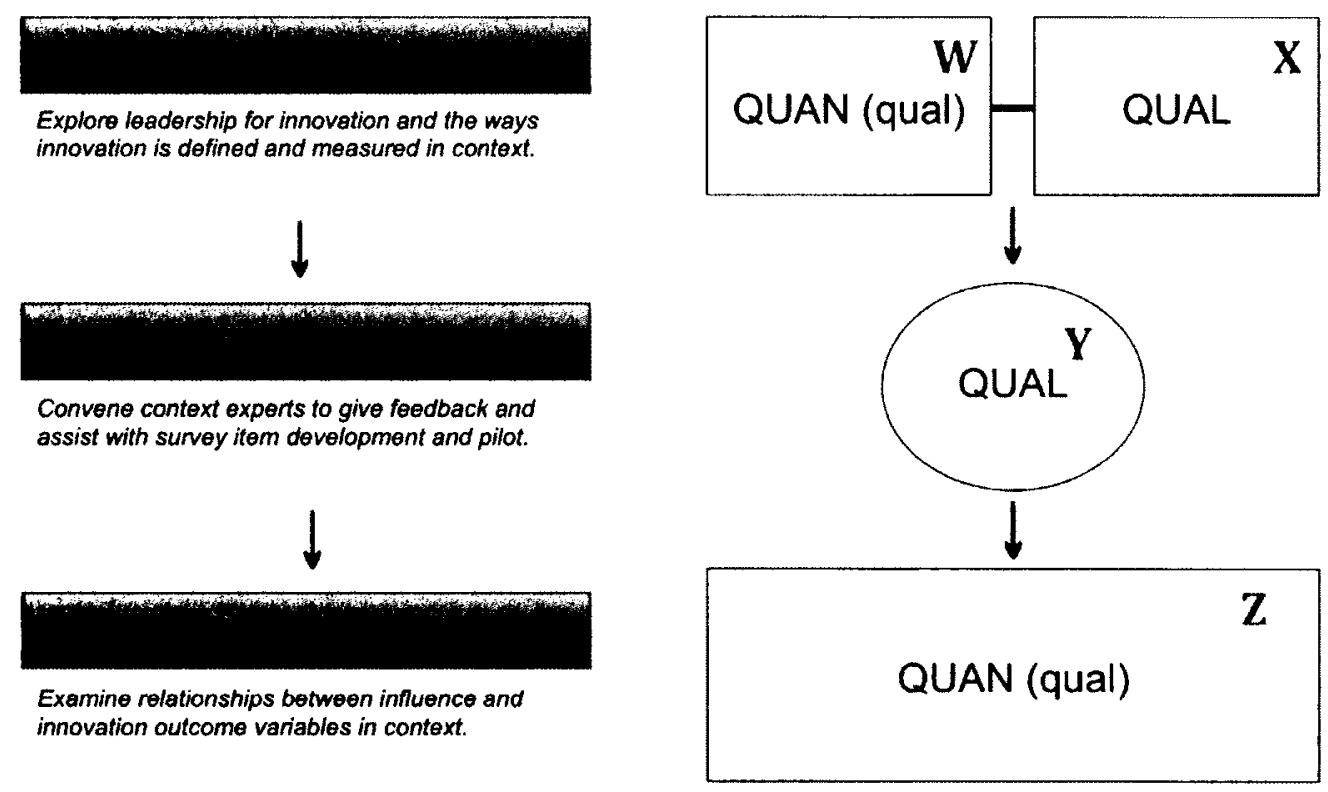

Figure 7. Study components reference 


\section{Phase Two: Qualitative - Advisory Group Working Session (Y)}

Phase Two (labeled $\mathrm{Y}$ in Figure 7) of this research study was intended to serve as a bridge between the exploration of innovation and strategic leadership in the experience context in Phase One and the examination of the relationships between innovation and strategic leadership in the third and final phase of the study. The purpose of the advisory group working session was two-fold. First, feedback from these industry experts assisted with analytical triangulation, as described by Patton (2002), who suggests that experts can verify that the researcher has interpreted their perspectives accurately, can assist in fleshing out potential political problems with the contents of research findings, and can provide deeper levels of understanding on issues. The second purpose of the advisory group working session was developmental. Members of the advisory group helped translate the three dimensions of strategic leadership that were theorized in Phase One into more definitive managerial and leadership practices that could be surveyed in Phase Three.

\section{Advisory Group Participants}

The advisory group was comprised of eight industry context experts-two senior executives from each of the lodging, dining, meetings/events, and attractions industry segments. One participant from each segment had been interviewed in the first phase of the study, and the other participant from each segment was new to the study. Both large corporations (with a San Diego presence) and smaller San Diego organizations were represented. There was one man and one woman from each of the four segments. Other diversity factors such as age and ethnicity were not considered key to the purpose of the advisory group. Participants were purposively selected for the respect they garnered 
from their peers and their willingness to work collaboratively. A text of the email inviting the executives to attend the advisory group working session is included as Appendix $\mathrm{H}$. The two-hour advisory group working session was videotaped. Feedback and Interpretation of Findings from Phase One Members of the advisory work group provided feedback and interpretation of the findings about innovation and strategic leadership from the first phase of the study. In some instances, they confirmed the findings. In other instances, the advisory group members offered contrary interpretations. In a few instances, the group made suggestions to expand upon the findings from Phase One.

Feedback on innovation findings. The advisory group confirmed that innovation strategy at the business unit level is not explicit or systematic in most organizations, but is instead a collective process of refreshing the guest experience. However, they felt that the interpretation of innovation strategy as a combination of products, services and other offerings that provide emotional, functional, and economic value needed expanding. Specifically, the advisory group thought that the Phase Three survey should include questions about how senior managers defined their organization's purpose and innovation strategy. They also suggested that the next survey include an opportunity for executives to indicate that innovation was not a part of the organizational strategy.

Assessing one's organization by comparing it to similar organizations in the industry segment was confirmed as a common method of evaluating business performance in the hospitality and tourism industry. Other measures of innovation performance included customer-related metrics, a percentage of revenues from new and 
improved products and services, the quantity of new and improved customer offerings implemented, and being able to charge a price premium. The advisory group was not surprised to learn that measuring specific innovation-related activities is not a widespread practice in the experience industry context, but they considered it important as well as difficult to do.

The advisory group did not think that categorizing the outputs of innovation activities in terms of product innovation, service innovation, and administrative innovation (as it was in the measures and outputs survey in Phase One) was the most effective approach. They suggested that the Phase Three survey differentiate between front of the house and back of the house initiatives regarding outputs of innovation activities. In the hospitality and tourism industry, front of the house is a term used to represent guest related and marketing types of activities, while back of the house usually implies behind the scenes, employee, or internal business process kinds of initiatives.

Feedback on strategic leadership findings. The advisory group confirmed that considering leadership of the organization as a whole was the right approach to measuring strategic leadership in the hospitality and tourism industry context. They indicated that the survey in Phase Three should target only members of senior management teams. They agreed that the hospitality and tourism industry was moving away from rigid service standards and toward influence strategies that were more collective, as well as empowering and engaging of the employees.

The advisory group agreed with the conceptual dimensions of the model of leadership for innovation in experience context. Specifically, the group confirmed that refreshing the guest experience was the focus of senior manager influence for innovation. 
They agreed that benchmarking and getting guest feedback was important for idea generation. They indicated that the types of data presented under the connect dimension-activities to encourage shared understanding of the unique guest experience-were instrumental in the way they exercised leadership of their organizations. Regarding the energize dimension, they suggested that it be renamed passion, noting that passion was a unique characteristic of the industry context that facilitated compelling experiences. This stimulated discussion, with one executive declaring, "we promote people right out of their passionate areas...something should be done that helps but does not squash this advantage we have."

\section{Development of Managerial Behaviors and Leadership Practices}

After providing general feedback on the conceptual model of strategic leadership in the experience context, participants were tasked with sorting through a preliminary list of managerial practices and leadership behaviors that came from the senior manager interview data in Phase One. The preliminary list, shown in Figure 24, has four columns of managerial behaviors and leadership practices. The first three columns list managerial behaviors and leadership practices taken from the senior manager influence interview data from Phase One-specifically the qualitative component (labeled X) in the methodology overview graphic (see Figure 6). The fourth column lists leadership behaviors from the leadership practices inventory (LPI) from Kouzes \& Posner (1987), the multi-factor leadership questionnaire developed by Bass \& Avolio (1995) to measure transformational leadership, and the flexible leadership constructs developed by Yukl (2004). The complete list of constructs referenced to create the final column of the leadership behaviors listed in Figure 24 is available as Appendix I. 
The advisory group members provided feedback regarding their approval and disapproval of the list of managerial behaviors and leadership practices shown in Figure 24. In most instances the group preferred the collection of leadership practices from the first three columns (taken from the senior manager interview data from Phase One) above the list of practices in the fourth column (from other leadership constructs). There were several suggestions about the wording of certain survey items. All of their feedback was taken into account when developing the pilot survey instrument and the final survey instrument that would be used in Phase Three of this dissertation research. 
From the Senior Manger Interview Data

Other Instruments

\begin{tabular}{|c|c|c|c|}
\hline $\begin{array}{c}\text { Refresh } \\
\text { Idea Generation }\end{array}$ & $\begin{array}{c}\text { Connect } \\
\text { Focus on Experience }\end{array}$ & & $\begin{array}{c}\text { Other } \\
\text { Leadership Behaviors }\end{array}$ \\
\hline $\begin{array}{l}\text { Benchmark other } \\
\text { organizations and the } \\
\text { competitive set }\end{array}$ & $\begin{array}{l}\text { Co-create the experience } \\
\text { with the customers, } \\
\text { employees and unique } \\
\text { offerings }\end{array}$ & $\begin{array}{l}\text { Seek balance of business } \\
\text { and memories }\end{array}$ & $\begin{array}{l}\text { Uses symbols and } \\
\text { emotional appeals to get } \\
\text { the group to achieve more } \\
\text { than self-interest }\end{array}$ \\
\hline $\begin{array}{l}\text { Bring in new managers to } \\
\text { the senior team to seek } \\
\text { new ideas }\end{array}$ & $\begin{array}{l}\text { Clarify the brand promises } \\
\text { in a variety of ways }\end{array}$ & $\begin{array}{l}\text { Engage people's passion } \\
\text { around the purpose of the } \\
\text { organization and the } \\
\text { memories of the experience }\end{array}$ & $\begin{array}{l}\text { Clarify and interpret the } \\
\text { organization's objectives } \\
\text { and priorities }\end{array}$ \\
\hline $\begin{array}{l}\text { Create structured programs } \\
\text { to get suggestions and } \\
\text { ideas }\end{array}$ & $\begin{array}{l}\text { Translate the memories into } \\
\text { brand standards to } \\
\text { operationalize the unique } \\
\text { characteristics }\end{array}$ & $\begin{array}{l}\text { Empower employees to } \\
\text { make decisions about the } \\
\text { guest experience }\end{array}$ & $\begin{array}{l}\text { Environmental scanning of } \\
\text { trends and market } \\
\text { conditions }\end{array}$ \\
\hline $\begin{array}{l}\text { Remodel, relaunch, refresh } \\
\text { the products and services }\end{array}$ & $\begin{array}{l}\text { Dialogue around the } \\
\text { intangibles of the total } \\
\text { experience }\end{array}$ & $\begin{array}{l}\text { Use a variety of employee } \\
\text { engagement strategies that } \\
\text { focus on the guest } \\
\text { experience }\end{array}$ & $\begin{array}{l}\text { Inspires commitment and } \\
\text { engagement in shared } \\
\text { vision }\end{array}$ \\
\hline $\begin{array}{l}\text { Stay on top of trends and } \\
\text { market segment changes to } \\
\text { get ahead in the industry }\end{array}$ & $\begin{array}{l}\text { Show employees how their } \\
\text { interests can serve the total } \\
\text { experience to make it more } \\
\text { unique }\end{array}$ & Align passions and projects & $\begin{array}{l}\text { Imports best practices from } \\
\text { others }\end{array}$ \\
\hline $\begin{array}{l}\text { Attend industry meetings } \\
\text { and association } \\
\text { conferences }\end{array}$ & $\begin{array}{l}\text { Tell stories to bring the } \\
\text { numbers to life }\end{array}$ & $\begin{array}{l}\text { Broaden the level of } \\
\text { employee involvement by } \\
\text { reducing standards and }\end{array}$ & $\begin{array}{l}\text { Delegates and empowers } \\
\text { subordinates }\end{array}$ \\
\hline $\begin{array}{l}\text { Think broader about the } \\
\text { purpose of the organization } \\
\text { or the roles departments } \\
\text { play in the experience }\end{array}$ & $\begin{array}{l}\text { Cross train employees to } \\
\text { broaden their connection to } \\
\text { the core messages of the } \\
\text { organization }\end{array}$ & $\begin{array}{l}\text { Match work assignments } \\
\text { with passions and interests } \\
\text { of employees }\end{array}$ & $\begin{array}{l}\text { Interprets events and } \\
\text { explains why changes are } \\
\text { needed }\end{array}$ \\
\hline $\begin{array}{l}\text { Share personal experiences } \\
\text { about great service }\end{array}$ & $\begin{array}{l}\text { Provide opportunities to } \\
\text { have guests and employees } \\
\text { interact as part of the } \\
\text { experience }\end{array}$ & $\begin{array}{l}\text { Create databases of } \\
\text { employee talents, interests, } \\
\text { and passions to expand the } \\
\text { ways they can contribute to } \\
\text { the experience }\end{array}$ & $\begin{array}{l}\text { Emphasizes a task } \\
\text { orientation }\end{array}$ \\
\hline $\begin{array}{l}\text { Rebranding efforts to } \\
\text { distinguish emotional } \\
\text { attributes of the total } \\
\text { experience }\end{array}$ & $\begin{array}{l}\text { Bring values alive using } \\
\text { multiple communication } \\
\text { methods and live events } \\
\text { like orientation/training. }\end{array}$ & $\begin{array}{l}\text { Make the soft side of the } \\
\text { business more tangible by } \\
\text { getting people involved in } \\
\text { projects they're passionate } \\
\text { about }\end{array}$ & Enables others to act \\
\hline $\begin{array}{l}\text { Stay in constant contact } \\
\text { with the guests as a source } \\
\text { of ideas and to solve } \\
\text { problems }\end{array}$ & $\begin{array}{l}\text { Let people connect the dots } \\
\text { on their own to get a sense } \\
\text { of the wholeness of it }\end{array}$ & $\begin{array}{l}\text { Align action and passion to } \\
\text { get people doing }\end{array}$ & Encourages the heart \\
\hline
\end{tabular}

Figure 24. Preliminary list of managerial and leadership behaviors and practices

Note: The column labeled other leadership behaviors was excerpted from the leadership practices inventory (Kouses \& Posner, 1987), multifactor leadership questionnaire (Bass \& Avolio, 1995), and flexible leadership (Yukl, 2004). For the complete list of the constructs referenced to generate the fourth column of this figure, see Appendix I. 
The first three columns of Figure 24 the ways in which senior managers from the Phase One interviews said they influenced innovation in their organizations--depict a preliminary list of 40 managerial behaviors and leadership practices, which was reduced to 24 potential survey items representative of the dimensions of strategic leadership labeled Refresh, Connect, and Energize. Members of the advisory group later participated in a pilot test that included these 24 leadership practices survey items. Based on the feedback from the pilot test survey, the list was pared down to 18 items.

Six leadership practices make up each of the three dimensions of leadership in the experience context. The refresh items are intended to measure the leadership practices representative of idea generation for continuous improvement of the guest experience. The connect items are intended to measure the ways in which leadership is exercised to focus innovative activities on the unique guest experience of the organization. The energize items are intended to measure the leadership practices associated with innovative idea implementation in service of the unique guest experience.

The summary document, shown in Figure 25, lists the 18 survey items retained to measure the refresh, connect, and energize dimensions of the conceptual leadership model developed in Phase One. This final list of survey items was developed using the advice of survey writing experts (Rea \& Parker, 2005), seeking to avoid things like double-barrel questions and excess wordiness. The preliminary list of practices, sourced from the senior manager interview data in Phase One (Figure 24) and the final list of 18 practices (Figure 25) are both offered here to demonstrate the continuity between the data collected and interpreted in Phase One and the eventual list of 18 practices that was used in the survey in Phase Three. 

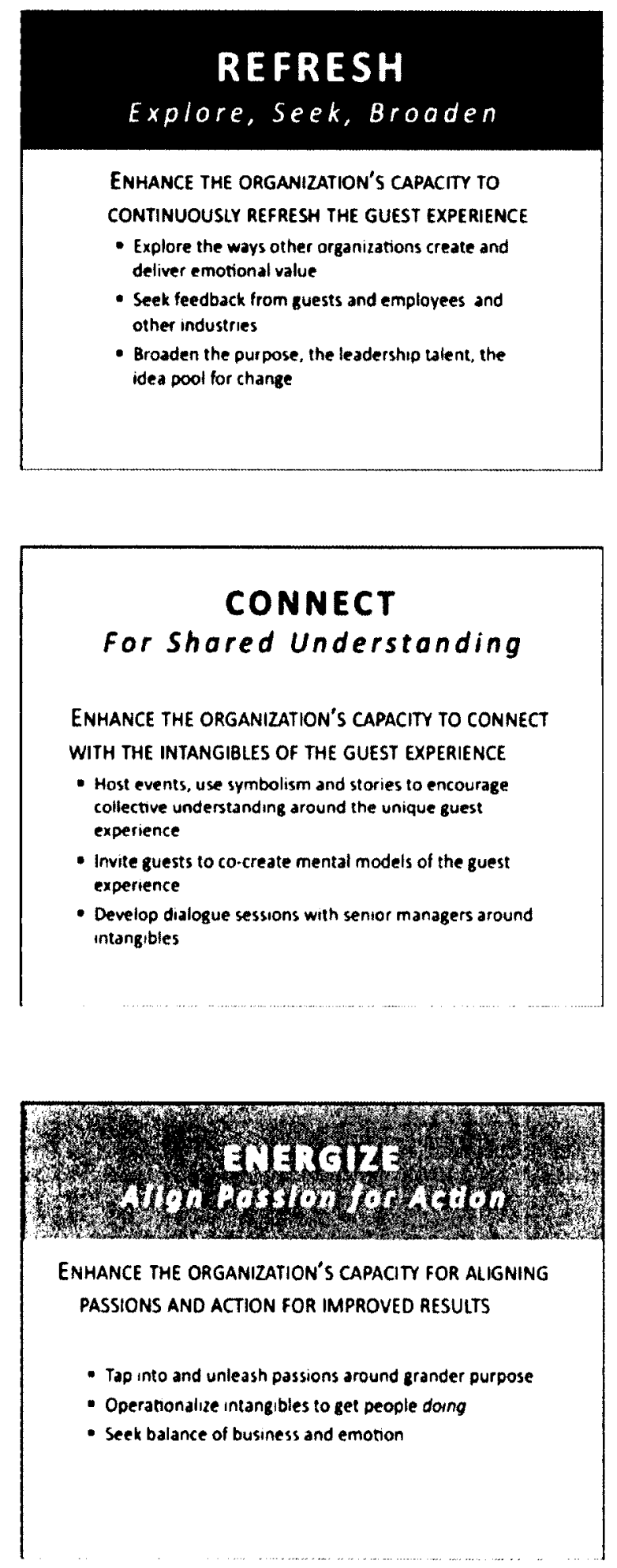

Leam about the ways other organizations deliver unique experiences to customers

Encourage employees to visit best practice/competitor organizations as a customer and share findings

Actively participate in a wide range of industry associations to expand thinking on key issues

Employ a systematic method for scanning trends and market conditions

Use novel approaches to seek feedback from guests, employees and other stakeholders

Bring in new perspectives to challenge assumptions and business as usual

Host events (orientation, training, meetings) that allow employees to talk about the unique characteristics of the guest experience

Use emotion-based communication methods (symbolism, storytelling) for collective understanding of the unique guest experience

Offer formal processes for employees to connect with the brand messaging of the organization

Show employees how their interests can be connected to the unique guest experience

Articulate a compelling vision of the unique guest experience

Provide formal methods for employees to learn about how other departments contribute to the unique guest experience

Clarify and interpret the organization's objectives and priorities

Develop systematic ways to find out about employee interests and passions

Encourage managers to balance business and emotion in their leadership practices

Provide ways for employees to contribute to the organization's purpose beyond the day-to-day job requirements

Match employees with work assignments based on their interests and passions

Empower employees to make decisions regarding the guest experience

Figure 25. Managerial behaviors and leadership practices in the experience context 


\section{Summary of Phase Two: Qualitative - Advisory Group (Y)}

Phase Two of this dissertation was designed to serve as a transition from Phase One, which was exploratory, to Phase Three, which was designed to examine the relationships between leadership and innovation in a local hospitality and tourism context. Participants of the advisory group working session provided feedback and interpretations of the innovation findings and strategic leadership findings from Phase One. They also offered feedback regarding potential managerial behaviors and leadership practices intended to measure the three leadership dimensions of a conceptual model of strategic leadership (depicted in Figure 18) in the experience context. Involving the advisory group was one way to translate the qualitative data from Phase One into leadership practices that could be surveyed by a large quantity of senior managers in a local hospitality and tourism industry.

Members of the advisory group went on to offer feedback on two iterations of a pilot survey developed for Phase Three of the overall inquiry. Several executives from the advisory group also agreed to champion the data collection in Phase Three by sending an advance email to their constituent industry association member email lists. Finally, the working session provided an opportunity for executives from the different segments of the industry to spend time hearing about innovation and strategic leadership from other executives outside of their particular industry segment. Some advisory group participants suggested follow-up meetings and communications to maintain the momentum of sharing ideas and perspectives initiated by the advisory group working session. The group's excitement about continuing to work together was an unintended, albeit welcomed, consequence of Phase Two. 


\section{Phase Three: Quantitative - Leadership and Innovation Survey (Z)}

The first two phases of the study were foundational for this final phase of the inquiry. Conducting the exploratory study provided insights into the ways in which innovation is viewed and measured in a local hospitality and tourism marketplace, and revealed how senior managers influence innovation in a variety of local hospitality and tourism organizations. The methodological purpose of Phase Three was to integrate the data collected in the earlier phases of the study in a way that allowed for examination of the relationships between strategic leadership and innovation, as perceived by senior managers in this local experience context. The quantitative study component (labeled Z), conducted during the final phase of the overall inquiry, was intended to help answer research question \#3: What are the relationships, if any, between senior manager influence and innovation in organizations

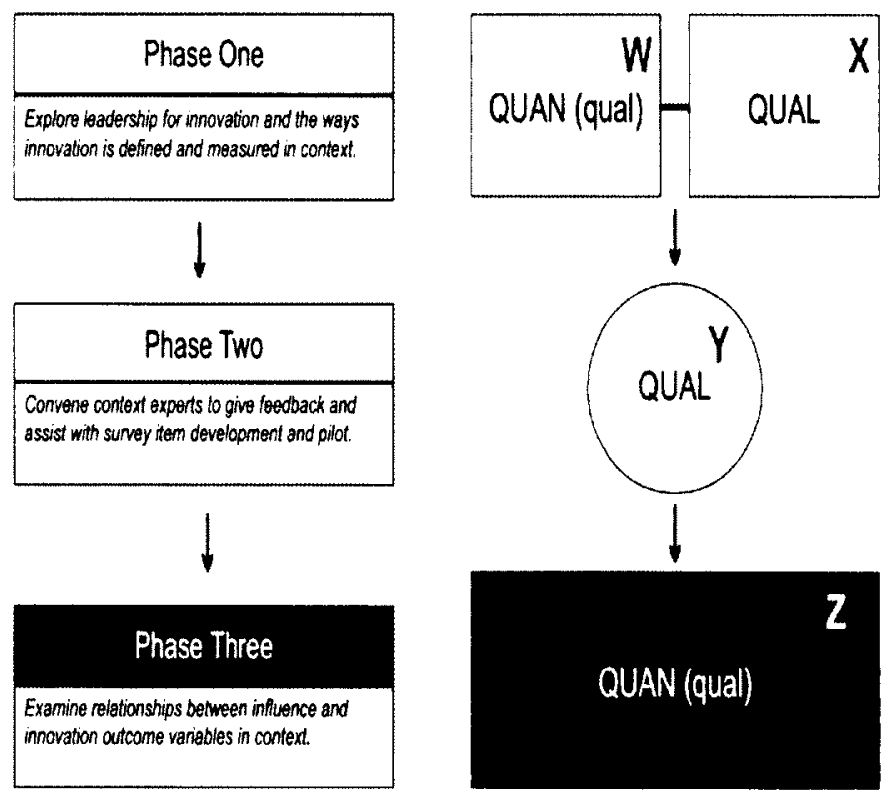

Figure 7. Study components reference

whose main economic offering is

an experience?

This question involves the degree of relationships among variables, and thus the analytical tools of multiple regression analysis were employed (Galloway, 2004). 


\section{Research Participants and Segments}

I originally intended to enlist participants for the survey using a stratified random sample of the membership database of the Convention and Visitors Bureau (CVB) of San Diego. The CVB membership database already asks members to self-identify their organization as lodging, dining and nightlife, events/meetings, attractions, or other. They also have the ability to sort their member database by title/level. At the time of this dissertation's proposal, the CVB membership database included in excess of 1100 organizations from which to draw a stratified sample of senior manager email addresses. However, because of a restructuring in Convention and Visitors Bureau that placed their membership in flux, I had to change strategies.

My goal continued to be to draw a sample that included the most senior level executives from each of the four major industry segments interviewed and surveyed in Phase One of this dissertation inquiry. As a result, the survey was sent to members of local chapters of five industry associations, inviting participation by executives who were part of a senior or strategic management team. Specifically, the survey was sent to the following: for hotel participants-members of the American Hotel and Lodging Association (AHLA) and the Tourism Marketing District (TMD), for the dining and nightlife segment-members of the local chapter of the California Restaurant Association (CRA), for meetings and events - the local chapter of Meetings Professional International (MPI) and for the attractions segment-members of the International Association of Amusements Parks and Attractions (IAAPA) with San Diego affiliation.

Table 3 summarizes the general characteristics of the participant organizations and industry segments represented in this quantitative component $(Z)$ of the study. 
Table 3

Leadership and innovation survey: segment, size, and longevity of participating organizations

\begin{tabular}{llll}
\hline \multicolumn{1}{c}{ Variable } & \multicolumn{1}{c}{ Category } & $(\mathbf{N = 2 3 6 )}$ & Percentage \\
\hline \multirow{2}{*}{ Industry Segment } & & \\
& Lodging & 78 & 33 percent \\
& Dining and Nightlife & 60 & 25 percent \\
& Meetings and Events & 57 & 24 percent \\
& Attraction & 26 & 11 percent \\
& Other & 15 & 6 percent \\
Size & Small: Less than 10 employees & 28 & 12 percent \\
& Mid: 11-100 employees & 53 & 23 percent \\
& Large: 101-300 employees & 64 & 27 percent \\
& Extra Large: More than 300 employees & 91 & 38 percent \\
Years in Operation & & 7 & 3 percent \\
& New: Less than 2 years & 22 & 9 percent \\
& Mid: 2-5 years & 27 & 12 percent \\
& Long: 6-10 Years & 181 & 76 percent \\
\hline
\end{tabular}

The organizations represented in the sample of senior managers responding to the leadership and innovation survey are representative of the major segments of the hospitality and tourism industry. Businesses with less than ten employees were included, as well as large companies who employ more than 300 employees annually. Most of these organizations have been in operation for a considerable amount time, with 76 percent longer than ten years.

\section{Data Collection and Analysis}

Survey instrument design and pilot. Writing surveys is both a science and an art (Rea \& Parker, 2005). Several efforts were made to enhance instrument quality for this leadership and innovation survey. For example, I followed the guidelines for assessing item construction and progression in a current textbook on survey research methods (Fowler, 2009). The author advises referencing other researchers' work and 
pilot testing and revising the instrument based on feedback from the eventual respondent population. Consistent with this advice, I adapted design principles used by other innovation-related and leadership-related research, and I conducted a pilot test of the survey instrument. I will discuss each of these in more detail. I also used a checklist compiled by Rea and Parker (p. 82) on survey design before finalizing the survey instrument. The email inviting participation in the survey is included in Appendix K. The leadership and innovation survey is included as Appendix L, with an online version available at http://www.surveymonkey.com/s/Leadership_and_Innovation in_HTM

The leadership and innovation survey contains sections about innovation and senior manager influence. The questions were written to provide independent variables about leadership (senior manager influence) and dependent variables that measure innovation performance, so that relationships between senior manager influence and innovation performance could be examined. The survey begins with general questions about the senior manager's organization. This section, based on input from managers in the first two phases, includes questions about viewpoints of innovation and the value proposition and purpose of the organization. Allowing the respondents to begin with questions that framed ways of thinking about innovation was designed to offer a nonthreatening and orienting question (Fowler, 2009).

The second section of the leadership and innovation survey comprises items developed from the theoretical model of strategic leadership in the experience context (see Figure 18) from Phase One, translated into managerial behaviors and leadership practices (see Figure 24) in Phase Two, and finalized into 18 survey items (see Figure 25) representing three dimensions of strategic leadership-reflect, connect, and energize. 
Respondents were asked to indicate the extent of use for 18 managerial practices on a five-point scale. The decision to use extent rather than frequency is supported by the literature when the frequency of a particular behavior does not necessarily associate with better outcomes (Jung, Chow \& Wu, 2003). Figure 26 provides the description of the rating scale used to introduce the leadership section of the leadership and innovation survey (Appendix L) used in Phase Three.

The following items describe 18 various ways senior managers exercise leadership of organizations. You are asked to consider each of the managerial practices and rate the extent to which the particular practice is utilized by your senior management team in your organization. The rating scale purposely asks about the extent a practice is used, not the frequency or number of times the practice is used. Please respond based on the following rating scale descriptions.

No Extent Not at all how we exercise organizational leadership

Very Little Extent We have utilized this practice in a minor way

Some Extent Moderate or spotty use of this practice

Large Extent We utilize this practice in a major or consistent way

Very Great Extent Crucial to how we exercise organizational leadership

To what extent does your senior management team utilize the following managerial practices as part of your organizational leadership?

Figure 26. Excerpt of survey item from the leadership and innovation survey introducing the five-point scale description

In the actual survey (Appendix L) the 18 managerial behaviors and leadership practices listed in Figure 25 followed the introduction provided in Figure 26. The online survey service, Survey Monkey, was used to design the leadership and innovation survey. One of the options for survey questions like the one introduced in Figure 26 is to randomize the list of items for the question. That box was checked during the design in 
Survey Monkey. Therefore, the list of 18 survey items appeared in a differing random order for each survey respondent.

The third section of the survey asks questions about innovation activities implemented in the past two years in order to measure the outputs of innovation activities. Similar questions were asked in the measures and outputs survey in Phase One (Appendix B). Specifically, senior managers were asked to assess the outputs of innovation activities of their organization by comparing them to similar organizations, using a five-point scale. The rating options were "much less innovative, somewhat less innovative, about the same level of innovativeness, somewhat more innovative, and much more innovative." The decision to use this rating scale is based on reported success with this approach in service related industries (Mathisen \& Einarsen, 2004). One innovation researcher indicated that this frame of reference was advantageous because it allowed respondents to answer without clear definitions of what poor, average, or excellent might mean (Prajogo, 2006).

Respondents were also given the opportunity to provide examples of recently implemented innovation activities, one for front of the house and one for back of the house. As noted earlier, in this industry, front of the house represents guest related and marketing types of activities, while back of the house usually implies behind the scenes, employee, or internal business process kinds of initiatives. The decision to include openended questions regarding types of innovation activities draws upon the work or Anderson and West (1996) and the work they did with healthcare work groups.

The last section of the leadership and innovation survey asks for responses about innovation performance measures. The input for these items came directly from the 
responses in the measures and outputs survey (Appendix B) conducted in Phase One of this inquiry. In that survey, data was collected about the ways that organizations in the hospitality and tourism industry currently measure innovation. A composite of these responses was intended to measure the dependent variable of innovation performance. Composite measures for business performance are frequently used in innovation studies (Jung, Chow \& Wu, 2003).

The version of the leadership and innovation survey introduced above (Appendix L) also reflects the input from seven of the advisory group members from Phase Two of this research inquiry, who suggested the following after piloting the survey:

- Delete items from the first survey of 24 items that are repetitive or hard to understand or seem to measure more than one leadership practice

- Define and use front of the house and back of the house distinctions when asking for innovation output examples

- Make sure to cover all four segments of the industry in the examples provided in the innovation outputs questions

- Delete the entire section on support for innovation climate because it is a given in the hospitality and tourism industry context that change is necessary and ongoing Data collection and cleaning. As noted earlier, I sent an online link to the survey through a variety of hospitality and tourism associations that have membership employed in the four segments of this study. A sample of the introductory email is included as Appendix K. In addition to the email surveys I took hard copies of the surveys to meetings of these associations to solicit participation in person. Members of the advisory group from Phase Two also followed up with personal emails to their 
constituent members of the industry associations targeted and listed earlier in this chapter.

There were 260 responses recorded after six weeks of data collection. The data was prepared for analysis by exporting the information into a spreadsheet and SPSS. The dataset was then examined for missing cases. 24 surveys were deleted due to lack of responses, leaving 236 cases of data. In some of these cases where there were minimal numbers of items left blank, the imputed mean was used.

Measures and variables. The measures and variables used for analysis in this survey were developed, in large part, from the findings of the first two phases of this inquiry. In most instances, they are also consistent with the innovation and leadership literature, adapted to represent the experience context. The independent variables listed in Table 4 are the 18 senior manager influence survey items developed from the senior manager interview data (Phase One) and revised based on input from members of the advisory group (Phase Two). There are six items intended to measure idea generation, or the reflect dimension of senior manager influence. There are six items intended to measure the ways senior managers encourage employees to connect innovation activities to the unique guest experience. The last six items listed in Table 4 are intended to measure idea implementation, or the energize dimension of senior manger influence. Responses were coded using a five-point scale to indicate extent used. 
Table 4

Summary of independent variables: senior manager influence

\begin{tabular}{|c|c|}
\hline Name & Survey Item \\
\hline Refresh 1 & $\begin{array}{l}\text { Learn about the ways other organizations deliver unique experiences to } \\
\text { customers }\end{array}$ \\
\hline Refresh 2 & $\begin{array}{l}\text { Encourage employees to visit best practice/competitor organizations as a } \\
\text { customer and share findings }\end{array}$ \\
\hline Refresh 3 & $\begin{array}{l}\text { Actively participate in a wide range of industry associations to expand } \\
\text { thinking on key issues }\end{array}$ \\
\hline Refresh 4 & Employ a systematic method for scanning trends and market conditions \\
\hline Refresh 5 & $\begin{array}{l}\text { Use novel approaches to seek feedback from guests, employees and other } \\
\text { stakeholders }\end{array}$ \\
\hline Refresh 6 & Bring in new perspectives to challenge assumptions and business as usual \\
\hline Connect 1 & $\begin{array}{l}\text { Host events (orientation, training, meetings) that allow employees to talk } \\
\text { about the unique characteristics of the guest experience }\end{array}$ \\
\hline Connect 2 & $\begin{array}{l}\text { Use emotion-based communication methods (symbolism, storytelling) for } \\
\text { collective understanding of the unique guest experience }\end{array}$ \\
\hline Connect 3 & $\begin{array}{l}\text { Offer formal processes for employees to connect with the brand } \\
\text { messaging of the organization }\end{array}$ \\
\hline Connect 4 & $\begin{array}{l}\text { Show employees how their interests can be connected to the unique guest } \\
\text { experience }\end{array}$ \\
\hline Connect 5 & Articulate a compelling vision of the unique guest experience \\
\hline Connect 6 & $\begin{array}{l}\text { Provide formal methods for employees to learn about how other } \\
\text { departments contribute to the unique guest experience }\end{array}$ \\
\hline Energize 1 & Clarify and interpret the organization's objectives and priorities \\
\hline Energize 2 & $\begin{array}{l}\text { Develop systematic ways to find out about employee interests and } \\
\text { passions }\end{array}$ \\
\hline Energize 3 & $\begin{array}{l}\text { Encourage managers to balance business and emotion in their leadership } \\
\text { practices }\end{array}$ \\
\hline Energize 4 & $\begin{array}{l}\text { Provide ways for employees to contribute to the organization's purpose } \\
\text { beyond the day-to-day job requirements }\end{array}$ \\
\hline Energize 5 & $\begin{array}{l}\text { Match employees with work assignments based on their interests and } \\
\text { passions }\end{array}$ \\
\hline Energize 6 & Empower employees to make decisions regarding the guest experience \\
\hline
\end{tabular}

Additional independent variables indicating the level of innovativeness of the various outputs of innovation activities are listed in Table 5. These responses were coded 
based on a five-point scale assessing their level of innovativeness in comparison to similar organizations in their industry segment.

Table 5

Summary of independent variables: innovativeness of front of the house and back of the house innovation activities

\begin{tabular}{ll}
\hline Name & Survey ltem \\
\hline Front Output & Front of the House Innovation versus Similar Organizations \\
Back Output & Back of the House Innovation versus Similar Organizations \\
\hline
\end{tabular}

Creating dummy variables is a method of transforming category variables into independent variables when regression analysis is intended as an analytical strategy (Field, 2005). Dummy variables were created for the category survey items related to general demographics, value proposition and purpose. These independent variables are listed in Table 6.

Table 6

Summary of dummy variables: general organization characteristics

\begin{tabular}{|c|c|c|c|}
\hline Variable & Type & Transformed & Purpose \\
\hline Segment & Category & $\begin{array}{l}\text { Lodge as control } \\
\text { Dine, meet, att, other dummies }\end{array}$ & Independent variable \\
\hline Size & Category & $\begin{array}{l}\text { Small as control } \\
\text { mid, large, } x \mid \text { dummies }\end{array}$ & Independent variable \\
\hline Longevity & Category & $\begin{array}{l}\text { New as control } \\
\text { mid, long, } x \mid \text { dummies }\end{array}$ & Independent variable \\
\hline Value Prop & Category & $\begin{array}{l}\text { Other as control } \\
\text { Funct, emot, econ dummies }\end{array}$ & Independent variable \\
\hline Purpose & Category & $\begin{array}{l}\text { Service as control } \\
\text { Exp, value, memories dummies }\end{array}$ & Independent variable \\
\hline
\end{tabular}

The dependent variables of innovation outcome metrics were derived from findings of the measures and outputs survey in the first phase of the study. These 
responses were coded using a five-point scale comparing their organization's innovation performance metrics to similar organizations in their industry segment. A composite measure of these variables was calculated to measure innovation performance. Table 7 summarizes the list of dependent variables used to measure innovation performance. Table 7

Summary of dependent variables: innovation performance

\begin{tabular}{ll}
\hline Name & Survey ltem \\
\hline Innovation 1 & A percent of revenue from new or improved products or services \\
Innovation 2 & Quantity of new products or services implemented \\
Innovation 3 & Ability to charge price premium \\
Innovation 4 & Proven results in customer related measures \\
Innovation 5 & Proven results in employee related measures \\
\hline
\end{tabular}

Data from the leadership and innovation survey (Appendix L) was prepared for analysis by assigning numerical codes for each of the variables listed in the variable tables. Since much of the survey was made up of five-point scale variables, it was easy to translate the responses numerically. All numerical codes in the survey represent the responses from senior managers of hospitality and tourism organizations in San Diego. Hence, the measures are all considered perceptions of those senior manager respondents from four segments of the industry-lodging, dining, meetings/events, and attractions.

Analytical strategies. The structure of the leadership and innovation survey used to collect data for the third and final phase of this dissertation (labeled $\mathrm{Z}$ on the study reference figure) included closed and open-ended questions. Descriptive and inferential statistical techniques made operational by Statistical Package for Social 
Sciences (SPSS) software were used to analyze the quantitative data and prepare summary charts. Charts illustrating responses to the initial questions about innovation viewpoints, value proposition and purpose were generated. The relevant results of the descriptive analytical strategies are presented in tables and figures in the results section of this chapter, which follows. These descriptive results can orient the reader to the data collected in this study component (labeled Z), as well as complement and expand upon (Greene, Caracelli \& Graham, 1989) the research conducted in Phase One and Phase Two.

After exploring the data in a general way, I conducted analytical strategies intended to help answer the relationship-oriented question central to this study component's purpose. These included factor analysis, regression analysis, and correlation analysis. I will introduce each of these in this section of the chapter and will further discuss the specific methods and procedures associated with each analytical strategy, as well as related tests to assess validity and reliability with their accompanying results in the subsequent sections.

Factor analysis consists of statistical techniques aimed at simplifying complex sets of data. A factor is a construct or dimension that represents the relationships between a set of variables (Kline, 1994). Principal component analysis is one method of factor analysis that estimates the underlying factors in a data set (Field, 2005). Principal component analysis (PCA) was used in this study component ( $\mathrm{Z}$ ) to identify the factor structure of the 18 independent variables of senior manager influence (Table 4) intended to measure three dimensions of strategic leadership in the experience context. A threefactor structure was, indeed, demonstrated by the data. 
As indicated in the study components reference (Figure 7) that began this chapter the central question in this particular study component (labeled $\mathrm{Z}$ ) is about the relationships between senior manager influence and innovation in the experience context. The analytical tools of multiple regression analysis are helpful when examining the degree of relationship among variables (Galloway, 2004). Multiple regression analysis was used to determine the relationships between the three factors-representing three dimensions of senior manager influence-and innovation performance. The specific methods and statistical tests associated with preparing the data for regression, as well as the tests that assessed the reliability of the scales used to measure the independent variables (three factors of senior manager influence) and innovation performance (composite measure of dependent innovation performance variables) are discussed with their accompanying tables in subsequent sections of this chapter.

Correlations are another way of examining the relationships between variables, with the correlation coefficient identifying whether and to what degree two variables corelate. Correlation coefficients were calculated, using SPSS software, for each of the 18 senior manager influence variables in relation to innovation performance. The specific steps taken to arrive at the tables of results and discussion of the utility of the information contained in them are discussed in detail in the next section of this chapter.

\section{Results from Leadership and Innovation Survey (Z)}

I used descriptive and inferential statistics methodology to analyze the data from the survey. Results using descriptive statistical techniques are presented first in order to orient the reader to responses in the general characteristics and innovation sections of the survey. This is followed by findings from the inferential statistical methods. 
Value proposition and purpose. During the interviews conducted in Phase One of the study (component X), senior managers were asked about their organization's purpose and innovation strategy, with responses coded and categorized as emotional, functional, and economic value to the customer (see Figure 19). When asked to identify their organization's purpose, senior managers used terms like experience, making memories, outstanding service, and other factors to describe their organization's unique guest experience. The advisory group from Phase Two (component Y) recommended that a broader collection of responses be gathered regarding organizational purpose and customer value. As a result, the survey included two questions designed to obtain a large quantity of responses about the value proposition and purpose of the respondents' organizations. As summarized in Figure 27, senior managers identified the purpose and core of their organization's value proposition in different ways. 

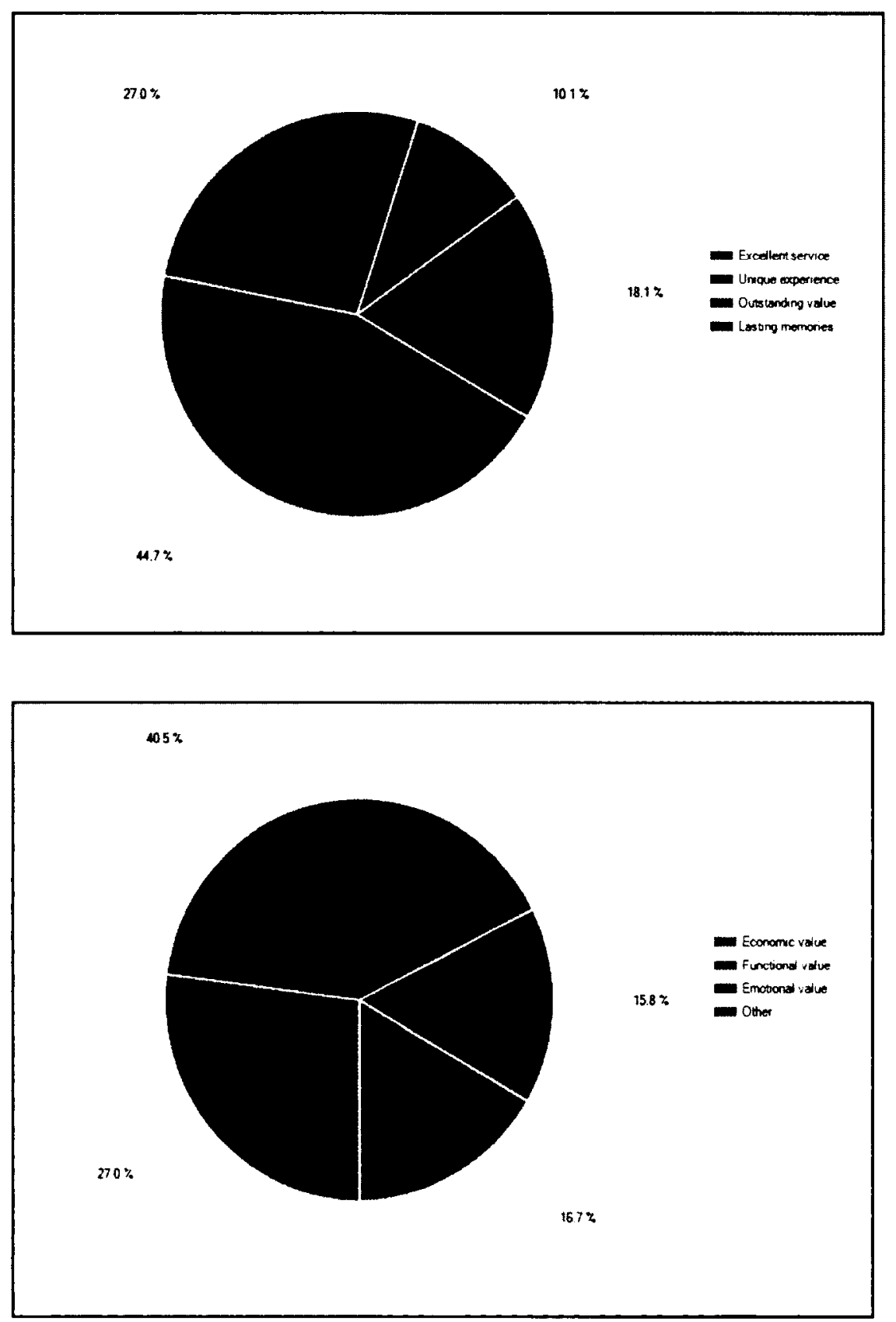

Figure 27. Leadership and innovation survey: value proposition and purpose

In regards to their organization's value proposition, nearly half of the respondents indicated that theirs is emotional value, 27 percent indicated theirs is functional value, and 15 percent of senior managers indicated economic value. When asked to select a purpose for their organization, almost half of the respondents identified service over 
unique experience and lasting memories. These results were a bit surprising, given the treatment in the literature that indicates service is not enough to compete in the experience economy (Pine \& Gilmore, 2011).

The two charts suggest that a combination of emotional, functional and economic attributes likely make up a total experience. Rather than one value proposition or purpose, the unique combination of tangible and intangible offerings, and the way in which this unique combination changes to meet customer expectations over time, may conceptually represent the innovation strategy of an organization in the experience context. Michael Porter, a well-known business strategy scholar, identified three generic business unit strategies as differentiation, cost, and focus (1980). Today, it is not unusual to ground innovation strategy in customer value (Chen \& Sawney, 2008).

Innovation strategy. In order to learn more about how innovation strategy is viewed by senior managers in the hospitality and tourism industry, the survey asked respondents to select all viewpoints of innovation that might be present in their organizations. The list of options came from the senior manager interview data in the qualitative component $(X)$ of Phase One of the inquiry (see Figure 20). Figure 28 and Figure 29 illustrate the nature of innovation strategy in the local hospitality and tourism marketplace, with those viewpoints selected by more than 50 percent of the respondents included in Figure 28 and those selected by less than 50 percent summarized in Figure 29. The data suggests that innovation in this local experience context is about new and unique offerings for the customer as well as continuous improvement of processes that occur behind the scenes. Everyone in the organization is involved in innovation. It is a collective process of enhancing the guest experience with measurable results. 


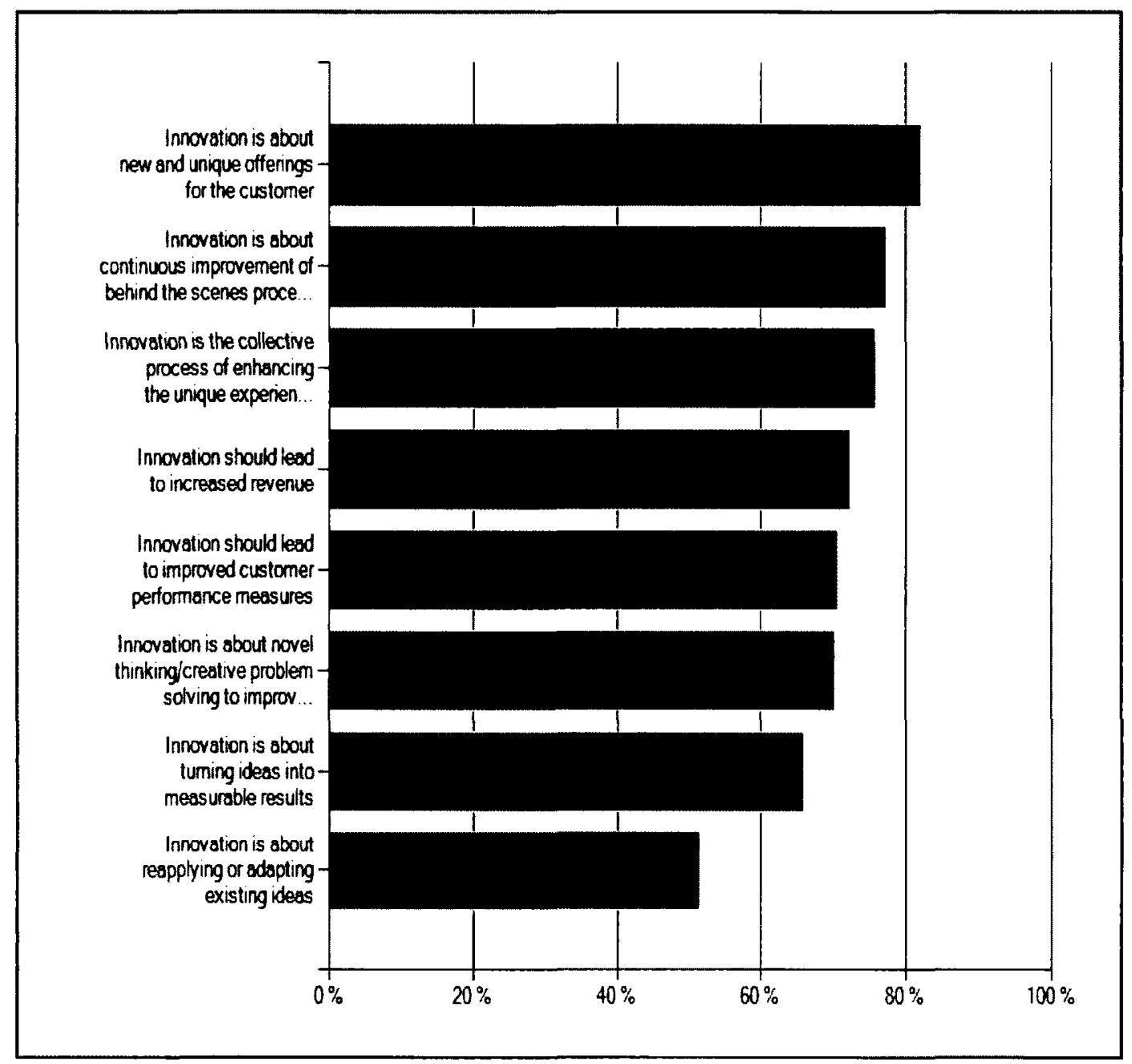

Figure 28. Innovation strategy: more than 50 percent respondents

Viewpoints about innovation shown in Figure 29 indicate that most senior managers consider innovation key to their operating strategy. However, for some, the economic climate plays a role in how much attention that innovation strategy receives in their organizations. Less than 10 percent of the senior managers believed that either their organization pays only lip service to the idea of innovation or does not consider it a part of the operating strategy. 


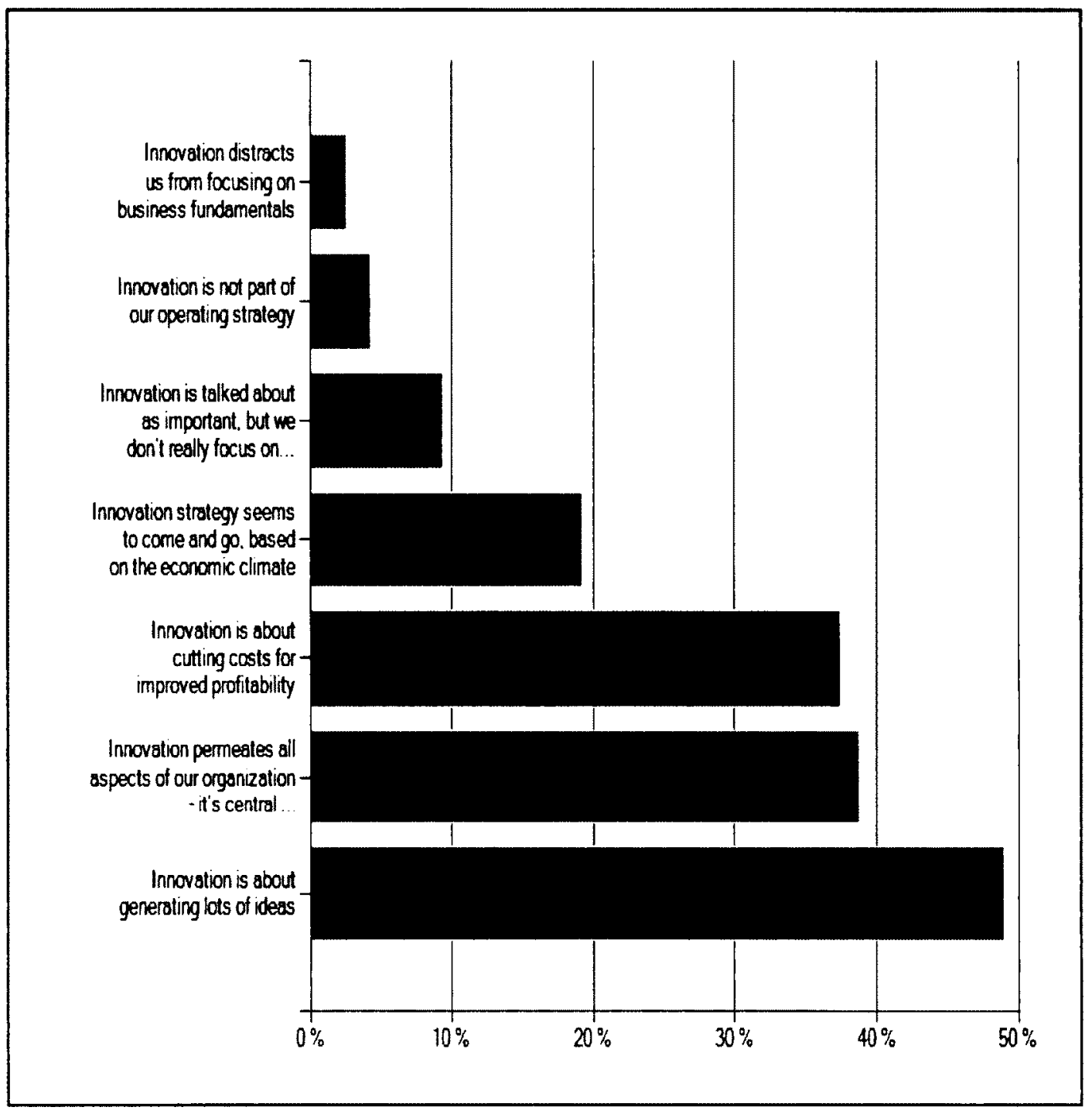

Figure 29. Innovation strategy: less than 50 percent respondents

Findings from factor analysis. The results of principal component analysis (PCA) conducted on the senior manager influence variables and the associated statistical tests are summarized next. Before conducting principal component analysis, two tests are necessary to determine if the data is suitable for PCA. The Kaiser-Meyer-Olkin (KMO) test scrutinizes the sample size adequacy. For this study, the KMO was .897 , which is considered excellent. Bartlett's Test of Sphericity ensures that there is a likelihood that clusters of variables will be found. This test was significant at $p<.001$. Using SPSS, 
both of these tests met the thresholds, indicating that the data was suitable for principal component analysis (Field, 2005). Additionally, the sample size of 236 was considered adequate. The general rule is that the larger the sample size the more effective factor analysis is, but the number of subjects, the number of items, and the number of factors also plays a role. In this case, the sample size of 236 and 18 items was considered good (Kline, 2004).

In sample sizes greater than 200 , it is recommended that factors with eigenvalues greater than one, be retained (Field, 2005). An eigenvalue provides a measure of the amount of variance that be explained by a proposed factor. Put more simply, if a factor has an eigenvalue of one then it can explain as much variance as one of the original independent variables (Hinton, 2004). This principal component analysis yielded three components with eigenvalues greater than one, at $6.23,1.65$, and 1.09 . The corresponding scree plot, shown in Figure 30, is a visual representation of the factors extracted from conducting principal component analysis. 


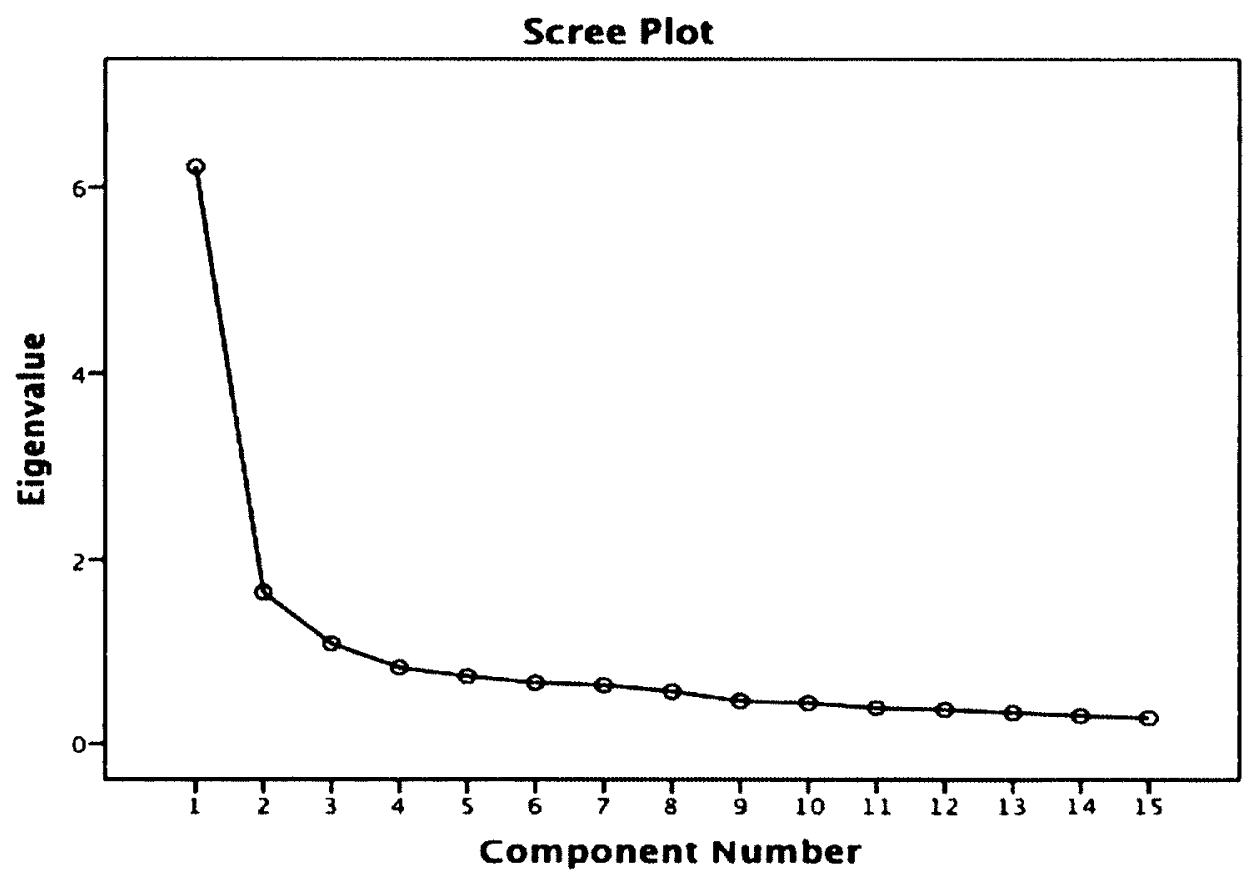

Figure 30. Scree plot showing eigenvalues of factors

Table 8 summarizes the findings from the principal component analysis. Using SPSS software, a rotated component matrix identified three components as theorized, although three of the 18 items with low loads required scrutiny. Those three items, refresh 5, refresh 6 and energize 1, were deleted due to cross-loading concerns. After removing those three items, the factor loadings lined up into three dimensions-connect, energize, refresh.

When a sample size is greater than 200 and the number of variables less than 30 , researchers suggest that factor loadings greater than .5 should be retained (Field, 2005). A factor load is the term used to describe the correlations between variables and factors. The matrix of variables and their factor loads are shown in Table 8. 
Table 8

Leadership and innovation survey: principal component matrix

\begin{tabular}{l|c|c|c}
\hline \multirow{2}{*}{ Item } & \multicolumn{3}{|c}{ Component } \\
\cline { 2 - 4 } & 1 & 2 & 3 \\
\hline Refresh1 & & & .849 \\
Refresh2 & & & .796 \\
Refresh3 & & & .714 \\
Refresh4 & & & .533 \\
Connect1 & .661 & \\
Connect2 & .725 & & \\
Connect3 & .717 & & \\
Connect4 & .638 & & \\
Connect5 & .643 & & \\
Connect6 & .697 & .647 & \\
Energize2 & & .769 & \\
Energize3 & & .729 & \\
Energize4 & & .717 & \\
Energize5 & & & \\
Energize6 & & & \\
\hline
\end{tabular}

Note: Rotated component matrix converged in 6 iterations. Connect 4 had factor loading of .427 with the energize factor. All other coefficients were below 4

The principal component matrix in Table 8 indicates we can be reasonably certain that the conceptual model developed from the senior manager interview data in Phase One and translated into specific managerial behaviors and leadership practices in the experience context in Phase Two, holds up statistically. The dimensions of refresh, connect, and energize are three clusters of variables. Each of the three clusters of variables or "factors" is distinct from the other two clusters of variables. Within each of the three clusters, however, the senior manager influence variables are highly correlated with each other. Very simply put, according to this data set there are three dimensions of strategic leadership in the experience context—refresh, connect, and energize. 
Innovation performance composite measure. In order to examine the relationships between the three factors from the principal component analysis (dimensions of leadership) and innovation, a dependent measure of innovation performance was developed. The collection of five dependent variables that make up innovation performance was listed in Table 7 earlier in this section. These dependent variables were determined based on the data from the measures and outputs survey conducted in Phase One (labeled W on the study component reference figure). They represent the top five ways innovation is currently measured by organizations in the hospitality and tourism industry, which are the percentage of revenue from new or improved products or services, the quantity of new products or services implemented, ability to charge a price premium, proven results in customer related measures, and proven results in employee related measures. Ideally, these dependent variables of innovation performance in the experience context would be measured in absolute quantities and dollar amounts. However, these measures were not available for this research study. Instead, the dependent variables of innovation performance represent the responses from survey items asking senior managers to assess their performance in comparison to similar organizations in their industry segment.

Findings from the composite score for innovation performance (consisting of the five dependent variables of innovation performance) are summarized in Table 9. The mean scores of innovation performance, based on the five-point comparison scale ranged from 3.69 to 3.95 depending on the particular industry segment of the respondents. 
Table 9

Innovation performance composite mean scores by industry segment

\begin{tabular}{lcc}
\hline Industry Segment of the Respondent & $\mathbf{N}=\mathbf{2 3 6}$ & Innovation Performance \\
\hline Lodging & 78 & 3.95 \\
Dining and Nightlife & 60 & 3.80 \\
Meetings and Events & 57 & 3.69 \\
Attractions & 26 & 3.70 \\
Other & 15 & 3.69 \\
Total of All Respondents & 236 & 3.81 \\
\hline
\end{tabular}

Equipped with three factors of leadership to represent independent variables and a composite measure of innovation performance to represent the dependent variable, an examination of the relationships between the variables could be employed using the statistical methods of regression. Prior to conducting regression analysis, however, it is recommended that each of the set of related items, sometimes referred to as scales, be tested for reliability.

Reliability of the scales. Reliability refers to the consistency of a scale. Cronbach alpha is the most common measure of scale reliability (Field, 2005). I conducted a test using SPSS to determine the reliability of the scales that would be used in the regression analysis. Table 10 summarizes the Cronbach alpha scores for each of the three dimensions of leadership and the composite measure of innovation performance. 
Table 10

Leadership and innovation survey: scale reliability

\begin{tabular}{|c|c|c|c|}
\hline Scale Name & Type of Scale & $\mathrm{N}$ of Items & Cronbach alpha \\
\hline Refresh & $\begin{array}{l}\text { Factor representing } \\
\text { leadership dimension }\end{array}$ & 4 & .764 \\
\hline Connect & $\begin{array}{l}\text { Factor representing } \\
\text { leadership dimension }\end{array}$ & 6 & .840 \\
\hline Energize & $\begin{array}{l}\text { Factor representing } \\
\text { leadership dimension }\end{array}$ & 5 & .807 \\
\hline Innovation & $\begin{array}{l}\text { Composite measure of } \\
\text { innovation performance }\end{array}$ & 5 & .817 \\
\hline
\end{tabular}

A reliable test should produce the same results when repeated (in the same circumstances). This is sometimes called internal consistency (Hinton, 2004). What the Cronbach alpha measures is the relationship between each item in the scale with the overall scale. This relationship can take on a Cronbach alpha score between 0 and 1 . Cronbach alpha values greater than .70 are considered reliable (Hinton, 2004). As indicated in Table 10, the scales for refresh, connect, energize, and innovation performance all have alpha values approaching or exceeding .80 . A note of caution is important to insert here. Each of the scales listed in Table 10 is based on survey items that ask managers about their perceptions of these items based on a five-point scale. Consequently, they should be considered perceptions of senior managers in four segments of the hospitality and tourism industry-lodging, dining, meetings/events, and attractions.

Findings from regression analysis. The analytical tools of regression were used to investigate the relationships between strategic leadership (refresh, connect, energize) and innovation performance in the experience context, as perceived by senior managers in a local hospitality and tourism marketplace. Multiple regression analysis predicts the 
variation in a dependent variable by a number of independent predictor variables (Hinton, 2004). The regression model shown in Table 11 summarizes the relationships among the senior manager influence (leadership) dimensions-refresh, connect, energize-with innovation performance.

Table 11

Leadership and innovation survey: senior manager influence and innovation

\begin{tabular}{|c|c|c|c|c|}
\hline \multicolumn{5}{|c|}{ Senior Manager Influence and Innovation Performance } \\
\hline \multirow{2}{*}{$\begin{array}{l}\text { Model } 1 \\
\text { Strategic Leadership Factors }\end{array}$} & \multicolumn{2}{|c|}{ Unstandardized Coefficients } & \multirow[t]{2}{*}{$\mathrm{t}$} & \multirow[t]{2}{*}{ Sig. } \\
\hline & B & Std. Error & & \\
\hline (Constant) & 1.783 & .196 & 9.078 & .000 \\
\hline Mean $1-4$ refresh & .099 & .052 & 1.972 & .051 \\
\hline Mean $1-6$ connect & .217 & .060 & 3.615 & .000 \\
\hline Mean 2-6 energize & .254 & .062 & 4.078 & .000 \\
\hline$R^{2}$ & \multicolumn{4}{|l|}{.340} \\
\hline F test stat & \multicolumn{4}{|l|}{39.04} \\
\hline
\end{tabular}

Each of the dimensions of strategic leadership in the experience context has a significant, positive association with innovation performance. The $\mathrm{R}^{2}$ value in the regression model indicates that the managerial behaviors and leadership practices represented by the three factors of strategic leadership account for 34 percent of the variation in the dependent variable of innovation performance. Additional models were run that included the dummy variables created for some of the general characteristics categories of variables. These models did not produce results that indicated there were significant differences between segments or the way they defined their purpose or value proposition. 
Obviously 34 percent of the variation accounted for by the three dimensions of leadership leaves 66 percent of the variation in innovation performance unaccounted for. Like many regression models, this model suffers from specification error. Clearly there are other factors associated with innovation performance that are important. Some of these factors, such as structure, organizational culture, and competitive environment, have been included in other studies that examine the inputs of innovation and the outputs of innovation performance. These other contextual factors are beyond the scope of this inquiry.

Correlations. Another method of identifying relationships is correlation. Correlations allow us to examine each of the 18 senior manager influence items individually. The Pearson correlation coefficient identifies the linear relationship between two variables (Field, 2005). Table 12 shows the correlation coefficient (Pearson r) for each of the senior manager influence (leadership practices) variables and innovation performance. 


\section{Table 12}

Leadership and innovation survey: correlations of leadership practices and innovation

Leadership Practice

Pearson r value

\begin{tabular}{|c|c|}
\hline $\begin{array}{l}\text { Learn about the ways other organizations deliver unique experiences to } \\
\text { customers }\end{array}$ & $289,+4+4$ \\
\hline $\begin{array}{l}\text { Encourage employees to visit best practice/competitor organizations as a } \\
\text { customer and share findings }\end{array}$ & 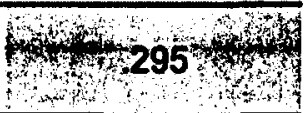 \\
\hline $\begin{array}{l}\text { Actively participate in a wide range of industry associations to expand } \\
\text { thinking on key issues }\end{array}$ & $+4,203,4+4$ \\
\hline Employ a systematic method for scanning trends and market conditions & 387 \\
\hline $\begin{array}{l}\text { Use novel approaches to seek feedback from guests, employees and other } \\
\text { stakeholders }\end{array}$ & 393 \\
\hline Bring in new perspectives to challenge assumptions and business as usual & $426,4+4$ \\
\hline $\begin{array}{l}\text { Host events (orientation, training, meetings) that allow employees to talk } \\
\text { about the unique characteristics of the guest experience }\end{array}$ & .367 \\
\hline $\begin{array}{l}\text { Use emotion-based communication methods (symbolism, storytelling) for } \\
\text { collective understanding of the unique guest experience }\end{array}$ & .394 \\
\hline $\begin{array}{l}\text { Offer formal processes for employees to connect with the brand messaging } \\
\text { of the organization }\end{array}$ & .386 \\
\hline $\begin{array}{l}\text { Show employees how their interests can be connected to the unique guest } \\
\text { experience }\end{array}$ & .365 \\
\hline Articulate a compelling vision of the unique guest experience & .447 \\
\hline $\begin{array}{l}\text { Provide formal methods for employees to learn about how other departments } \\
\text { contribute to the unique guest experience }\end{array}$ & .389 \\
\hline Clarify and interpret the organization's objectives and priorities & \\
\hline Develop systematic ways to find out about employee interests and passions & \\
\hline $\begin{array}{l}\text { Encourage managers to balance business and emotion in their leadership } \\
\text { practices }\end{array}$ & \\
\hline $\begin{array}{l}\text { Provide ways for employees to contribute to the organization's purpose } \\
\text { beyond the day-to-day job requirements }\end{array}$ & \\
\hline $\begin{array}{l}\text { Match employees with work assignments based on their interests and } \\
\text { passions }\end{array}$ & \\
\hline Empower employees to make decisions regarding the guest experience & \\
\hline
\end{tabular}


The list of the 18 survey items and their correlation coefficients are color-coded based on the dimension of leadership. The first six items are refresh, color-coded blue, the next six items are connect, color-coded yellow, and the last six items are energize, color-coded orange. All of the 18 items, when considered individually, are positively associated with innovation performance. Each of the coefficients listed in Table 12 is significant at $p<.001$. This means that there is less than a 1 in 1000 chance that the positive association of each of these leadership practices and innovation performance happened by mere chance.

Digging a bit deeper into importance and extent of use. While we need to be careful not to make mathematical assumptions about the correlation coefficients relative to each other, it is fair to say that we could place the 18 items into a rank order based on their Pearson r-values. This rank order list might represent the relative importance of each leadership practice to innovation performance. We also have data that represents the extent that each leadership practice is used from the mean scores per leadership practice. Thus, without making mathematical assumptions about these mean scores relative to each other, we could rank order each of the 18 items based on the mean score of extent use, which Table 13 provides in descending order. Next to the column with the mean score, the correlation coefficient for that particular leadership practice is shown. 


\section{Table 13}

Leadership and innovation survey: extent of use (mean score all segments) and importance (Pearson $r$ )

\begin{tabular}{|c|c|c|}
\hline Leadership Practice & $\begin{array}{l}\text { Extent Use } \\
\text { Mean }\end{array}$ & $\begin{array}{l}\text { Importance } \\
\text { Pearson r-value }\end{array}$ \\
\hline Empower employees to make decisions regarding the guest experience & 4.06 & .405 \\
\hline Clarify and interpret the organization's objectives and priorities & 4.00 & .453 \\
\hline Articulate a compeling vision of the unique guest experience & 3.87 & .447 \\
\hline $\begin{array}{l}\text { Use novel approaches to seek feedback from guests, employees and other } \\
\text { stakeholders }\end{array}$ & 3.73 & .393 \\
\hline $\begin{array}{l}\text { Show employees how their interests can be connected to the unique guest } \\
\text { experience }\end{array}$ & 3.69 & .365 \\
\hline Employ a systematic method for scanning trends and market conditions & 3.63 & .387 \\
\hline $\begin{array}{l}\text { Actively participate in a wide range of industry associations to expand } \\
\text { thinking on key issues }\end{array}$ & 3.63 & .203 \\
\hline $\begin{array}{l}\text { Encourage managers to balance business and emotion in their leadership } \\
\text { practices }\end{array}$ & 3.61 & .336 \\
\hline $\begin{array}{l}\text { Provide ways for employees to contribute to the organization's purpose } \\
\text { beyond the day-to-day job requirements }\end{array}$ & 3.60 & .417 \\
\hline $\begin{array}{l}\text { Learn about the ways other organizations deliver unique experiences to } \\
\text { customers }\end{array}$ & 3.56 & .289 \\
\hline $\begin{array}{l}\text { Match employees with work assignments based on their interests and } \\
\text { passions }\end{array}$ & 3.50 & .362 \\
\hline $\begin{array}{l}\text { Host events (orientation, training, meetings) that allow employees to talk } \\
\text { about the unique characteristics of the guest experience }\end{array}$ & 3.50 & .367 \\
\hline Bring in new perspectives to challenge assumptions and business as usual & 3.47 & .426 \\
\hline $\begin{array}{l}\text { Offer formal processes for employees to connect with the brand messaging } \\
\text { of the organization }\end{array}$ & 3.47 & .386 \\
\hline $\begin{array}{l}\text { Provide formal methods for employees to learn about how other departments } \\
\text { contribute to the unique guest experience }\end{array}$ & 3.36 & .389 \\
\hline $\begin{array}{l}\text { Use emotion-based communication methods (symbolism, storytelling) for } \\
\text { collective understanding of the unique guest experience }\end{array}$ & 3.24 & .394 \\
\hline Develop systematic ways to find out about employee interests and passions & 3.24 & .460 \\
\hline $\begin{array}{l}\text { Encourage employees to visit best practice/competitor organizations as a } \\
\text { customer and share findings }\end{array}$ & 3.07 & .295 \\
\hline
\end{tabular}


Taking the rank-ordered lists of extent use and correlation with innovation, a graph was prepared that may have utility for practitioners. The importance of each practice with innovation performance and extent use of each leadership practice was plotted on a graph, using relatively low, medium, and high distinctions only. To carve up the rank ordered lists into low, medium, and high distinctions, first the list of correlation coefficients and the list of mean scores were indexed. Each item on the list, was then categorized as relatively low, medium, or high (by percentile) for extent use and then categorized as relatively low, medium, or high (by percentile) for correlation. Then each practice was plotted as can be seen on the chart in Figure 31.

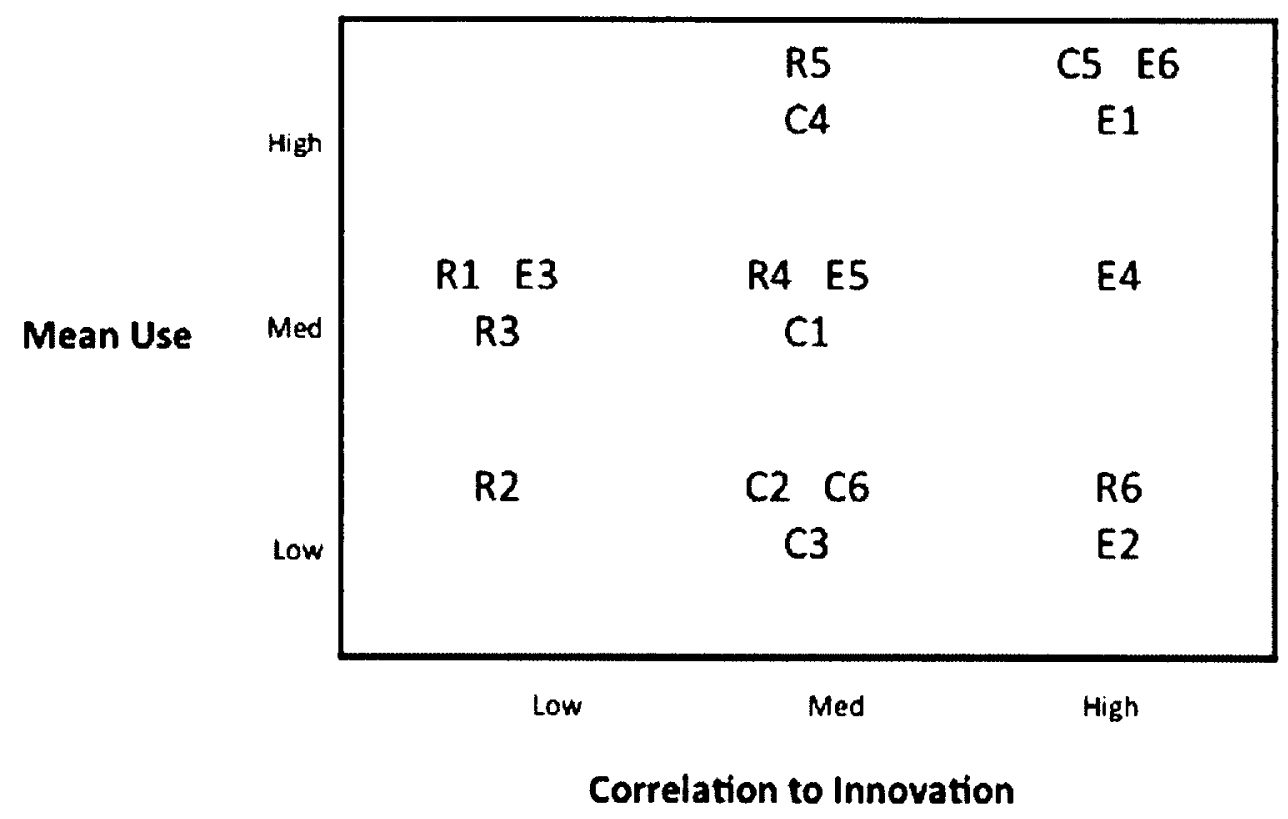

Figure 31. Senior manager influence vs. correlation with innovation based on low, medium, high distinctions per rank ordered list

Notice, for example, that C5, E6, and Elwere in the top third (high category) for correlation, and they were in the top third (high category) for extent used. R6 and E2 were both in the top third (high category) for correlations, but they were in the bottom 
third (low category) for extent used. We might conclude, then, that senior managers in the local hospitality and tourism marketplace, in the aggregate, need to employ the R6bring in new perspectives to challenge assumptions and business as usual-and E2 develop systematic methods for finding out about employee passions and interestsmore, since these two items have relatively high importance in regards to innovation performance. Even given their high rating, responses from the leadership and innovation survey conducted during this third phase of the inquiry indicate the extent of use of these practices is low.

Findings from the regression and correlation analyses offer empirical evidence of the relationships between senior manager influence and innovation performance in the local hospitality and tourism industry. The specific managerial behaviors and leadership practices that make up the three dimensions of strategic leadership provide insights for senior managers who seek to continuously enhance their organization's innovation performance by exercising strategic leadership of their organizations.

Outputs of innovation activities. Another opportunity to see the ways in which senior managers influence innovation is by examining the specific outputs of innovation activities in different segments of the hospitality and tourism industry. As was the case in the measures and outputs survey in Phase One, senior managers who took the leadership and innovation survey in Phase Three were asked to provide examples of outputs from innovation activities. The leadership and innovation survey (Appendix L) asked senior managers to assess their level of innovation activities in comparison to other similar organizations in their industry segment using a five-point comparison scale for both front of the house and back of the house outputs. Rating options from the five-point scale were 
"much less innovative, somewhat less innovative, about the same level of innovation, somewhat more innovative, and much more innovative."

The quantitative and qualitative data from senior manager respondents about front of the house and back of the house outputs of innovation activities are summarized in Figures 32 and 33 . The mean score for each industry segment is included in the figures. There were 103 front of the house innovation output examples offered in the survey data. This qualitative data was coded first by industry segment. Then, the collection of examples of innovation activities was coded within the segment based on elemental coding methods (Saldana). The mean scores provided by the senior manager respondents ranged from 3.57 for attractions to 4.07 for those senior managers responding from the lodging segment, based on a five-point scale.

Figure 32 lists the industry segments and the categories under each segment that resulted from the coding of the front of the house output examples. A representative output from the write-in examples is provided for each of the categories. 
Front of the House Innovation Outputs by Segment

\section{Lodging}

Social Spaces

Food \& Beverage

Personalization

Technology

Customer Relationships

\section{Dining}

Unique Spaces

Interaction

Hybrid Consumer

Meetings/Events

Personalization

Technology

Attractions

Interaction

Surprises
Poolside upgrade includes cabanas, boat rentals, enhanced

Mean $=4.07$ seating and firepits for more open gathering spaces day and night.

Flexible buffet, hybrid menu offerings, specialty meal services.

Mixology program - develop customized cocktail for event with client's favorite ingredients, colors, that reflect the event.

Interactive food and beverage interface allows guests to order but go pick up food on their own, saving room service charge showed increased revenues.

Personal handwritten notes and gifts during and after using information from previous stays.

Created lunch area using outside garden.

Brewery tours and making a show of the food preparation.

Pet friendly spaces.

Bar expanded and opened with high tables that are kid friendly.

Mean $=\mathbf{3 . 5 8}$

Pre-client meeting with all department heads to consider how to provide this client with personal touches.

I-pad program guide to customize the event for the group. Integrate traditional and contemporary collateral that suits the client's culture and needs.

\section{Mean $=3.57$}

Trading posts introduced throughout the park to enable employees to interact with guests.

Share your animal guest interactions.

Incentives for employees to create surprising moments for guests.

Figure 32. Leadership and innovation survey: front of the house output examples

Front of the house outputs of innovation activities were defined as the ability to

bring new and/or improved products, services, and experiences to the hospitality and 
tourism marketplace with proven results in customer-related performance measures. The list of codes includes social spaces and unique spaces in the lodging and dining segments. Several front of the house examples relate to innovating the physical space and surroundings of the venue. These physical upgrades included large-scale remodels as well as updating spaces to become more open to socializing. Existing physical spaces were re-purposed to create unique dining environments. To illustrate, one of the examples provided in Figure 32 mentions a garden space of a lodging facility being repurposed as a garden lunch location.

A technology category is included in the lodging and meetings/events segments, with examples such as the I-pad program guide to demonstrate how technology is used to increase the efficiency of the service. Other ways that this segment used technology was to customize a group's event as well as improve efforts to involve input from a broader range of departments prior to the event in order to offer more personalized service.

Personalizing food and beverage choices were also apparent, as indicated in Figure 32, with references to signature cocktails and customized specialties as front of the house examples. Personalization of the guest experience was a recurring category in front of the house output examples. Categories for each of the four industry segments address engaging the customer in quality interactions from a personalized standpoint. It seems that finding ways to enable employees to engage, interact, and surprise the guest is part of the ongoing commitment to enhance the total guest experience.

In addition to blending technology and personal touches for the guest experience, the front of the house offerings included upgrading and re-purposing physical spaces in order to respond to the ever-changing expectations of savvy consumers. All of the front 
of the house categories and the examples of innovation activities provided per category are consistent with the notion that experiences are an integration of the customer, the environment, and interactions (Prahlahad \& Ramsey, 2009).

Back of the house outputs of innovation activities were defined as the ability to implement novel and/or improved managerial practices, business processes, and employee experiences into the organization with proven results in employee related performance measures. The mean score for back of the house innovation outputs, as rated by the senior manager respondents for each industry segment is included in Figure 33. There were 103 back of the house examples of innovation activities offered in the survey data.

This qualitative data was coded first by industry segment. Then, the collection of examples of innovation activities was coded within the segment based on elemental coding methods (Saldana). The mean scores provided by the senior manager respondents ranged from 3.39 in the attractions segment to 3.85 for lodging, based on a five-point scale. Figure 33 lists the industry segments and the categories under each, which back of the house coding produced. A representative output from the write-in examples is provided for each of the categories. The activities and categories provided in Figure 33 are representative of the examples provided by more than half of the survey respondents in this Phase Three leadership and innovation survey. 
Back of the House innovation Outputs by Segment

\section{Lodging}

Social media

Learning about other departments

Employee experiences

Feedback and Evaluation

\section{Dining}

Employee sharing with guests

Employee engaged with core experience

\section{Meetings/Events}

Employees engaged with core experience

Refreshing talent pool

\section{Attractions}

Employees learning about other departments

Sharing about core experience
Mean $=3.85$

Tracking social media information and integrating it so front desk staff has feedback in real time.

Employees can recognize employees from other departments with cards and earn rewards.

Refreshed the employee dining experience in the cafeteria. We want it to be as good as the guest dining experience.

Measure and bonus system created with employees includes trip advisor, social media tags, and suggestive selling new offerings.

Mean $=\mathbf{3 . 5 5}$

Tell show try feedback approach is new training method for sharing specialty menus.

Create your own special allows employees to suggest a special menu item or menu for an event that ties into our culture.

Mean $\mathbf{=} \mathbf{3 . 4 7}$

Employee teambuilding using the cook together program we offer clients. Their feedback was used to refresh the program sheet.

New sales director comes from world of speakers... has entirely revamped our leads regarding client groups.

Mean $=\mathbf{3 . 3 9}$

Employees can take tours of other departments and give feedbackdepartment rotations every six weeks

Best practice mobile website to share ways to create guest surprise moments.

Figure 33. Examples of back of the house innovation outputs

The back of the house innovations also focused on enhancing the guest

experience. Like the front of the house examples, many of the categories in the back of the house (Figure 33) are about quality interactions with employees and guests. 
Technology is also represented with examples such as social media and mobile websites to encourage feedback and sharing of guest experiences.

It is interesting to note that some of the managerial behaviors and leadership practices from the senior manager interviews in Phase One and translated into survey items for Phase Three of this inquiry are present in the categories and examples in Figure 33. The refresh capacity is represented by the novel approaches for getting guest feedback. The connect capacity is represented by several examples related to connecting the employees with the intangible nature of the guest experience. Tapping into the passions of employees in order to create specialties, and providing training around the intangibles of the service interaction, are consistent with the energize capacity.

\section{Summary of Phase Three: Quantitative - Leadership and Innovation Survey}

The purpose of the leadership and innovation survey was to gather a large quantity of responses about senior manager influence for innovation, the outputs of innovation activities, and innovation performance. The results of this section provided summary tables and figures from data collected from 236 senior managers of organizations in the lodging, dining, meetings/events and attractions segments of the hospitality and tourism industry in San Diego.

Descriptive statistics were used to chart the various ways in which senior managers identified their organization's purpose, value proposition, and innovation strategy. These findings complemented and expanded upon the interview data collected from a small sample of senior managers in Phase One. Nearly half of the senior managers who took the survey viewed their organization's core purpose as to offer emotional value to its customers, followed by 27 percent who view the main value 
derived from their offerings as functional. Most respondents indicated that their organization views innovation as a collective process of enhancing the guest experience that leads to increased revenue, ability to charge a premium price, and improved customer related measures.

Several analytical strategies were used to examine the relationships between independent variables of strategic leadership and dependent variables of innovation performance in the experience context. First, a principal component analysis (PCA) was conducted, which confirmed three factors of senior manager influence as theorized in the first phase of the research inquiry. These three dimensions, or clusters of variables, representative of 15 leadership practices, were regressed with a scale representing a composite measure of innovation performance. The $\mathrm{R}^{2}$ value in the regression model indicated that the leadership practices represented by the dimensions account for 34 percent of the variation in the dependent variable of innovation performance.

Correlations were examined for each of the leadership practices and innovation performance. Pearson r-values ranged from .203 to .447 . All leadership practices had positive associations with innovation performance that were significant. The mean scores indicating the extent of use rating for each of the leadership practices were listed in descending order. The mean scores ranged from 3.07 to 4.06 on a five-point scale of extent used. Lastly, a matrix was developed using the mean value of each leadership practice (indicating the extent used) and the correlation of that leadership practice (indicating importance) with innovation performance. The potential utility of this chart was discussed. 


\section{Conclusions from Phase Two/Three}

The first phase of this dissertation study was exploratory. The purpose of the second and third phase, then, was to translate the exploratory data into specific leadership practices and measures of innovation so that a survey could be developed to send to a large quantity of senior managers in the San Diego hospitality and tourism industry. Whereas the first phase of the dissertation emphasized obtaining information about innovation and strategic leadership in the experience context, the second and third phases placed more emphasis on the relationships between strategic leadership and innovation.

Although much has been written about innovation in business, most of the research has been conducted in the context of new product development. In contrast to manufacturing companies, the major challenge for hospitality and tourism organizations seeking to compete through continuous innovation of the guest experience is the integration and collaboration required to pull it off. The essence of experience innovation seems to require continuously enhancing and clarifying the brand promise, while simultaneously delivering in all operational aspects, keeping the guest experience at the core (Kwortnik \& Thompson, 2009).

\section{Innovation Findings}

In the conclusion of Chapter Four of this dissertation, which chronicled Phase One of the research journey, the findings about innovation were summarized. Innovation was defined, primarily, as a collective process of keeping the guest experience fresh for increasingly demanding consumers of the hospitality and tourism industry. The exploratory data indicated that most organizations in the local experience context don't have an explicit innovation strategy, that measuring innovation is not a widespread 
business practice, and that it is difficult to distinguish between product and service innovation activities.

In Phase Two and Three of the research journey, more data was collected regarding the nature of innovation, innovation strategy and innovation measurement in the experience context. Findings suggested that innovating the guest experience begins by understanding the unique combination of tangible and intangible attributes that combine to make up the total experience offered by a hospitality organization. According to summary results, innovation strategy involves a collective approach to continuously improving and changing the unique combination of emotional, functional, and economic value derived by the customer.

Phase Two/Three also expanded upon Phase One findings regarding measuring innovation in the experience context. The top five ways that hospitality organizations currently measure innovation, which were findings from Phase one, were developed into a composite measure of innovation performance and used in the Phase Three leadership and innovation survey. Although measuring innovation performance is not a widespread business practice, senior managers were able to assess their innovation performance by comparing their organizations to similar organizations in their industry segment on five measures. The mean scores of innovation performance indicated that most respondents assessed their organization's innovation performance as somewhat more innovative than similar organizations in their industry segment.

Phase Two/Three results provided additional information about the ways in which innovation activities are defined by senior managers in the local hospitality industry, specifically the distinction between front of the house and back of the house 
innovations. Still, measuring the outputs of specific innovation-related activities is rare, at least at the business unit level in the local hospitality and tourism marketplace.

\section{Strategic Leadership Findings}

In the conclusion of Chapter Four of this dissertation, which chronicled Phase One of the research journey, the findings about strategic leadership were summarized. A conceptual model of strategic leadership in the experience context (see Figure 18) was presented and discussed. This theoretical depiction of strategic leadership in context was derived from the qualitative interview data. The conceptual model was comprised of three dimensions of senior manager influence (strategic leadership).

Qualitative findings from Phase One demonstrated that the experience context presents challenges for senior managers responsible for leadership of organizations whose main economic offering is an experience. The complex and co-created nature of a total experience cannot be managed with strict adherence to a set of rigid service standards. Instead, senior managers influence continuous improvement of the guest experience by exercising strategic leadership of the organization in three ways-Idea generation practices such as benchmarking, seeking feedback from guests and other stakeholders, and staying on top of current trends in the marketplace, all of which allow the organization to continuously refresh its unique guest experience. Focusing innovation activities on the unique guest experience requires leadership practices that help develop shared understanding of the total experience. This requires influence strategies to help employees connect with the vision and brand messaging of the organization. Idea implementation in this strategic context involves exercising leadership to energize and enable employees to enhance the guest experience. The energize 
dimension of leadership is about aligning employee passions with projects to improve the customer experience. Among other things, this dimension of leadership involves empowering employees to make guest improvements and encouraging managers to balance business and emotion in their leadership practices.

Phase Two of this dissertation was largely about translating the conceptual model of strategic leadership, developed inductively in Phase One, into managerial behaviors and leadership practices that could be surveyed with a large group of senior managers in the local hospitality and tourism industry. The survey responses "clustered" into three factors of closely related survey items, with one cluster or factor measuring the refresh dimension of strategic leadership, one measuring the connect dimension and the third measuring the energize dimension of strategic leadership in context. These clusters or factors, which lined up with the conceptual dimensions of strategic leadership theorized in Phase One and translated in Phase Two, provided some evidence of the validity of using the three factors to measure senior manager influence (strategic leadership) for innovation.

\section{The Relationships Between Innovation and Strategic Leadership}

By the end of Phase Two three dimensions of strategic leadership conceptualized in Phase One had been translated into a list of independent variables of senior manager influence for innovation in the experience context. In many regards, the findings about innovation and strategic leadership from Phase One had been complemented and expanded in Phase Two/Three. Output from the principal component analysis (PCA) in Phase Three indicated that senior influence (as captured by three clusters or factors of strategic leadership) could be measured. However, I will reiterate what I concluded at the 
end of Chapter Four, which chronicled the research journey of Phase One-the data did not offer much in the way of empirical evidence about the relationships between innovation and the conceptual dimensions of strategic leadership. Phase Three, then, provided additional information about these relationships among senior manager influence (strategic leadership) and innovation performance in the local hospitality and tourism industry.

The findings from Phase Three offered evidence of a positive and significant association between senior manager influence for innovation and innovation performance, as perceived by senior managers in the San Diego hospitality and tourism marketplace. The three dimensions of senior manager influence or strategic leadershiprefresh, connect, and energize-accounted for 34 percent of the variation in innovation performance. Each of the 18 managerial behaviors and leadership practices translated from the conceptual model of strategic leadership in the experience context was positively and significantly correlated with innovation performance. However, that still leaves much of the variation in innovation performance unaccounted for, opening the door for further examination of the other factors that may relate to experience innovation.

\section{Summary of Research Journey}

For this dissertation, I used a mixed methods design, integrating qualitative and quantitative methods to answer research questions about senior manager influence and innovation in the experience economy context. Mixed methods studies require that the researcher have the skills and desire to take on complex projects requiring both quantitative and qualitative techniques (Creswell \& Plano Clark, 2011). Similarly, wading through a mixed methods dissertation requires a willingness on the reader's part 
to follow alongside a complex path as the chronological research journey unfolds and the findings are integrated.

To assist the reader, I referenced a methodology graphic figure throughout the last three chapters. In Chapter Three the methodology overview graphic (see Figure 6), depicting three phases of inquiry was provided as an orientation, in general, to the priority, timing, and interfacing (Creswell \& Plano Clark, 2011) of the quantitative and qualitative components of this study. The study components were labeled, W, X, Y, and Z. I inserted a simplified version of the methodology overview graphic and called it a study components reference (see Figure 7) as a way to help readers follow along as the overall inquiry progressed in four study components within three phases of research.

I chose to present the quantitative and qualitative techniques (methods) used to present the stories and numbers (results) of the dissertation in two chapters corresponding to the inquiry's phases. These chapters were titled Methods and Results Phase One and Methods and Results Phases Two/Three. While this is a bit of a break from the fivechapter dissertation model, it offers an opportunity for the reader to experience the research journey as it unfolded. This is important because of the mixed methodology and phased nature of this particular inquiry.

The purpose of this Chapter Five of the dissertation was to present the methods and results for Phases Two/Three of the research journey. The methods and findings in this chapter complemented and expanded upon what was learned in the previous chapter of methods and results for Phase One, titled Chapter Four, of the research journey. At the end of Chapter Four and Chapter Five I presented a conclusion that summarized 
what was learned about innovation, strategic leadership, and the relationships between strategic leadership and innovation in the experience context.

In the final chapter, titled Chapter Six Discussion and Implications, I will explore what was learned about innovation, strategic leadership, and the relationships between strategic leadership and innovation by anchoring the results to the three research questions of this dissertation inquiry. I will summarize the results of the quantitative and qualitative study components in a less chronological and more blended way. After presenting the blended results, I will discuss the findings in terms of the background and problem statement presented in the first chapter and the literature review presented in the second chapter of this dissertation. The implications of this research and possible utility for senior managers in the hospitality and tourism industry will also be discussed. Finally, as a researcher steeped in curiosity after conducting this exploration into leadership for experience innovation, I will seek to identify potential directions for future research. 


\section{CHAPTER SIX}

\section{DISCUSSION AND IMPLICATIONS}

The hospitality and tourism marketplace, comprising organizations offering lodging, dining, transportation, events, and attractions, is one of the largest industries in the world. It fuels economic growth in many countries while providing lasting memories to travelers across the globe. The World Tourism Organization estimates that there will be almost one billion tourists a year by 2013 , increasing to two billion by 2030 (WTO, 2011). The future traveler will be more global, more experienced, more informed, and more varied in their desires than ever before (Williams, 2006), challenging hospitality businesses to continuously innovate to provide compelling experiences to an increasingly demanding consumer.

Organizations in the hospitality and tourism marketplace may find keeping pace with the future traveler even more challenging as the industry transitions to what some have called the experience economy. This term, originally introduced by Pine and Gilmore (1998), suggests that the economy has evolved from the delivery of commodities to the delivery of goods, from goods to services, and presently, from services to experiences. Consider coffee as an example of this evolution. Coffee beans were originally considered an undifferentiated commodity. Then, companies like Folgers created grounded coffee products (in cans for example) that consumers could purchase at the grocery store and prepare at home. During the service economy, the delivery of coffee became a service offered by restaurants and coffee carts, and even drive-thru coffee kiosks. Today, Starbucks is most often credited with transforming coffee into a total customer experience. 
As indicated, this transition from a service economy to an experience economy means that as services become more commoditized, perceptions of competitive advantage diminish. Therefore, all actions of the organization must contribute to delivering experiential offerings that engage customers in a memorable way (Petkus, 2002). Destinations are viewed as a collection of engaging experiences, delivered over time, accompanied by the goods and/or services components of the destinations, resulting in lasting memories (Richards, 2001). It stands to reason that to continuously provide memorable experiences to destination travelers, organizations throughout the hospitality and tourism marketplace may need to transform the way their offerings are "deployed, configured, staffed, marketed, and sold" (Erdly \& Kesterson-Townes, 2003).

A commitment to promoting innovation is undoubtedly a prerequisite for organizational transformation. It hardly seems necessary to tout the benefits of continuous innovation anymore (Wolcott \& Lippitz, 2009). Innovation has long been considered a major source of competitive advantage and economic growth, especially in turbulent environments (Schumpeter, 1934; Lawless \& Anderson, 1996; Porter \& Ketels, 2003; Chen \& Sawhney, 2008; Wolcott \& Lippitz, 2009). In contexts where the customer is always looking for new and different ways to satisfy their rising expectations, ongoing innovation of the guest experience may be necessary to sustain economic growth. Indeed, Pine (2010) recently declared that experience innovation is the future of hospitality and tourism strategy.

The management of comprehensive organizational transformation, strategy, and culture in business has long been considered the purview of senior level managers. Strategic leadership theory emphasizes the influence of top-level managers on an 
organization's ability to adapt and change (House, Wright, \& Aditya, 1997). Strategic leadership theory, with its emphasis on leadership of organizations, as distinguished from leadership in organizations, is consistent with the notion of broad-based organizational change efforts. The salient question becomes: What does leadership for innovation within the context of the experience economy look and feel like?

The purpose of this research inquiry was to examine strategic leadership for innovation in organizations whose main economic offering is an experience. It was intended to explore the definitions and measures of innovation in four segments of a local hospitality and tourism marketplace. Moreover, it was intended to examine the ways in which senior managers, as members of a strategic management team, influence continuous innovation in their own organizations.

\section{Significance of the Research}

There are several reasons, both theoretical and practical, why studying leadership for innovation in the context of the experience economy is important. First, it provides an updated perspective on the innovation-in-business framework. Service organizations generate 85 percent of the current U.S. economy's gross domestic product (Rayport, 2012). However, most innovation studies in business organizations are informed by research conducted in the manufacturing sector. The current state of the innovation literature is narrow, fragmented, and partial, limiting innovation to new product development, R\&D processes, and the adoption and implementation of technology (Chen \& Sawhney, 2008). This existing framework of business innovation ignores the "propensity of an organization to continually innovate as an organizational objective" (Siguaw, Simpson \& Enz, 2006, p. 556). 
Studying leadership for innovation in the experience economy also provides an example of contemporary strategic leadership theory within a particular industry context. Leadership researchers agree that there is no universal theory or definition of leadership due to the "innumerable situational and contextual factors" (Lord, Brown, Harvey \& Hall, 2001). Studying leadership in an industry context affords the opportunity to deepen our understanding of how leaders make meaning in an industry characterized by intangible customer offerings. Sometimes when we try to make something broad enough to include everybody, it stops being relevant for anybody. By examining the relationships between leadership and innovation in a local context, we are able to tease out the nuances of existing leadership theories. Context specific leadership practices provide more relevant insights for practitioners.

Finally, the dynamic qualities that characterize the innovation and leadership relationships lend themselves to adaptive methods of inquiry. Quantitative and qualitative approaches can measure both different and overlapping facets of these complex constructs. This expanded perspective of the two concepts, as well as the relationships between the variables, may yield an elaborated, richer understanding of leadership for innovation (Creswell \& Plano Clark, 2011). Employing a mixed approach to data collection, analytical techniques, and interpretation strategies also broadens the utility of the research products—-bridging theory and application.

\section{Discussion of Findings}

This dissertation study was designed to help us better understand innovation and strategic leadership in organizations whose main economic offering is an experience. The overarching research question was: How does strategic leadership influence 
innovation in organizations whose main economic offering is an experience? Qualitative and quantitative study components helped answer three questions embedded in the overall research inquiry. As at various other times throughout this dissertation, a reference figure is provided, in this case the methodology overview (Figure 6), to serve as a reminder of the various study components that provided the sources of data during the three phases of this inquiry.

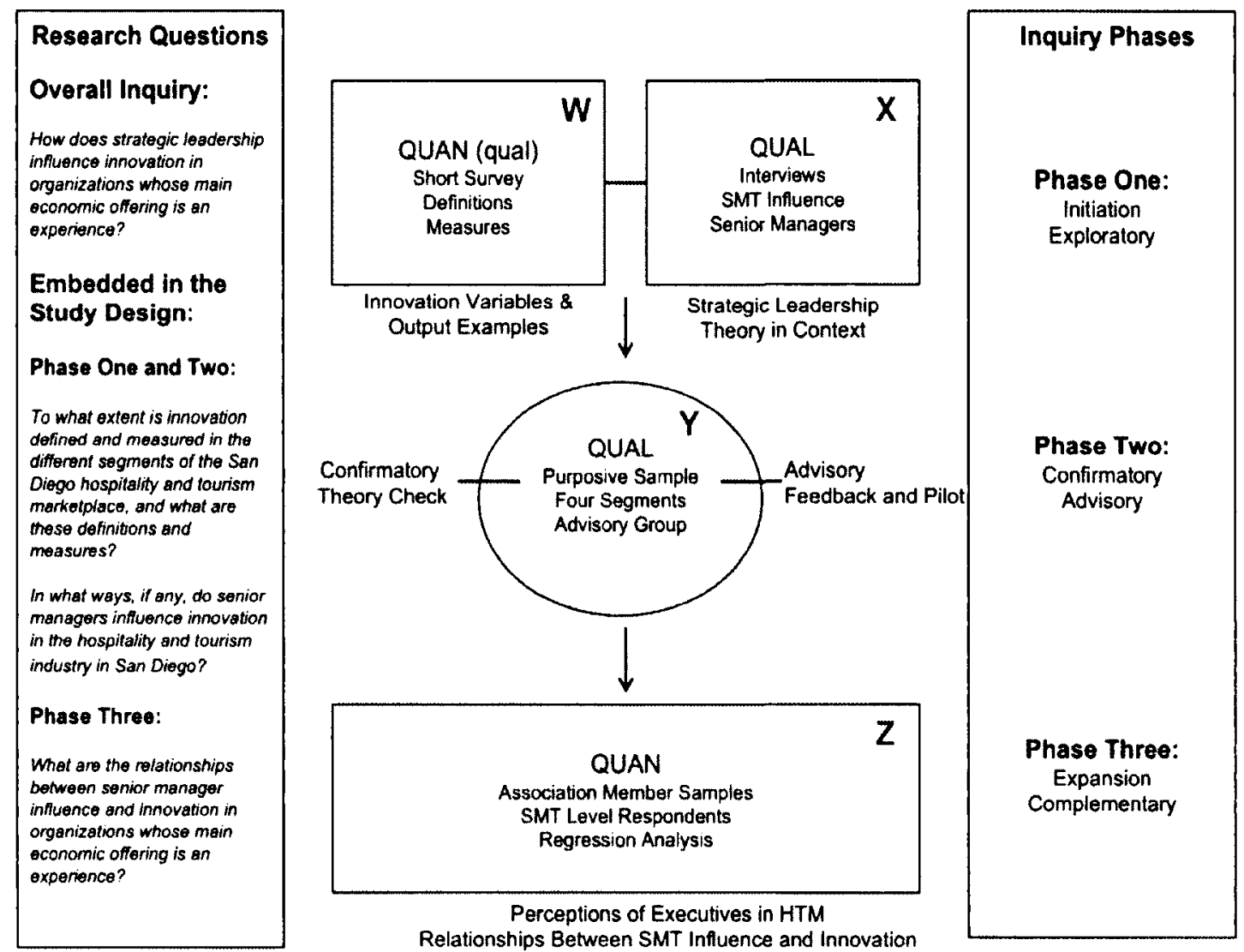

Figure 6. Methodology overview (from Chapter Three) is repeated here

In this final chapter, I will discuss what was discovered throughout the three-

phase research journey, in order to help answer the dissertation's research questions. In the preceding chapters, findings were discussed relative to each study component ( $\mathrm{W}, \mathrm{X}$, 
$\mathrm{Y}$, and Z). Conclusions were also offered at the end of the chapters four and five that summarized what was learned about innovation, strategic leadership, and the relationships between innovation and strategic leadership in the experience context. The methods and findings were presented chronologically to demonstrate how the findings from the exploration phase informed the work of subsequent phases. Offering sequential, connected chapters are valuable options when writing up mixed methods studies (Creswell \& Plano Clark, 2011). In the case of this dissertation, the approach was intended to save the reader from going back and forth between methods and results chapters, and instead be privy to the research journey as it unfolded.

In this chapter, I will consider the findings from this research by discussing how the collection of data from all of the study components helped answer the three research questions of this dissertation inquiry. Hence, rather than offering a condensed or summarized version of what was presented in the results sections of Chapter Four and Chapter Five, the findings and discussion in this final chapter will take advantage of multiple sources of data gathered over the life of the inquiry. In some instances this blending of the data offers confirmation of previous conclusions. In other instances, conclusions may stem from the fact that there is a more robust collection of data to draw from. Sometimes the compilation of the data raises new questions. Therefore, this chapter will offer what mixed methods researchers call a merged summary.

This merged summary will be segmented by the research questions. After presenting key findings about the definitions and measures of innovation (the first research question) and senior manager influence for innovation in the experience context (the second research question), I will discuss what was learned about the relationships 
between these two phenomena in a local hospitality and tourism marketplace (the third research question). Limitations of the research will be discussed, followed by a broad discussion of the implications of the results from the overall research project as well as suggestions for potential future research.

\section{Research Question \#1: Definitions and Measures of Innovation}

To what extent is innovation defined and measured in the segments of the San Diego hospitality and tourism marketplace, and what are these definitions and measures?

As in other business contexts, the data provided by senior managers in a local hospitality and tourism marketplace confirm that innovation is considered a route to competitive advantage and economic sustainability. Offering something novel to the marketplace often pays off in terms of increased volume and revenues. However, in contrast to other business contexts such as the computer industry or medical field, innovation is not about the annual product launch, big idea, or breakthrough technology. Radical or disruptive innovation, terms used by innovation researchers to describe industry or market-altering products and services, is rare in the local hospitality and tourism context, at least at the business unit level studied in this dissertation. Instead, qualitative and quantitative data sources indicate that innovation is defined as a collective process of continuously enhancing the unique guest experience to bring about improved business results.

Experience innovation is collective, incremental and ongoing. Some of the particular aspects of experience innovation embedded in the definition above are worth examining in more detail. First, innovation is considered a collective process. Unlike new product development, which often involves a small group of research and 
development specialists, innovation in the experience context involves employees at all levels and across all work groups and departments. Second, innovation is incremental and ongoing. Instead of a few big "game changing" ideas or new products, the collective process of innovation is about making small enhancements over time. Third, employeerelated initiatives "behind the scenes" are frequently the impetus for enhancing the unique guest experience. As I discovered over the life of the research inquiry, and will discuss throughout this final chapter of the dissertation, these distinctions of innovationcollective, incremental, and ongoing-have implications for leadership of organizations whose main economic offering is an experience.

In many regards, the ways in which perspectives regarding the nature of innovation shared by senior managers in this experience context differ from those of the manufacturing sector, is not terribly surprising. In the background section of this dissertation, theoretical and anecdotal evidence was offered that suggested that innovation in the experience economy entailed ongoing efforts to foster and encourage suggestions about how the guest experience is delivered, as well as continuously providing new and improved products and services to customers with ever-rising expectations.

Evidence to support the nature of innovation in the experience context was provided by qualitative and quantitative data gathered in this study and reported in the findings sections of chapters four and five. A table of responses summarizing innovation definitions from the interviews in Phase One contained four categories-a way of thinking differently, the collective process of enhancing the guest experience, staying ahead of market trends and the competition, and novel outputs that impact business 
performance measures. When senior managers were asked to select from a list of viewpoints that reflected the nature of innovation in their own organizations, the top three responses were that innovation is about new and unique customer offerings, innovation is about continuous improvement of behind the scenes processes, and innovation is the collective process of enhancing the unique guest experience. Almost 80 percent of senior managers in the innovation and leadership survey in Phase Three selected these top three viewpoints to express how innovation is defined in their organizations.

\section{Experience innovation involves front and back of the house initiatives.}

Further evidence of the nature of innovation in the experience context was supplied by respondents who took the measures and outputs survey (Phase One) or the leadership and innovation survey (Phase Three) in which they were asked to provide examples of recent innovation activity initiatives. 362 examples were given, offering more detailed support for the nature of experience innovation in four segments of the hospitality and tourism marketplace, as well as corroborating the incremental and collective aspects of innovation in the experience context that is embedded in the definitions above.

Using definitions suggested by the advisory group of senior managers from Phase Two of this study, front of the house innovation refers to the ability to bring new and/or improved products, services, and experiences to the hospitality and tourism marketplace with proven results in customer-related performance measures. Back of the house innovation refers to the ability to implement novel and/or improved managerial practices, business processes, and employee experiences into the organization with proven results in employee related performance measures. 
The front of the house innovation activities offered by survey respondents were coded, and then sorted into categories. Categories were social spaces, food and beverage, technology, customer relationships, interaction, hybrid consumer, personalization, technology, and surprises. As indicated in these category descriptors, front of the house innovation activities involve new and improved products like food and beverage offerings, as well as updates to physical spaces and environments where guests gather. But they also include more intangible guest offerings such as interactions, relationships, surprises, and personalization. These categories, representing more than 100 examples of front of the house innovation activities from the leadership and innovation survey (Phase Three) illustrate the nature of the economic offering in the hospitality and tourism industry - a co-created experience of the guest with his/her surroundings and interactions with employees.

The back of the house innovation activities, as evidenced by the categories that resulted from coding the examples by industry segment, also focused on enhancing the guest experience. Many of the categories from the back of the house were about quality interactions with employees and guests. According to senior managers in this study, it makes good business sense to use employee-related initiatives to provide focus for continuous improvement efforts, given how integral employee interactions are to the overall guest experience.

The back of the house innovation activities supplied by senior managers in this dissertation were categorized as social media, learning about other departments, employee experiences, feedback and evaluation, employee sharing with guests, employees engaged with the core experience of the organization, refreshing the talent 
pool, and sharing experiences. Data from back of the house innovation activities illustrate the collective nature of innovation in the experience context. These categories, representing more than 100 ways in which hospitality organizations are enhancing the guest experience by developing and improving employee-guest interactions, provide additional support for the notion that experience innovation involves all levels of employees-it is a collective process.

In addition to providing an example of an innovation activity, survey respondents in Phase Three were asked to assess their organization's level of innovativeness regarding different types of innovation activities in comparison to similar organizations. Without reiterating each of the findings provided in chapters four and five, the incremental (as opposed to radical or breakthrough) aspect of innovation in this local industry context was demonstrated in the survey and interview components of the inquiry. The perception of the majority of respondents, as evidenced by mean ratings of innovativeness on two surveys, was that their organization's level of innovativeness was about the same or somewhat more innovative than similar organizations in their industry segment. Using a five-point scale with a rating of 3 representing average or about the same level of innovativeness as similar organizations in their industry segment, the quantitative ratings of innovativeness ranged from 3.32 to 4.07 , dependent on the type of innovation being rated and the industry segment of the respondent. These ratings of average to somewhat more than average were consistent with the qualitative data gathered during the interview component of the study. This researcher's perception, after coding and categorizing innovation activity examples, also confirms the notion that innovation in this local 
context, for the most part, is about incremental, rather than "game-changing" improvements.

Experience innovation should lead to improved business performance. In addition to defining innovation as collective, incremental, and ongoing (top three viewpoints), senior managers indicated that innovation in their organizations should bring about measurable improvements in business performance. The fourth and fifth highest rated viewpoints were selected by approximately 70 percent of the respondents. These were that innovation should lead to increased revenue, and innovation should lead to improved customer performance measures. This data supports the belief that innovation in the business industry context goes beyond generating lots of ideas, or being creative. According to senior managers in this study, innovation requires ideas to be transformed into offerings that customers value and are willing to pay for or transformed into improved business processes in support of enhancing the guest experience.

In addition to learning about the ways innovation is defined and the specific innovation activities implemented by organizations across four industry segments of the San Diego hospitality and tourism marketplace, the first research question sought answers to the specific ways that innovation is measured by these organizations. Consequently, the measures and outputs survey from Phase One asked respondents to identify the ways they measure innovation in their organization. Respondents could select all measures that applied from a provided list of metrics and/or they could write in additional measures that were not listed. It was discouraging to discover that almost one-fourth of those surveyed indicated that they did not measure innovation in their organization. For those that did measure innovation, the metrics they used were improved guest service and 
operational process measures, the percent of revenues from new/improved products and services, and the ability to charge a price premium. For the purposes of this research inquiry, these top five measures were used to develop a composite measure of innovation performance. Not without its limitations, the composite measure of business performance did provide an acceptable dependent variable for innovation that could be used to help answer the third research question of this overall inquiry.

Is this really innovation? My sampling frame for the interviews conducted during Phase One of the dissertation project was intended to select senior managers known for innovation in their industry segments. Even so, two of the interview subjects said innovation was not central to their organization's competitive advantage or that it distracted the organization from focusing on business fundamentals. Although I assumed that these subjects represented a larger faction of the industry that were either neutral or negative towards innovation as a success strategy, this was not supported by the quantitative results from Phase 3 .

It was rare to find senior managers who didn't believe innovation, as defined in the paragraphs above, was important. Less than 5 percent agreed with the statement that innovation is not part of their organization's operating strategy. Additionally, more than half of the respondents who took the two surveys in this overall inquiry were willing to provide a back of the house and a front of the house innovation example in addition to rating their organization's level of innovation as compared to similar organizations in their industry segment. Needless to say, ongoing change seems to be the norm for most senior managers in this experience context. However, less than 40 percent of senior managers agreed with the statement that "innovation permeates all aspects of our 
organization-it's central to who we are." This, plus the fact that innovation is not measured in nearly 25 percent of the organizations surveyed, brings into question the degree to which a comprehensive approach to innovation is really embraced in this local marketplace. We might be tempted to conclude that the summary findings expressed in the preceding paragraphs don't define innovation at all; or that continuous improvement is merely a business fundamental in the hospitality and tourism industry.

This researcher's opinion is that whether one considers innovation to reflect the definition offered above or as a business fundamental depends largely on one's own mental model of the innovation concept. My sense from the various sources of data analyzed over the life of this inquiry is that senior managers in this local hospitality and tourism marketplace are wrestling with the same problems identified in the background and problem statement that began this dissertation. What the data regarding the definitions and measures of innovation in this study exposed is the problem of researchers addressing innovation in the experience context using the same frame as the manufacturing industry, which were identified in Chapter One as contextual issues, measurement, and narrow focus. The findings in this study, supported by a preponderance of qualitative and quantitative data, indicate that innovation in the experience context is collective, incremental, and ongoing. As I discovered through the process, these three distinguishing characteristics foreshadow the challenges of exercising leadership for innovation in organizations whose main economic offering is an experience.

Summary of findings about innovation. Based on the merged summary of findings presented to help answer the first research question about definitions and 
measures, it is fair to conclude that senior managers believe experience innovation is important and key to sustaining competitive advantage. Their organizations are engaged in a variety of back of the house and front of the house innovation activities. Most managers perceive that these activities illustrate that they are about as innovative as or somewhat more innovative than the competition. However, it seems to require a leap of faith to assume that these activities are responsible for improved business performance. The measures currently used to measure innovation performance are not all directly linked to specific innovation activities. One-quarter of the marketplace represented in this study does not currently measure innovation at all.

Investigating how organizations go about collective, continuous, incremental innovation of customer experience tendered an updated perspective on innovation theory. The data about the nature of innovation in the experience context suggests a way of looking at the construct that differs from that provided by the body of literature focused in manufacturing industry contexts. The data presented here provides empirical evidence in support of the experience economy paradigm examined in the review of the literature. Given that the nature of business in general seems to be moving faster and becoming more complex, an industry context like this one that accepts ongoing change as normative, may offer unique perspectives into the challenges facing senior managers in a variety of other industry contexts. This has particular value in light of the fact that these findings provided a foundation for examining the ways in which senior managers in organizations whose main economic offering is an experience influence the innovative process. 


\section{Research Question \#2: Senior Manager Influence for Innovation}

In what ways, if any, do senior managers influence innovation in the hospitality and tourism industry in San Diego?

The findings about innovation in the experience context summarized in the previous section provide empirical support for the theoretical and anecdotal propositions and hypotheses synthesized in the first two chapters of this dissertation. Indeed, the theoretical background of this dissertation is grounded in the argument that a transition from a service economy to an experience economy requires an updated perspective on innovation theory that tends to the unique characteristics of the experience context.

As noted, senior managers in the local hospitality and tourism marketplace see experience innovation as collective, incremental, and ongoing, involving front and back of the house innovation activities that should result in improved business performance. As evidenced in the findings about senior manager influence, innovation of the total experience requires senior managers to exercise strategic leadership of the organization in unique ways, based on their specific context.

Leadership for experience innovation requires idea generation. Idea general is not surprisingly one of the themes that the data from structured interviews provided regarding how senior managers influence innovation. The collection of six leadership practices represented by this theme are labeled refresh to convey the nature of idea generation in this local hospitality and tourism marketplace. Idea generation practices such as benchmarking, seeking feedback from guests and other stakeholders, and staying on top of current trends in the marketplace allow the organization to continuously refresh the unique guest experience that it provides. 
One of the leadership practices, for example, reads, learn about the ways other organizations deliver unique experiences to customers. Because of the relative ease with which competitors can copy guest enhancements in the hospitality and tourism industry, it makes sense that senior managers generate ideas by visiting other organizationswhether dining out, traveling or staying in hotels. It is particularly easy to take note of front of the house innovation activities from the consumer perspective. Ideas from similar organizations in one's industry segment can be adapted fairly easily to one's own organization. This cycle of experiencing, copying and/or adapting what others are doing seems to lead to ongoing and incremental improvements. The title refresh, then, also conveys the incremental and ongoing nature of innovation in this context. It is a continuous cycle of making incremental enhancements to the total guest experience.

\section{Leadership for innovation requires shared understanding of an experience.}

Perhaps the most challenging contextual factor of the hospitality and tourism industry concerns the intangible nature of the experience offering. The total experience refers to a unique combination of products, services, employee interactions, and other offerings. While some of the aspects that make up a total experience are indeed tangible, it is generally accepted that the customer value derived from a hotel stay, dining experience, theme park visit, or company conference, rests largely on the guest's memories that remain after the experience has ended.

The theme of leadership titled connect represents six leadership practices aimed at developing shared understanding of the uniqueness of the experience provided by an organization. These practices include hosting events that allow employees to talk about the unique characteristics of the guest experience, offering formal processes for 
employees to connect with the brand messaging of the organization, and articulating a compelling vision of the unique guest experience.

The collective nature of innovation as discussed earlier in this chapter is apparent in these practices. Improving the guest experience requires that people across the organization understand what makes up the total experience. Some of the more intangible aspects that make an experience truly special may not be easy to talk about, let alone described in a memo. A specific example of this practice in action is new hire orientations and training programs that focus on organizational culture, as opposed to rules and policies. It is reasonable to assume that senior managers would want to be able to focus innovation activities in areas that provide the best value for the guest. By extension, it makes sense that senior managers would spend time developing shared understanding of what is truly special about the experiential offering before making enhancements to the experience.

Leadership for experience innovation requires idea implementation. The cocreated nature of the experience offering in which the guest simultaneously produces and consumes a total experience over time, poses unique challenges for senior managers. The third theme of senior manager influence strategies includes leadership practices that mitigate these sorts of challenges through the idea implementation process. Referred to as energize, this category reflects the realization that employee/guest interactions are frequently a key component of a total experience in hospitality businesses.

Senior managers seek to energize employees to engage in the total customer experience by aligning their talents and passions with innovation activities. For example, one of the practices included in the energize theme reads provide ways for employees to 
contribute to the organization's purpose beyond the day-to-day requirements. A specific example of this practice in action is taken from the dining category of the front of the house innovation activities developed from the qualitative data, where employees are allowed to pitch ideas for signature meals and signature cocktails to convey the particular personality of a client or theme of an event.

Another practice in the energize theme reads empowering employees to make decisions regarding the guest experience. Based on a five-point scale of extent of use, empowering employees to make decisions regarding the guest experience had an overall mean score of 4.07 , the highest out of all eighteen leadership practices. As suggested by the data, senior managers seem to think it important to empower employees to make decisions regarding the guest experience since their interactions with guests are often a memorable part of the overall experience.

Senior managers influence innovation at the business unit level. For the most part, the interview and survey respondents who provided the data that resulted in these three themes-refresh, connect, and energize-were members of senior management teams responsible for leadership of a single organization. Their organizations, however, were sometimes part of an even larger corporate structure. For example, a general manager at a San Diego hotel might be responsible for one hotel that is under an umbrella of a lodging corporation with hundreds of hotels. A restaurant general manager may be responsible for operating a single franchised facility of a multi-unit dining corporation.

What this means, is that their influence regarding innovation is limited to the business unit level. In fact, innovation activities may be constricted by the standards and restrictions of corporate brands. Some of these specific constraints were mentioned in the 
senior manager interviews. Adaptation and change occurs within the boundaries of a larger corporate strategy, in many instances. This may be why the innovation activities summarized in the front of the house and back of the house figures presented in Chapter Five represent mostly incremental improvements. Breakthrough improvements may not fall within the responsibility of business-unit level executives. Therefore, the leadership for innovation in this study represents the influence of top-level managers at the business unit level.

Toward a theory of leadership for innovation in the experience context. Senior managers in the hospitality and tourism industry indicated that they influence innovation in their organizations by employing a variety of managerial behaviors and leadership practices. The data in this inquiry resulted in three themes based on eighteen leadership practices that originated from the qualitative component. After eliminating three items, a principal component matrix identified a three-factor structure that lined up with the three themes of senior manager influence as theorized and outlined in this section. One factor comprises a collection of four leadership practices intended to represent idea generation to refresh the guest experience. Another factor comprises a collection of six practices to develop shared understanding of the guest experience. A third factor comprises five leadership practices that represent ways to energize idea implementation in the hospitality and tourism industry context. The summary list of leadership practices and the three themes they represent (Figure 25) are inserted here as a reference. 

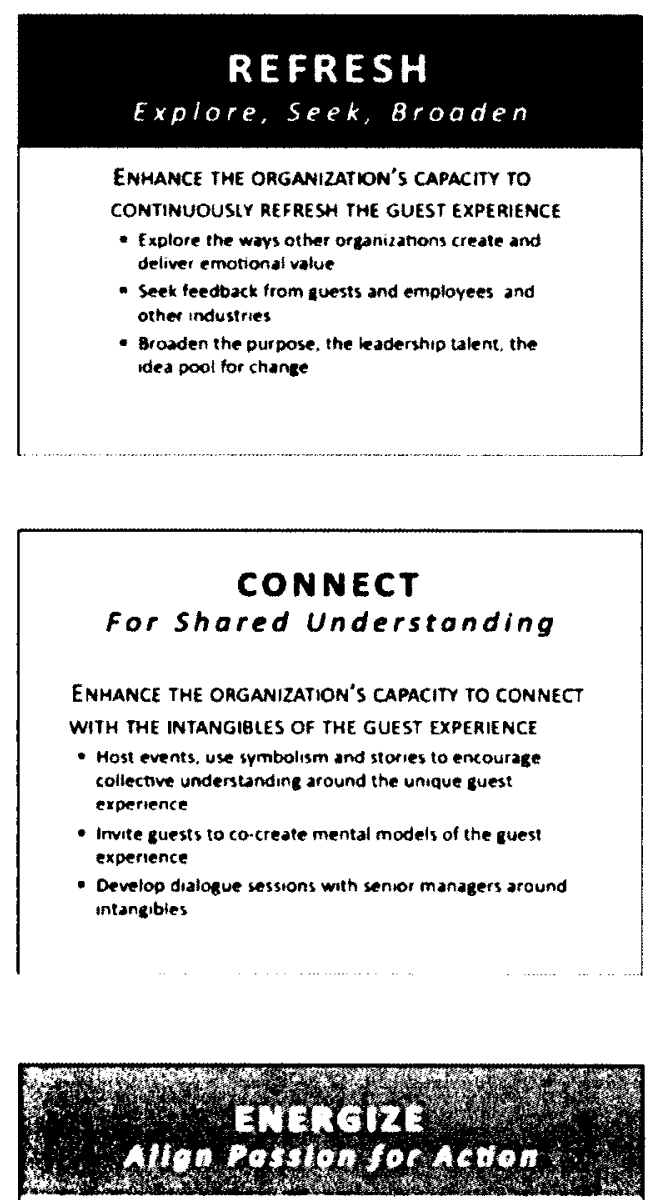

ENHANCE THE ORganization's CAPACITY for aLIGNING PASSIONS AND ACTION FOR IMPROVED RESULTS

- Tap into and unleash passions around grander purpose

- Operamonalize intangibles to get people dorng

- Seek balance of business and emotion
Leam about the ways other organizations deliver unique experiences to customers

Encourage employees to visit best practice/competitor organizations as a customer and share findings

Actively participate in a wide range of industry associations to expand thinking on key issues

Employ a systematic method for scanning trends and market conditions

Use novel approaches to seek feedback from guests. employees and other stakeholders

Bring in new perspectives to challenge assumptions and business as usual

Host events (orientation, training. meetings) that allow employees to talk about the unique characteristics of the guest experience

Use emotion-based communication methods (symbolism, storytelling) for collective understanding of the unique guest experience

Offer formal processes for employees to connect with the brand messaging of the organization

Show employees how their interests can be connected to the unique guest experience

Articulate a compeiling vision of the unique guest experience

Provide formal methods for employees to leam about how other departments contribute to the unique guest experience

Clarify and interpret the organization's objectives and priorities

Develop systematic ways to find out about employee interests and passions

Encourage managers to balance business and emotion in their leadership practices

Provide ways for employees to contribute to the organization's purpose beyond the day-to-day job requirements

Match employees with work assignments based on their interests and passions

Empower employees to make decisions regarding the guest experience

Figure 25. Managerial behaviors and leadership practices in the experience context (from Chapter Five) is repeated here

These findings supported the theoretical premise that three themes of leadership practices comprised a conceptual model of leadership for innovation in the hospitality and tourism industry. This is encouraging because the findings suggest that it is possible to develop innovation-related measures, in this case senior manager influence for innovation, for the local hospitality and tourism industry context. They may also provide 
a foundation for researchers wanting to study innovation in contexts other than new product development. They also provide a starting point-a list of potential leadership practices-for senior managers in related industry contexts who seek insights into how to influence innovation and change at the business unit level.

Summary of findings about strategic leadership. Based on the merged summary of findings presented to help answer the second research question, the conclusion is that senior managers influence innovation in their hospitality and tourism organizations by exercising leadership for ongoing change. Leadership practices for experience innovation are aimed at engaging employees at all levels of the organization to collectively enhance the unique experience offered by the organization.

The main economic offering of most hospitality and tourism organizations is a unique customer experience. These organizations are living systems that are constantly changing. Leadership for innovation in this context meant dealing with the intangible nature of the experience offering, mitigating the challenges of the guest as co-creator of the total experience, and generating and implementing ideas in an industry where ideas are easily copied. Leadership practices must adapt to the contextual issues and unique characteristics of the hospitality and tourism industry, as well as the ever-changing needs of increasingly savvy customers.

According to senior managers interviewed in this study, they exercise leadership for innovation as members of their organization's senior management team. In the definitions and terms list offered earlier in this dissertation, strategic leadership was defined as the influence of top-level managers on the organization's ability to adapt and change the leadership of organizations as a whole. The merged summary of findings 
that represents the ways in which senior managers influence innovation and change within their organizations is consistent with this definition of strategic leadership. Taken together, the qualitative interview data and quantitative data from the leadership and innovation survey provided an overview of the leadership of organizations in a local hospitality and tourism marketplace. Specifically, this is a context-specific example of what strategic leadership looks like at the business unit level.

Leadership of organizations at the business unit level suggests three things, based on this research. First, this level of leadership requires the ability to adapt and change by addressing the complexities of the fluctuating marketplace while considering the unique characteristics of the industry context. Second, this kind of leadership means being a part of a senior management team. Finally, exercising leadership in this context means engaging employees at all levels because the nature of the economic offering requires it.

This view of leadership is consistent with the direction of recent theories in the leadership literature. For example, relational leadership focuses on interactions, exchanges, and collective actions of many people to accomplish shared objectives (UhlBien, 2006). Complexity theory examines organizations as complex adaptive systems (Wheatley, 2010). As such, this context-specific view of leadership may also offer insights for senior managers in a variety of complex human systems.

\section{Research Question \#3: Innovation and Senior Manager Influence Relationships} What are the relationships, if any, between senior manager influence and innovation in organizations whose main economic offering is an experience?

Leadership and innovation are two phenomena that have a lot in common-they are both about change. Much has been written, theoretically, that suggests a relationship 
between leadership and innovation. Still, there are few empirical studies about the relationships between leadership and innovation in business, particularly at the organization level. Prior studies connecting leadership and innovation have mostly focused on creativity in sub-units (Mumford et al, 2002). Few have gone beyond individual behaviors of leaders and their influence on individual followers. This research project was designed to address this gap in the research by examining leadership and innovation at the organizational level.

This dissertation inquiry was designed as three phases. The first phase provided information about leadership and innovation. The qualitative data pointed to relationships between how senior managers influence innovation and innovation outcomes. Findings from the first phase were translated into independent and dependent variables in Phase Two. The third phase was designed specifically to examine the relationships between senior manager influence and innovation, utilizing a large sample of senior managers. These three phases were necessary due to the lack of information about innovation in the experience context and the struggles with measuring innovation outlined by innovation researchers. Much of what was learned empirically about the relationships between senior manager influence and innovation performance came as a result of the quantitative study component $(Z)$ conducted during Phase Three. However, the qualitative data from Phase One certainly pointed to theoretical relationships among leadership and innovation, as well as informed the research in Phase Three.

The empirical evidence confirms a relationship. The relationship between senior manager influence and innovation performance was assessed using the statistical techniques of regression analysis. Senior manager influence was measured as three 
factors of independent variables-refresh (idea generation), connect (shared

understanding of experience, and energize (idea implementation). A composite measure of innovation performance constituted the dependent variable in the regression model. The regression analysis results indicated there was a positive and significant association between senior manager influence for innovation and innovation performance. Each of the three factors of senior manager influence was shown to have a positive association with innovation performance on its own as well. These positive relationships were all significant, meaning these relationships were unlikely to be the result of randomness or chance.

The senior manager influence factors accounted for 34 percent of the variation in the innovation performance dependent variable, affirming the critical value of leadership. However, the leadership practices that make up the refresh, connect, and energize factors of senior manager influence do not account for all of the variation in innovation performance. There are clearly other factors that influence innovation performance as well, which are not included in the regression model. We can hypothesize what those factors might be, although they are beyond the scope of this particular study.

Leadership practices associated with innovation performance. The leadership practices that make up the three themes of senior manager influence for innovation in the experience context provide insights for researchers and practitioners. They may provide a foundation from which to test constructs of strategic leadership in the experience context at the business unit level. Although instrument development was not the primary purpose of this particular inquiry, results of the principal component analysis provide encouragement in terms of being able to establish innovation-related measures beyond 
what is used in new product development studies. The list of leadership practices also provides a parsimonious summary that captures the essence of the qualitative data gathered during the senior manager interviews. It could be a resource for senior managers in hospitality and tourism organizations outside San Diego who are looking for ways to influence innovation performance.

Examining each of the leadership practices offers a deep well to explore the ways in which senior managers exercise leadership to improve innovation performance. In keeping with the designed boundaries of this particular research initiative, the analysis stopped at identifying the correlations with innovation performance. Later research projects, however, could draw from these quantitative and qualitative data sources to examine more specific types of relationship-oriented research questions.

\section{Limitations}

Like any research initiative, the results offered here should be considered within the context of the study's limitations. This research inquiry suffered from many of the measurement problems identified by other innovation researchers. Although the composite innovation measure represents the ways in which innovation is measured in this local context, it is based on the respondents' self-reported comparison of their performance to similar organizations in the industry segment regarding these five metrics. Likewise, the innovativeness ratings are self-reported comparison ratings based on definitions and examples. It is not uncommon to find proxy measures or ratings supplied by senior managers to represent business performance when other measures are unavailable. Some studies have shown that ratings from those with access to the financial information, for example, hold up quite well (Jung, Chow \& Wu, 2003) 
However, robust measures from objective sources would better support claims of relationships between internal factors and business performance.

The quantitative data from the final survey comes from only one source, a member of the business unit's senior management team. Some leadership researchers advocate using other members of a management team or a group of subordinates to provide information about a senior manager's leadership behaviors. These strategies are employed to reduce common source bias. In this study, the independent and dependent variables were measured by ratings from the same senior manager, representing their perceptions.

The four samples used in this three-phase study omitted certain groups of the local hospitality and tourism marketplace that may have offered unique perspectives for a study about innovation in context. Members of five associations used in the final quantitative phase, for example, represent what one might call the mainstream of the hospitality and tourism marketplace. Organizations that cannot afford, don't know about, or don't consider industry association membership important, were not represented in the leadership and innovation survey.

Extreme opinions might also not be represented. For example, very innovative senior managers might opt out because they don't want to share cutting edge secrets. Senior managers that don't consider themselves innovative, likewise, might opt out because they don't believe they have anything to offer a survey about innovation. We know from the measures and outcomes survey data from Phase One that 25 percent of respondents indicated they don't measure innovation in their organizations. It is likely that senior managers who don't measure innovation were underrepresented in some of the 
study components. Likewise, the interview participants were selected precisely because they had reputations for innovation in their industry segment. They provide the voices of best practices in their segments and thus their responses cannot be taken as representative of the typical senior manager in their industry segment. In light of the limitations described above, this inquiry is best described as an initial exploration of the perceptions of senior managers representing mainstream organizations in four segments of a local hospitality and tourism marketplace.

Finally, this study does not provide detailed descriptions of the latest trends in guest amenities or highlights of novel products introduced in the hospitality and tourism industry. It was purposely limited to the ways senior managers exercise leadership "behind the scenes" to influence innovation in their organizations.

\section{Implications}

The results of this dissertation offer an updated perspective on innovation and strategic leadership at the business unit level. Innovation in this context is less about creating new things and more about creating lasting memories. Senior managers influence ongoing change of the organization by exercising leadership that balances business and emotion. As noted, this context-specific illustration of strategic leadership is consistent with the direction of other contemporary leadership theories, and thus may offer insights for senior managers in a variety of complex human systems.

\section{Bridging Theory and Application}

The spirit of this research project was to bridge theory and application. By studying a particular local hospitality and tourism marketplace, I hoped to establish a baseline of results informed by senior managers-a helpful tool for managers 
transitioning from a service to an experience economy mindset. The results from the three phases of the study also expand our knowledge of innovation in business and what we know about strategic leadership. The unique characteristics of the experience context made it challenging to apply extant manufacturing sector research and required wrestling with different approaches in this study. While this means that our understanding of how senior managers exercise leadership in response to their industry is context-specific, it does contribute to the knowledge base of contemporary leadership theory. The implications of some of the specific findings about innovation, strategic leadership, and the relationships between these two concepts were discussed in each of the sections of the merged summaries of this final chapter. The implications below relate to the research results as a whole.

\section{Dive Deeply into Conversations about Experience}

The updated perspective of innovation in this context revolves around enhancing the unique guest experience. Implicit in this perspective is shared understanding of what makes the experience unique. Continuous enhancement of the guest experience begins with deep understanding of what makes it special and valuable. What memories are created for these guests? What is the essence of the value as perceived by the customers? If outstanding service defines the purpose of the organization, knowing as much about the unique characteristics of that service, as well as understanding how that service value is delivered, becomes critical. Best practices tend to be easily copied or adapted in the hospitality and tourism context, where benchmarking is easy, and customer switching costs are usually minimal. The implication is that differentiation, then, requires a 
commitment to dive deeply into conversations about the unique aspects of the total experience offered by the organization.

There was a lot of variation in the ways that senior managers defined and discussed their organization's experiential offerings during interviews conducted for this dissertation. Some emphasized the tangible products and amenities. Others talked about the functional aspects, like being responsive to client needs. Emotions and memories were part of some discussions regarding organizational purpose. A few wrestled with finding words that conveyed the unique "soul" of the total experience. Descriptive results from survey data only partially converged with qualitative responses about how organizations define the unique aspects of their customer experience. This study is only a start in investigating what that might mean. These preliminary findings suggest that executives in all segments could benefit from dialogue about their organization's unique experience. Future research into the connections between manager perceptions of the uniqueness of their offerings and innovation may provide additional insights for executives charged with continuously innovating in the experience economy.

\section{Refresh The Leadership Toolkit—From Service to Experience}

Based on the results of this study, there is widespread agreement that innovation in this context is important. Innovation was defined as collective, incremental, and ongoing. On the other hand, consistency and standards have been at the heart of service quality, especially in business units that are part of larger brands, for decades. The struggles between continuously innovating and maintaining consistent service levels evidenced in this study echoed what has been published in recent trade journal literature about hospitality companies. Award winning companies like Ritz Carlton admit to 
struggling with the desire for authenticity versus standardization of service delivery in recent years (Robinson, 2006). Managing the tension between reliance on standardization and embracing the complexity that makes up a guest experience is sure to present challenges. Practitioners may find guidance in the six leadership practices that make up the connect theme of strategic leadership in this study. These practices are intended to measure the ways in which senior managers exercise leadership in order to develop shared understanding of their organization's experiential offerings. Implicit in these practices is the ability to articulate and make meaning of the intangible offerings that make up the guest experience. Developing shared understanding of the total experience, using efforts to help employees connect with the brand messaging, and other intangible and emotional aspects of the organization's offerings are replacing rigid adherence to service standards. Findings support the perception that enhancing the organization's capacity to develop shared understanding—by connecting employee interests to the organization's unique experience--is positively related to innovation performance. It follows that some senior management teams in organizations whose main economic offering is an experience may need to update their leadership toolkits and improve competencies like dialogue and storytelling.

\section{Define Innovation Strategy at the Business Unit Level}

The respondents in this study overwhelmingly agreed that innovation was important in their organizations. Less than 5 percent agreed with the statement that innovation is not part of their organization's operating strategy. However, less than 40 percent of senior managers agreed with the statement that "innovation permeates all aspects of our organization - it's central to who we are." Qualitative data supported the 
notion that innovation strategy is not explicitly defined in many organizations. Being able to articulate how the business unit will balance attending to business fundamentals while simultaneously engaging in innovation-related activities seems important. This balancing act has been called the innovation paradox by well-known innovation researchers (Christensen, 1997). Senior management teams in hospitality and tourism organizations are sure to wrestle with similar challenges of balancing idea generation and idea implementation activities. The challenges might be amplified given the collective nature of innovation as defined by senior managers in this dissertation.

\section{Transition to an Experience Scorecard}

The hospitality and tourism industry, based on this study, lacks evaluation methods to support experience innovation. The collection of metrics used to evaluate business performance today is similar to measures that have been used in the service industry for decades. Financial metrics, guest satisfaction scores, and employee climate survey results form the foundation for many organizations in this study. Some novel approaches in evaluating employee engagement, as well as updated methods to measure guest/employee interactions from the guest perspective are sprinkled throughout the qualitative data. The use of social media and a reliance on third party sites like Yelp and Trip Advisor to evaluate guest satisfaction in comparison to the competition seems to be growing. However, there is little evidence of assessment methods or metrics that evaluate experience or innovation directly, other than new products or services with discrete revenue sources. The implications are challenging for practitioners in terms of where to focus innovation efforts beyond responding to guest suggestions or experimentation. 
Measuring experience innovation as an ongoing organizational objective will likely necessitate development of a comprehensive framework of assessment. This dissertation offers some insights into what developing an experience innovation scorecard might involve. For example, senior manager influence for innovation might be one area of a scorecard. The three factors (capturing fifteen leadership practices) used in this study's regression analysis may offer a foundation from which to develop measures of leadership for experience innovation. Innovation activities, like those offered in the back of the house and front of the house summaries in this dissertation could make up another section of an experience innovation scorecard.

The examples of innovation outputs summarized in this study's results chapters demonstrate the potential to gather qualitative data about innovation activities. An organization might be able to examine its innovation activities and assess the level of innovativeness they represent, for example. Another section of the scorecard could comprise the metrics that made up the composite measure of innovation performance developed from the findings of this dissertation. In this study, it was necessary to use a manager rating of the five innovation performance metrics. A more robust experience scorecard would go beyond manager perceptions and include items such as concrete measures of increased revenue and ability to charge a price premium. Although measurement problems certainly will persist, this study does offer encouragement for the possibility of transitioning to an innovation experience scorecard for organizations whose main economic offering is an experience. 


\section{Make the Business Case for Passion}

This collection of data, consumed in its entirety, makes the business case for passion. Creating an emotional bond with consumers often pays off in price premium in the memories business. As suggested by the organizations representing a local hospitality and tourism marketplace, guest/employee interactions are a considerable piece of the co-constructed experience. Because it is not possible to control every facet of the multiple guest/employee interactions, it is important to develop shared understanding of the intangible guest offerings so that all employees are mobilized to tap into their own supply of passions in service of the co-created experience.

Passion makes good business sense in this context. The list of leadership practices grounded in the qualitative data, as well as the quantitative results of the extent these leadership practices are used, offer an updated perspective on leadership of organizations where passion is important. The perspective provided by senior managers of a local hospitality and tourism marketplace may have even larger implications for business leaders considering whether or not they should integrate emotion into their own leadership practices.

\section{Directions For Future Research}

This dissertation inquiry offers a broad perspective of innovation and leadership in a local hospitality and tourism industry. Results of the study components provide a solid foundation of information about a local marketplace from which to delve deeper into applied research with this population. The updated perspectives offered in this study also open the door to additional research directions that may enhance our knowledge about the nature of innovation and leadership in a variety of industry contexts. 
Further testing of the leadership for innovation model originating from the qualitative data is necessary. The list of leadership practices represented by three factors of senior manager influence should be tested with additional samples of senior managers. The list of practices could be further refined with additional testing of the specific survey questions developed for the survey in Phase Three of this study. Additional testing of the model could attend to some of the limitations discussed earlier in this chapter. For example, a modified version of the leadership and innovation survey conducted during Phase Three could be used to mitigate single source bias. Different data sources could be used for the leadership questions and the innovation questions. Attempts to triangulate the perceptions of innovation with external measures could be added. Additional contextual factors from the literature could be tested using path analysis or structural equation modeling. Finally, in order to support managers, going deeper into each of the eighteen leadership practices that comprise senior manager influence for innovation would be helpful and require further testing.

It would be interesting to go deeper into the ways that leaders make meaning of the organization's purpose and its influence on innovation. The use of language seems important, particularly when exercising leadership involves developing shared understanding of intangible offerings. The findings from this study were preliminary, but puzzling. The literature on senior management team identity and/or collective sense making may provide background in this regard. Analyzing data from the entire senior management teams of organizations may offer alternative insights into the ways language is used to develop shared understand in a collective way. 
There is an opportunity to do more with the large quantity of examples of innovation activities provided by senior managers who responded to the two survey components of this dissertation inquiry. This could include examining the collection of examples and offering theoretical typologies that could be expanded with additional data. One example could also provide the starting point of a deeper case study of a single company that investigates their overall innovation strategy by mapping broad-based innovation efforts and projects.

There is a tremendous opportunity to do more in the way of assessment and measurement in contexts with intangible offerings. More adaptive approaches that integrate assessment of the organization's experiential offerings and strategic management team learning could be helpful for researchers and practitioners.

Finally, the mixed methods approach is worth studying. As an emerging methodology, insights from researchers about the ways to integrate data and data sources can only help those who use numbers and stories to answer research questions.

\section{Conclusion}

The purpose of this dissertation inquiry was three-fold. First, this study was intended to provide measures of innovation within the context of the experience economy paradigm. Second, this study was intended to explore the ways senior managers, those key to organization-wide change and innovation strategy, influence what they perceive as organizational innovation, broadly conceived. And finally, this study was designed to examine the relationships of senior manager influence (leadership), and various innovation outcomes, within a local hospitality and tourism context. 
In Phase One, I used descriptive statistics from a short survey to identify potential metrics to measure innovation performance. Concurrent to the quantitative survey, I conducted interviews and borrowed from the interpretation strategies of qualitative researchers to develop a theoretical model of strategic leadership for innovation in the hospitality and tourism industry context. In Phase Two, I facilitated an advisory group to provide feedback on the results and data interpretations from the first phase. The conceptual model was translated into a list of management behaviors and leadership practices grounded in the senior manager interview data. A composite measure of innovation performance was finalized. The results and interpretations from the first two phases informed the design of a survey for Phase Three of the overall inquiry. Statistical techniques of factor analysis and regression were used to examine the relationships among the independent variables of strategic leadership (senior manager influence) and the dependent variables of innovation.

A merged summary of the findings from the three phases of inquiry provided an updated perspective on the business innovation framework applied to the experience economy. First, innovation is considered a collective process. Unlike new product development, which often involves a small group of research and development specialists, innovation in the experience context involves employees at all levels and across all work groups and departments. Second, innovation is incremental and ongoing. Instead of a few big "game changing" ideas or new products, the collective process of innovation is about making small enhancements over time. Third, the impetus for continuously enhancing the unique guest experience frequently relies on employeerelated initiatives that take place behind the scenes or back of the house. 
The back of the house view of innovation in the experience context also offered a context-specific look at strategic leadership at the business unit level. Senior managers influence innovation in organizations whose main economic offering is an experience by exercising leadership in ways that consider the contextual factors of the industry. The six leadership practices that make up the dimension of strategic leadership titled refresh reflect idea generation in an industry context where ideas are easily copied and guests have rising expectations. The connect dimension of strategic leadership includes six leadership practices intended to develop shared understand of the unique, and often intangible offerings that comprise the total guest experience. The energize dimension of leadership for innovation includes six leadership practices intended to measure idea implementation in the experience context. Implementation of innovation activities requires leadership practices that align employee passions with projects that continuously refresh the total customer experience.

Results of regression analysis indicated there was a positive and significant association between senior manager influence for innovation and innovation performance. Each of the three factors of senior manager influence (strategic leadership dimensions) was shown to have a positive association with innovation performance. Correlation coefficients for each of the eighteen leadership practices offered further evidence of the positive and significant relationship between senior manager influence and innovation performance in organizations whose main economic offering is an experience.

The collection of qualitative and quantitative results of this dissertation inquiry in the experience context contributes to the literature on innovation and contemporary 
leadership theory as well as offering utility to managers in the hospitality and tourism industry. It also offers up a potentially more optimistic picture of what organizational life could look like in the back of the house for senior management teams that are intent on competing in the memories business. A quote from David Whyte, an organizational consultant and poet, reads: "Work, paradoxically, does not ask enough of us yet exhausts the narrow part we bring to the door" $(1994$, p. 22$)$. Twenty years later, despite the tireless efforts of many researchers, organizational consultants, and managers, for-profit businesses still convey workplaces where we are expected to keep the most personal parts of ourselves out of the office. On the other hand, the collective and incremental nature of innovation, as well as the intangible and co-constructed nature of a unique customer experience, rewards discovering and tapping into the passions of all employees. The implications, then, of the leadership practices revealed in this study, may have much broader utility for both managers and scholars as they shape organizations of the future. 


\section{REFERENCES}

Adams, R., Bessant, J., \& Phelps, R. (2006). Innovation management measurement: A review. International Journal of Management Reviews, 8(1), 21-47.

Alotaibi, E., Al-Sabbahy, H., \& Lockwood, A. (2011). Interaction quality in service encounter: Scale development and validation. Paper presented at the International CHRIE Conference.

Amabile, T. (1998). How to kill creativity. Harvard Business Review, 9(2), 77-87.

Anderson, N.R, \& West, M. A. (1996). The team climate inventory: Development of the TCI and its applications in teambuilding for innovativeness. European Journal of Work and Organizational Psychology, 5(1), 53-66.

Anderson, N.R. \& West, M.A. (1998). Measuring climate for work group innovation: Development and validation of the team climate inventory. Journal of Organizational Behavior, 19(3), 235-258.

Anthony, S., Eyring, M., \& Gibson, L. (2006). Mapping your innovation strategy. Harvard Business Review, 84(5), 104-113.

Barras, R. (1986). Towards a theory of innovation in services. Research Policy, 15(4), 161-173.

Barret, P., \& Sexton, M. (2006). Innovation in small, project-based construction firms. British Journal of Management, 17, 331-346.

Bass, B. (1990). Concept of leadership: The beginnings. In J. Wren (Ed.), The leader's companion (pp. 49-59). New York: The Free Press.

Bass, B., \& Avolio, B. (1995). MLQ multifactor leadership questionnaire. Redwood City, CA: Mindgarden.

Beckman, C. (2011). The influences of founding team company affiliations on team behavior. Academy of Management Journal, 49(4), 741-758.

Bennis, W. G., \& Thomas, R. J. (2002). Geeks and geezers: How era, values, and defining moments shape leaders. Boston: Harvard Business School Publishing.

Birkinshaw, J., \& Gibson, C. (2004). Building ambidexterity into an organization. MIT Sloan Management Review, 45(4), 47-55.

Birnbaum, D., \& Somers, M. J. (1986). The influence of occupational image subculture on job attitudes, job performance, and the job attitude-job performance relationship. Human Relations, 39(7), 661-672. 
Boal, K. (2004). Strategic leadership. In G. R. Goethals, G. L. Sorenson \& J. M. Burns (Eds.), Encyclopedia of leadership (pp. 1497-1504). Thousand Oaks, CA: Sage Publications.

Boal, K., \& Hooijberg, R. (2000). Strategic leadership research: Moving on. Leadership Quarterly, 11(4), 515-549.

Boone, L. E., \& Kurtz, D. L. (2004). Contemporary Marketing. Mason: South-Western: Cenage Learning.

Boyd, D. (2012). How to lead in time of chaos. Fast Company.

Bryman, A. (2004). Qualitative research on leadership: A critical but appreciative review. The Leadership Quarterly, 15(6), 729-769.

Burch, G., \& Anderson, N. (2004). Measuring person-team fit: development and validation of the team selection inventory. Journal of Managerial Psychology, 19(4), 406-419.

Burns, J. M. (1978). Leadership. New York: Harper \& Row, Publishers, Inc.

Carlzon, J. (1987). Moments of Truth. New York: Harper \& Row, Publishers, Inc.

Carmeli, A., Gelbard, R., \& Gefen, D. (2010). The importance of innovation leadership in cultivating strategic fit and enhancing firm performance. The Leadership Quarterly, $2 l(3), 339-349$.

Carmen, C., Luz, F, \& Salustiano, M. (2006). Influence of top management team vision and work team characteristics on innovation: The Spanish case. European Journal of Innovation Management, 9(2), 179-201.

Charmaz, K. (2000). Grounded theory: Objectivist and constructivist methods. In N. Denzin \& Y. Lincoln (Eds.), Handbook of qualitative research. Thousand Oaks, CA: Sage Publications.

Charmaz, K. (2006). Constructing grounded theory: A practical guide through qualitative analysis. Thousand Oaks, CA: Sage Publications.

Chemers, M. (1984). Contemporary leadership theory. In J. Wren (Ed.), The leader's companion. New York, NY: The Free Press.

Chen, G., Chen, Z., Ho, J., \& Lee, C. (2009). In-depth tourism's influences on service Innovation. International Journal of Culture, Tourism and Hospitality Research, $3,326-336$.

Chen, J., \& Sawhney, J. (2008). A proposal to improve our understanding of innovation using Innovation Radar 2.0. Kauffman Organization Data Symposium. Retrieved from http://Kaufman.org. 
Christensen, C. M. (1997). Innovator's Dilemma: When new technologies cause great firms to fail. Cambridge, MA: President and Fellows of Harvard College.

Cohen, W., \& Levinthal, D. (1990). Absorptive capacity: A new perspective on learning and innovation. Administrative Science Quarterly, 35(1), 128-152.

Cooper, C. (2006). Knowledge management and tourism. Annals of Tourism Research, 33(1), 47-64.

Creswell, J. W., \& Clark, V. L. P. (2011). Designing and conducting mixed methods research (2 ed.). Thousand Oaks, CA: Sage Publications.

Damanpour, F. (1991). Organizational innovation: A meta-analysis of effects of determinants and moderators. Academy of Management Journal, 34(3), 555-590.

Damanpour, F. (1996). Organizational complexity and innovation: developing and testing multiple contingency models. Management Science, 42(5).

Damanpour, F., \& Schneider, M. (2006). Phases of the adoption of innovation in organizations: effects of environment, organization, and top managers. British Journal of Management, $I 7(3), 215-236$.

Davenport, T. \& Beck, J. (2001). The attention economy: understanding the new currency if business. Boston, MA: Harvard Business Press.

De Jong, J., \& Hartog, D. (2007). How leaders influence employees' innovative behaviour. European Journal of Innovation Management, 10(1), 41-64.

Denison, D. R., \& Mishra, A. K. (1995). Toward a theory of organizational culture and effectiveness. Organization Science, 6(2), 204-223.

Denning, S. (2005). The leader's guide to storytelling: Mastering the art of discipline of business narrative. San Francisco,CA: Jossey-Bass.

Driskill, G. W., \& Brenton, A. L. (2005). Organizational culture in action: A cultural analysis workbook. Thousand Oaks, CA: Sage Publications, Inc.

Drucker, P. F. (1985). Innovation and Entrepreneurship. New York: Harper \& Row, Publishers. Inc.

Dube, L., \& Renaghan, L. M. (2000). Sustaining advantage competitive: Lodging-industry best practices. The Cornell Hotel and Restaurant Administration Quarterly, 40(6), 27-33. 
Enz, C. (2010). Commentary: Competitive dynamics and creating sustainable advantage. In C. Enz (Ed.), Handbook of applied hospitality strategy. Thousand Oaks, CA: Sage Publications.

Enz, C. , \& Siguaw, J. A. (2003). Revisiting the best of the best: Innovations in hotel practice. Cornell Hotel and Restaurant Administration Quarterly, 44(5/6), 115-123.

Erdly, M. \& Kesterson-Townes, L. (2003). Experience rules: A scenario for the hospitality and leisure industry. Strategy \& Leadership, 31(3), 12-18.

Fiedler, F. (1978). The contingency model and the dynamics of the leadership process. In L. Berkowitz (Ed.), Advances in experimental social psychology. New York, NY: Academic Press.

Field, A. (Ed.). (2005). Discovering statistics using SPSS. London: Sage Publications.

Flikkema, M., Jansen, P., \& Sluis, L. V. D. (2007). Identifying neo-schumpeterian innovation in service firms: A conceptual essay with a novel classification. Economics of Innovation and New Technology, 16(7), 541-558.

Fowler, F. (2009). Survey research methods. Thousand Oaks: Sage Publications.

Gallouj, F. (2002). Innovation in services: and the attendance of old and new myths. Journal of Socio-Economics, 31(2), 137-154.

Gallouj, F., \& Weinstein, O. (1997). Innovation in services. Research Policy, 26(4-5), 537-556.

Galloway, F. (2004). A methodological primer for conducting quantitative research inpostsecondary education at lumina foundation for education. Lumina Foundation for Education.

Garcia, R., \& Calantone, R. (2002). A critical look at technological innovation typology and innovativeness terminology: A literature review. Journal of Product Innovation Management, 19(2), 110-132.

Gardner, J. W. (1990). On leadership. New York: The Free Press.

Gilmore, J. H., \& Pine, B. J. (2007). Authenticity: What consumers really want. Boston: Harvard Business School Publishing.

Glesne, C. (2006). Becoming qualitative researchers. Boston, MA: Pearson Education Inc.

Gil, F., Rico, R., Alcover, C. M., \& Barrasa, A. (2005). Change-oriented leadership satisfaction and performance in work groups. Journal of Managerial Psychology, 20(3/4), 312-329. 
Glisson, C., \& James, L. R. (2002). The cross-level effects of culture and climate in human service teams. Journal of Organizational Behavior, 23(6), 767-794.

Graen, G., \& Cashman, J. (1975). A role making of leadership in formal organizations: A developmental approach. In H. Larson (Ed.), Leadership frontiers. Kent, OH: Kent State University Press.

Greene, J., Caracelli, V., \& Graham, W. (1989). Toward a conceptual framework for mixedmethod evaluation designs. Education Evaluation and Policy Analysis, 11(3), 255-274.

Griffin, A. (1997). Modeling and measuring product development cycle time across industries. Journal of Engineering and Technology Management, 14(1), 1-24.

Gronroos, C. (1990). Service management and marketing:managing the moments of truth in service competition. Lexington, MA: Lexington Books.

Gronroos, C. (2000). Service management and marketing: A customer relationship management approach. Chichester: John Wiley \& Sons, Inc.

Gumusluoglu, L., \& Ilsev, A. (2009). Transformational leadership and organizational innovation: The roles of internal and external support for innovation. Journal of Prodict Innovation Management, 26(3).

Hall, M. C., \& Allan, W. (2008). Tourism and innovation. New York: Routledge.

Hambrick, D. C., \& Mason, P. A. (1984). Upper echelons: The organization as a reflection of its top managers. Academy of Management Review, 9(2), 193-206.

Han, J. K., Kim, N., \& Srivastava, R. K. (1998). Market orientation and organizational performance: Is innovation a missing link? Journal of Marketing, 62(4), 30-45.

Hargadon, A. \& Sutton, R. (2000). Building an innovation factory. Harvard Business Review 78(3), 157-164.

Hauser, J., Tellis, G. J., \& Griffin, A. (2006). Research on innovation: A review and agenda for marketing science. Marketing Science, 25(6), 687-717.

Heifetz, R. (1994). Leadership without easy answers. Cambridge: Harvard University Press.

Hersey, P. H., Blanchard, K. H., \& Johnson, D. E. (1977). Management of organizational behavior. Englewood Cliffs Prentice Hall.

Heskett, J., Jones, T., Loveman, G., Sasser, W., Schlesinger L. (1994). Putting the service profit chain to work. Harvard Business Review 72(2) March-April 1-13, 164-174. 
Hidalgo, A., \& Albors, J. (2008). Innovation management techniques and tools: A review from theory and practice. $R \& D$ Management, 38(2), 113-129.

Hill, C. W. L., \& Jones, G. R. (1998). Strategic management theory: An integrated approach. Mason: South-Western Cengage Learning.

Hinton, P. (2004). Statistics explained. New York, NY: Routledge.

Hippel, E., Thomke, S., \& Sonnack, M. (1999). Creating breakthroughs at 3M. Harvard Business Review on Innovation. Boston, MA: Harvard Business School Press.

Hjalager, A. (2009). A review of innovation research in tourism. Tourism Management, 3 I(1), 112.

Hosany, S., \& Gilbert, D. (2010). Measuring tourists' emotional experiences toward hedonic holiday destinations. Journal of Travel Research, 49(4), 513-526.

Hosany, S. \& Witham, M. (2009). Dimensions of cruisers' experiences, satisfaction and intention to recommend. The School of Management Working Paper Series. London: Royal Holloway University of London.

House, R. J. (1971). A path goal theory of leader effectiveness. Administrative Science Quarterly, 16(3), 321-339.

House, R. J., Wright, N., \& Aditya, R. N. (1997). Cross-cultural research on organizational leadership: A critical analysis and a proposed theory. In P. C. Earley \& M. Erez (Eds.), New perspectives on international/organizational psychology (pp. 535-625). San Francisco, CA: New Lexington.

Hunt, J. G. (1991). Leadership: A new synthesis. Newbury Park: Sage Publications, Inc.

Hunt, J. G., \& Ropo, A. (1995). Multi-level leadership: Grounded theory and mainstream theory applied to the case of general motors. The Leadership Quarterly, 6(3), 379-412.

Jaruzelski, B., Loehr J. , \& Holman R. (2011) The global innovation 1000: why culture is key. Strategy and Business, 65.

Jones, P. (1996). Managing hospitality innovation. Cornell Hotel and Restaurant Administration Quarterly, 37(5), 86-96.

Jung, D., Chow, C., \& Wu, A. (2003). The role of transformational leadership in enhancing organizational innovation: Hypotheses and some preliminary findings. Leadership Quarterly, I4(4/5), 525-544. 
Jung, D., Wu, A., \& Chow, C. W. (2008). Towards understanding the direct and indirect effects of CEO's transformational leadership on firm innovation. The Leadership Quarterly, $19(5), 582-594$.

Keller, K. L. (2003). Brand synthesis: The multidimensionality of brand knowledge. Journal of Consumer Research, 29(4), 595-600.

Kelly, T., \& Littman, J. (2005). The ten faces of innovation: IDEO's strategies of defeating the devil's advocate \& driving creativity throughout your organization. New York: Doubleday.

Kemp, S., \& Dwyer, L. (2001). An examination of organizational culture- the regent hotel. International Journal of Hospitality Management, 20(1), 77-93.

Kim, W., \& Mauborgne, R. (2005). Blue ocean strategy: How to create uncontested market space and make competition irrelevant. Boston: Harvard Business School Publishing.

Kim, W., \& Mauborgne, R. (2005). Knowing a winning business idea when you see one. Harvard Business Review on Innovation. Boston, MA: Harvard Business School Press.

Kline, P. (1994). An easy guide to factor analysis. London: Routldege.

Kotter, J. P., \& Heskett, J. L. (1992). Corporate culture and performance. New York: The Free Press.

Kouzes, J. M., \& Posner, B. Z. (1987). The leadership challenge. San Francisco: Jossey-Bass.

Kvale, S. (1996), Interviews. Thousand Oaks: Sage Publications.

Kwortnik, R. (2008). Shipscape influence on the leisure cruise experience. International Journal of Culture, Tourism and Hospitality, 2(4), 289-311.

Kwortnik, R. J., \& Thompson, G. M. (2009). Unifying service marketing and operations with service experience management. Journal of Service Research, 1/(4), 389-406.

Lawless, M. W., \& Anderson, P. C. (1996). Generational technological change: Effects of innovation and local rivalry of performance. Academy of Management Journal, 39(5), $1185-1217$.

LeBel, J., Dube, L., Sears, D., \& Renaghan, L. (2010). Strategic experiential branding in the hospitality industry. In C. Enz (Ed.), Handbook of applied hospitality strategy. Thousand Oaks, CA: Sage Publications.

LeBlanc, C. L., \& Mills, K. E. (1995). Competitive advantage begins with positive culture. Nation's Restaurant News, 29(39), 22-24. 
Lin, H.E., \& McDonough, E. F. (2011). Investigating the role of leadership and organizational culture in fostering innovation ambidexterity. IEEE Transactions on Engineering Management, 58(3), 497-507.

Loo, R. (2003). Assessing "team climate" in project teams. International Journal of Project Management 2l(7), 511-517.

Lord, R., Brown, D., Harvey, J., \& Hall, R. (2001). Contextual constraints on prototype generation ad their multilevel consequences for leadership perceptions. Leadership Quarterly, 12(3), 311-338.

Lowe, K. B., \& Gardner, W. L. (2000). Ten years of the leadership quarterly: Contributions and challenges for the future Leadership Quarterly, 11(4), 459-514.

March, J. (1991). Exploration and exploitation in organizational learning. Organization Science, 2(1), 71-87.

Mathisen, G. E., \& Einarsen, S. (2004). A review of instruments assessing creative and innovative environments within organizations. Creativity Research Journal, 16(1), 119140.

Merriam, S. (1998). Qualitative research and case study applications in education. San Francisco, CA: Jossey Bass.

Miles, R. E., \& Snow, C. (1978). Organizational strategy: Structure and process. New York: McGraw-Hill.

Mumford, M. D., Scott, G. M., Gaddis, B., \& Strange, J. M. (2002). Leading creative people: Orchestrating expertise and relationships. The Leadership Quarterly, 13(6), 705-750.

Neef, D. (1998). The economic impact of knowledge. Woburn, MA: Heinemann.

Neustadt, R. E., \& May, E. R. (1986). Thinking in time: the uses of history for decision-makers. New York: The Free Press.

Nijs, S. (2003). Imagineering: Engineering for imagination in the emotion economy. Paper presented at the ICHRIE Conference, Thessoloniki, Greece.

O'Brien, T. (2010). FunWorld.Alexandria, VA.

OECD. (2005). Oslo manual: Guidelines for collection and interpreting technological innovation data. Paris: OECD Publications.

Oh, H., Fiore, A, \& Jeoung, M. (2007). Measuring experience economy concepts: tourism applications. Journal of Travel Research, 46, 119-132. 
Ospina, S., \& Sorenson, G. (2006). A construction lens of leadership: Charting new territory. In G. Goathals \& G. Sorenson (Eds.), The quest for a general theory of leadership (pp. 188207). Northampton, MA: Edward Elgar Publishing Limited.

Ottenbacher, M., \& Gnoth, J. (2002). The role of employee management in NSD. Journal of Hospitality and Tourism Research, 31, 431-454.

Ottenbacher, M., \& Gnoth, J. (2005). How to develop successful hospitality innovation. Cornell Hotel and Restaurant Administration Quarterly, 46(2), 205-222.

Palmer, A. (2008). Customer experience management: A critical review of an emerging idea. Journal of Services Marketing, 24(3), 196-208.

Patton, M. (2002). Qualitative research and evaluation methods. Thousand Oaks, CA: Sage Publications.

Petkus, E. (2002). Enhancing the application of experiential marketing in the arts. International Journal of Non-profit and Voluntary Sector Marketing, 9(I), 49-56.

Pine, B., \& Gilmore, J. (1998). Welcome to the experience economy Harvard Business Review, $76(4), 97-105$.

Pine, B., \& Gilmore, J. (2011). The experience economy. Boston, MA: Harvard Business School Publishing.

Pine, J. (2010). [What about experience innovation?]. Personal conversation.

Porter, M., \& Ketels, C. (2003). Competitiveness: Moving to the next stage. Strategic Management Journal, 24, 415-431.

Prahalad, C. \& Ramaswamy, V. (2004). Co-creation experiences: the next practice in value creation. Journal of Interactive Marketing, 18(3), 5-14.

Prahalad, C. \& Ramaswamy, V. (2004). The future of competition: Co-creating unique value with customers. Boston, MA: Harvard Business School Press.

Prajogo, D. (2006). The relationship between innovation and business performance-a comparative study between manufacturing and service firms. Journal of Knowledge and Process Management, 13, 218-225.

Prange, C., \& Schlegelmilch, B. B. (2010). Heading for the next innovation archetype? The Journal of Business Strategy, 31(1), 46-55.

Quan, S., \& Wang, N. (2004). Towards a structural model of the tourist experience: An illustration from food experiences in tourism. Tourism Management, 25(3), 297-305. 
Ragazzoni, P., Baiardi, P., Zotti, A. M., Anderson, N., \& West, M. (2002). Italian validation of the team climate inventory: A measure of team climate for innovation. Journal of Managerial Psychology, 17(4), 325-337.

Rayport. (2012). Expanding the view of innovation. HBR Online. Retrieved from http://www.harvardbusinessonline/leadblog. Harvard Business Review Press.

Rea, L. \& Parker, R. (2005). Designing and conducting survey research. San Francisco, CA: Jossey-Bass Publishers.

Richards, G. (2001). Tourism attractions systems: exploring cultural behavior. Annals of tourism research 29(4), 1048-1064.

Rifkin, J. (2000). The age of access: The new culture of hypercapitalism, where all of life is a paid-for experience. New York: Penguin Putnam Inc.

Robinson, J (2006). How the ritz-Carlton is reinventing itself. Gallup Business Journal. Retrieved from http://www.Gallup.com

Rooke, D., \& Torbet, W. R. (2005). Seven transformations of leadership. Harvard Business Review, 83(4), 66-76.

Rosing, K., Frese, M., \& Bausch, A. (2011). Explaining the heterogeneity of the leadershipinnovation relationship: Ambidextrous leadership. The Leadership Quarterly, 22(5), 956974.

Rost, J. C. (1991). Leadership for the twenty-first century. Westport, CT: Praeger Publishers.

Safian, R. (2012). The secrets of generation flux. Fast Company.

Saldana, J. (2009). The coding manual for qualitative researchers. Thousand Oaks, CA: Sage Publications.

Sarros, J. C., Cooper, B. K., \& Santora, J. C. (2008). Building a climate for innovation through transformational leadership and organizational culture. Journal of Leadership and Organizational Studies, 15(2), 145-158.

Savitt, M. (2012). Above and beyond. Lodging.

Schneider, B. Salvaggio, A. Subirats, M. (2002). Service climate: a new direction for climate research. Journal of applied psychology 87, 220-229

Schumpeter, J. A. (1934). The theory of economic development: An inquiry into profits, capital, credit, interest, and the business cycle. Cambridge: Harvard University Press. 
Scott, S. G., \& Bruce, R. A. (1994). Determinants of innovative behavior: A path model of individual innovation in the workplace. Academy of Management Journal, 37(3), 580-607.

SDCVB. (2012). Fact sheet. San Diego Convention and Visitors Bureau. Retrieved from http://www.sandiego.org.

Selznick, P. (1984). Leadership in administration: A sociological interpretation. London, England : University of California Press.

Senge, P. M. (1990). The fifth discipline: The art \& practice of the learning organization. New York: Doubleday.

Shamir, B., \& Howell, J. M. (1999). Organizational and contextual influences on the emergence and effectiveness of charismatic leadership. Leadership Quarterly, lO(2), 257-283.

Shaw, C., \& Ivens, J. (2002). Building customer experiences. New York: Palgrave Macmillian.

Shaw, C., \& Ivens, J. (2005). Building great customer experiences. New York: Palgrave Macmillian.

Siguaw, J. A., Simpson, P. M., \& Enz, C. A. (2006). Conceptualizing innovation orientation: A framework for study and integration of innovation research. Journal of Product Innovation Management, 23(6), 556-574.

Smircich, L. (1983). Concept of culture and organizational analysis. Administrative Science Quarterly, 28(3), 339-358.

Smircich, L., \& Morgan, G. (1982). Leadership: The management of meaning. The Journal of Applied Behavioral Science, 18(3), 257-273.

Sternberg, R. J. (2008). The WICS approach to leadership: Stories of leadership and the structures and process that support them. The Leadership Quarterly, 19(3), 360-371.

Subramanian, A., \& Nilakanta, S. (1996). Organizational innovativeness: Exploring the relationship between organizational determinants of innovation, types of innovations, and measures of organizational performance. Omega, 24(6), 631-647.

Sullivan, T. (2011). Embracing complexity. Harvard Business Review

Sundbo, J. (2009). Innovation in the experience economy: A taxonomy of innovation organizations. The Service Industries Journal, 29(4), 431-455.

Tashakkori, A., \& Creswell, J. (2007). Exploring the nature of research questions in mixed methods research. Journal of Mixed Methods Research, I(3), 207-211. 
Tashakkori, A., \& Teddlie, C. (2003). Handbook of mixed methods in social \& behavioral research. Thousand Oaks, CA: Sage Publications.

Teddlie, C., \& Tashakkori, A. (1998). Foundations of mixed methods research: Integrating quantitative and qualitative approaches in the social and behavioral sciences. Los Angeles: Sage Publications.

Tejeddini, K. (2011). Customer orientation, learning orientation, and new service development: An empirical investigation of the Swiss hotel industry. Journal of Hospitality and Tourism Research, 35 (4) 437-468.

Tidball, K. H. (1988). Creating a culture that builds your bottom line. Cornell Hotel and Restaurant Administration Quarterly, 29(1), 63-69.

Toffler, A. (1970). Future shock New York: Bantam Books.

Trefry, M. G. (2006). A double-edged sword: Organizational culture in multicultural organizations. International Journal of Management, 23(3), 563-575.

Tushman, M., \& Nadler, D. (1986). Organizing for innovation. California Management Review, 28(3), 74-93.

Tushman, M. L., \& O'Rielly, C. (1996). Ambidextrous organizations: Managing evolutionary and revolutionary change. California Management Review, 38(4), 8-30.

Uhl-Bien, M. (2006). Relational leadership theory: Exploring the social processes of leadership and organizing. Leadership Quarterly, 17 (6), 654-676.

Utterback, J. M. (1994). Mastering the dynamics of innovation. USA: Harvard Business School Press.

Van de Ven A., Angle, H. L., \& Poole, S. (2000). Research on the management of innovation: The Minnesota studies. New York: Oxford University Press.

Van der Aa, W. \& Elfring, T. (2002). Realizing innovation in services. Scandinavian Journal of Management, 18, 155-171.

Wheatley, M. (2010). Innovation means relying on everyone's creativity, Leader to Leader. Retrieved from http://www.margaretwheatley.com

Whyte, D. (1994). The heart aroused: Poetry and the preservation of the soul in corporate America. New York: Currency Doubleday Publishing.

Wilber, K. (2000). A theory of everything: An integral vision for business, politics, science and spirituality. Boston, MA: Shambhala Publications, Inc. 
Williams, A. (2006). Tourism and hospitality marketing: fantasy, feeling and fun. International Journal of Contemporary Hospitality Management, 18(6), 482-495.

Wolcott, H. (2009). Writing up qualitative research. Thousand Oaks, CA: Sage Publications.

Wolcott, R., \& Lippitz, M. (2009). Grow from within. Chicago: McGraw-Hill.

World Tourism Organization (2006). WTO Tourism 2020 Vision: Global Forecasts.

Worren, Morre, \& Cardona (2002). Modularity, strategic flexibility and firm performance. Strategic Management Journal, 23(12), 1123-1140.

Wren, J. T. (1995). The leader's companion: Insights on leadership through the ages. New York: The Free Press.

WTO. (2012). World tourism organization 2030 vision: Global forecasts.

Xenikou, A., \& Simosi, M. (2006). Organizational culture and transformational leadership as predictors of business unit performance. Journal of Managerial Psychology, 21(6), 566579.

Yin, R. K. (2009). Case study research design and methods (Fourth ed.). Thousand Oaks: Sage Publications.

Yoon, E., \& Lilien, G. L. (1985). New industrial product performance: The effects of market characteristics and strategy. Journal of Product Innovation Management, 2(3), 134-144.

Yukl, G. (2004). Tridimensional leadership theory: A road-map for flexible, adaptive leaders. In R. Burke \& C. Cooper (Eds.), Leading in turbulent times (pp. 75-91). Oxford: Blackwell.

Yukl, G. (2008). How leaders influence organizational effectiveness. The Leadership Quarterly, 19(6), 708-722.

Yukl, G., Gordon, A., \& Taber, T. (2002). A hierarchical taxonomy of leadership behavior: Intergrating a half century of behavior research. Journal of Leadership and Organizational Studies, 9(1), 15-32.

Zeithaml, V, Berry, L. \& Parasuraman, A. (1990). Delivering quality service: balancing customer perceptions and expectations. New York: The Free Press.

Zeithaml, V., Parasuraman, A., \& Berry, L. (1985). Problems and strategies in services marketing. Journal of Marketing, 49(2), 33-36. 
APPENDIX A

Sample Email Invitation for Measures and Outputs Survey 
Hello,

My name is Lori Sipe, faculty member in the School of Hospitality and Tourism Management at San Diego State University. I am also a doctorate student pursuing my PhD in leadership studies at the University of San Diego. I am conducting a research study about innovation in San Diego organizations in the Hospitality and Tourism industry, and I would like to know more about your perceptions of innovation in your organization.

The attached survey contains 5 questions about innovation in your organization and 5 general questions about your organization. It should take less than 10 minutes to complete the short survey, and your responses will be used to prepare a summary of manager perceptions in the lodging, dining, attractions, and events segments of the industry.

I am looking for a broad collection of perceptions regarding innovation in the industry, so there are no right or wrong responses, and your responses will be confidential. I will not share any of your survey responses or examples unless you give me explicit permission, and I will not use your name or organization in anything I write, unless you give me explicit permission.

I hope you will spend a few minutes now taking the Innovation Perceptions survey. Click on the link to begin http://www.surveymonkey.com/s/measuresandoutputssurvey I am excited to partner with industry professionals in my research endeavors. If you would like additional information, please contact me at Isipe@mail.sdsu.edu.

Thank you for your time, Lori Sipe 


\section{APPENDIX B}

Measures and Outputs Survey 


\section{Measures and Outcomes in HTM}

Innovation Perceptions

This brief survey is a starting point for a research initiative regarding innovation in the San Diego hospitality and tourism marketplace. It should take less than 5 minutes to complete

You will be surveyed about

PRODUCT INNOVATION - the ability to bring new or improved products to the marketplace

SERVICE INNOVATION - the ability to bring new or improved services to the marketplace

ADMINISTRATIVE INNOVATION - the ability to implement new or improved business processes and practices within the company or organization

OVERALL INNOVATION PERFORMANCE - successful development and implementation of novel ideas.products. and/or services to enhance the overall guesticustomer experience

Please respond to the survey items based on your perception about your company or organization. There are 10 total survey items - the first 5 items are about innovation and the last 5 items are about your company or organization in generat. 
Measures and Outcomes in HTM

1. PRODUCT INNOVATION is the abllity to bring new or improved products to the hospitallty and tourism marketplace.

Example: The Fun Card introduced by SeaWorid that allows customers to purchase a Fun Card for the price of one day's full admission and visit free the rest of the year.

Indicate your perception of your organization's PRODUCT INNOVATION against similar organizations in your industry segment during the past 5 years:

$\begin{array}{lcccc} & \text { Much less innovative } & \begin{array}{c}\text { Somewhat less } \\ \text { innovative }\end{array} & \begin{array}{c}\text { About the same level } \\ \text { of innovation }\end{array} & \begin{array}{c}\text { Samewnat more } \\ \text { innovative }\end{array} \\ \text { PRODUCT INNOVATION in } & r & r & r & r\end{array}$

Please provide an example of a PRODUCT INNOVATION in your organization implemented during the past 5 years

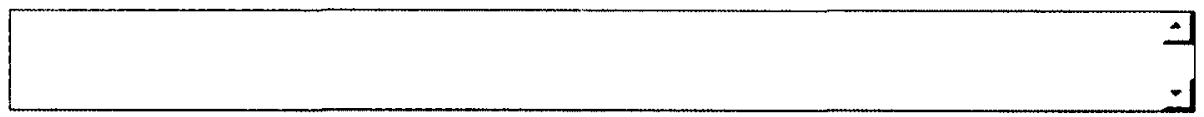


Measures and Outcomes in HTM

2. SERVICE INNOVATION is the ability to bring new or improved services to the hospitality and tourism marketplace.

Example: Curbside service Introduced by Chilis that allows customers to phone in orders and pick them up from a restaurant employee at designated parking spaces outside the restaurant.

Indicate your perception of your organization's SERVICE INNOVATION against similar organizations in your industry segment during the past 5 years:

$\begin{array}{ccccc}\text { Much less innovative } & \begin{array}{c}\text { Somewhat less } \\ \text { innovative }\end{array} & \begin{array}{c}\text { About the same level } \\ \text { of innovation }\end{array} & \begin{array}{c}\text { Somewhat more } \\ \text { innovative }\end{array} & \begin{array}{c}\text { Much more innovative } \\ r\end{array} \\ r & r & r & r\end{array}$

SERVICE INNOVATION in $r$

$r$

$r$

$r$

my organization

Please provide an example of a SERVICE INNOVAIION in your organization implemented during the past 5 years 


\section{Measures and Outcomes in HTM

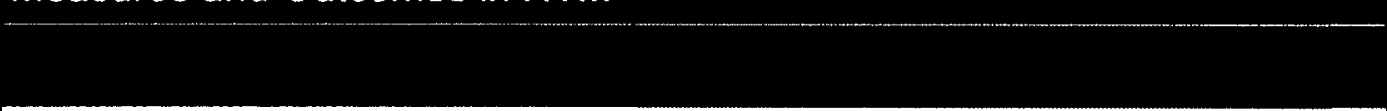

3. ADMINISTRATIVE INNOVATION is the ability to implement new and improved business processes and practices within the hospitality and tourism organization.

Example: The system-wide, values based, leadership development program at Marriott that makes it possible for managers to focus their development in personalized ways.

Indicate your perception of your organization's ADMINISTRATIVE INNOVATION against similar organizations in your Industry segment during the past 5 years:

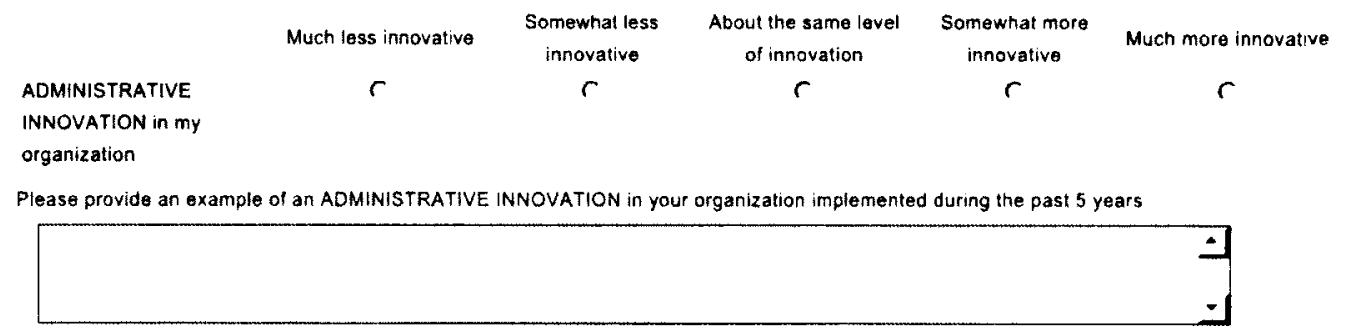




\section{Measures and Outcomes in HTM}

4. OVERALL INNOVATION PERFORMANCE is the successful development and implementation of novel ideas, products, and/or services to enhance the overall guest/customer experience.

Indicate your perception of your organization's OVERALL INNOVATION PERFORMANCE against similar organizations in your industry segment during the past 5 years:

Much less innovative

OVERALL INNOVATION PERFORMANCE in my organization
Somewhat less innovative

$r$

$$
\begin{gathered}
\text { Aboul the same leve } \\
\text { of innovation }
\end{gathered}
$$

$r$
Somewhat more innoyative

Much more innovative 


\section{Measures and Outcomes in HTM}

5. Please Indicate the ways, if any, your organization measures innovation. Please check all that apply to your organization.

$\Gamma$ we do not measure innovation in our organization

$\Gamma \%$ of revenue from new and/or improved products or services

$\Gamma$ quantity of new products or services implemented

$\Gamma$ quantity of ideas submitted through formalized idea generation processes

$\Gamma$ ability to charge price premium compared to competitors

$\Gamma$ quantity of training hours related to innovation-related activities

$\Gamma$ improved guest service measure(s)

$\Gamma$ improved operational process measure(s)

$\Gamma$ other organization-specific measure(s) of innovation

Please use the space provided below to list the other ways, if any, your organization measures/evaluates innovation Essentially, how do you know if your innovation-related activities are successful?

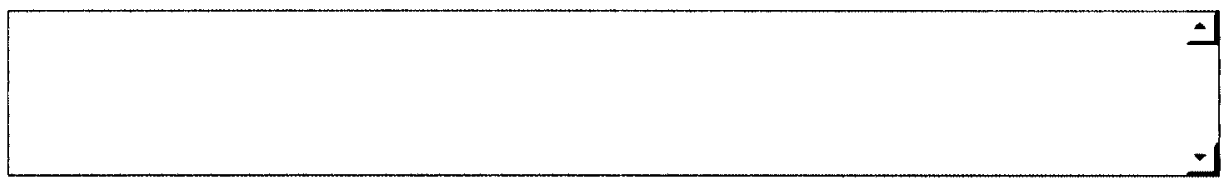




\section{Measures and Outcomes in HTM}

\section{General Company Information}

The following survey iterns ask you to enter general information about your company and its purpose as well as contact information. The information you provide will be used only to contact you for further research information (ie: inclusion in best practices summary) and to provide you a copy of the study's overall findings. No specific information about your company or organization will be shared without explicit permission.

\section{Indicate the industry segment for your company or organization.}
$r$ Lodging
$r$ Dining and Nightilife
C Meeting/Event Services
$r$ Altraction
Other

\section{What is the current size of your company or organization?}
$r$ Less than 10 employees
C $\quad 11.50$ employees
C 51.100 employees
C 101.300 employees
$r$ Greater than 300 employees

\section{How long has your company or organization been in operation?}
C Less than 2 years
C 2.5 years
c 6.10 years
C Longer than 10 years

9. Please provide your contact information. This information will not be shared without your explicit permission. List your name and position, company name, and your email address in the box provided below.

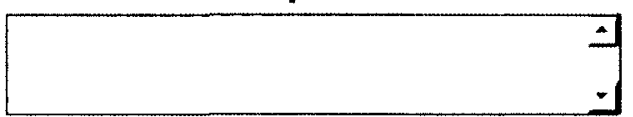


Measures and Outcomes in HTM

10. If you would like to provide any additional information or comments, please use the space below. Proceed to the next page to submit your survey electronically.

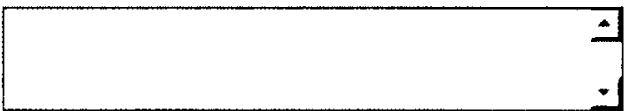


APPENDIX C

Consent Form for Measures and Outputs Survey 


\section{Measures and Outcomes in HTM}

\section{Survey Participant Consent and Submittal}

Thank you so much for taking time to complete the survey! You will submit your survey by clicking an the DONE button at the bottom of this page.

Prior to submitting your survey. please review the following information regarding consent. Submission of the survey assumes your implied consent to participate in the research outlined below.

Research Participant Consent

Instifutional Review Board - University of San Diego

For the research study entitied:

Leadership for innovation in the Memories Business

A Mixed Methods Study of a Hospitality and Tourism Marketplace

1. Purpose of the research study

Lori Sipe is a doctoral candidate in the School of Leadership and Ecucation Sciences at the University of San Diego You are invited to participate

in a research study she is conducting. The purpose of this research is: to explore perceptions of innovation in a hospitality and tourism industry

11. What you will be asked to do

If you decide to be in this study, you will be asked to

Provide responses to about 10 survey questions about innovation in your organization.

Your participation in this survey will take a total of $5-10$ minutes.

III. Foreseeable risks or discomforts

This study involves no more risk than the risks you encounter in dally life.

IV Benefits

While there may be no difect benefit to you from participating in this study, the indirect benefit of participating will be knowing that you heiped

researchers better understand how hospitality leaders perceive innovation in a hospitality and tourism marketplace.

$\checkmark$ Confidentiality

Any information provided and/or identifying records will remain confidential and kept in a locked file and/or password-prolected computer file in the researcher's office for a minimum of five years. All data collected from you will be coded with a number or pseudonym (fake name). Your real name will not be used. The resulls of this research project may be made public and information quoted in professional journals and meetings, but information from this study will only be reported as a group. and not individually.

Vi. Compensation

You will receive no compensation for your participation in the study.

VII. Voluntary Nature of this Research

Participation in this survey is entirely voluntary. You do not have to submit it, and you can refuse to answer any question or quit at any lime

VIII. Contact intormation

If you have any questions about this research. you may contact eitner

1) Lori Sipe

Email. Isipe@mail. sdsu edu

Phone: 858.722 .8458

2) Dr. Robert Donmoyer

Emait: donmoyer@sandiego edu

Phone: 619-260-7445 


\section{APPENDIX D}

Sample Email Invitation for Senior Manager Interviews 
Hello Mr. Cohn,

My name is Lori Sipe, faculty member in the School of Hospitality and Tourism Management at San Diego State University. I am also a doctorate student pursuing my PhD in leadership studies at the University of San Diego. I am writing to invite you to participate in my dissertation research about innovation in the San Diego hospitality and tourism industry. I hope to have face-to-face interviews with 12 or so industry professionals, like you, that are members of a senior management team in one four industry segmentslodging, dining, meetings/events, attractions.

If you interested in participating, I would enjoy talking with you about your organization and your role as a senior manager in the hospitality and tourism industry. I expect the conversation to last approximately one hour, and I am happy to conduct the interview at your place of business or on campus at SDSU, wherever is most convenient.

I am looking for a broad collection of opinions regarding innovation in the industry, so there are no right or wrong responses to any of my questions, and your responses will be confidential. I will not share anything we discuss unless you give me explicit permission, and I will not use your name or organization in anything I write, unless you give me explicit permission.

Please let me know if you are interested, or if you would like additional information, and we can move forward with scheduling a convenient interview date. I am excited to partner with industry professionals in my research endeavors, and I look forward to hearing your insights.

Warm regards,

Lori J. Sipe

Lecturer, School of Hospitality and Tourism Management, SDSU

PhD Student, School of Leadership Studies, USD 
APPENDIX E

The Interview Guide 


\section{Interview Guide}

These questions are designed to glean a broad range of responses about how senior managers influence innovation in their organizations. These are conversation starters; every single question may not be asked of each participant.

\section{Purpose}

Tell me about your organization's mission.

What is your overall organizational objective?

\section{Strategy}

What is the overall strategic positioning of the organization?

What makes it unique?

When you hear the word innovation in your business, what does that mean?

Do you have an innovation strategy?

\section{Innovation}

Tell me about innovation in your organization. How does it stack up to the competition? What are the challenges facing organizations like yours in which innovation is an overarching organizational objective?

Is innovation a limiting factor for your organization? If so, how?

If you perceive innovation as limiting, what alternatives do you utilize?

What are the ways in which innovation is enhanced in your organization?

\section{Idea Generation/Idea Implementation}

How does your organization get new ideas?

How does your organization go about moving an idea into the marketplace?

What is the implementation process?

What facilitates/hinders idea generation?

What facilitates/hinders idea implementation?

\section{Culture}

For your organization, what have you found most important in shaping an innovation enabling culture?

What role does leadership play around here in shaping your organizational culture? In what ways do you and other members of the senior management team sustain an environment conducive to continuous experience innovation?

\section{Outcomes/Results/Projects}

What are the outcomes of innovation in your organization? Product, service, experience? What are the types of projects members of your leadership team are working on?

\section{Privilege/Measurement}

How do you know how well your organization is doing related to experience innovation? What are you measuring on a consistent basis? How do you assess your progress?

\section{Concluding Comments}

Is there anything else you would like to add that we haven't covered? 


\section{APPENDIX F}

Consent Form for Senior Manager Interviews 


\section{University of San Diego \\ Institutional Review Board}

\section{Research Participant Consent Form}

For the research study entitled:

Leadership for Innovation in the Memories Business: A Mixed Methods Study of a Hospitality and Tourism Marketplace

\section{Purpose of the research study}

Lori Sipe is a student in the School of Leadership and Education Sciences at the University of San Diego. You are invited to participate in a research study she is conducting. The purpose of this research study is: to explore leadership for innovation in the hospitality and tourism industry.

\section{What you will be asked to do}

If you decide to be in this study, you will be asked to:

- Arrange a convenient time with the researcher to meet in person at your workplace or other convenient location for a conversational interview some time prior to January $30,2013$.

- Participate in a 60-minute face-to-face conversational interview about the ways you and your senior management team influence innovation in your hospitality and tourism organization.

- Respond to follow-up emails for clarification (if necessary)

You will be audio taped during the interview (not mandatory).

Your participation in this study will take a total of $60-90$ minutes.

\section{Foreseeable risks or discomforts}

This study involves no more risk than the risks you encounter in daily life.

\section{Benefits}

While there may be no direct benefit to you from participating in this study, the indirect benefit of participating will be knowing that you helped researchers better understand how hospitality leaders influence innovation in their organizations.

\section{Confidentiality}

Any information provided and/or identifying records will remain confidential and kept in a locked file and/or password-protected computer file in the researcher's 
office for a minimum of five years. All data collected from you will be coded with a number or pseudonym (fake name). Your real name will not be used. The results of this research project may be made public and information quoted in professional journals and meetings, but information from this study will only be reported as a group, and not individually.

\section{Compensation}

You will receive no compensation for your participation in the study.

\section{Voluntary Nature of this Research}

Participation in this study is entirely voluntary. You do not have to do this, and you can refuse to answer any question or quit at any time. Deciding not to participate or not answering any of the questions will have no effect on any benefits you're entitled to, like your health care, or your employment or grades. You can withdraw from this study at any time without penalty.

\section{Contact Information}

If you have any questions about this research, you may contact either:

\section{1) Lori Sipe}

Email: Isipe@mail.sdsu.edu

Phone: 858.722.8458

\section{2) Dr. Robert Donmoyer}

Email: donmoyer@sandiego.edu

Phone: 619-260-7445

I have read and understand this form, and consent to the research it describes to me. I have received a copy of this consent form for my records.

\begin{tabular}{lc}
\hline Signature of Participant Date &
\end{tabular}

Name of Participant (Printed) 


\section{APPENDIX G}

Theme Pages 


\section{Theme Pages - Data Interplay}
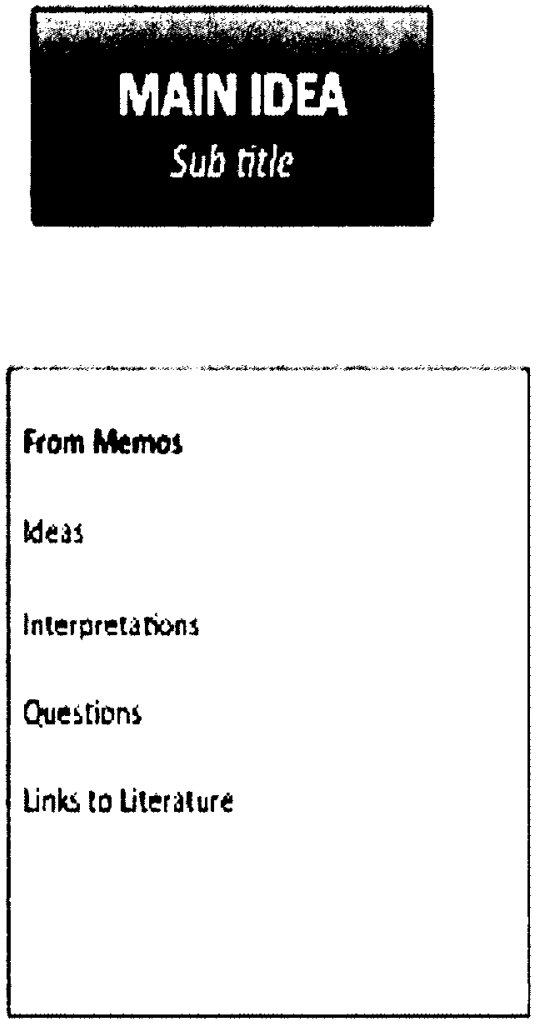

1. Context - Intangibles

2. Discussing Purpose of the Organization

3. Leadership - Make Meaning of Purpose

4. Innovation - Definitions and Viewpoints

5. Innovation As.... New Context

6. Innovation As Outputs

7. Innovation - Getting ideas

8. Innovation - Implementing Ideas

9. Tensions

10. Innovation as Projects

11. Leadership - Enhance Refresh Capacity 12. Leadership - Enhance Connect Capacity 13. Leadership - Enhance Energize Capacity 


\section{Context- Requires Translating Intangibles}

Cowillat
Economic Offering is
Emotional

CONTEXT IS INTANGIBLTY SO SHARED VISON BECOMES MORE MPORTANT

Using transformatonal leadershio

Lots of time talking sbout the experience

Intersction is part of the experience
- It isn't one thing. It's everything. It's the wholeness of it. n's importunt for people to connect the dots on their own. People want to teel like they can interpret the experience in their own way - makes them feel special - makes them want to pass along their commitment.

- Our senior management team has quarterly reveas and all we do is wlk about our values and share specitle stories of haw people in the fietd have brought these values alive

- I use these pennies and these containers when we get togethet. Talk about simple. This is how we deepen our understanding of our decisions around prottes. We phrysically seart with 100 pennies and divide up into these trays...then we move penties... that's lood cost going up..

- Each event is unique. We start with the end, and we ask questoons, trying to get the client to paint a picture of the teelings, the emotions, the values, they want in the event. ti's not about the props, and the off the shall theme as much as we try to get ater the memories intended...

\section{Discussing Purpose of the Organization}

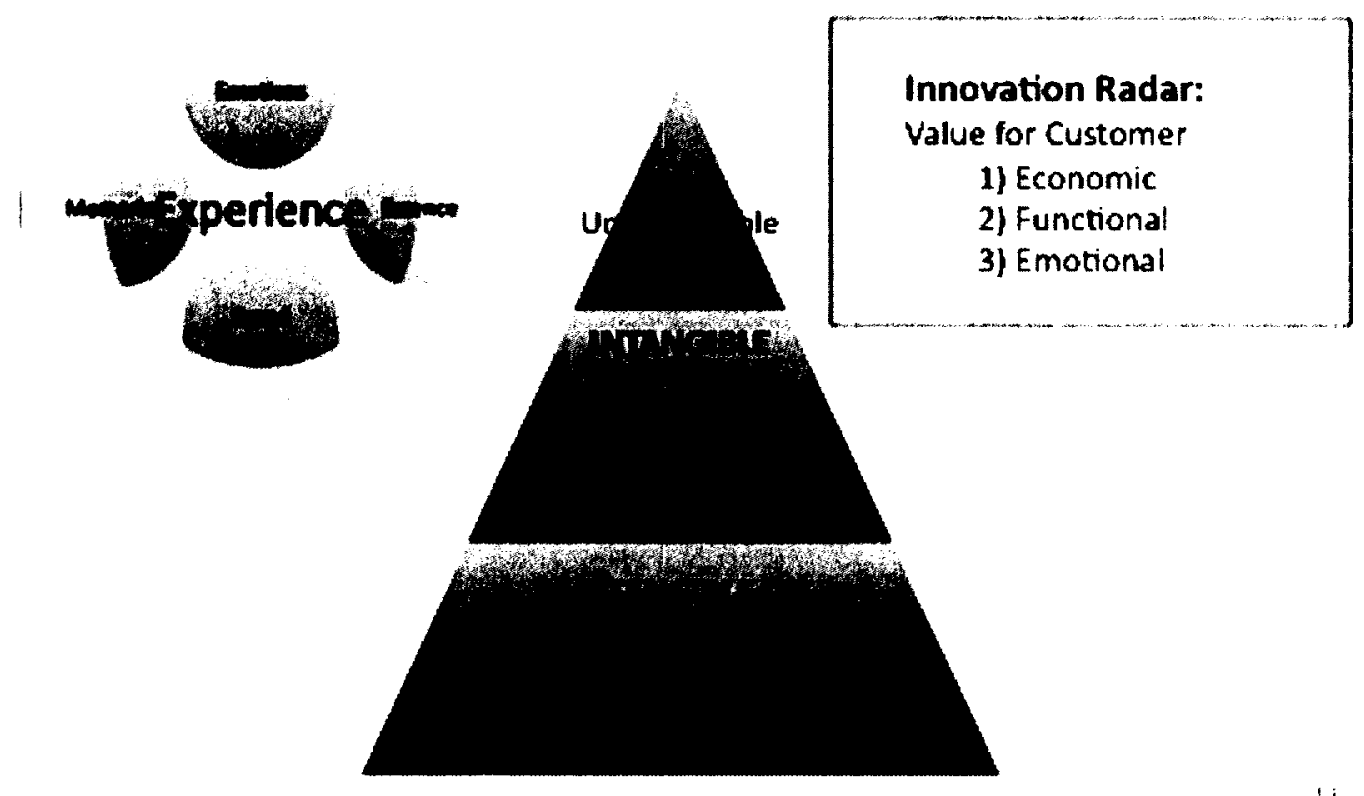




\section{Leadership: Make Meaning of Purpose}

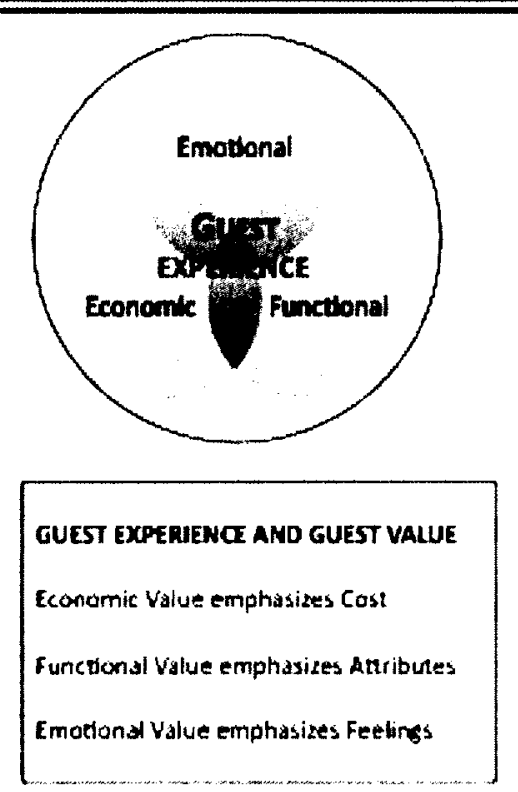

- We provide the guest comlort, nexibility, and convenuence

- A unique dining expetience-lood, service, people. We just added soul as the $4^{\text {th }}$ leg of the stool, it's what provides the stabdity

- Every guest ledues satsfied and lakes away a percerved value, above dl other competitors, in their exper ience

- We offer a home away from home because it's our hame loo

- We are a global conseryation organization, wildlife is endangered, and you can make a difference

- We start from the end, with each new cliem, and we work logethet to deffne what that experience looks like, what it lesls like, what they want their guests to walk away with, what memories will they shate?

- Deliver on the rand slandards

- Client's trusted advisor, guaranteeing peace of mind

- Solutions oriented approakh

- Live and lead from the heart - give, connect, hope

- World dass venue to host conventions and ewents that will generate economic impact for the region

\section{Innovation}

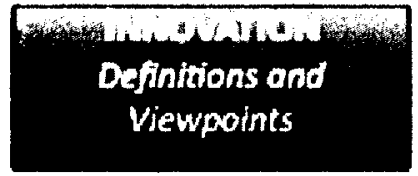

\section{CONTWTUOUS ATTENTION FROM ALL LFYELS TO KEEP INE GUEST EXPEQUENCE FRESH AND DIFFERENTIATED}

Centered arownd improwing the guest experience

All leveb od involvement encouraged

incremental and breskthrough based on culture of the brand and the managers

Projects and people
- Change is a constant, 101 spend a lot of my time checking with the stafl and staving in ture with how they are doing and how they think they carn make the dining experience more unique because of their strengths.

- Being ahead al the curve, by coming up with either a process, concept, or even technology to lurther pour business, guest experience, and advantage over the competion of even sets you ahedd in the industry

- We hiane a power ol one program._Our managers are messaging all the time about how each person can make a diflerence in their own way. We believe it too.

- Keeping brands fresh and differentided is a continuous' collective process that involves peaple close to the guest

- always on the lookout lor new ideas - travels, dines, and Lalks a lot to like-minded people sbout guest experiences and trends.

- A lot of idess on the wall, things stways in the works, many projects going on at one tome sll ower the business unts. 


\section{Innovation As... New Context}

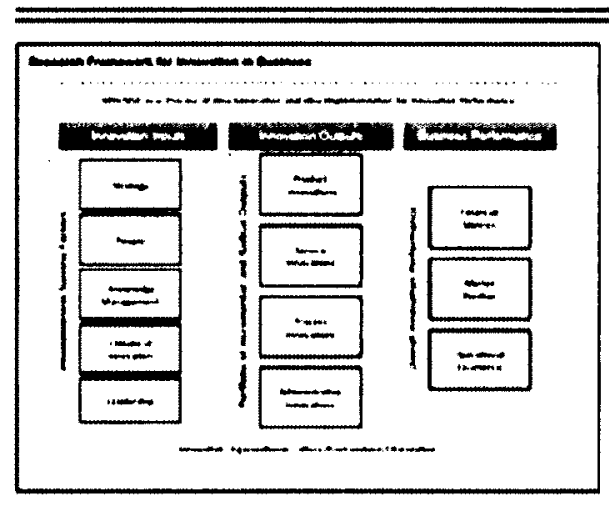

Continuous improvement

Generating Lots of Ideas

New and Unique Offerings to Guests

Central to Who We Are

Creative Problem Solving

Improving Service

Adapting Existing Ideas

Learning from others

Cutting Costs for Profitability

Collective Process

Distracts from Business Fundamentals

Ideas into Measurable Results 


\section{Innovation As Outputs}

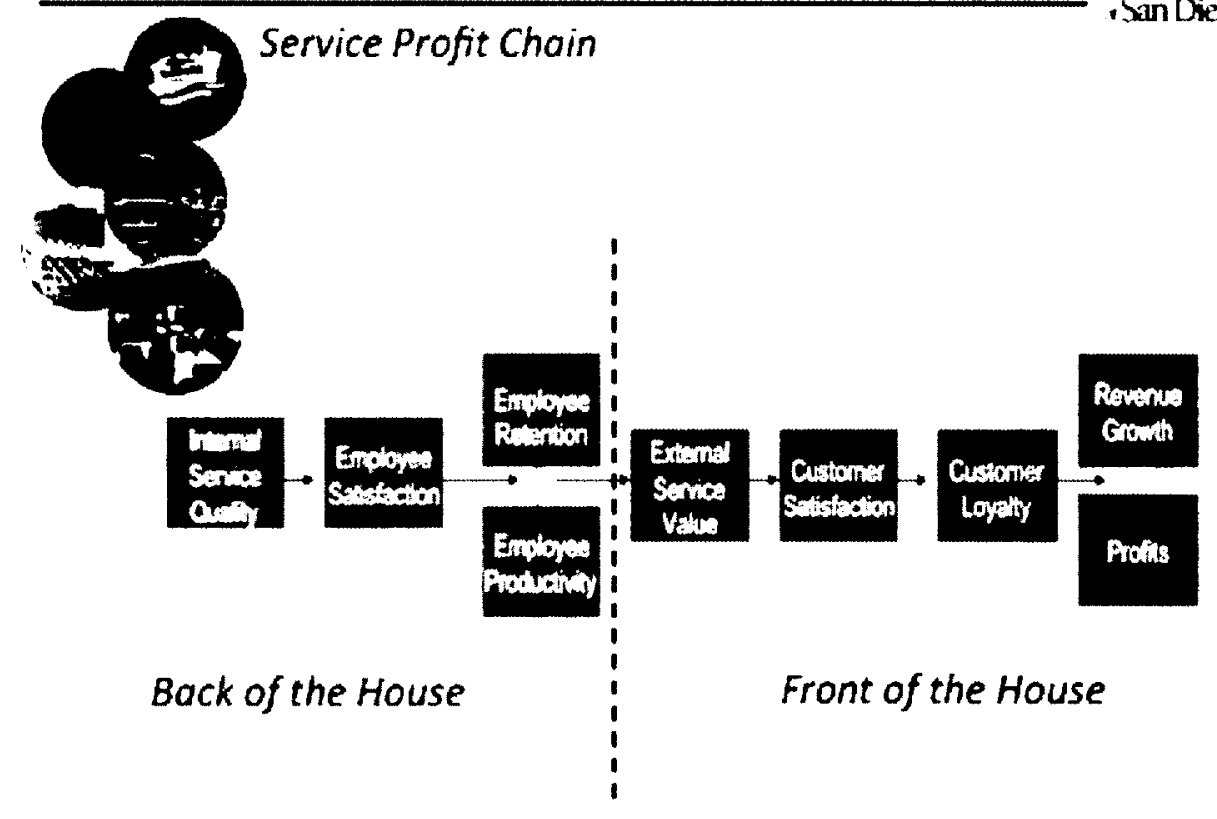

\section{Innovation - Getting New Ideas}

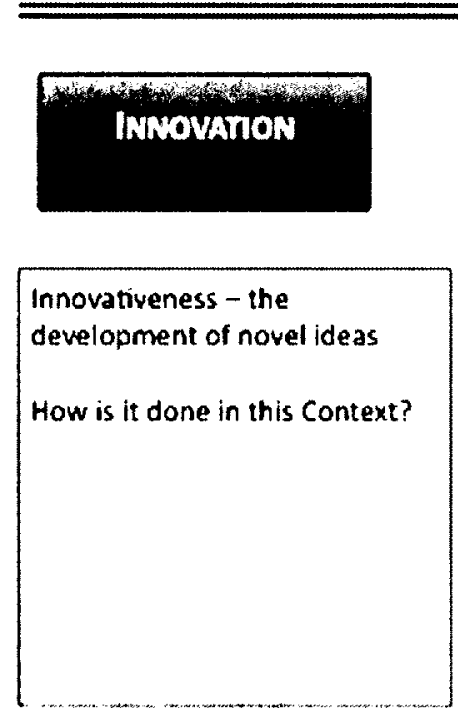

- When times were good. we hired two people who's anly pot was to go around the country and see what else was out the te. They brought in pictures, exumples. techniques, all kinds of ideds - it kept us on our toes

- I don't kjow why we dorit have someone wha's sale purpose is to make sian we gre ahesd of the curve on creating experientes - l'm making a nate though

- We are in constant contact with our guests and we implemert a lot of dess they oring us. Froblems are another source of ideas. We are slwsys workmg on projects that the guests borought us.

- We hifed in two new executive commate members that thought about thospitslity different than us// hite chels that are entrepene urial bu want the systems we provide to complement their imovation skills.

- Exponding our purpurse gal people to think differently aboul their role. It used to be that recreation was just the park, education was arimals, and conservaton was outside science - now people think braader about wis to bring themsetves to the mission and purpose 


\section{Innovation - Implementation}

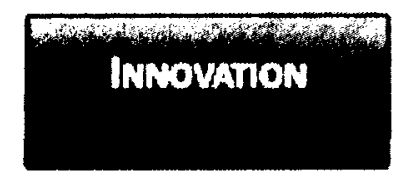

Outputs - new or improved

Products or services or processes to bring about improved business performance

How is it done in this Context?

\section{Tensions}

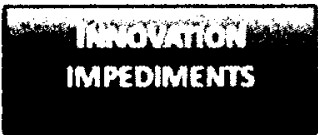

Brand sunisards vs, service

Distances

Corporme ms business urti:

Global us. loeal morketplace

Owner us. Ir manchise

Fundamentals ys. Change

Change with tiends/beep values

in tronl vs. responsure

Memarnes us Business
Energy and excitement is conbagious. The remodel has served as a launching of point to start fresh corversations about the experience at the Brig and how it's better than the competition around the ared. It gives people a new spart.

Our managers begin every meeting with a reflection. n's $\Delta$ way to aperationalise our soft side and remind everyone the value of leading from the heart.

We are high energy here too. People take the ledd Iram me and the management team in terms of atways wanting to be "doing" something.

the cream that rises to the top of our company are the people that posses the ability to nol just bridge but they can literally be amazingly erestive but at the same time they can to bsck and lollow through on the logatios.

Hight energy and activity and creaton of a whole set af brands standards backed by aperational commitrnents. 


\section{Innovation as Projects}

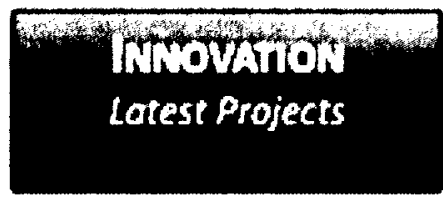

Translate intangibles

Solve problems

Engage customers

Engage employees

Physical space
- Problem resolution - role play

- Loyalty program revamp

- Social media initiatives

- Translating brands at the local level

- Meeting/event technologies

- Power of one program

- Branding guest courtesy

- Convey the soul

- Technology - kitchen

- Re engaging hybrid customer

- Engaging customers

- Menu items/plate presentation

- Rebranding safaris

- Translate brand standards across departments

\section{Leadership: Enhance REFRESH Capacity}

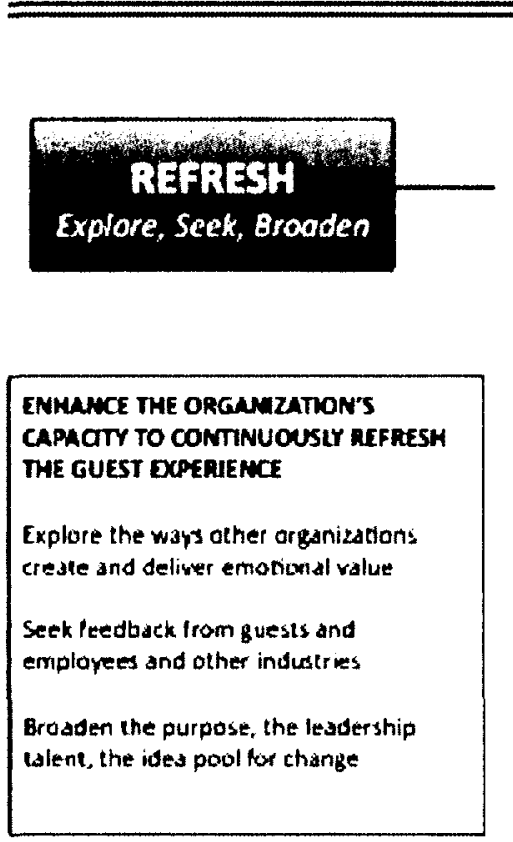

- When times were good, we hired ewo people who's only fow was to go dround the tountry and see what else was out there. They brought in pictures, examples. texhniques. all kinds of ideds - il kepl us on our toes

- I don't know why we don't have someone who's sole purpase is to make sure we are ahesd of the curve on creading experiences - I'm making s note though

- We are in constant contact with our guests and we implement a lot of deds they bring us. Problems are arother source of iseas. We are alursys working on projects that the guests brought us.

- We hired in two new executive comminee members that thought about hospitality different than us// I hite chels tha are entrepreneurial but want the spstems we provide to complement their innowation skills.

- Expsnding our purpose gat people to think differently about their role. It used to be that recreadon was just the park, educadon was animals, and conservation was outside sciente - now people think brodder doout wass to bring themselwes to the mission and purpase 


\section{Leadership: Enhance Connect Capacity}

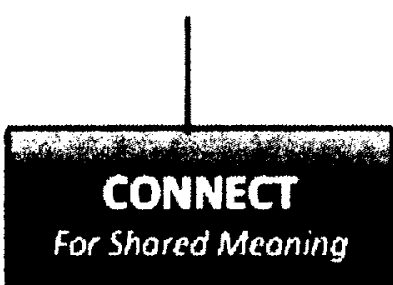

ENHANCE THE ORGANZZATIN'S CAPAOTY TO CONNECT WITH THE ESSENCE OF THE GUEST EXPERIENCE

Most Eventsuluse Symbolism Stories to

Encour age Collective Understanding around Experierxe

Insite Guesis to Co-Create Mental

Madels of Guest Experience

Devetop Dislogue Sessions wh 5enior Mandgers around Intangibles
- $n$ isn't one thing. lt's everything. It's the wholeness of it. n's important for people to connect the dots on their own. People warth to leel tike they can interpret the experience in their own way - makes them leel special - mathes them want to pass alore their commitment.

- Our senior management team has quarterly reureats and all we do is talk abowt our values and share specific stories of haw people in the keld have brought these values alive

- I use these pennies and theste containers when we get together. Talk about simple. This is how we deepen our understand ing of our decisions around profies. We physically sart with 100 pennies and divide up into these Usys...then we move permies...that's lood cost going wo...

- Each erent os unique. We shrt with the end, and we sak questions, trying to get the client to paint a picture of the teelings, the emotions, the ralues. they want in the event. $n$ 's not sbout the props, and the of the shefl theme as muxh as we try to get ater the memories intended. 


\section{Leadership: Enhance Energize Capacity}

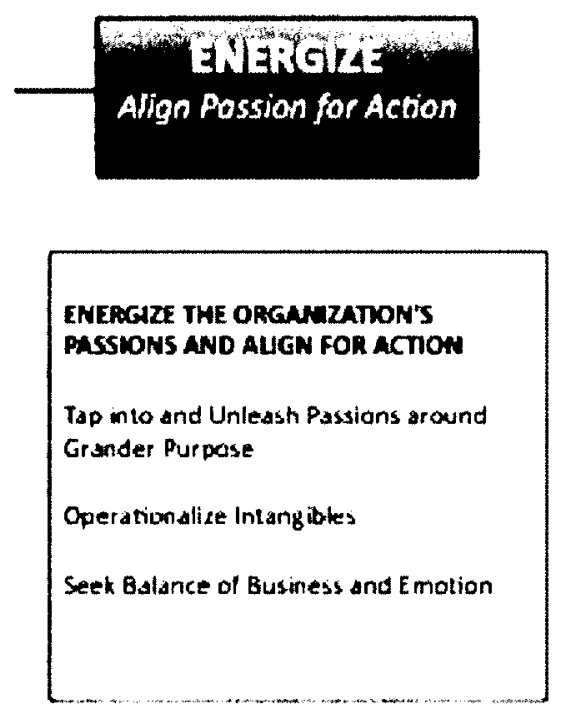

- We implemented Round with Purpose - a way for our ledders to anchor everything to the essence instead of jus walking wound. There's locus.

- Out managers besin every meeting with a reflection. It's a way to opera tionalist our sath side and remind everyone the value of leading from the heart

- I took the reports we shared at aur quarterly team metings, and I highlighted what was going on behind the numbers. I told searies - I tried to bring them to tile. I was really proud of that, becaluse I had been doing it for myself, and I knew it helped athers siry motwated

- We have a power of one program. We celebrate when someone makes the gutst experience great by doing whatever ther can lor the guest. Our managers are mesaging all the time aboul how each person can make a difference in their uwn way. We believe it too. It's part of aur culture.

\section{From Interviews to Theory}

\section{CODEFOR}

MEANING

\section{UNITS}

Transcribe Conversation

Highlight Meaning Units

Write Memo

Create Initial Codes

Second Pass Coding

Phases

\section{COMBINE}

CODES INTO

CATEGORIES

\& THEMES

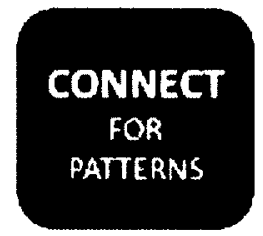

Themes to Relationshios

Categorits by Segment

Categories by Hesding

Context

Innoristion

Leadership

What What I Do?

Theme PAges
Research Questions

Literalure

Energize

Connect

Aetresh

Theoretical Modet

LEADERSHUP IN CONTEXT 


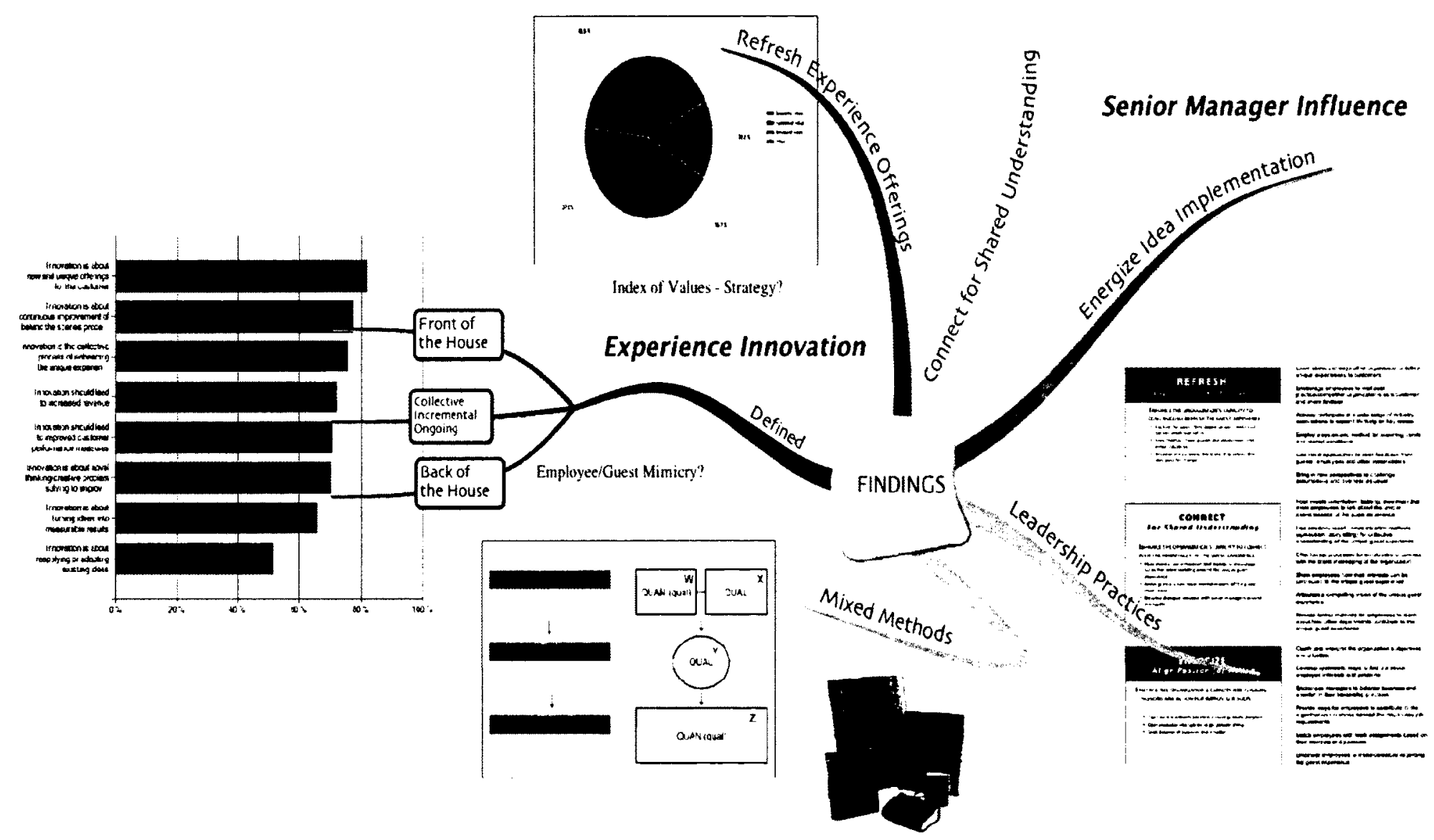




\section{APPENDIX H}

Sample Email Invitation for Advisory Group Working Session 
Hello,

First, thank you to those of you have already given your time in the past months to discuss leadership and innovation in your organizations with me. I have completed the initial exploration phase of my research, and I would like to get some feedback from a small group of context experts (that's you) on what I've put together thus far.

Please take a look at the information below about a one-time advisory/working group session I am conducting the morning of December 18, 2012, 9:00 - 11:00 a.m. at San Diego State University's School of Hospitality and Tourism Management.

The purpose of this meeting is to present a summary of some in-depth interviews (12-14) and surveys (150) I completed, get your feedback in terms of it "making sense" and then to ask your help in translating this work into a new survey to be distributed in January. The agenda of the working group meeting is:

Overview Purpose/Introductions

Presentation/Feedback on Theory

Survey Item Construction Exercise Pilot and Next Steps
15 minutes

30 minutes

60 minutes

15 minutes
Industry Experts

Sipe Facilitated

Sipe Facilitated

Sipe Facilitated

I will make every effort to shorten up the time frames in the agenda above and try and conclude within 90 minutes. Please respond and let me know if you are available to participate in this small group session. I am looking forward to working together.

I will send along directions and parking passes to you individually once I receive your response.

Thank you in advance for considering to give a bit of your time and expertise as I move forward with this research of the San Diego hospitality and tourism marketplace.

Warmly, Lori Sipe

Faculty - School of Hospitality and Tourism Management/SDSU Doctoral Candidate - Leadership Studies/University of San Diego 
APPENDIX I

Leadership Constructs Referenced During Advisory Group 


\section{Organizational Capacities}

Leadership OF the organization

- Influence systems, structure, programs

- Develop and focus collection of skills, knowledge, and behaviors of individuals

- Climate and Culture

\section{Existing Constructs - Influence}

\section{Leader Influence for Innovation and Adaptation}

- Competitor and market analysis programs (market surveys, focus groups, consumer panels, comparative product testing, benchmarking of competitor products and processes)

- Innovation programs (entrepreneurship programs, quality circles, innovation goals)

- Knowledge acquisition (consultants, joint ventures, importing best practices from others)

- Organizational learning (knowledge management systems, after-activity reviews, joint ventures)

- Temporary structural forms for implementing change (steering committee, task forces)

- Growth and diversification programs (mergers, acquisitions, franchises, joint ventures)

- Structural forms (research departments, small product divisions, product managers, cross functional product development teams)

- Appraisal, recognition, and reward systems focused on innovation and customer satisfaction 


\section{Existing Constructs - Leadership}

Flexible Leadership Behaviors (Task, relationship, change) (Yukl)

- Planning and scheduling work activities

- Showing support and positive regard

- Environmental scanning

- Determining staffing and other resource needs

- Coaching and mentoring

- Articulating an inspiring vision

- Assigning tasks

- Consulting

- Building a coalition of supporters for change

- Clarifying objectives and priorities

- Delegating and empowering subordinates

- Taking risks to promote change

- Directing, controlling and monitoring operations

- Encouraging cooperation and teamwork

- Interpreting events and explaining why change is needed

- Dealing with day-to-day operational problems

- Building a network of resources inside and outside the organization

- Determining how to implement change

Transformational Leadership (Bass \& Avolio - based on Burns/House)

- Idealized Influence/Charisma

- Act as role models and followers seek to emulate them

- Provide a vision and sense of mission

- Inspirational Motivation

- Inspires commitment and engaged in shared vision of the organization

- Uses symbols/ emotional appeals - group to achieve more than self-interest

- Intellectual Stimulation

- Stimulates followers to be creative and innovative

- Try new approaches

- Individualized Consideration

- Supportive climate - listen to needs

- Act as coaches and advisors encouraging self actualization

Transactional Leadership

- Contingent Reward

- Management by exception - active or passive

\section{Laissez-Faire Leadership}

- Abdicates responsibility

- Delays decisions

- Gives no feedback

\section{Leadership Challenge Instrument (Transformational) (Kouzes \& Pozner)}

- Model the way

- Inspire a shared vision

- Challenge the Process

- Enable Others to Act

- Encourage the Heart 


\section{Existing Constructs - Climate for Innovation}

\section{Team Climate for Innovation (Anderson \& West)}

- Vision-Commitment to objectives and worthwhile to the wider society

- Participative Safety - Keep each other informed, accept each other, in it together

- Support for Innovation - Open to change, new ideas, always moving, seeking ideas

- Task orientation - achieve high standards, self -monitor, encourage to do best work

- Interaction frequency -

Support for Innovation (Scott \& Bruce)

- Creativity / encouraged in this organization

- Allowed to solve the same problems in different ways

- Get to pursue creative ideas

- Organization /flexible and always opens to change

- Organization publicly recognizes / rewards those innovative

Climate for Innovation (Ekvall \& Nyström)

- Challenge and Involvement

- Freedom

- Emotional safety in work relationships

- Time to elaborate new ideas

- Spontaneity and ease in workplace

- Personal and emotional tensions (negative)

- Idea support

- Debate

- Risk-taking 


\section{Potential Practices for Survey}

From the Senior Manger Interview Data

\begin{tabular}{|c|c|c|c|}
\hline $\begin{array}{l}\text { Refresh } \\
\text { Idea Generation }\end{array}$ & $\begin{array}{l}\text { Connect } \\
\text { Focus on } \\
\text { Experience }\end{array}$ & 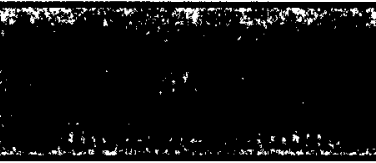 & $\begin{array}{l}\text { Other } \\
\text { Leadership } \\
\text { Behaviors }\end{array}$ \\
\hline $\begin{array}{l}\text { Benchmark other } \\
\text { organizations and the } \\
\text { competitive set }\end{array}$ & $\begin{array}{l}\text { Co-create the experience } \\
\text { with the customers, } \\
\text { employees and unique } \\
\text { offerings }\end{array}$ & $\begin{array}{l}\text { Seek balance of business and } \\
\text { memories }\end{array}$ & $\begin{array}{l}\text { Uses symbols and emotional } \\
\text { appeals to get the group to } \\
\text { achieve more than self- } \\
\text { interest }\end{array}$ \\
\hline $\begin{array}{l}\text { Bring in new managers to } \\
\text { the senior team to seek new } \\
\text { ideas. }\end{array}$ & $\begin{array}{l}\text { Clarify the brand promises in } \\
\text { a variety of ways }\end{array}$ & $\begin{array}{l}\text { Engage people's passion } \\
\text { around the purpose of the } \\
\text { organization and the } \\
\text { memories of the experience }\end{array}$ & $\begin{array}{l}\text { Clarify and interpret the } \\
\text { organization's objectives } \\
\text { and priorities }\end{array}$ \\
\hline $\begin{array}{l}\text { Create structured programs } \\
\text { to get suggestions and ideas }\end{array}$ & $\begin{array}{l}\text { Translate the memories into } \\
\text { brand standards to } \\
\text { operationalize the unique } \\
\text { characteristics }\end{array}$ & $\begin{array}{l}\text { Empower employees to make } \\
\text { decisions about the guest } \\
\text { experience }\end{array}$ & $\begin{array}{l}\text { Environmental scanning of } \\
\text { trends and market } \\
\text { conditions }\end{array}$ \\
\hline $\begin{array}{l}\text { Remodel, relaunch, refresh } \\
\text { the products and services }\end{array}$ & $\begin{array}{l}\text { Dialogue around the } \\
\text { intangibles of the total } \\
\text { experience }\end{array}$ & $\begin{array}{l}\text { Use a variety of employee } \\
\text { engagement strategies that } \\
\text { focus on the guest experience }\end{array}$ & $\begin{array}{l}\text { Inspires commitment and } \\
\text { engagement in shared vision }\end{array}$ \\
\hline $\begin{array}{l}\text { Stay on top of trends and } \\
\text { market segment changes to } \\
\text { get ahead in the industry }\end{array}$ & $\begin{array}{l}\text { Show employees how their } \\
\text { interests can serve the total } \\
\text { experience to make it more } \\
\text { unique }\end{array}$ & Align passions and projects & $\begin{array}{l}\text { Imports best practices from } \\
\text { others }\end{array}$ \\
\hline $\begin{array}{l}\text { Attend industry meetings } \\
\text { and association conferences }\end{array}$ & $\begin{array}{l}\text { Tell stories to bring the } \\
\text { numbers to life }\end{array}$ & $\begin{array}{l}\text { Broaden the level of } \\
\text { employee involvement by } \\
\text { reducing standards and }\end{array}$ & $\begin{array}{l}\text { Delegates and empowers } \\
\text { subordinates }\end{array}$ \\
\hline $\begin{array}{l}\text { Think broader about the } \\
\text { purpose of the organization } \\
\text { or the roles departments } \\
\text { play in the experience }\end{array}$ & $\begin{array}{l}\text { Cross train employees to } \\
\text { broaden their connection to } \\
\text { the core messages of the } \\
\text { organization }\end{array}$ & $\begin{array}{l}\text { Match work assignments } \\
\text { with passions and interests } \\
\text { of employees }\end{array}$ & $\begin{array}{l}\text { Interprets events and } \\
\text { explains why changes are } \\
\text { needed }\end{array}$ \\
\hline $\begin{array}{l}\text { Share personal experiences } \\
\text { about great service }\end{array}$ & $\begin{array}{l}\text { Provide opportunities to } \\
\text { have guests and employees } \\
\text { interact as part of the } \\
\text { experience }\end{array}$ & $\begin{array}{l}\text { Create databases of emplayee } \\
\text { talents, interests, and } \\
\text { passions to expand the ways } \\
\text { they can contribute to the } \\
\text { experience }\end{array}$ & $\begin{array}{l}\text { Emphasizes a task } \\
\text { orientation }\end{array}$ \\
\hline $\begin{array}{l}\text { Rebranding efforts to } \\
\text { distinguish emotional } \\
\text { attributes of the total } \\
\text { experience }\end{array}$ & $\begin{array}{l}\text { Bring values alive using } \\
\text { multiple communication } \\
\text { methods and live events like } \\
\text { orientation/training. }\end{array}$ & $\begin{array}{l}\text { Make the soft side of the } \\
\text { business more tangible by } \\
\text { getting people involved in } \\
\text { projects they're passionate } \\
\text { about }\end{array}$ & Enables others to act \\
\hline $\begin{array}{l}\text { Stay in constant contact with } \\
\text { the guests as a source of } \\
\text { ideas and to solve problems }\end{array}$ & $\begin{array}{l}\text { Let people connect the dots } \\
\text { on their own to get a sense of } \\
\text { the wholeness of it }\end{array}$ & $\begin{array}{l}\text { Align action and passion to } \\
\text { get people doing }\end{array}$ & Encourages the heart \\
\hline
\end{tabular}




\section{APPENDIX J}

Consent Form for Advisory Group Working Session 


\section{University of San Diego \\ Institutional Review Board}

\section{Research Participant Consent Form}

For the research study entitled:

Leadership for Innovation in the Memories Business: A Mixed Methods Study of a Hospitality and Tourism Marketplace

\section{Purpose of the research study}

Lori Sipe is a student in the School of Leadership and Education Sciences at the University of San Diego. You are invited to participate in a research study she is conducting. The purpose of this research study is: to explore leadership for innovation in the hospitality and tourism industry.

\section{What you will be asked to do}

If you decide to be in this study, you will be asked to:

- Attend a two-hour meeting at San Diego State University to be attended by 57 senior executives of the San Diego Hospitality and Tourism industry.

- Listen to a summary of interview and survey research conducted by Lori Sipe regarding leadership for innovation in a hospitality and tourism marketplace.

- Provide feedback, based on your expertise in the industry, about the summary research presentation. The researcher, Lori Sipe, will facilitate the advisory meeting.

- Provide feedback, based on your expertise in the industry, about potential survey items for a future survey about the relationships between senior manager influence and innovation in hospitality and tourism organizations.

- You will be videotaped during the meeting so Lori Sipe, the researcher can review the specific feedback after the meeting.

- Your participation in this advisory group meeting will take a total of 2-3 hours.

\section{Foreseeable risks or discomforts}

This study involves no more risk than the risks you encounter in daily life.

\section{Benefits}


While there may be no direct benefit to you from participating in this study, the indirect benefit of participating will be knowing that you helped researchers better understand how hospitality leaders influence innovation in their organizations.

\title{
V. Confidentiality
}

Any information provided and/or identifying records will remain confidential and kept in a locked file and/or password-protected computer file in the researcher's office for a minimum of five years. All data collected from you will be coded with a number or pseudonym (fake name). Your real name will not be used. The results of this research project may be made public and information quoted in professional journals and meetings, but information from this study will only be reported as a group, and not individually.

\section{Compensation}

You will receive no compensation for your participation in the study.

\section{Voluntary Nature of this Research}

Participation in this study is entirely voluntary. You do not have to do this, and you can refuse to answer any question or quit at any time. Deciding not to participate or not answering any of the questions will have no effect on any benefits you're entitled to, like your health care, or your employment or grades. You can withdraw from this study at any time without penalty.

\section{Contact Information}

If you have any questions about this research, you may contact either:

\section{1) Lori Sipe}

Email: Isipe@mail.sdsu.edu

Phone: 858.722.8458

2) Dr. Robert Donmoyer

Email: donmoyer@sandiego.edu

Phone: 619-260-7445

I have read and understand this form, and consent to the research it describes to me. I have received a copy of this consent form for my records.

\author{
Signature of Participant \\ Date
}

Name of Participant (Printed) 


\section{APPENDIX K}

\section{Email Invitation for Leadership and Innovation Survey}


Hello,

My name is Lori Sipe, faculty member in the School of Hospitality and Tourism Management at San Diego State University. I am also a doctorate student pursuing my PhD in leadership studies at the University of San Diego. I am conducting a research study about innovation in San Diego organizations in the Hospitality and Tourism industry, and I would like to know more about leadership for innovation from the perspectives of members of senior management teams.

The attached survey contains questions about organizational leadership practices and innovation in your organization. It should take less than 15 minutes to complete the short survey, and your responses will be used to prepare a summary of senior manager perceptions in the lodging, dining, attractions, and events segments of the industry.

I am looking for a broad collection of senior manager responses regarding innovation in the industry, so there are no right or wrong responses, and your responses will be confidential. I will not share any of your survey responses or examples unless you give me explicit permission, and I will not use your name or organization in anything I write, unless you give me explicit permission.

I hope you will spend a few minutes now taking the Leadership and Innovation survey. Click on the link to begin http://www.surveymonkey.com/s/leadershipandinnovation. I am excited to partner with industry professionals in my research endeavors. If you would like additional information, please contact me at Isipe@mail.sdsu.edu.

Thank you for your time, Lori Sipe 
APPENDIX L

Leadership and Innovation Survey 


\section{Introduction to the Survey}

This survey is part of a research initiative regarding innovation in the San Diego hospitality and tourism marketplace. Members of senior management leams from lodging, dining, meetings/events, attractions, and other tourism related organizations will be responding. It requires LESS THAN 10 MINUTES to complete.

The survey contains items about:

YOUR ORGANIZATION IN GENERAL - 5 general questions about segment, sIze. offerings

VIEWS OF INNOVATION- 1 question: click any of the views of innovation that apply to your organization

ORGANIZATIONAL. LEADERSHIP - respond to 18 practices based on the exlent used by the leadership team

OUTCOMES \& MEASURES - perceptions of your organization's innovation vs similar organizations in the industry segment

EXAMPLES -2 open-ended questions about front of the house and back of the house innovations

Please respond to the survey items based on your personal perceptions, as a member of the senior management team, for your company or organization. There are no right or wrong answers, we are seeking responses from a broad range of organizations in the local hospitality and tourism marketplace. 


\section{General Questions About the Organization}

1. Indicate the industry segment for your company or organization.

C Lodging

$r$ Dining and Nightlife

$r$ Meeting/Event Services

Attraction

$r$ Other

2. What is the current size of your company or organization?

$r$ Less than 10 employees

r 11.50 employees

r 51-100 employees

C $101-300$ employees

$r$ Greater than 300 employees

3. How long has your company or organization been in operation?

$r$ Less than 2 years

r $2-5$ years

r 6.10 years

$r$ Longer than 10 years

4. Which of the following best expresses the essence of your company or organization's value proposition. Essentially, what type of value is the guestcustomer looking for when they make a purchase decision about your company or organization?

$r$ Economic value

$r$ Functional value

$r$ Emotional value

$r$ Other

Omer (please specify) 
5. If you had to select just one of the following to describe the overall purpose of your company or organization which one would you select?
$r$ Excellent service
$r$ Unique experience
$r$ Outstanding value
$r$ Lasting memories 


\section{Views of Innovation}

6. The following statements describe viewpoints of innovation in business organizations. Consider each statement as it relates to the way your organization views or approaches innovation. Click on only those statements that are true for your organization currently. If the statement does not describe the viewpoint of innovation in your organization, leave it unchecked. You are not limited in the number of statements you select.

CLICK ALL STATEMENTS THAT APPLY to your organization currently.

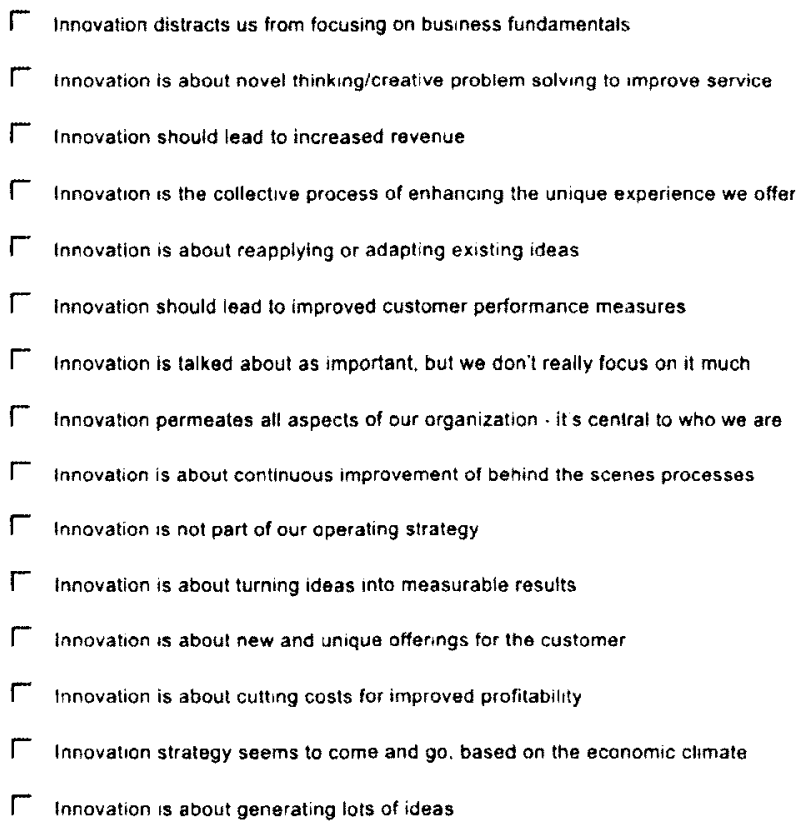




\section{Organizational Leadership}

The following items describe 18 various ways senior managers exercise leadership of organizations. You are asked to consider each of the managerial practices and rate the extent to which the particular practice is utilized by you and your senior management team.

The rating scale purposely asks about the extent a practice is used, not the frequency or number of times the practice is used. Please respond based on the following rating scale descriptions

NO EXTENT Not at all how we exercise organizational leadership

VERY LITTLE EXTENT We have utilized this practice in a minor way.

SOME EXTENT Moderate or spotty use of this practice.

LARGE EXTENT We utilize this practice in a major or consistent way.

VERY GREAT EXTENT Crucial to how we exercise organizational leadership 
264

7. To what extent do you and members of the senior management team utilize the following managerial practices as part of your organizational leadership?

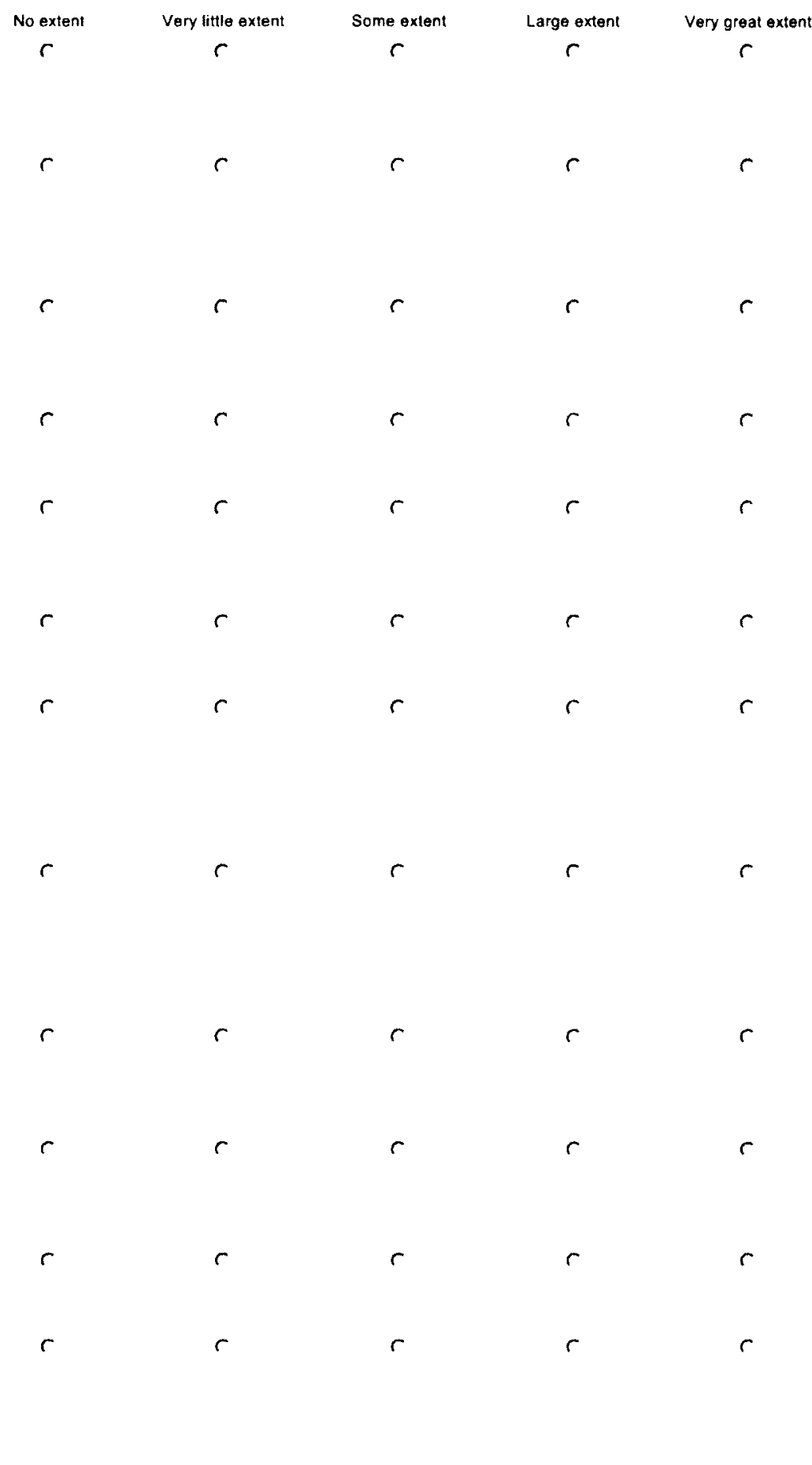




\begin{tabular}{|c|c|c|c|c|c|}
\hline $\begin{array}{l}\text { Clarify and interpret the } \\
\text { organization's objectives } \\
\text { and priorities }\end{array}$ & $r$ & $r$ & $r$ & $r$ & $r$ \\
\hline $\begin{array}{l}\text { Develop systematic ways to } \\
\text { find out about employee } \\
\text { interests and passions }\end{array}$ & $r$ & $r$ & $r$ & $r$ & $r$ \\
\hline $\begin{array}{l}\text { Encourage managers to } \\
\text { balance business and } \\
\text { emotion in their leadership } \\
\text { practices }\end{array}$ & $r$ & $r$ & $r$ & $r$ & $r$ \\
\hline $\begin{array}{l}\text { Provide opportunities for } \\
\text { employees to contribute to } \\
\text { the organization's purpose } \\
\text { beyond the day-to-day job } \\
\text { requirements }\end{array}$ & $r$ & $r$ & $r$ & $r$ & $r$ \\
\hline $\begin{array}{l}\text { Match employees with work } \\
\text { assignments based on their } \\
\text { interests and passions }\end{array}$ & $r$ & $r$ & $r$ & $r$ & $r$ \\
\hline $\begin{array}{l}\text { Empower employees to } \\
\text { make decisions regarding } \\
\text { the guest experience }\end{array}$ & $r$ & $r$ & $r$ & $r$ & $r$ \\
\hline
\end{tabular}




\section{Outcomes and Measures}

These last three questions ask you to rale your organization vs. similar organizations in your industry segment in terms of innovation performance and outcomes measures. For the purposes of this survey, please refer to the following definitions.

FRONT OF THE HOUSE INNOVATION

Ability to bring new and/or improved products, services, and experiences to the hospitality and tourism marketplace with proven results in customer related performance measures

BACK OF THE HOUSE INNOVATION

Ability to implement novel and/or improved managerial practices, business processes, and employee experiences into the organization with proven results in employee related performance measures

8. FRONT OF THE HOUSE INNOVATION is the ability to bring new or improved products, services, and experiences to the hospitality and tourism marketplace with proven results in customer related measures.

Example: The Fun Card introduced by an attraction that allows customers to purchase a Fun Card for the price of one day's full-price admission and visit free the rest of the year.

Example: Curbside service introduced by a restaurant that allows customers to phone in orders and pick them up from a restaurant employee at designated parking spaces outside the restaurant.

Indicate your perception of your organization's FRONT OF THE HOUSE INNOVATION against similar organizations in your industry segment during the past 2 years:

$$
\begin{aligned}
& \text { Much less innovative Somewhat less About the same level Somewhat more Much more innovative } \\
& \text { FRONT OF THE HOUSE } r \quad r \quad r \quad r
\end{aligned}
$$

INNOVATION in my

organization

Please provide an example of a FRONT OF THE HOUSE INNOVATION in your organization implemented during the past 2 years 
9. BACK OF THE HOUSE INNOVATION is the ability to implement novel and improved managerial practices, business processes, and employee experiences in the organization with proven employee related measures

Example: Employee role-play events - employee pairs act out potential hot spots and touch points in the guest experience at the start of each hotel shift.

Example: Employee passions are matched with event bookings to bring refreshed energy to each new convention event. Employee driven ideas are integrated into the event prospectus.

Indicate your perception of your organization's BACK OF THE HOUSE INNOVATION against similar organizations in your industry segment during the past 2 years:

BACK OF THE HOUSE

Much less innovative

$r$
Somewhat less

$r$

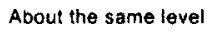

About the same level

of innovation

$r$

Somewhat more innovative

Much more innovative $r$

OVATION in my

organization

Please provide an example of a BACK OF THE HOUSE INNOVATION implemented in your organization in the last 2 years

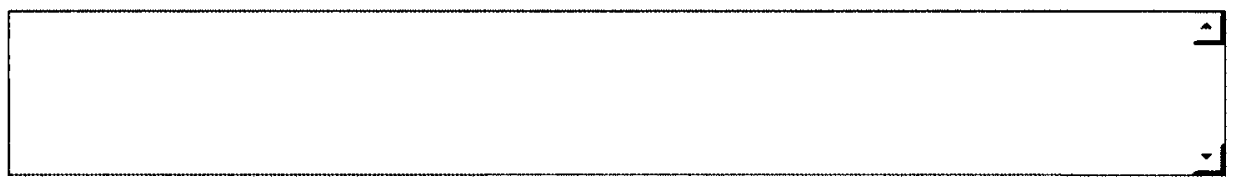

10. Indicate your perception of your organization's outcomes and measures of innovation against similar organizations in your industry segment during the past 2 years:

\begin{tabular}{|c|c|c|c|c|c|}
\hline & $\begin{array}{l}\text { Much less than } \\
\text { segment avg. }\end{array}$ & $\begin{array}{l}\text { Somewhat less than } \\
\text { segment avg. }\end{array}$ & $\begin{array}{l}\text { About the same as } \\
\text { segment avg }\end{array}$ & $\begin{array}{l}\text { Somewhat more than } \\
\text { segment avg. }\end{array}$ & $\begin{array}{l}\text { Much more than } \\
\text { segment avg. }\end{array}$ \\
\hline $\begin{array}{l}\% \text { of revenue from new } \\
\text { and/or improved products or } \\
\text { services }\end{array}$ & $r$ & $r$ & $r$ & $r$ & $r$ \\
\hline $\begin{array}{l}\text { Quantity of new products or } \\
\text { services implemented }\end{array}$ & $r$ & $r$ & $r$ & $r$ & $r$ \\
\hline $\begin{array}{l}\text { Ability to charge price } \\
\text { premium }\end{array}$ & $r$ & $r$ & $r$ & $r$ & $r$ \\
\hline $\begin{array}{l}\text { Proven results in customer } \\
\text { related measures }\end{array}$ & $r$ & $r$ & $r$ & $r$ & $r$ \\
\hline $\begin{array}{l}\text { Proven results in employee } \\
\text { related measures }\end{array}$ & $r$ & $r$ & $r$ & $r$ & $r$ \\
\hline $\begin{array}{l}\text { Please use the space provide } \\
\text { know if your innovation-relate }\end{array}$ & $\begin{array}{l}\text { below to list the of } \\
\text { activities are succe }\end{array}$ & $\begin{array}{l}\text { ways, if any your orga } \\
\text { ful? }\end{array}$ & zation measures/eva & uates innovation. Esse & lly. how do you \\
\hline
\end{tabular}


Contact Iniormation

\section{Contact Information}

The information you provide will be used only to contact you for further research information (ie: inclusion in best practices summary) and to provide you a copy of the study's overall findings. No specific information about your company or organization will be shared without explicit permission.

11. Please provide your contact information. This information will not be shared without your explicit permission. List your name and position, company name, and your email address in the box provided below.

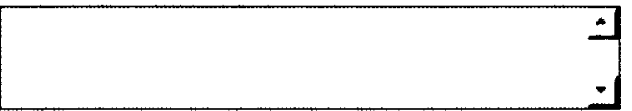

12. If you would like to provide any additional information or comments, please use the space below. Proceed to the next page to submit your survey electronically.

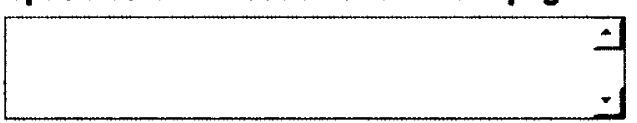




\section{APPENDIX M}

Consent Form for Leadership and Innovation Survey 
Survey Participant Consent and Submittal

Thank you so much for laking time to complete the survey! You will submit your survey by clicking on the DONE button at the boltom of this page.

Prior to submitting your survey, please foview the following information regarding consent. Submission of the survey assumes your implied consent to participate in the research outined below.

Research Participant Consent

Instilutional Review Board - University of San Diego

For the research study entitled

Leadership for Innovation in the Memories Business

A Mixed Methods Study of a Hospitality and Tourism Marketplace

1. Purpose of the research study

Lori Sipe is a doctoral candidate in the School of Leadership and Education Sciences at the University of San Diego. You are invited to participate

in a research study she is conducting. The purpose of this research is: to explore perceptions of innovation in a hospitality and tourism industry

11. What you will be asked to do

If you decise to be in this study. you will be asked to.

Provide responses to about 12 survey items about leadership and innovation in your organization.

Your participation in this survey will take a total of 10-12 minutes.

13!. Foreseeable risks or discomforts

This study involves no more risk than the risks you encounter in daily life.

IV. Benefits

While there may be no direct benefil to you from participating in this study. the indirect benefit of participating witl be knowing that you helped researchers better understand how hospitality leaders perceive innovation in a hospitality and tourism marketplace.

$\checkmark$. Confidentiality

Any information provided and/or identfying records will remain confidential and kept in a locked file and/or password-protected computer fite in the researcher's office for a minimum of five years. All data collected from you will be coded with a number or pseudonym (fake name). Your real name will not be used. The results of this research project may be made public and information quoted in professional journals and meetings. but information from this study will only be reported as a group. and not individually

VI Compensation

You will receive no compensation for your participation in the study

VII. Voluntary Nature of this Research

Participation in this survey is entirely voluntary. You do not have to submit it. and you can refuse lo answer any question or quit at any time

V1:1 Contact Intormation

If you have any questions about this research, you may contact either:

1) Lori Sipe

Email: Isip@@mail.sdsu.edu

Phone: 858.722 .8458

2) Dr. Robert Donmoyer

Email: donmoyer@sandiego edu

Phone: $619-260.7445$ 